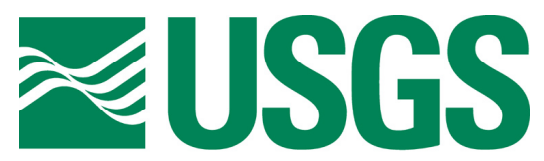

science for a changing world

\title{
Structure of the San Bernardino Basin Along Two Seismic Transects: Rialto-Colton Fault to the San Andreas Fault and Along the I-215 Freeway (I-10 to SR30)
}

R.D. Catchings', M.J. Rymer', M.R. Goldman', G. Gandhok', and C.E. Steedman'

Open-File Report 2008-1197

2008

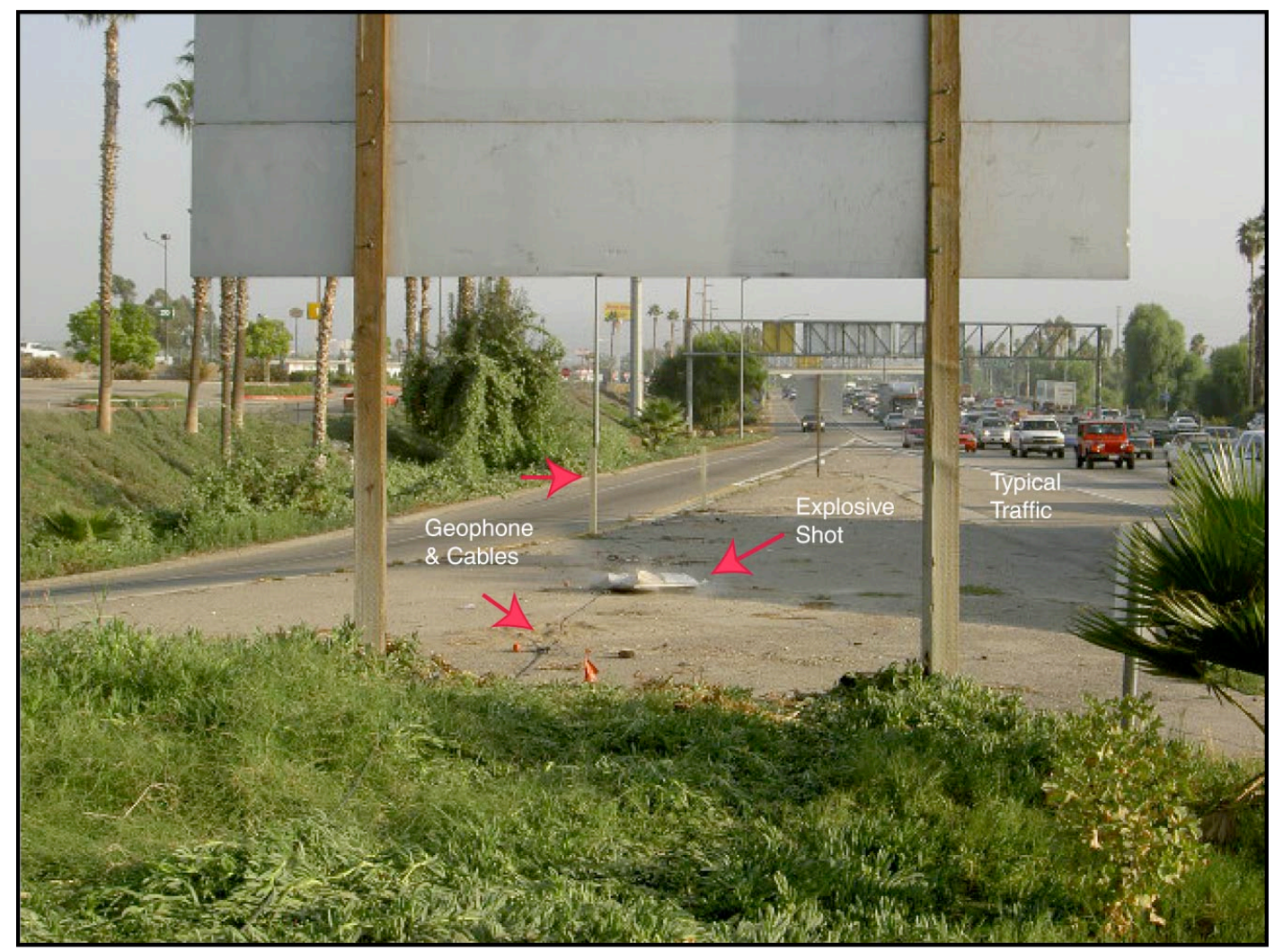

U.S. Department of the Interior U.S. Geological Survey

${ }^{1}$ Menlo Park, Calif. 


\title{
U.S. Department of the Interior DIRK KEMPTHORNE, Secretary
}

\section{U.S. Geological Survey \\ Mark D. Myers, Director}

\author{
U.S. Geological Survey, Reston, Virginia 2008
}

For product and ordering information:

World Wide Web: http://www.usgs.gov/pubprod

Telephone: 1-888-ASK-USGS

For more information on the USGS-the Federal source for science about the Earth, its natural and living resources, natural hazards, and the environment: World Wide Web: http://www.usgs.gov

Telephone: 1-888-ASK-USGS

Suggested citation:

Catchings, R.D., Rymer, M.J., Goldman, M.R., Gandhok, and G., Steedman, C.E., 2008, Structure of the San Bernardino Basin along two seismic transects; Rialto-Colton fault to the San Andreas fault and along the I-215 freeway (I-10 to SR30): U.S. Geological Survey, Open-File Report 2008-1197

[http://pubs.usgs.gov/of/2008/1197/].

Any use of trade, product, or firm names is for descriptive purposes only and does not imply endorsement by the U.S. Government.

Although this report is in the public domain, permission must be secured from the individual copyright owners to reproduce any copyrighted material contained within this report. 


\section{Summary}

In this report, we present seismic data and acquisition parameters for two seismic profiles acquired in the San Bernardino, California area in May and October 2003. We refer to these seismic profiles as the San Bernardino Regional (SBR) and San Bernardino High-Resolution (SBHR) seismic profiles. We present both un-interpreted and interpreted seismic images so that the structure of the area can independently interpreted by others. We explain the rationale for our interpretations within the text of this report, and in addition, we provide a large body of supporting evidence.

The SBR seismic profile extended across the San Bernardino Basin approximately $\mathrm{N} 30^{\circ} \mathrm{E}$ from the town of Colton to the town of Highland. The data were acquired at night when the signal-to-noise ratios were reasonably good, and for the larger shots, seismic energy propagated across the $\sim 20-\mathrm{km}$-long array. Tomographic velocity data are available to depths of about $4 \mathrm{~km}$, and low-fold reflection data are available to depths in excess of $5 \mathrm{~km}$. The SBR seismic data reveal an asymmetric, fault-bound basin to about 5 $\mathrm{km}$ depth.

The SBHR seismic profile trended along the I-215 freeway from its intersection with the Santa Ana River to approximately State Road 30 in San Bernardino. Seismic data acquired along the I-215 freeway provide detailed images, with CDP spacing of approximately $2.5 \mathrm{~m}$ along an approximately $8.2-\mathrm{km}$-long profile; shot and geophone spacing was $5 \mathrm{~m}$. Walk-away noise tests showed that freeway noise levels were low enough during the night hours to propagate seismic signals fairly well. However, for logistical reasons, the high-resolution (SBHR) seismic data were acquired during daylight hours on the shoulder of the I-215 freeway and within 5 to $10 \mathrm{~m}$ of high-traffic volumes. The resulting signal-to-noise noise ratios for the SBHR seismic survey were low, and although we increased out shot sizes to help compensate for the high-noise levels, the resulting seismic data contain significant noise in the reflection images. Due to the limited offset at which refracted first-arrivals could be measured along the SBHR seismic profile, tomographic refraction velocities are limited to relatively shallow $(<150 \mathrm{~m})$ depths. The SBHR reflection data reveal a basin with complex structural details within the upper kilometer.

The two seismic profiles show internal consistency and consistency with other existing geophysical data. Collectively, the data suggest that the I-215 freeway trends along the faulted edge of a pull-apart basin, within a zone where the principal slip of the San Jacinto Fault is transferred to the San Andreas Fault (see Figure 26-28). Because the I-215 freeway trends at low angles to these flower-structure faults, both primary and numerous secondary faults are apparent between the I-10 exchange and State Road-30, suggesting that much of the 8-km-long segment of the I-215 freeway could experience movement along primary or secondary faults. 


\section{Introduction}

The San Bernardino Basin is located in the county of San Bernardino, approximately $100 \mathrm{~km}$ east of Los Angeles, California (Fig. 1). The basin is bounded on the northeast, northwest, southwest, and southeast by the San Bernardino Mountains, the San Gabriel Mountains, the San Timoteo Badlands, and the Crafton Hills, respectively. The area has a population of approximately 1.7 million people (2000 U. S. Census), distributed among several cities, including Colton, Grand Terrace, Fontana, Highland, Loma Linda, Redlands, Rialto, and San Bernardino. The city of San Bernardino is the largest city in the area, with a population of approximately 185,000 (2000 U. S. Census), and it encompasses the principal area of this study.

Two major interstate freeways, I-215 and I-10, trend through the city of San Bernardino, and both freeways are heavily traveled lifelines that connect cities to the east and west (including Los Angeles) and to the north and south (including San Diego). To relieve traffic congestion on the I-215 freeway in San Bernardino, the California Department of Transportation (Caltrans), in a joint venture with the San Bernardino Association of Governments (SANBAG), plans to widen a 6.6-mile section of the I-215 freeway between the I-10 and State Road-30 (SR-30) intersections. The effort includes widening of bridges and reconstruction of interchanges (Aragoan, 2004). Because the area is situated between at least two major fault zones, the San Jacinto fault zone (SJFZ) to the southwest and the San Andreas Fault zone (SAFZ) to the northeast, Caltrans is incorporating expected ground shaking and rupture into the design of the roadways and bridges along the section of the freeway to be widened. However, one of the principal factors that affect ground shaking and structural failure during an earthquake, the proximity of faults to the structures in question, is not known because the area is covered by alluvium (Morton and Miller, 2003).

The U.S. Geological Survey's (USGS) Earthquake Hazards Team (EHZ) is part of the National Earthquake Hazards Reduction Program (NHERP), which conducts research designed to reduce hazards associated with earthquakes. The USGS-EHZ program includes an active-source seismic imaging effort designed to locate details of faults and basin structure. To accomplish the common goals of the USGS and Caltrans, both organizations jointly conducted seismic imaging investigations in May 2003 and October 2003 across the San Bernardino Valley and along the I-215 freeway, respectively. The primary goals of these seismic investigations were to more accurately locate known and unknown (buried) fault strands relative to structures and major lifelines in the San Bernardino area. In addition, we evaluated seismic velocities, basin depth and geometry, and fault geometry, all of which affect ground-shaking resulting from earthquakes. This report presents results of the seismic imaging studies to Caltrans and is part of a more comprehensive report that details fault structures in the San Bernardino area (Catchings et al., in prep).

\section{Tectonic Setting}

The $1300-\mathrm{km}$-long San Andreas fault (SAF) system, which extends from near the U.S.-Mexican border to Cape Mendocino, California, represents the boundary between two of the Earth's major tectonic plates, the Pacific Plate to the west and the North American Plate to the east. Deformation associated with the SAF system largely occurs along a zone that averages about $120 \mathrm{~km}$ in width, but most of the deformation is concentrated along a relatively narrow zone near the surface trace of San Andreas fault zone (Wallace, 1990). The City of San Bernardino is located near a particularly complex 
area of the SAF system where the fault system splays into multiple strands and deviates from its largely $\mathrm{N} 40^{\circ} \mathrm{W}$ orientation. At the latitude of the San Bernardino area,

deformation is distributed among numerous faults from the Mojave Desert to the Pacific Ocean. Faults within this zone have a wide range of orientations and include strike-slip, reverse, and dip-slip components of motion. Although deformation is distributed over a wide zone, most of the deformation is concentrated along three principal fault zones, the San Andreas, San Jacinto, and Elsinore fault zones (Wallace, 1990). In the City of San Bernardino, the San Andreas and San Jacinto fault zones are less than $10 \mathrm{~km}$ apart, and the distance between the two fault zones decreases to less than $3 \mathrm{~km}$ in the northwestern part of the San Bernardino Basin (Fig. 1).

The San Jacinto fault zone (SJFZ) is a right-lateral, strike-slip fault zone that extends approximately $250 \mathrm{~km}$ from the northwestern Imperial Valley to Cajon Pass. It is by far the most seismically active fault zone in southern California for earthquakes less than $\mathrm{M}$ 7 (Vernon, 1989; Hill et al., 1990; Hauksson et al., 2003). The SJFZ has produced at least nine events registering M 6.0 or stronger since 1890 and four since 1932. The last three large (M6+) earthquakes on the SJFZ were the 1968 M 6.4 Borrego Mountain earthquake and the 1987 M 6.0 and M 6.6 Superstition Hills earthquakes (Hill et al., 1990).

Although the principal motion in the fault zone is strike-slip, locally there is also a small vertical component of offset. The SJFZ does not have a continuous linear surface trace, rather it forms multiple sub-parallel surface strands along the zone (Sharp, 1972).

Seismicity data indicate that the SJFZ is composed of discontinuous splays and strands in a zone that is up to 6 to $10 \mathrm{~km}$ wide (Hill et al., 1990; Hauksson et al., 2003). These subparallel surface strands vary in length from 30 to $70 \mathrm{~km}$ and form complicated substructures within the general linear trend of the fault zone, making identification of the near-surface active strand or strands difficult (Vernon, 1989).

The San Andreas fault zone (SAFZ) is an $\sim 10-\mathrm{km}$-wide zone that includes numerous individual strands. Regionally, the SAFZ is separated into multiple branches, including the Banning fault zone, the Mill Creek fault zone, and many others (Matti and Morton, 1993; Yule and Sieh, 2002). However, for purposes of discussion in this report, we refer to the SAFZ as the several-kilometer-wide zone of faults near its mapped surface traces in the San Bernardino area (Morton and Miller, 2003). Much like the SJFZ, faults in the SAFZ have right-lateral, predominantly strike-slip components (Fig. 1). In the San Bernardino area, seismicity is most concentrated near the SJFZ, with relatively little seismicity near the surface trace of the SAF (Hauksson et al., 2003). However, farther south, the SAFZ generates a large amount of seismicity (Hill et al., 1990; Hauksson et al., 2003). Recent paleoseismological investigations show that some segments of the SAF have experienced at least 14 large-magnitude earthquakes in the past 1500 years and is now likely near failure again (Fumal et al., 2002).

\section{Local Geology}

The I-215 freeway is underlain by road construction materials at shallow depths (upper few meters), but the underlying, near-surface deposits consist of Quaternary sediments ranging in age from late Pleistocene to late Holocene (Morton and Miller, 2003). Specific deposits along the seismic profile consist of late Holocene wash deposits, late Holocene alluvial valley deposits, middle Holocene alluvial valley deposits, middle to early Pleistocene alluvial valley deposits, and Holocene to late Pleistocene eolian (sand dune) deposits (Miller and Morton, 2003). Water-well borings show that deposits at several hundred meters depth are Holocene alluvium (unconsolidated dune sand, riverchannel deposits, and younger alluvium), late Pleistocene alluvium, Tertiary-to- 
Quaternary partly consolidated to consolidated continental deposits, and pre-Tertiary basement complex (Dutcher and Garrett, 1963; Woolfenden and Kadhim, 1997; Izbicki et al., 1998). On the basis of driller's logs and water-level data from more than 800 wells, Dutcher and Garrett (1963) divided the valley fill sediments into upper, middle, and lower zones, where each zone includes a fine-grained, less-permeable hydrologic unit overlying a coarse-grained permeable hydrologic unit. The near-surface equivalent of these hydrologic units could be important for purposes of determining liquifaction potential along the I-215 freeway (T. Noce, Pers. Comm., 2004). The basement complex is composed of metamorphic and igneous rocks that crop out in the surrounding mountains and at various places within the valley (Dutcher and Garrett, 1963; Morton and Miller, 2003).

Sediment thickness or basement depth is poorly determined in the San Bernardino Valley and is particularly poorly known along the I-215 freeway between its intersection with I-10 and SR-30. Several 300-m-deep water wells along I-215 freeway did not encounter basement rocks (Izbicki et al. 1998), but a recent seismic reflection survey suggests that maximum depth to basement is about $1.7 \mathrm{~km}$ near the I-215/I-10 Interchange, with basement decreasing in depth toward the northwest (Stephenson et al., 2002).

\section{Seismic Surveys}

In 2003, the U.S. Geological Survey and Caltrans conducted two seismic surveys in the San Bernardino Basin (Fig. 1). The first survey was a regional-scale seismic survey that was acquired in May 2003 from the southern part of the City of Colton to the City of Highland, largely along the trend of the Santa Ana River. We refer to this seismic survey as the San Bernardino Regional (SBR) seismic survey (Fig. 2). The SBR seismic survey was principally designed to provide regional-scale velocity images and relatively lowfold reflection images of the upper few kilometers of the San Bernardino Basin. A second seismic survey was acquired in October 2003 along the northbound shoulder of the I-215 freeway between the I-215/I-10 Interchange and State Road-30 (SR-30) (Fig. 2). We refer to this survey as the San Bernardino High-Resolution (SBHR) seismic survey, which was designed to provide high-resolution reflection and velocity images of the upper $\sim 2 \mathrm{~km}$ along the I-215 freeway. In this report, we first present acquisition and processing parameters and images for the SBR and SBHR surveys, followed by interpretations and discussions of the seismic images and fault structures.

\section{SBR Seismic Data Acquisition}

The SBR survey consisted of a N30 ${ }^{\circ}$ E-trending seismic transect that extended $\sim 20 \mathrm{~km}$ from Tropicana Ranch Road in Colton to slightly northeast of the San Andreas fault near Highland (Figs. 1 and 2). Seismic sources were generated by 15 explosions in $\sim 5-\mathrm{m}$ - to $\sim 18$-m-deep (15 to $60 \mathrm{ft}$ ) boreholes, with explosions ranging in size from 2 to $35 \mathrm{~kg}(5-75$ lbs). The seismic sources were spaced approximately $1 \mathrm{~km}$ apart. Data were recorded with 456 "Texan"seismographs, borrowed from the Program for Array Seismic Studies of the Continental Lithosphere (PASSCAL), a division of the National Science Foundation. The Texan seismographs are small, stand-alone seismic recorders that are about $20 \mathrm{~cm}(8$ in.) in height, $8 \mathrm{~cm}$ (3in.) in diameter, and weigh about $0.9 \mathrm{~kg}$ (2 lbs). We attached the Texan seismographs to vertical-component, single-element, Mark Products 1-10B, 4.5$\mathrm{Hz}$ sensors (geophones). Individual Texan seismographs were spaced approximately 50 $\mathrm{m}$ apart along the profile, and they were programmed to turn on at specific times that correlated with planned shot times. The internal timing of the seismographs was checked 
using Global Positioning System (GPS) clocks before and after deployment. Internal seismograph clock drift is typically less than $2 \mathrm{~ms}$ between deployment and pickup. The data were recorded and retrieved within a 24-hour period, whereby the seismographs were deployed during the day, the 15 shots were recorded during the night (12:00 A.M. to 5:00 A.M.), and the seismographs were retrieved and downloaded the following day. The seismic data were recorded at a 2-ms sampling rate. See Table 1 for principal acquisition parameters of the SBR profile.

Table 1. Acquisition Parameters for the SBR Profile. Distance is relative to the first geophone.

\begin{tabular}{|l|l|l|l|l|l|l|l|l|l|l|}
\hline Profile & Orient. & $\begin{array}{l}\text { Array } \\
\text { Length }\end{array}$ & $\begin{array}{l}\text { \# of } \\
\text { Seismographs }\end{array}$ & $\begin{array}{l}\text { Shot } \\
\text { Type }\end{array}$ & $\begin{array}{l}\text { \# of } \\
\text { Shots }\end{array}$ & $\begin{array}{l}\text { Shot } \\
\text { Spacing }\end{array}$ & $\begin{array}{l}\text { Geo. } \\
\text { Spacing }\end{array}$ & $\begin{array}{l}\text { Geo. } \\
\text { Freq. }\end{array}$ & $\begin{array}{l}\text { Record } \\
\text { Length }\end{array}$ & $\begin{array}{l}\text { Sample } \\
\text { Rate }\end{array}$ \\
\hline LR & NE-SW & $\sim 20 \mathrm{~km}$ & 456 & Explosion & 15 & $\sim 1 \mathrm{~km}$ & $50 \mathrm{~m}$ & $4.5 \mathrm{~Hz}$ & $60 \mathrm{~s}$ & $2 \mathrm{~ms}$ \\
\hline
\end{tabular}

\section{SBR Array Geometry}

To account for variations in geometry, each shot point and geophone location was surveyed using a Global Positioning System (GPS) with theoretical lateral accuracies of about $1 \mathrm{~m}$. The geometry data for the SBR profile are presented in Appendix 1. Relief along the profile was about $275 \mathrm{~m}$ (Fig. 3a). The array of geophones varied from a bestfit line (linearity) by about $600 \mathrm{~m}$ along the length of the $\sim 20 \mathrm{~km}$-long array (Fig. 3b). Shot points varied in elevation by about $220 \mathrm{~m}$ (Fig. 3c), and the shot-point array varied in linearity by about $1 \mathrm{~km}$ (Fig. 3d). The deviations in the linearity of the shot-point and seismograph arrays were necessary because of limitations on shot-point and seismograph placement imposed by the highly urban setting.

\section{SBR Seismic Data}

We present shot gathers from each shot point along the SBR seismic profile (Fig. 4ao). Although only $6 \mathrm{~s}$ of seismic data are presented in figure 4, 60-s-long records were recorded for each shot so that all angles of the wavefield could be recorded. We minimally processed the shot gathers presented in this report (Fig. 4a-o) by editing noisy or dead traces, applying automatic gain control (AGC Window $=4000 \mathrm{~ms}$ ), and applying low bandpass (2-4-12-24 Hz) filtering. Compressional waves (P-waves), surface waves, air waves, and some shear waves are apparent in the shot gathers. Near-vertical and wide-angle reflections are also present on all shot gathers, which allow low-fold reflection images to be developed. Although the urban environment was noisy, seismic energy propagated across the entire seismic profile for most shots. However, small explosions $(\sim 2 \mathrm{~kg})$ in shallow boreholes $(5 \mathrm{~m})$, used near residential property or in bedrock locations, did not propagate as well. The larger shots generally provided the strongest seismic signal at the greatest offsets. Propagation of the seismic signal was, in some cases, related to the structure of the Earth, whereby sharp-edged basin boundaries reflected much of the seismic energy. Also, in some cases, propagation was related to the shot location, whereby shots within the basin generally propagated well. Empirical observations elsewhere have shown that shots located within basins generally propagate seismic energy better than shots outside of basins.

Asymmetry in first-arrival travel times is apparent for shot point 2-7, with earlier arrivals to the south. This pattern reverses for shot point 8, and shot points 9-12 are not markedly asymmetric. At shot point 7, an appreciable delay in the first arrival at the shot gather is indicative of vertically offset (down to the northeast) shallow-depth strata immediately beneath the shot point (Fig. 4g). The overall variation in the symmetry of 
first-arrival refractions is consistent with deepening of basement northward from shot points 2-7, shoaling from shot points 8-13, deepening from shot points 13 to 14 , and shoaling from shot points 14 to 15 (Fig. 5).

\section{SBR Seismic P-Wave Velocity Analysis and Image}

To develop P-wave tomographic seismic-velocity models of the subsurface along the SBR seismic profile, we inverted first-arrival travel times from usable seismograms using a modified version of an algorithm by Hole (1992). The velocity inversion method uses 2- and 3-dimensional ray tracing to match observed and calculated travel times until a suitable fit is obtained for all arrivals from all shots. In parameterizing the model, we used $50-\mathrm{m}$ by $50-\mathrm{m}$ horizontal and vertical grid spacings and 2-D starting models derived from composite 1-D velocity models calculated from the shot gathers. When inverting the seismic data for velocity structure, we used multiple 2-D velocity starting models, given the asymmetry of shot gathers, as discussed above. Regardless of the starting model used, successive velocity inversions yielded similar 2-D final velocity models (Fig. 5a), suggesting that the velocity structure along the profile is well resolved. In general, the model is best resolved where we have the highest density of ray coverage (Fig. 5b). For the final velocity model, we applied a smoothing routine to the inversion that yielded an approximately 100- to 300-m vertically and horizontally smoothed model.

The minimum depth of velocity imaging is related to the shot $(\sim 1 \mathrm{~km})$ and geophone $(\sim 50 \mathrm{~m})$ spacings, the model grid spacing $(\sim 50 \mathrm{~m})$, frequency of the data, and the amount of smoothing used in modeling. Therefore, velocities in the upper $100 \mathrm{~m}$, for example, are a smoothed average of the velocities within those depth ranges. The maximum depth of velocity imaging was limited by the maximum distance that clear first-arrival refractions could be measured on the shot gathers (Fig. 4). Because of the noisy urban environment, clear first-arrival refractions were measurable to varying distances for each shot. However, propagation was greater than $10 \mathrm{~km}$ from the source for most shots, which allowed us to develop a P-wave velocity image to maximum depths of approximately $4 \mathrm{~km}$ (Fig 5a). Observed velocities are highly variable across the model but are generally highest $(>6 \mathrm{~km} / \mathrm{s}$ ) below depths of about $2 \mathrm{~km}$ along most of the seismic profile and near the surface on the southwestern end of the profile. Velocities are lowest $(<2 \mathrm{~km} / \mathrm{s})$ within the upper few hundred meters along most of the profile, but relatively low velocities $(<3 \mathrm{~km} / \mathrm{s})$ extend to depths as great as $1 \mathrm{~km}$ between meters 3000 and 7000 of the velocity model. These deep regions of low-velocity can be interpreted as a well-developed basin that is about $5 \mathrm{~km}$ wide at its deepest points (Fig. 5). The velocity image suggests that the basin gradually shoals to the northeast but is abruptly terminated on the southwest (Fig. 5a). A prominent feature of the velocity image is the high near-surface velocity $(\sim 6 \mathrm{~km} / \mathrm{s})$ that is underlain by relatively lower velocities $(\sim 4 \mathrm{~km} / \mathrm{s})$ on the south end (La Cadena Drive) of the profile. Such reversals in velocity are indicative of complex structures, such as thrust faults and variable geologic layering, because on crustal scales, lower-velocity rocks usually overlie higher-velocity rocks. Geologic interpretations of the velocity images are discussed in later sections of this report.

\section{SBR Seismic Reflection Processing}

In acquiring the seismic data, we used a "shoot-through" geometry, whereby shots were systematically fired through the stationary recording array. The combination of multiple sources and multiple receivers, which were spread over long distances, permitted both refraction and reflection data to be simultaneously acquired. This 
geometrical setup enables recording of wide-angle reflections from steeply dipping structures, which can be migrated to their proper geographical locations (Hole et al., 2002).

In seismic reflection data processing, we used procedures similar to those outlined by Brouwer and Helbig (1998), but we adapted the procedures to accommodate the low fold of the SBR data. Processing steps for stacked images included geometry installation, independent trace editing, timing corrections, elevation static corrections, AGC, bandpass filtering, surgical muting, velocity analysis (from refractions, semblence, and hyperbolic moveout), NMO correction, stretch muting, common-depth-point stacking, post-stack AGC, post-stack bandpass filtering, and post-stack deconvolution. For migrated sections, we used Kirchoff pre-stack depth migration after velocity analysis. Principal parameters used in processing are listed in Table 2. In trace editing, noisy traces (due to cultural noises) or redundant traces (due to profile geometry) were removed from the shot gathers before stacking or migrating, leaving approximately 400 channels per shot gather. Elevation statics, migration, and velocity analyses were accomplished using the tomographic velocity model (Fig. 5a). For velocities at depths greater than those determined by the tomography velocity model, we used parabolic methods, and we inferred velocities based on laboratory-based velocity-depth (pressure) relations (Christensen, 1982; Carmichael, 1989) and refraction velocities from similar rocks in nearby terranes (Fuis et al., 2001).

Table 2. Reflection Processing Parameters for the SBR Profile

\begin{tabular}{|l|l|}
\hline Maximum Fold & 15 \\
\hline CDP Spacing & $25 \mathrm{~m}$ \\
\hline $\begin{array}{l}\text { AGC } \\
\text { Prestack } \\
\text { Poststack }\end{array}$ & $1000 \mathrm{~ms}$ \\
& $1000 \mathrm{~ms}$ \\
\hline $\begin{array}{l}\text { Bandpass Filter } \\
\text { Prestack } \\
\text { Poststack Low }\end{array}$ & $1-2-10-20 \mathrm{~Hz}$ \\
\hline Surgical Mute & $2-4-50-100 \mathrm{~Hz}$ \\
\hline & $\begin{array}{l}\text { Top (refraction) mute } \\
\text { Bottom (surface- and air- }\end{array}$ \\
\hline Deconvolution & wave) mute \\
\hline $\begin{array}{l}\text { Migration (max freq., } \\
\text { aperture, emergence angle) }\end{array}$ & $80 \mathrm{~Hz}, 8000 \mathrm{~m}, 30$ degrees \\
\hline
\end{tabular}

\section{SBR Low-fold Migrated Reflection Image}

A migrated reflection image was developed for the SBR profile using low-fold reflections from the shot gathers (Fig. 6). Because of the design of the SBR survey and because the data were bandpass filtered with dominant frequencies between 1 and $20 \mathrm{~Hz}$, reflectors are best resolved at the higher end of the frequency spectrum. Assuming velocities of 1500 and $6000 \mathrm{~m} / \mathrm{s}$, frequencies between 1 and $20 \mathrm{~Hz}$, and the quarterwavelength criteria for a reflection to be generated (Dobrin and Savit, 1988), only layers that are at least $20 \mathrm{~m}$ thick are likely to be imaged with the SBR data. However, most layers imaged in the upper few kilometers by these low-frequency data are likely to be about $40 \mathrm{~m}$ thick.

Strong, shallow-depth reflections are observed along most of the seismic profile, but most reflections below depths of about $200 \mathrm{~m}$ are less laterally continuous. Apparent 
reflections from the basement dip southward for locations northward of meter 3000 of the seismic profile. Although apparent noise is observed on the seismic image, clear reflections are observed to several kilometers depth.

\section{SBR Combined Velocity and Seismic Reflection Image}

We superimposed the velocity model (Fig. 5a) onto the seismic reflection image (Fig. 6) so that direct comparisons between velocities and reflections could be made (Fig. 7). The combined images show that the strong shallow-depth reflectors correspond to strata with P-wave velocities less than about $3000 \mathrm{~m} / \mathrm{s}$ and that these low-velocity reflectors are deepest $(\sim 1 \mathrm{~km})$ beneath the I-215/I-10 Interchange and beneath the Tippecannoe Avenue area. The low-velocity reflectors largely dip southward between meters 19000 to 5000 (San Andreas fault to south of the I-215/I-10 Interchange), where they are abruptly offset to shallow $(\sim 200 \mathrm{~m})$ depths on the south of meter 5000 . Strong reflectors within basement rocks $(>4000 \mathrm{~m} / \mathrm{s})$ also dip southward (Fig. 7). A peculiarly thick low-velocity $(<4000 \mathrm{~m} / \mathrm{s}$ ) basement (?) interval is seen between model coordinates 6500 and 9500 , which we discuss below in the interpretative section.

\section{SBHR (I-215) Data Acquisition}

We acquired an approximately 8.2-km-long, high-resolution, combined reflection and refraction profile from the intersection of I-215 and Fairview Drive (Santa Ana River) to the intersection of I-215 and $28^{\text {th }}$ Street (Fig. 8). The seismic profile, which we refer to as the San Bernardino High-Resolution (SBHR) profile, was acquired along the northbound shoulder of I-215. Acquisition parameters for the SBHR profile are shown in Table 3. Seismic sources were generated by a combination of $\sim 1500$ Betsy-Seisgun $^{\mathrm{TM}}$ blasts (400 grain) and $\sim 0.9 \mathrm{~kg}$ ( $2 \mathrm{lb}$.) explosions in 3-m-deep boreholes. The data were recorded on an array of four Geometrics Strataview ${ }^{\mathrm{TM}} \mathrm{RX} 60$ seismographs, with a total of 240 active channels. The sensors were coupled to the ground via Mark Products L$40 \mathrm{~A}^{\mathrm{TM}}$ single element $40-\mathrm{Hz}$ geophones and 60-pair refraction cables. Both shots and geophones were spaced at 5-m intervals, with the geophones and shots laterally offset by $1 \mathrm{~m}$. For seisgun blasts, shot timing was determined electronically at the seismic source when a hammer, used to trigger the seisgun, electrically closed contact with the BETSY Seisgun $^{\mathrm{TM}}$, sending an electrical signal by radio to the seismograph. For downhole explosive blasts, the shooter's box simultaneously triggered the blast and a radio signal that turned on the seismographs. Three seconds of data for each seisgun blast and $5 \mathrm{~s}$ of data for each explosive blast were recorded in SEG-2 format on the hard drive of the seismographs during field acquisition. The data were later transferred to 4-mm tape in SEG-Y format for long-term storage.

Prior to acquiring the data, we surveyed geophone and shot locations using a measuring tape. After acquisition, more precise (several centimeters) geophone and shot locations were surveyed using a GPS receiver.

\section{SBHR Array Geometry}

In seismic reflection imaging, artifacts can be mistaken for structure if geophones and/or shot locations have significant elevation variations and non-linear alignments that are not included in processing the data. To properly account for such variations in geometry, each shot point and geophone location was surveyed using a Global Positioning System (GPS) with theoretical accuracies of a several centimeters. The geometry data for SBHR seismic profile are presented in Appendix 2. 
Four RX-60 seismographs with 240 active channels were utilized to record the data. The geophone array was stationary while the first 180 shots were recorded. Afterward, 120 channels of the array were moved to the north end of the array, and 120 additional shots were recorded. This process was repeated until the end of the profile was reached. During field data acquisition, two channels of each 60-channel seismograph were overlapped as an additional constraint on timing between the seismographs. A total of 1505 shots were fired into the array, with 175 shot points not utilized due to cultural features.

Data were acquired from south to north, and the total length of the SBHR profile was $8332 \mathrm{~m}$. Elevations of geophones along the profile varied by more than $67 \mathrm{~m}$ over a distance of about $8332 \mathrm{~m}$ (Fig. 9a), and the geophone alignment varied from a linear array by less than $283 \mathrm{~m}$ (Fig. 9b). Variations in shot-point elevation (Fig. 9c) and linearity (Fig. 9d) along SBHR profile are similar to those of the geophones.

Fold along the SBHR profile (Fig. 9e) was not smoothly varying because the recording array was not stationary for all shots. Maximum fold was about 173 near the ends of the SBHR profile, but fold of approximately 100 was obtained for most of the profile.

Table 3. Acquisition parameters for the SBHR seismic profile. Distance is relative to the first (southern-most) geophone (Channel).

\begin{tabular}{|l|l|l|l|l|l|l|}
\hline $\begin{array}{l}\text { Profile } \\
\text { Name }\end{array}$ & Orientation & $\begin{array}{l}\text { Geophone } \\
\text { Array } \\
\text { Length }(\mathrm{m})\end{array}$ & $\begin{array}{l}\text { Shotpoint } \\
\text { Array Length } \\
(\mathrm{m})\end{array}$ & No. of Shots & $\begin{array}{l}\text { No. } \\
\text { of } \\
\text { CDPs }\end{array}$ & $\begin{array}{l}\text { Maximum } \\
\text { Fold }\end{array}$ \\
\hline $\begin{array}{l}\text { SBHR } \\
(\mathrm{I}-215)\end{array}$ & S-N & 8332.52 & 8246.32 & $\begin{array}{l}1505 \text { total shots } \\
181 \text { exp } \\
1324 \text { shotgun }\end{array}$ & 1681 & 173 \\
\hline
\end{tabular}

\section{SBHR Seismic Data}

Example shot gathers near the ends and middle of the SBHR seismic profile are shown in figure 10 . The shot gathers have been minimally processed, whereby bandpass filtering (8-16-200-400 Hz) and AGC (300) were applied. Whereas the down-hole explosions provided lateral propagation to offsets of approximately $500 \mathrm{~m}$, propagation from the shotgun blasts were limited to about $100 \mathrm{~m}$ lateral offset. Because of the relatively long recording array (240 channels or $1200 \mathrm{~m}$ ), both reflection and refraction data were simultaneously acquired. We processed the seismic data as both shallow-depth velocity images and reflection images. Seismic data from both the shotgun blasts and the explosions were stacked at high fold (Fig. 9e) in an attempt to add the seismic signals and cancel random noises. Generally, the combined sources produced good images in the upper few hundred meters, but the deeper reflections contained appreciable noise due to the low-signal-to-noise ratios of the seisgun blasts. Generally, the explosions were energetic enough to provide good signals to depths in excess of $1500 \mathrm{~m}$, but when the seisgun blasts and the explosive blasts were stacked together, the seisgun data significantly degraded the combined stack at depths in excess of a few hundred meters. However, the seisgun data significantly improved the stack at shallow $(<100 \mathrm{~m})$ depth. Thus, we present several reflection images, whereby some images include only explosive sources and other include both explosive and seisgun blasts.

The quality (resolution and depth) of the seismic data was degraded by the high level of traffic noise along the I-215 freeway during the daylight hours (see cover of this report). Prior to data acquisition, we conducted walk-away tests during the daylight and night-time hours, and we concluded that night-time data acquisition would be most 
advantageous. We anticipated nighttime data acquisition in planning the seismic survey; however, logistical support needed to conduct nighttime data acquisition was not available. Thus, all of the seismic data were acquired during daylight hours when cultural and traffic noises were highest.

\section{SBHR (I-215) Velocity Analysis and Image}

To develop tomographic P-wave seismic velocity models of the subsurface along the SBHR seismic profile, we inverted first-arrival travel times from usable seismograms from the SBHR shot gathers in a similar manner as done for the SBR velocity image. In parameterizing the SBHR model, we used 5-m by 5-m horizontal and vertical grid spacings and 2-D starting models derived from composite 1-D velocity models, calculated from shot gathers. Multiple 2-D starting velocity models yielded consistently similar 2-D final velocity models (Fig. 11a), suggesting that the velocity structure along the profile is well resolved. Although only two reversing raypaths are required to obtain accurate velocities, the SBHR model is best resolved where we have the highest density of ray coverage (Fig. 11b). For the final velocity model, we applied a smoothing routine to the inversion that yielded an approximately 10 - to $15-\mathrm{m}$ vertically and horizontally smoothed model.

The minimum depth of velocity imaging is related to the shot $(\sim 5 \mathrm{~m})$ and geophone $(\sim 5 \mathrm{~m})$ spacing, the model grid spacing $(\sim 5 \mathrm{~m})$, frequency of the data, and the amount of smoothing used in modeling. Therefore, velocities in the upper $10 \mathrm{~m}$, for example, are a smoothed average of the velocities within those depth ranges. The maximum depth of velocity imaging was limited by the maximum distance that clear first-arrival refractions could be measured on the shot gathers (Fig. 10). For the SBHR profile, the high noise level limited the maximum distance to about $600 \mathrm{~m}$ for the explosions and only to about $100 \mathrm{~m}$ for the seisgun blasts. Typically, refractions penetrate to depths equal to about $25 \%$ of the maximum distance first arrivals can be measured, resulting in maximum imaging depths of about 100-150 m along much of the SBHR profile.

Along the SBHR (I-215) profile, P-wave velocities in the upper $150 \mathrm{~m}$ range between about $800 \mathrm{~m} / \mathrm{s}$ and $2800 \mathrm{~m} / \mathrm{s}$ (Fig. 11a). Low-velocity $(<1500 \mathrm{~m} / \mathrm{s})$ deposits thicken appreciably from south to north along the profile, with a maximum thickness of about $75 \mathrm{~m}$ on the north end of the profile. As discussed in the sections below, the 1500 $\mathrm{m} / \mathrm{s}$ velocity contour largely coincides with the ground water table in unsaturated sediments (Schon, 1996; Catchings et al., 1999; 2000; Gandhok et al., 1999). Because of the importance of the ground-water table in delineating structures such as faults (Woolfenden and Kadhim, 1997; Izbicki et al. 1998), we highlight the $1500 \mathrm{~m} / \mathrm{s}$ contour here in white (Fig. 11a). The apparent ground-water table $(1500 \mathrm{~m} / \mathrm{s})$ (not including perched or thin ground-water aquifers) is offset by about 10 to $15 \mathrm{~m}$ at multiple locations along the profile. However, between meters 800 to 1200 of the SBHR profile, the 1500 $\mathrm{m} / \mathrm{s}$ contour is vertically offset by about $25 \mathrm{~m}$, with thicker low-velocity deposits to the southwest. Deposits with velocities above $2000 \mathrm{~m} / \mathrm{s}$ also show appreciable vertical offset along the seismic profile. As discussed below, such vertical displacements in the saturated sediments $(1500 \mathrm{~m} / \mathrm{s})$ can be indicative of fault zones (Catchings et al., 1999; 2000; Gandhok et al., 1999).

\section{SBHR (I-215) Reflection Processing}

As with the SBR profile, the combination of multiple sources and multiple receivers, which were spread over long distances, permitted both shallow refraction and 
near-vertical reflection data to be simultaneously acquired along the SBHR profile. To process the seismic reflection data, we used procedures similar to those outlined by Brouwer and Helbig (1998). Processing steps for stacked images included geometry installation, independent trace editing, timing corrections elevation static corrections, AGC, bandpass filtering, surgical muting, velocity analysis (from refractions, semblence, and hyperbolic moveout), NMO correction, stretch muting, common-depth-point stacking, post-stack AGC, Post-stack bandpass filtering, and post-stack deconvolution. We removed noisy traces (due to highway noises) or redundant traces (due to line geometry) from the shot gathers before stacking, leaving approximately 232 channels per shot gather. Elevation statics and shallow depth conversion were accomplished using the SBHR tomographic velocity model (Fig. 11a). For velocities deeper than those determined by the SBHR tomography velocity model, we used parabolic methods, inferred velocities based borehole lithologies, and refraction velocities from the SBR profile.

We also used Kirchoff prestack depth migration to remove diffractions and properly account for dipping strata. For unmigrated stacks, we laterally combined every three traces to enhance the reflection signals. This effectively smoothed the image over three CDP's or about $7.5 \mathrm{~m}$. For the migrated images, we chose not to laterally combine signals so that locations of specific structures could be more clearly determined.

\section{SBHR Seismic Reflection Images}

We developed depth images for the SBHR profile by either stacking (1) approximately 181 explosive blasts and/or (2) more than 1300 seisgun blasts, with approximately 232 channels per shot (Fig. 12). Fold (with all shot points) along the seismic profile was laterally varying but was generally between 100 and 175 , except at the very ends of the seismic profile (Fig. 9e). Common-depth-point (CDP) spacing along the profile is $2.5 \mathrm{~m}$, such that a seismic trace was produced every $2.5 \mathrm{~m}$ along the $\sim 8250$ $\mathrm{m}$-long profile. The reflection images were processed to approximately 2000 milliseconds ( 2 seconds), which included a datum above the topography of the seismic profile; however, the signal-to-noise ratio is low for depths in excess of $1200 \mathrm{~m}$ (Fig. 12).

When only the explosive sources are stacked and every three traces are laterally summed, reflectors can be traced across most of the seismic transect, but most of the reflectors appear to be vertically offset at multiple locations (Fig. 12a). To visually enhance the reflectors, we highlighted (in yellow) the spaces between every other reflector to depths of about $900 \mathrm{~m}$ (Fig. 12b). The visually enhanced image suggests dipping and vertically offset layers across much of the seismic profile. We used the SBHR and SBR tomographic velocity models and other velocity analyses to develop a Kirchoff, pre-stack migrated depth image along the SBHR profile (Fig. 12c). The migration image shows many of the same features, as does the stack; however, as is typical of Kirchoff migration images, the resolution is lower than the stacked image. The migrated image shows multiple near-vertical zones along the seismic transect where strata are disrupted or truncated. We attempted to correlate these zones with variations in acquisition parameters (such as fold, missing shots, street crossings, etc.), but most of the zones do not correlate with changes in acquisition parameters. We also varied migration parameters and migrated the images multiple times, but the apparent disrupted zones were present on each migrated image. As discussed below, we conclude that these apparent disrupted zones are likely due to the subsurface structure and not to acquisition or processing parameters. The near-surface (upper $50 \mathrm{~m}$ ) is not well imaged with only the explosive sources because the explosive sources were spaced at about $40 \mathrm{~m}$. However, 
by combining the seisgun sources, which were spaced at 5-m increments, details of the near-surface stratigraphy were better imaged (Fig. 12d).

We used relatively low bandpass filtering (15-30-60-120 or $20-40-80-160 \mathrm{~Hz}$ ) in developing the seismic reflection images because the recorded signals were dominated by relative low-frequency energy. The relative low-frequency of the recorded seismic energy is probably due to either highly attenuating near-surface materials or to disrupted subsurface layering. At higher frequencies, poorly consolidated and laterally variable deposits that contain boulders, large rock fragments, or gravel generally do not image well with seismic reflection methods. These types of deposits are known to underlie parts of the SBHR profile at shallow depths (Dutcher and Garret, 1963; Morton and Miller, 2003; T. Noce, Pers. Comm., 2004). Furthermore, boulders, faults, and other sharp discontinuities tend to scatter and attenuate the seismic energy and produce numerous diffractions at higher frequencies. As a result, the best seismic images from the SBHR profile utilize relatively low-frequency energy, which is less scattered and attenuated. The resulting lower frequency images show larger scale features and thicker layer sequences. Assuming velocities between 1000 and $3000 \mathrm{~m} / \mathrm{s}$, frequencies between 15 and $60 \mathrm{~Hz}$, and the quarter-wavelength criteria for a reflection to be generated (Dobrin and Savit, 1988), only reflectors that are at least $4 \mathrm{~m}$ thick are likely to be imaged in the near surface with the SBHR data. However, deeper reflectors imaged by the SBHR data are likely to be $10 \mathrm{~m}$ or more thick. Because of the Fresnel zone limitation (Dobrin and Savit, 1988), individual reflectors at $100 \mathrm{~m}$ depth must be radially continuous for at least $6 \mathrm{~m}$ to produce good reflections. At depths of $1 \mathrm{~km}$, similar reflectors must be radially continuous for at least $55 \mathrm{~m}$ to generate good reflections with $20-\mathrm{Hz}$ data. For deeper images, the Fresnel zone requirement became progressively more important because, in such a tectonically active area as San Bernardino, reflectors may be too disturbed over the distances needed to generate strong, continuous reflections.

\section{Lithology (SBR Profile)}

\section{Interpreted Images}

We broadly categorize the major lithologic units along the SBR profile as (1) unsaturated and unconsolidated alluvium, (2) saturated and unconsolidated alluvium, (3) consolidated to partially consolidated alluvium, (4) Pliocene and Pleistocene (old) alluvium, and (5) basement (metamorphic or crystalline). These broad categories are largely based on comparison of our measured seismic velocities with our reflection images and observations of deposits in nearby well borings (Izbicki et al., 1998). Reflection images are not particularly good at differentiating among the various rock types listed above because all can be reflective. However, broad categories of lithologic units, such as sediments and basement, can be inferred on the basis of reflectivity because sediments are likely to be more reflective and have lower velocities and densities than crystalline basement rocks (Fig. 13).

Within the sedimentary section, deposits with velocities less than $1500 \mathrm{~m} / \mathrm{s}$ are not imaged on the SBR profile because these deposits are largely confined to the upper few tens of meters, and the SBR seismic data averages the velocities and reflectors in that depth range (Fig. 7). Deposits with average velocities between about $1500 \mathrm{~m} / \mathrm{s}$ and 2200 $\mathrm{m} / \mathrm{s}$ (upper few hundred meters) are probably saturated but are mostly composed of unconsolidated alluvium, as observed in well borings in the area (Izbicki et al, 1998). Deposits with velocities between about $2200 \mathrm{~m} / \mathrm{s}$ and $3000 \mathrm{~m} / \mathrm{s}(\sim 300 \mathrm{~m}$ to $1000 \mathrm{~m}$ depth) are likely to be partially consolidated to consolidated (Brocher et al., 1997). Similar relations between the physical condition of sediments, their seismic velocities, 
and depth of burial have been observed elsewhere in pre-Tertiary sedimentary basins in California (Catchings et al., 1999; in prep; Gandhok et al., 1999). Sediments with velocities between 3000 and $3800 \mathrm{~m} / \mathrm{s}$ are likely to be older Pliocene to Pleistocene deposits, like those exposed on in the San Timoteo Badlands to the southeast of the seismic profiles (Morton and Miller, 2003). We observed these velocities only in the deeper parts of the San Bernardino Basin (Fig. 7). All of these sedimentary deposits are reflective in the seismic reflection images. Rocks with velocities greater than $4000 \mathrm{~m} / \mathrm{s}$ are interpreted to be metamorphic (Pelona Schist) or crystalline (tonalite or granodiorite) rocks, similar to rocks that crop out in the hills within the San Bernardino Basin and within the surrounding mountains. These rocks are less reflective than the overlying sediments (Figs. 7 and 13).

\section{Basin Structure (SBR Profile)}

We use both the seismic velocities and the seismic reflection images to infer the depths and dimensions of the San Bernardino Basin. The reflection and velocity images suggest that basement is only a few hundred meters deep on the southwestern end of the SBR profile, but basement abruptly deepens along several faults to a depth of about 1200 $\mathrm{m}$ between meters 3000 and 8000 of the seismic profile (Fig. 13). The deepest part of the San Bernardino Basin along the SBR profile is about $5 \mathrm{~km}$ wide, but the base of the basin has considerable topography. Both basement and the overlying sediments also appear to be folded and uplifted in the central part of the basin. From about Tippecanoe Avenue ( $\sim$ meter 8000$)$ to Highway SR-30 (meter 14000), we interpret basement to rise along a series of faults, with an average slope of about 7 degrees.

The basement rocks ( $\sim 4000$ to $6000 \mathrm{~m} / \mathrm{s}$ ) contain strong reflectors that dip predominantly southwestward. The basement reflectors are more prominent northeast of meter 3000, suggesting that basement rocks are probably not the same on both sides of the San Jacinto fault zone (near meter 3000). We suggest that basement rocks northeast of meter 3000 are probably composed of Pelona Schist for several reasons. First, Pelona Schist is observed in outcrop a few kilometers southeast of the northeastern end of the SBR profile, within the Crafton Hills, and to the northwest of the SBR profile, within the Shandin Hills (Morton and Miller, 2003). The basement topographic high observed between meters 12000 and 16000 of the SBR profile (Fig. 13) is probably part of a northwest-trending structure between the Crafton Hills, Perris Hills, and the Shandin Hills. Second, the upper basement rocks along the SBR profile have P-wave velocities of $\sim 4000$ to $5000 \mathrm{~m} / \mathrm{s}$ (Fig. 7), which are similar to velocities observed by Fuis et al. (2001) for the Pelona Schist at shallow depths in the San Gabriel Mountains. Third, because the Pelona Schist is likely to be more reflective than crystalline igneous rocks, the more reflective rocks northeast of meter 3000 of the SBR profile are more consistent with Pelona Schist than crystalline igneous rocks. Fourth, although the sedimentary rocks to the northeast of the deep part of the basin are thinner than those near meter 3000, the Bouguer gravity anomaly remains relatively low to the northeast (Anderson et al., 1999), suggesting less dense basement rocks to the northeast (Fig. 13).

On the southwestern end of the profile, however, we interpret the underlying high-velocity ( $6000 \mathrm{~m} / \mathrm{s}$ ) rocks to be crystalline (granodiorite and tonalite) basement rocks (Fig. 7) like those exposed in the nearby hills (Morton and Miller, 2003). The velocity reversal ( $\sim 4000 \mathrm{~m} / \mathrm{s})$ below $\sim 500 \mathrm{~m}$, however, is somewhat curious; it may suggest that crystalline rocks have been thrust over lower-velocity rocks. 


\section{Fault Structures (SBR)}

Due to the low-fold design of the SBR profile, interpretations of the seismic reflection images are non-unique. However, we use several criteria in interpreting faults along the SBR and SBHR seismic profiles. First, we interpret faults on the seismic reflection images where a series of reflectors are vertically offset over a range of depths. Second, because empirical studies have shown that seismic P-wave velocities within fault zones are typically 17 to $40 \%$ lower than that of the surrounding materials (Aki and Lee, 1976; Mooney and Luetgert, 1982; Catchings 1999; Catchings et al., 2002), we consider coincident low-velocity zones and layer offsets to be indicative of fault zones. Third, we interpret faults on the reflection images where the dips of reflectors abruptly change. We are more confident of our fault interpretations where all three of these observations geographically coincide. We interpret fault patterns for both the SBR and SBHR profiles, but because of the differing orientations and the difference in basin width along the two profiles, individual strands of the faults cannot be confidently correlated from profile to profile. In this section, we discuss fault structures along the SBR profile (Fig. $14)$.

There are abrupt near-vertical offset of basement rocks and an appreciable increase in sediment thickness southwest of the I-215/I-10 Interchange (near meter 3000) that correlates with the projected near-surface trace (Morton and Miller, 2004) of the Rialto-Colton fault zone (RCFZ) (Figs. 13 and 14). Because of the appreciable vertical offset in basement northeast the RCFZ, we suggest that the RCFZ, rather than the SJFZ, bounds the southwestern edge of the San Bernardino Basin. There are likely several strands of the RCFZ, along which the sedimentary basin deepens (Catchings et al., in prep), but the RCFZ may merge with the San Jacinto fault zone (SJFZ) at depth. The SJFZ consists of multiple strands that merge at depth, with the near-surface trace of the SJFZ is centered slightly northeast of the I-215/I-10 Interchange (Fig. 14). In the upper few kilometers, individual strands of the SJFZ encompass about a $3.5-\mathrm{km}$-wide zone, and most of these strands are within or bound the deepest part of the San Bernardino Basin. Additional faults that may merge with the SJFZ at depth are located between meters 7000 and 11000 of the SBR profile. The most recognizable cultural feature that is closest to these faults is Tippecanoe Avenue. For purposes of discussion, we refer to these faults as the Tippecanoe fault zone (TFZ). Although the TFZ may extend from the Loma Linda fault to the southeast, it appears to be one of the primary faults that accommodates the transfer of slip from the San Jacinto fault to the San Andreas fault, and unlike the mapped part of the Loma Linda fault, the TFZ is not parallel to the San Jacinto fault farther north, beneath the central part of the San Bernardino Basin. To the northeast, a fourth principal fault zone is located near Highway SR-30. We interpret strands of this fault zone to extend from about meter 12,000 to about meter 16,000 of the SBR profile. This fault zone appears to be related to a relative high in basement rocks that likely trends parallel to the San Andreas Fault from the northern Crafton Hills to the Shandin Hills. For purposes of discussion in the report, we refer to this fault zone as the East Highlands fault zone (EHFZ). We do not see a clear expression of a possible San Andreas Fault zone (SAFZ) because the seismic profile does not extend far beyond its surface expression, but there appears to be a possible expression of it at meter 19000, where it appears that the fault dips to the northeast at about 38 degrees.

\section{Seismicity Along the SBR Profile}

Earthquakes recorded in southern California during the years 1984 to 2002 have been relocated (Hauksson et al., 2003) using double difference techniques, which are 
currently considered the most accurate location techniques (Waldhauser, 2001). We used the double-difference earthquake locations of Hauksson et al., (2003) to construct cross sections of seismic events within $3 \mathrm{~km}$ (Fig. 15) and $1 \mathrm{~km}$ (Fig. 16) of the SBR seismic profile. The events are projected normal to our seismic profile. The seismicity cross sections show that earthquakes occur along most of the SBR seismic profile, suggesting a wide area of faulting along the profile. Many of the events outline well-defined, nearvertical fault zones that extend to more than $20 \mathrm{~km}$ depth. In the upper $10 \mathrm{~km}$, hypocenters are most concentrated beneath the TFZ, with fewer events beneath the SJFZ and EHFZ (Figs. 15 and 16). At depths below $10 \mathrm{~km}$, the largest concentration of events is located between the near-surface expressions of the SJFZ and TFZ, suggesting that the faults may merge well above $20 \mathrm{~km}$ depth. Although the SJFZ is considered the most seismically active fault in the area, the bulk of the seismicity is located northeast of its mapped surface trace at all depths (Figs. 15 and 16). For earthquake hazard purposes in the upper crust, the SJFZ and the other faults to the northeast within the San Bernardino Basin could be considered separate faults.

\section{Lithology (SBHR Profile)}

As discussed for the SBR profile, we generally categorize the rock types along the SBHR profile as (1) unconsolidated and unsaturated alluvial deposits, (2) unconsolidated and saturated alluvial deposits, (3) partially consolidated to consolidated alluvial deposits, (4) Pliocene and Pleistocene (old) alluvial deposits, and (5) basement. Along the SBHR profile, we have seismic tomographic velocities for only the first three categories of rock types.

Empirical studies have shown that saturated sediments (water table) have P-wave velocities of about $1500 \mathrm{~m} / \mathrm{s}$ in unconsolidated sediments (Schon, 1996) and can be mapped in the subsurface by seismically mapping the $1500 \mathrm{~m} / \mathrm{s}$ velocity contour (Catchings et al., 1999; Gandhok et al. 1999). Along the SBHR profile, deposits with Pwave velocities less than about $1500 \mathrm{~m} / \mathrm{s}$ are probably unsaturated and unconsolidated (Fig. 17). Shallow-depth and thin (a few meters thick) aquifers in the upper few meters along parts of the seismic profiles would be considered part of the largely unsaturated sediments because such thin aquifers may not be imaged with relatively low-frequency seismic data. The unconsolidated and largely unsaturated sediments range in thickness from about $25 \mathrm{~m}$ near Inland Drive to more than $75 \mathrm{~m}$ near $28^{\text {th }}$ Street. Lithologically, these low-velocity sediments correspond to the same deposits observed at the surface and near surface (Dutcher and Garrett, 1963; Izbicki et al., 1998; Morton and Miller, 2003). Saturated (unconsolidated) deposits have velocities between about 1500 and $2200 \mathrm{~m} / \mathrm{s}$, and they are highly variable in thickness along the seismic profile. These deposits comprise the bulk of the shallow water table.

We have velocity measurements $(2200 \mathrm{~m} / \mathrm{s}$ to $3000 \mathrm{~m} / \mathrm{s})$ for only the very tops of the partially consolidated to consolidated deposits, but these deposits extend for hundreds of meters in depth, varying between unconsolidated and partially consolidated (Izbicki et al., 1998). These deposits are highly variable in velocity along the profile and are segmented into multiple relatively low- and high-velocity zones and apparently tilted blocks (Fig. 17).

Because velocity data are largely limited to the upper $150 \mathrm{~m}$ along the SBHR profile, our interpretation of deeper basin structure and lithology along the SBHR profile is largely based on reflection patterns (Figs. 17 and 18). The sediments are not highly reflective at frequencies above $10 \mathrm{~Hz}$, suggesting that high-frequencies are highly attenuated within the near-surface deposits, the sediments are not well layered, and/or 
they are highly deformed. However, relatively low frequencies, combined with the densely spaced shots and geophones largely delineate the prominent features of the subsurface along the SBHR profile.

\section{Basin Structure (SBHR Profile)}

The sediment/basement interface is not apparent as a high-amplitude reflector along the SBHR profile, suggesting that the transition from sedimentary rocks to metamorphic/crystalline rocks may be gradational. If such is the case, the top of the metamorphic/crystalline rocks is probably weathered. On the basis of the SBR seismic images, we interpret basement to be at least $1000 \mathrm{~m}$ deep on the south end of the profile, but based on its proximity to the SBR seismic profile, the basin is probably much deeper than $1000 \mathrm{~m}$. Unfortunately, the SBHR data do not have sufficient signal-to-noise ratios to image much deeper than about $1000 \mathrm{~m}$. The SBHR images show basin sediments that dip sharply northward near the southern end of the profile and more gently southward from the northern end (Fig. 18). From the southern end of the seismic profile to just north of Orange Show Drive (meter 1800), sediments below $100 \mathrm{~m}$ depth are largely subhorizontal; however, from about meter 1800 to about meter 3000 along the SBHR profile, these sediments dip steeply. From about meter 3000 to about meter 7000, sediments below $100 \mathrm{~m}$ depth dip more gently southward, as seen along the SBR profile. The basin shape, as revealed by the seismic reflection images, is consistent with gravity measurements (Fig. 18a), whereby gravity values decrease markedly from the south and moderately from the north, toward the center of the profile. The gravity high near the southern end of the profile is likely due to the regional effect of high-density rocks immediately south of the SBHR profile (see Fig. 14).

\section{Fault Structures (SBHR Profile)}

We interpret multiple fault strands along the SBHR profile on the basis of (a) vertically offset layers on the reflection images, (b) inferred lateral variations in the depths of the ground water table, (c) low-velocity zones in the upper few hundred meters and (d) topographic variations (Figs. 19 and 20).

We interpret vertical offsets in reflectors over a range of depths on the seismic reflection images to indicate faults. In many cases, the apparent faults are also accompanied by changes in dip of the reflectors (Fig. 20). On the velocity image, vertical offsets of a few tens of meters in the $1500 \mathrm{~m} / \mathrm{s}$ velocity contour, which is often indicative of the ground water table, suggest that some of these faults may locally act as ground-water barriers (Fig. 19b). Between the apparent faults, there are segments of the SBHR profile where the topography has consistent dips over hundreds of meters to several kilometers (Fig. 19a), suggesting that the faults may bound blocks that are rotated. Some of the apparent faults coincide with low-velocity zones seen on the velocity image (Fig. 19b), and empirical studies elsewhere have shown that faults form lowvelocity zones (Catchings et al., 2002).

On the basis of the cumulative data, we suggest that the SBHR seismic profile obliquely crosses three to four faults, each with near-surface splays, along the $8.2-\mathrm{km}$ long SBHR seismic profile. Similar numbers of splays within relatively short distances are exposed at the surface in multiple locations in the nearby San Bernardino Mountains, and along the northwest projection of the SJF, near its intersection with the SAF (Fig. 1). Such fault splays in the near surface are probably not individual faults that extend through the crust; instead, most of these near-surface fault splays probably merge to form several well-defined fault zones at relatively shallow depths. 
The RCFZ is located south of the I-215/I-10 Interchange and should not be imaged on the SBHR profile (Figs. 1 and 20). However, the principal part of the SJFZ is imaged in the vicinity of Inland Drive, with individual strands extending between Orange Show Road (meter 800) and Inland Center (meter 2000). This part of the SJFZ correlates with its northwestward projection from the SBR profile (Fig. 14). There is a large $(>50$ m) vertical offset in shallow reflectors (Fig. 20) and refractors (Fig. 19b) associated with the SJFZ, with the largest vertical offsets occurring between Orange Show Drive and Inland Drive. Along the SBHR profile, the northwestward continuation of the TFZ is probably centered near downtown San Bernardino, near $3^{\text {rd }}$ Street. As discussed above, this fault may be a continuation of the Loma Linda faults zone, but the TFZ likely acts as a fault that transfers slip from the SJF to the SAF. The series of faults north of $16^{\text {th }}$ Street are probably additional transfer faults.

\section{Seismicity Along the SHBR Profile}

Double-difference-located earthquakes (Hauksson et al., 2003) within $1 \mathrm{~km}$ and 3 $\mathrm{km}$ of the SBHR seismic profile are shown in figure 21. Within $3 \mathrm{~km}$ of the SBHR profile, near-vertical alignments of hypocenters infer several fault zones that extend from the near surface to at least $20 \mathrm{~km}$ depth, suggesting that separate faults extend through the seismogenic crust. Because the hypocenters are distributed over the length of the SBHR profile, the seismicity data suggest that there are multiple faults at all levels of the crust, much like those seen in our seismic images. Although distribution of seismic events suggest that there has likely been movement on many of the imaged fault zones at depth during the past 20 years, the TFZ appears to have been most active fault zone in the San Bernardino Basin.

\section{Comparison with the Stephenson et al. (2002) Seismic Profile}

Stephenson et al. (2002) acquired a seismic reflection profile from Colton to the Perris Hills (Fig. 1). Because their profile was located approximately half way between our SBHR and SBR profiles (north of I-10), we can use their reflection image and interpretations to help constrain the $3-\mathrm{D}$ variation in the large-scale structures observed on our seismic profiles. We refer to the Stephenson et al. (2002) profile as the SBS reflection profile (Fig. 22a,b). The SBS reflection profile was largely coincident with the SBR profile between La Cadena Avenue and the I-215/I-10 Interchange. Northward of the Interchange, the SBS reflection profile trended more northerly than our SBR profile and more northeasterly than our SBHR profile. The SBS and SBR reflection images (Fig. 22) show the similar general reflectors in the upper $1000 \mathrm{~m}$, and both images show a likely basement reflection beneath the I-215/I-10 Interchange.

Because tomographic velocity data were not available for the SBS reflection profile, Stephenson et al. (2002) principally based their structural interpretation on reflection and gravity data, which provide limited constraints. Although the SBS reflection model and our combined seismic images show similar overall structural features of the San Bernardino Basin, there are some differences in the structural interpretations based on the two data sets. On the basis of comparisons of the SBR and SBS reflection data (Fig. 22) and velocity data (Fig. 23), we suggest several modifications to the Stephenson et al. (2002) model. First, the relatively low velocities beneath the I-215/I-10 Interchange area indicate that the San Bernardino Basin extends farther south than suggested by Stephenson et al. (2002), whereby the Rialto-Colton fault forms the basin boundary (Fig. 23). Second, the San Bernardino Basin appears to be deeper than indicated by the SBS model, whereby low-velocity $(<4000 \mathrm{~m} / \mathrm{s})$ strata 
extend more than $2 \mathrm{~km}$ in depth (Figs. 22 -24). Third, the depth to basement may depend on the definition of basement, but the relatively high velocities $(>4000 \mathrm{~m} / \mathrm{s})$ below $2 \mathrm{~km}$ depth at the I-215/I-10 Interchange suggest the presence of crystalline or metamorphic rocks. (Christensen, 1982; Catchings et al. in press). Fourth, high-velocity rocks south of the I-215/I-10 Interchange are underlain by lower velocity, layered rocks, suggesting that sedimentary or metamorphic rocks may underlie the near-surface crystalline rocks (Fig. 23). Fifth, although Stephenson et al. (2002) acknowledge that additional faults could be interpreted from their reflection image, they showed only 8 faults along the profile (Fig. 24a). We interpret faults similar to those interpreted along the SBS seismic profile, but on the basis of offset strata, tilted sedimentary packages, and offset basement reflectors, we interpret additional faults within the San Bernardino Basin (Fig. 24b, c). Our interpreted fault structures also correlate with variations in basement velocities (Fig. 23), whereby a prominent low-velocity zone is associated with the active TFZ, and lateral low-velocity zones in basement coincide with strands of the SJFZ and EHFZ.

\section{Faults Lengths and Orientations}

Although the SBR, SBHR, and SBS reflection profiles are not oriented in the same directions, each profile can be interpreted similarly. In particular, the deep $(\sim 2000$ $\mathrm{m})$ basin near the I-215/I-10 Interchange, a northeastward rise in basement, and several zones of faulting are consistent features on all three (SBR, SBS, and SBHR) profiles. Because the RCFZ, SJFZ, TFZ, EHFZ, and additional faults (herein collectively called "basin faults") can be inferred from all three seismic profiles, we suggest these fault zones to have lateral continuity of at least $9 \mathrm{~km}$, the maximum distance between the profiles along a northwest regional trend.

To better estimate the 3-D variation in the imaged fault zones, we plotted doubledifference earthquake locations for the San Bernardino Basin area in map view (Fig. 25). The epicenters show several linear trends that geographically coincide with the imaged faults. The trends of epicenters imply that a series of "connector" faults extend from the SJFZ to the SAFZ at high angles ( 75 to 80 degrees) to both principal faults (Figs. 2527). Collectively, these faults form classic structures associated pull-apart basins (Aydin and Nur, 1982; Hempton and Neher, 1986) and strike-slip fault duplexes (Woodcock and Fisher, 1986). In cross section and in seismic reflection images, these faults form a negative flower structure that accommodates the stepover between the two fault zones. The basin faults may be up to $30 \mathrm{~km}$ long, suggesting that they can generate moderatemagnitude earthquakes. However, because these basin faults connect both the San Jacinto and San Andreas faults, the maximum-magnitude earthquakes on the basin faults could be considered the same as those of the San Andreas and San Jacinto faults.

Some of the imaged faults trend along the deepest parts of the San Bernardino Basin, as inferred by gravity anomalies (Fig. 26). Generally, high gravity gradients can indicate large changes in basement depth. In the San Bernardino area, lateral variations in the high gravity gradients probably indicate near-vertical offsets in basement caused by faulting. The northwesterly trend of the high gravity gradients is consistent with the concept that the basin fault zones trend northwestward across San Bernardino Basin, connecting to the San Andreas Fault. A similar, but smaller, linear trend in the gravity field can be inferred near the center of the San Bernardino Basin (Fig. 26). Assuming that vertical slip is less than the lateral slip, the geographic correlation between the deepest basin depths and the highest seismicity rates suggest that the basin faults may have been active for a long period of time. 


\section{Discussion}

The seismic images and existing geologic surface mapping suggest that the San Bernardino Basin is associated with parts of at least five fault zones. These fault zones include the Rialto-Colton (RCFZ), San Jacinto (SJFZ), San Andreas (SAFZ), and two lesser known or unknown fault zones, which we refer to here as the Tippecanoe (TFZ) and East Highlands (EHFZ) fault zones. Each of these fault zones appear to be several kilometers wide and contain multiple fault strands that likely merge at depth. Most of the fault zones appear to form flower structures that are commonly associated with strike-slip fault zones (Harding, 1985).

The RCFZ bounds the southwestern end of the San Bernardino Basin, where basement rocks have apparent vertical offsets of about $1000 \mathrm{~m}$. The RCFZ probably has several near-surface strands in the upper crust where it crosses the SBR profile. The SJFZ, also located near the southwestern edge of the San Bernardino Basin, has additional apparent vertical offsets of basement rocks of about 1000 meters. Although the SJFZ is centered near the I-215/I-10 Interchange, individual strands of the fault zone probably extend about $1.5 \mathrm{~km}$ to the northeast and about $2 \mathrm{~km}$ to the south west along the SBR profile. The RCFZ and SJFZ may merge at depths of 5 to $10 \mathrm{~km}$ in the vicinity of the I-215/I-10 Interchange. Thus, the two faults can probably be considered one fault zone that is more than $5 \mathrm{~km}$ wide near the southwestern edge of the San Bernardino Basin. The TFZ may also be part of the SJFZ and may merge with the SJFZ at greater depths. Over the past 20 years, appreciable seismicity has been focussed on TFZ (Figs. 15, 16, 21 and 25), and based on seismicity trends, the TFZ be an extension of the Loma Linda fault (Fig. 25). There also are likely additional faults that transfer slip from the San Jacinto Fault to the San Andreas Fault northeast of the TFZ, but these faults probably merge with other faults at depth. Farther northeast, we interpret a fourth fault zone (EHFZ), centered along a basement high, possibly connecting the Shandin and Crafton Hills. In the upper few kilometers, the EHFZ is several kilometers wide, and there has been a moderate amount of seismicity associated with this fault zone east of I-215 over the past 20 years. However, west of I-215, there appears to be considerable seismicity associated with the EHFZ where it merges with transfer faults in the Shandin Hills area (Figs. 25-27). The SAFZ is located on the northeast boundary of the San Bernardino Basin, but fault strands, including the main trace of the SAFZ, are not clearly imaged on our profiles. The lack of a clearly imaged fault zone near the SAFZ may indicate that the SAFZ zone dips northeastward. There is relatively little seismicity associated with the SAFZ over the past 20 years, suggesting that it is either locked or that most of its slip is transferred to the SJFZ south east of San Bernardino.

Strands of each of the SJFZ, TFZ, and other slip-transfer faults extend beneath the I-215 freeway. In the upper $100 \mathrm{~m}$, these fault strands appear to tilt and offset nearsurface alluvial layers and vertically offset the ground-water table by about 10 to $25 \mathrm{~m}$ in places (Figs. 28 and 29). Most individual fault strands correlate with low-velocity zones in the near-surface sedimentary deposits. In the near surface, the largest vertical offsets of alluvial deposits are associated with the SJFZ, where fault strands located in the vicinities of Orange Show Road to Inland Drive offset near-surface sediments (Fig. 19). Similarly, strands of transfer faults between $18^{\text {th }}$ Street to Highland Avenue also bound southerly dipping sediments at several hundred meters depth. At depth, the seismicity data suggest that most of the basin fault zones have been active over the past 20 years, with earthquakes occurring across most of the San Bernardino Basin. The wide lateral and vertical distribution of earthquakes demonstrates the distributed nature of faulting in the San Bernardino area, as faulting is not confined to one or two discrete fault planes 
(Figs. 25, 26, 28, and 29). We interpret multiple fault splays to underlie much of the I215 freeway between the I-215/I-10 Interchange and Highway SR-30, but many of these fault splays may be part of a few discrete fault zones at depth. The I-215 freeway trends sub parallel to these faults that transfer slip from the SJFZ to the SAFZ (see Figs. 25-27).

To better understand the faulting in the vicinity of the I-215 freeway and in the

San Bernardino Basin, we recommend conducting more targeted high-resolution imaging at lower angles to the slip-transfer faults and perpendicular to I-215. However, we suggest that data be acquired at night, during periods of low traffic volume, and/or along side streets away from the freeway noises. Remote methods, such as INSAR, may be useful in locating potential sites to seismically image. We also recommend trenching studies to understand which faults have been most active at the surface in the recent past.

\section{Acknowledgements}

We thank the City of San Bernardino, the San Bernardino Valley Water District, and Caltrans for granting permission to place seismographs and shot points along the seismic profiles. We also thank Caltrans for providing boreholes that were used as shot points. We thank John Bowman and Martha Merriam (both with Caltrans) for invaluable help in setting up the seismic profiles. We thank L. Behera, Coyn Criley, Sam Gudino, Sr., Sam Gudino, Jr., Linda Nyguen, G. Rao, Jose Rodriguez, Mike (of Caltrans), and Beldon Schroeder for assistance in data acquisition. We thank the PASSCAL (Marcos Alveraz, Mike Fort, Tim Parker; Galen Kaip-UTEP), Rob Williams, and John Childs for providing seismic equipment and assistance. We thank scientists form the National Geophysical Research Institute - India for technical assistance. Caltrans and the USGS Earthquake Hazards Program provided funding for the work. Reviews by Gary Fuis and Janice Murphy are greatly appreciated.

\section{References}

Aki, K., and W.H.K. Lee, 1976, Determination of three-dimensional velocity anomalies under a seismic array using P-arrival times from location earthquakes. I. A homogenous initial model, J. Geophys. Res., 81, 4381-4399

Anderson, M.L., R. Jachens, and L. Woolfenden, 1999, Structural model of the San Bernadino strike-slip basin, southern California, from regional gravity data: Eos, Transactions AGU, v.80, p. F 1002.

Aragaon, G., 2004, On the road in southern California: A review of major projects and priorities in http://california.construction.com/features/archive/0304.

Aydin, A. \& A. Nur, 1982, Evolution of pull-apart basins and their scale independence. Tectonics 1, 91-105.

Brocher, T.M., A. L. Ruebel, and E. E. Brabb, 1997, Compilation of 59 sonic and density logs form 51 oil test wells in the San Francisco Bay area, California, U.S. Geol. Surv. Open-File Report 87-987, 75 pp.

Brouwer, J. and K. Helbig, 1998, Shallow High-Resolution Reflection Seismics, Handbook of Geophysical Exploration, Volume 19, Section I. Seismic Exploration (K. Helbig and S. Treitel, eds.), Elsevier, New York, 391 pp.

Carmichael, R. S., 1989, Practical Handbook of Physical Properties of Rocks and Minerals, CRC Press, Boca Raton, Florida, 583 pp.

Christensen, N. I., 1982, Seismic velocities in R. S. Carmichael ed., Handbook of Physical Properties of Rocks, V. II, CRC Press, Boca Raton, Florida, 583 pp. 
Catchings, R. D., G. Gandhok, M. R. Goldman, E. Horta, M. J. Rymer, P. Martin, and A. Christensen, 1999, Subsurface, high-resolution seismic images from Cherry Valley, San Bernardino County, California: Implications for water resources and earthquake hazards, U.S. Geol. Surv. Open-File Report 99-26, 57 pp.

Catchings, R. D., M. R. Goldman, G. Gandhok, M. J. Rymer, and D. H. Underwood, 2000, Seismic imaging evidence for faulting across the northwestern projection of the Silver Creek fault, San Jose, California, U.S. Geol. Surv. Open-File Report 00-125, 29 pp.

Catchings, R. D., M. J. Rymer, M. R. Goldman, J. A. Hole, R. Huggins, and C. Lippus, 2002, High-resolution seismic velocities and shallow structure of the San Andreas fault zone at Middle Mountain, Parkfield, California, Bull. Seism. Soc. Am., 92, 2493-2503

Catchings, R. D. M. J. Rymer, M. R. Goldman, G. Gandhok, and C. E. Steedman, (in press), Structure of the San Bernardino Basin from the Rialto-Colton/San Jacinto fault zone to the San Andreas fault zone, U.S. Geol. Surv. Open-File Report.

Catchings, R. D., G. Gandhok, M. R. Goldman, and R. Hansen (in press), Basin structure and velocities from the 2000 Santa Clara Seismic Investigation (SCSI) as related to earthquake hazards and water resources, western Santa Clara Valley, California, U.S. Geol. Surv. Open-File Report.

Dobrin, M. B., and C. H. Savit, 1988, Introduction to geophysical prospecting, McGrawHill Book Co., San Francisco, California, 867 pp.

Dutcher, L. C. and Garrett, A. A., 1963, Geologic and hydrologic features of the San Bernardino area, California-with special reference to underflow across the San Jacinto fault: U.S. Geol. Surv. Water-Supply Paper 1419, 114p.

Fuis, G. S., Ryberg, T., Godfrey, N. J., Okaya, D. A., and J. M. Murphy, 2001, Crustal structure and tectonics from the Los Angeles basin to the Mojave Desert, southern California, Geol. Soc. Am. Bull, 29, 15-18.

Fumal, T. E., R. J. Weldon, II, G. P. Biasi, T. E. Dawson, G. G. Seitz, W. T. Frost, and D. P. Schwartz, 2002, evidence for large earthquakes on the San Andreas fault at the Wrightwood, California, Paleoseismic site: A.D. 500 to Present, Bull. Seism. Soc. Am., 92, 2726-2760.

Gandhok, G., R. D. Catchings, M. R. Goldman, E. Horta, M. J. Rymer, A. Christensen, and P. Martin, 1999, High-resolution seismic reflection/refraction imaging from I10 to Cherry Valley Blvd., Cherry Valley, Riverside County, California: Implications for water resources and earthquake hazards, U.S. Geol. Surv. OpenFile Report 99-320, 56 pp.

Harding, T. P., and J. D. Lowell, 1979, Structural styles, their plate tectonic habitats, and hydrocarbon traps in petroleum provinces, Am. Assoc. Pet. Geol. Bull., 63, 10161058.

Hill, D. P., J. P. Eaton, and L. M. Jones, 1990, Seismicity, 1980-86, in The San Andreas Fault System, California, R. E. Wallace, editor, pp. 115-151, U.S. Geol. Surv. Profess. Paper 1515, Washington, D.C., 283 pp.

Hauksson, E., 2000, Crustal structure and seismicity distributions adjacent to the Pacific and North American plate boundary in southern California, J. Geophys. Res., 105, 13875-13903. 
Hauksson E., W-C. Chi, P. Shearer, and A. Michael, Comprehensive waveform crosscorrelation of southern California seismograms: Part 1. Refined hypocenters obtained using the double-difference method and tectonic implications (abstract), Fall. Ann. Meeting, American Geophys. Un., Dec. 8-12, 2003, San Francisco CA.

Hempton, M. R., and K. Neher, 1986, Experimental fracture, strain and subsidence patterns over en echelon strike-slip faults: implications for the structural evolution of pull-apart basins, J. Structural Geol., 8, 597-605

Hole, J. A., 1992, Nonlinear high-resolution three-dimensional seismic traveltime tomography, Journal of Geophysical Research, v. 97, p. 6553-6562.

Hole, J. A., R. D. Catchings, K. C. St. Clair, M. J. Rymer, D. A. Okaya, and B. J. Carney, 2001, Steep-dip seismic imaging of the shallow San Andreas fault near Parkfield, Science, 294, 1513-1515

Izbicki, J. A., W.R. Danskin, and G.O. Mendez, 1998, Chemistry and isotopic composition of ground water along a section near the Newmark area, San Bernardino County, California, U.S. Geological Survey Water Resources Investigation Report 97-4179

Matti, J. C. and D. M. Morton, 1993, Paleographic evolution of the San Andreas fault in southern California: A reconstruction based on a new cross-fault correlation, in $\mathrm{R}$.

E. Powell, R. J. Weldon, and J. C. Matti, editors, The San Andreas Fault System: displacement, Palinspastic Reconstruction, and Geologic Evolution, Geol. Soc. Am. Mem. 178, 107-159.

Matti, J. C., D. M. Morton, B. F. Cox, and K. J. Kendrick, Geologic map and digital database of the Redlands 7.5' Quadrangle, San Bernardino and Riverside Counties, Califonia, U.S. Geol. Surv. Open-File Report 03-30

Mooney, W. D., and J. H. Luetgert, 1982, A seismic refraction study of the Santa Clara Valley and southern Santa Cruz Mountains, west-central California, Bull. Seism. Soc. Am., 72, 901-909.

Morton, D.M., and J.C. Matti, 1993, Extension and contraction within an evolving divergent strike-slip fault complex: The San Andreas and San Jacinto fault zones at their convergence in southern California, in R.E. Powell, R.J. Weldon II, and J.C. Matti, editors., The San Andreas Fault System: Displacement, Palinspastic Reconstruction, and Geologic Evolution, Geol. Soc. Am. Mem. 178, 107-159

Morton, D.M., and F.K. Miller, 2003, Preliminary Geologic Map of the San Bernardino 30’x 60’ Quadrangle, California., U. S. Geol. Surv. Open-File Report 03-293, $189 \mathrm{pp}$.

Schon, J. H., 1996, Physical Properties of Rocks: Fundamentals and Principals of Petrophysics, Handbook of Geophysical Exploration, Seismic Exploration, Volume 18, Elsevier Science, Inc., Tarrytown, New York

Sharp, R.V., 1972, Map showing recently active breaks along the San Jacinto fault zone between the San Bernardino area and Borrego Valley, California: U.S. Geol. Surv. Misc. Geol. Invest., Map I-675, scale 1:24,000, 3 sheets

Stephenson, W. J., J. K. Odum, R. A. Williams, and M. L. Anderson, 2002, Delineation of Faulting and Basin Geometry along a Seismic Reflection Transect in Urbanized San Bernardino Valley, California, Bull. Seismol. Soc. Am., 92, 2504-2520

Vernon, F.L., 1989, Analysis of Data Recorded on the ANZA Seismic Network, Doctor of Philosophy in Earth Sciences Thesis, University of California San Diego 
Waldhauser, F., 2001, HypoDD - A program to compute double-difference hypocenter locations (hypoDD version 1.0 - 3/2001). U.S. Geol. Surv. Open-File Report 01113

Wallace, R. E., 1990, General Features, in The San Andreas Fault System, California, R. E. Wallace, editor, pp. 3-14, U.S. Geol. Surv. Prof. Paper 1515, U. S. Government Printing Office, Washington, D.C., 283 pp.

Woolfenden, L. R., and D. Kadhim, 1997, Geohydrology and water chemistry in the Rialto-Colton basin, San Bernardino County, California: U.S. Geological Survey Water-Resources Investigations Report 97-4012, 101p.

Woodcock, N. H., and M. Fisher, 1986, Strike-slip duplexes, J. Structural Geol., 8, 725735 .

Yule, D. and K. Sieh, 2003, Complexities of the San Andreas fault near San Gorgonio Pass: Implications for large earthquakes, J. Geophys. Res. 108, 2548, doi:10.1029/2001JB000451. 


\section{Figures}

Figure 1. Map of the San Bernardino area showing the locations of seismic profiles relative to known geologic structures, major roadways, and various cities. The profiles jointly acquired by the USGS and Caltrans are shown in red. The dashed gray line between the USGS/Caltrans profiles shows a seismic profile acquired by Stephenson et al., (2002). Yellow lines are seismic profiles acquired by the USGS (Catchings et al., in prep). The gray shaded areas refer to bedrock outcrops. Major known faults are shown by solid (mapped) and dotted (inferred below alluvium) lines. Geology from Morton and Miller (2003).

Figure 2. Part of the San Bernardino South, San Bernardino North, Harrison Mountain, and Redlands USGS 7.5-minute quadrangle maps, with the locations of the San Bernardino Low Resolution (SBR) and the San Bernardino High Resolution (SBHR) seismic profiles. Individual seismograph locations (dots) and shot point (SP \#) locations are shown along the SBR profile. Because of the 5-m spacing of geophones along the SBHR profile, the general location of the SBHR profile is shown with dashed black lines.

Figure 3. Seismograph and shot geometry for the SBR seismic profile. (a) Elevation of seismographs as a function of distance along the profile. (b) Variation of seismographs from a linear array as a function of distance along the seismic profile. (c) Shot point elevation as a function of distance along the profile. (d) Variation of shot points from a linear array along the profile. All of the above measurements are in units of meters. (e) Fold as a function of distance along the profile for stacked images.

Figure 4. (a) Shot gather from shot point 1 (see figure 2 for geographic location) of the SBR profile. The horizontal axis shows the channel numbers. The vertical axis is time in milliseconds. Elevation along the SBR profile is shown above the shot gather. (b) Shot gather from shot point 2, plotted as in figure 4a. (c) Shot gather from shot point 3, plotted as in figure 4a. (d) Shot gather from shot point 4, plotted as in figure 4a. (e) Shot gather from shot point 5, plotted as in figure 4a. (f) Shot gather from shot point 6, plotted as in figure 4a. (g) Shot gather from shot point 7, plotted as in figure 4a. (h) Shot gather from shot point 8, plotted as in figure 4a. (i) Shot gather from shot point 9, plotted as in figure 4a. (j) Shot gather from shot point 10, plotted as in figure 4a. (k) Shot gather from shot point 11, plotted as in figure 4a. (1) Shot gather from shot point 12, plotted as in figure 4a. (m) Shot gather from shot point 13, plotted as in figure 4a. (n) Shot gather from shot point 14, plotted as in figure 4a. (o) Shot gather from shot point 15, plotted as in figure $4 \mathrm{a}$.

Figure 5. (a) Seismic velocity model along the SBR seismic profile. Depth and distance are in meters. Velocities are in meters per second. Shot points and various cultural features are shown above the velocity model. (b) Ray density diagram showing the areas of the SBR velocity model with the number of ray paths in each $50-\mathrm{m}$ by $50-\mathrm{m}$ square. Depth and distance are in meters. The velocity model is constrained best in areas with the greatest number of ray paths.

Figure 6. Migrated seismic reflection image along the SBR seismic profile, plotted with 2:1 vertical exaggeration. Depth and distance are in meters. Fold, elevation, shot points, and various cultural features are shown above the seismic reflection image. 
Figure 7. Seismic reflection image from figure 6 , with the velocity image from figure $5 \mathrm{a}$ superimposed.

Figure 8 (a) Part of the USGS 7.5-minute San Bernardino South quadrangle map. The black line along the I-215 freeway shows the location of the SBHR seismic profile. The distance scale from the SBHR velocity and reflection images is shown, along with various cultural features. (b) Part of the USGS 7.5-minute San Bernardino North topographic map with the northward continuation of the SBHR profile (black line).

Figure 9. Geophone and shot geometry for the SBHR seismic profile. (a) Elevation of geophones as a function of distance along the profile. (b) Variation of geophones from a linear array as a function of distance along the seismic profile. (c) Shot point elevation as a function of distance along the profile. (d) Variation of shot points from a linear array along the profile. All of the above measurements are in units of meters. (e) Fold as a function of distance along the profile for stacked images.

Figure 10. (a) Shot gather from a shot point (1054) along the southern end of the SBHR profile. Shot points range from 1001 through approximately 2640 along the SBHR profile. The horizontal axis shows the channel numbers. The vertical axis is time in milliseconds. The elevation is shown above the shot gather, which has been top muted. (b) Shot gather from a shot point (1364) along the south-central part of the SBHR profile, plotted as in figure 10a. (c) Shot gather from a shot point (1503) along the central part of the SBHR profile, plotted as in figure 10a. (d) Shot gather from a shot point (2278) along the north-central part of the seismic profile, plotted as in figure 10a. (e) Shot gather from a shot point (2466) on the northern part of the seismic profile, plotted as in figure 10a.

Figure 11. (a) Seismic velocity model along the SBHR seismic profile. Depth and distance are in meters. Velocities are in meters per second. Shot points and various cultural features are shown above the velocity model. The velocity model is plotted with 10:1 vertical exaggeration. (b) Ray density diagram showing the areas of the SBHR velocity model with multiple ray paths in each $5-\mathrm{m}$ by $5-\mathrm{m}$ square. Depth and distance are in meters. The velocity model is constrained best in areas with the greatest number of ray paths.

Figure 12. (a) Seismic reflection image along the SBHR seismic profile, plotted with 2:1 vertical exaggeration. This image includes only the explosive sources. CDP spacing is every 2.5 meters along the profile. Every three traces have been laterally combined. The vertical axis is plotted in units of time (milliseconds), and the horizontal axis is plotted in units of meters. Fold (for all sources), elevation, shot points, and various cultural features are shown above the seismic reflection image. (b) Seismic reflection image from figure 12a. Spaces between every other reflector are highlighted in yellow. (c) Pre-stack Kirchoff-depth-migrated reflection image using only the explosive sources. (d) Seismic reflection depth image along the SBHR profile with both explosives and seisgun blasts included. Shot and geophone spacing is $5 \mathrm{~m}$, CDP spacing is $2.5 \mathrm{~m}$. Vertical exaggeration is $2: 1$. (d) Vertical exaggeration is $4: 1$. The vertical and horizontal axes are plotted in units of meters. Other features are plotted as in figure 12a.

Figure 13. (a) Bouger gravity profile along the SBR profile (data from Anderson et al., 1999). (b) Seismic reflection image from figure 6 with spaces between reflectors 
highlighted in yellow. Seismic velocities (Fig. 5a) indicate that the deeper layered rocks are probably not sedimentary. Vertical exaggeration is $2: 1$.

Figure 14. Image from figure 13, with interpretative faults along the SBR seismic profile. Parts of at least four near-surface fault zones are interpreted along the SBR seismic profile. RCFZ, SJFZ, TFZ, and EHFZ refer to the Rialto Colton fault zone, the San Jacinto fault zone, the Tippecanoe (Loma Linda?) fault zone, and the East Highlands fault zone, respectively.

Figure 15. Seismic reflection image from figure 13 with double-difference-located earthquakes (red dots) within $3 \mathrm{~km}$ of the SBR seismic profile, recorded from 1984-2002 (Hauksson et al., 2003).

Figure 16. Same plot from figure 15, except earthquakes are within $1 \mathrm{~km}$ of the SBR seismic profile.

Figure 17 (a) The upper $500 \mathrm{~m}$ of the seismic reflection depth image along the SBHR profile from figure $12 \mathrm{~d}$, plotted with 2:1 vertical exaggeration. (b) Seismic reflection image from figure $12 \mathrm{~d}$, plotted with 4:1 vertical exaggeration. (c) Seismic reflection image from figure $12 \mathrm{~d}$ with the velocity model from figure $11 \mathrm{~b}$ superimposed.

Projections of various water wells and logs near the seismic profile (from Izbicki et al., 1998) are shown in yellow. The $1500 \mathrm{~m} / \mathrm{s}$ velocity contour is shown in red. (d) Seismic reflection image from figure $12 \mathrm{~d}$, with the velocity model from figure 11a superimposed, plotted with vertical exaggeration of $4: 1$.

Figure 18. (a) Gravity profile along the SBHR seismic profile (data from Anderson et al., 1999). (b) Seismic reflection image along the SBHR seismic profile, plotted as in figure $13 b$.

Figure 19. (a) Topographic profile along the SBHR seismic profile. (b) Velocity image along the SBHR profile with faults from figure 18b. (c) Migrated reflection image along the SBHR profile (from figure 12c). The purple box outlines the dimensions of the velocity model in figure $19 \mathrm{~b}$.

Figure 20. Seismic image from figure 18 with interpreted faults zones.

Figure 21. (a) Seismic reflection image from figure 20 with double-difference-located earthquakes (red dots) within $3 \mathrm{~km}$ of the SBHR seismic profile. (b) Seismic reflection image from figure 20 with double-difference located earthquakes (red squares) within 1 $\mathrm{km}$ of the SBHR seismic profile. Note the multiple near-vertical alignments of seismic events beneath the SBHR profile. Earthquake locations from Hauksson et al. (2003).

Figure 22. (a) Uninterpreted seismic reflection image from Stephenson et al. (2002) (see figure 1 for the location of the SBS seismic profile). (b) Low-fold reflection image along the SBR seismic profile. The magenta box outlines the approximate area of the SBS seismic profile shown in figure 22a. Note, however, that the SBS profile trended more northerly than our seismic profile. Comparison of the SBR and the SBS reflection images show similar structures in the shallow subsurface and in the deeper parts of the San Bernardino Basin. 
Figure 23. Comparison of the (a) SBS velocity model of Stephenson et al. (2002) and (b) the SBR velocity model from this study. The white box in figure $23 \mathrm{~b}$ outlines the approximate area of the SBS velocity model. The dashed white lines out the $2000 \mathrm{~m} / \mathrm{s}$ (upper) and the $2800 \mathrm{~m} / \mathrm{s}$ (lower) velocity contours show in the SBS velocity model.

Figure 24. Comparison of interpretations of the SBS and SBR reflection images. (a) Interpreted reflection image from a seismic reflection profile from Stephenson et al. (2002) (SBS seismic profile) located between the SBR and SBHR seismic profiles (see figure 1). (b) Un-interpreted reflection image from Stephenson et al. (2002) with interpretative faults from this study superimposed. (c) SBR seismic reflection image from this study with interpretative faults.

Figure 25. (a) Location map from figure 1 with double-difference-located earthquakes (red dots) recorded during the period 1984-2002 (Hauksson et al., 2003). Note the linear alignments of earthquakes, which correlate with interpreted faults along the SBR and SBHR seismic profiles. (b) Map and earthquakes from figure 25a with the interpretative trend of faults (dashed blue lines) based on seismicity trends. The interpretative trend of faults is associated with the deepest part of the San Bernardino pull-apart basin. Imaged faults at the SBR seismic profile crossing are shown in purple.

Figure 26. (a) Gravity map of the San Bernardino area (from Anderson et al., 1999) with double-difference-located earthquakes (red dots) recorded during the period 1984-2002 (Hauksson, et al., 2003). Note that the I-215 freeway trends obliquely to the highest gravity gradient. (b) Gravity map from figure 26a with interpretative trend of faults (cyan dotted lines) superimposed. Our interpretative trend of faults correlate with the high gravity gradients and the depression in basement rocks as inferred by the low gravity gradients.

Figure 27. (a) Map view of the theoretical orientation of faults that form a pull-apart basin (adapted from Woodcock and Fisher, 1986). The dashed red lines show the orientations of the SBR and SBHR seismic profiles relative to our interpretative trend of faults across the San Bernardino pull-apart basin (see fig. 25b). (b) Block diagram showing the theoretical 3-D geometry of faults that form a pull-apart basin (adapted from Woodcock and Fisher, 1986), with the orientation of the SBR and SBHR seismic profiles relative to our interpretative trend of faults that form the San Bernardino pull-apart basin. In cross section, these faults form a negative flower structure. (c) Line drawings (map view) from clay experiments with from $16 \mathrm{~cm}$ of displacement on strike-slip faults (from Hempton and Neher, 1986). The faults that formed at acute angles to the main strike-slip faults are similar those seen in Fig. 27a and inferred in fig. 25b, and are commonly know as Riedel shears. Such faults are expected in a pull-apart basin that develops between stepovers of two discontinuous parallel strike-slip faults. The dashed red lines show the orientation of the SBR and SBHR seismic profiles relative to a similar San Bernardino pull-apart basin. (d) Same diagram as in Figure 27c, except there has been $20 \mathrm{~cm}$ of displacement on the strike-slip faults. Note that the acute-angle, slip-transfer faults (Riedel shears) become dominant over high-angle shears (Riedel shears) with greater slip on the main strike-slip faults. 
Figure 28. (a) Part of the San Bernardino South USGS 7.5-minute quadrangle map with double-difference-located earthquakes (red dots) recorded during the period 1984-2002 (Hauksson, et al, 2003). RCFZ, SJFZ, and TFZ refer to the Rialto-Colton, San Jacinto, and Tippecanoe fault zones. The stars show the approximate location of our interpretative faults where they cross the SBHR seismic profile. (b) Part of the San Bernardino North USGS 7.5-minute quadrangle map with earthquakes and interpretative faults plotted as in figure $28 \mathrm{a}$.

Figure 29. (a) Cross section along the I-215 area (from Izbicki et al., 1998) based on groundwater and borehole data. The approximate location of the SBHR seismic profile is shown by the box. Interpretative faults are shown in red, wells are show in white, and well logs are shown in yellow. (b) Cross section from figure 29a with the SBR seismic image, interpretive faults splays (green), and revised interpretative basin structure from this study superimposed. Most of the splay faults (green) are likely near-surface splays associated with stepover faults between the San Jacinto and the San Andreas faults. The seismic profile crosses the stepover faults at low angles. 


\section{Appendix 1}

Geometry for the SBR seismic profile. Distances are relative to the southwestern-most (first) shot point along the profile, and elevations are relative to topographically lowest shot point along the profile. Geo No. refers to seismograph number, Geo X refers to the distance of each seismograph from the first shot point, Geo Y refers to the lateral variation from a line connecting the first and last seismograph, Geo Z. refers to the elevation of each shot point relative to the first shot point. Shot No. refers to the shot point number, Shot $X$. refers to the distance of each shot point from the first shot point, Shot $Y$ refers to the lateral variation of each shot point relative to a line connecting the first and last shot point, Shot Z. refers to the elevation of each shot point relative to the first shot point.

\begin{tabular}{|c|c|c|c|c|c|c|c|}
\hline Geo No. & Geo X (m) & $\begin{array}{c}\text { Geo Y } \\
\text { Variation } \\
(\mathrm{m})\end{array}$ & Geo Z (m) & Shot No. & Shot X (m) & $\begin{array}{c}\text { Shot } Y \\
\text { Variation }(\mathrm{m})\end{array}$ & Shot Z $(\mathrm{m})$ \\
\hline 1 & 4.00 & 217.50 & 2.20 & 1 & 0.00 & 225.38 & 2.00 \\
\hline 2 & 51.44 & 215.27 & 2.50 & 2 & 763.43 & 355.34 & 5.00 \\
\hline 3 & 98.35 & 212.99 & 2.80 & 3 & 1777.61 & 171.81 & 6.71 \\
\hline 4 & 151.76 & 215.77 & 3.00 & 4 & 2578.17 & -141.94 & 7.71 \\
\hline 5 & 201.92 & 216.03 & 3.14 & 5 & 3658.40 & 57.72 & 16.29 \\
\hline 6 & 257.17 & 219.61 & 2.86 & 6 & 4098.74 & -214.82 & 24.00 \\
\hline 7 & 303.59 & 225.87 & 3.00 & 7 & 5240.80 & 280.93 & 29.14 \\
\hline 8 & 345.73 & 226.96 & 3.00 & 8 & 6057.66 & -213.61 & 32.14 \\
\hline 9 & 398.74 & 230.65 & 3.00 & 9 & 7693.34 & 203.58 & 43.57 \\
\hline 10 & 446.77 & 233.25 & 3.00 & 10 & 9708.08 & -268.94 & 60.14 \\
\hline 11 & 496.42 & 232.18 & 3.14 & 11 & 10728.21 & -366.79 & 68.00 \\
\hline 12 & 550.89 & 247.45 & 3.43 & 12 & 13797.03 & -1021.63 & 99.14 \\
\hline 13 & 591.96 & 263.37 & 4.14 & 13 & 14961.18 & -541.28 & 106.00 \\
\hline 14 & 636.91 & 285.36 & 4.14 & 14 & 16458.47 & -124.99 & 129.00 \\
\hline 15 & 682.66 & 305.53 & 4.71 & 15 & 19429.56 & 34.98 & 220.00 \\
\hline 16 & 765.45 & 286.29 & 5.71 & & & & \\
\hline 17 & 818.87 & 224.60 & 6.00 & & & & \\
\hline 18 & 869.60 & 144.23 & 6.00 & & & & \\
\hline 19 & 908.47 & 105.63 & 5.71 & & & & \\
\hline 20 & 948.58 & 74.13 & 5.14 & & & & \\
\hline 21 & 985.03 & 41.02 & 4.86 & & & & \\
\hline 22 & 1032.48 & 49.91 & 5.43 & & & & \\
\hline 23 & 1084.50 & 60.82 & 5.71 & & & & \\
\hline 24 & 1134.36 & 64.22 & 6.57 & & & & \\
\hline 25 & 1184.44 & 72.09 & 7.86 & & & & \\
\hline 26 & 1233.61 & 79.56 & 8.57 & & & & \\
\hline 27 & 1282.77 & 87.02 & 9.29 & & & & \\
\hline 28 & 1332.45 & 95.80 & 9.43 & & & & \\
\hline 29 & 1382.53 & 103.67 & 8.43 & & & & \\
\hline 30 & 1432.21 & 112.45 & 8.14 & & & & \\
\hline 31 & 1479.76 & 123.58 & 7.43 & & & & \\
\hline 32 & 1531.38 & 135.40 & 6.43 & & & & \\
\hline 33 & 1577.69 & 139.42 & 5.14 & & & & \\
\hline 34 & 1628.69 & 147.70 & 4.57 & & & & \\
\hline 35 & 1676.64 & 157.91 & 4.43 & & & & \\
\hline
\end{tabular}




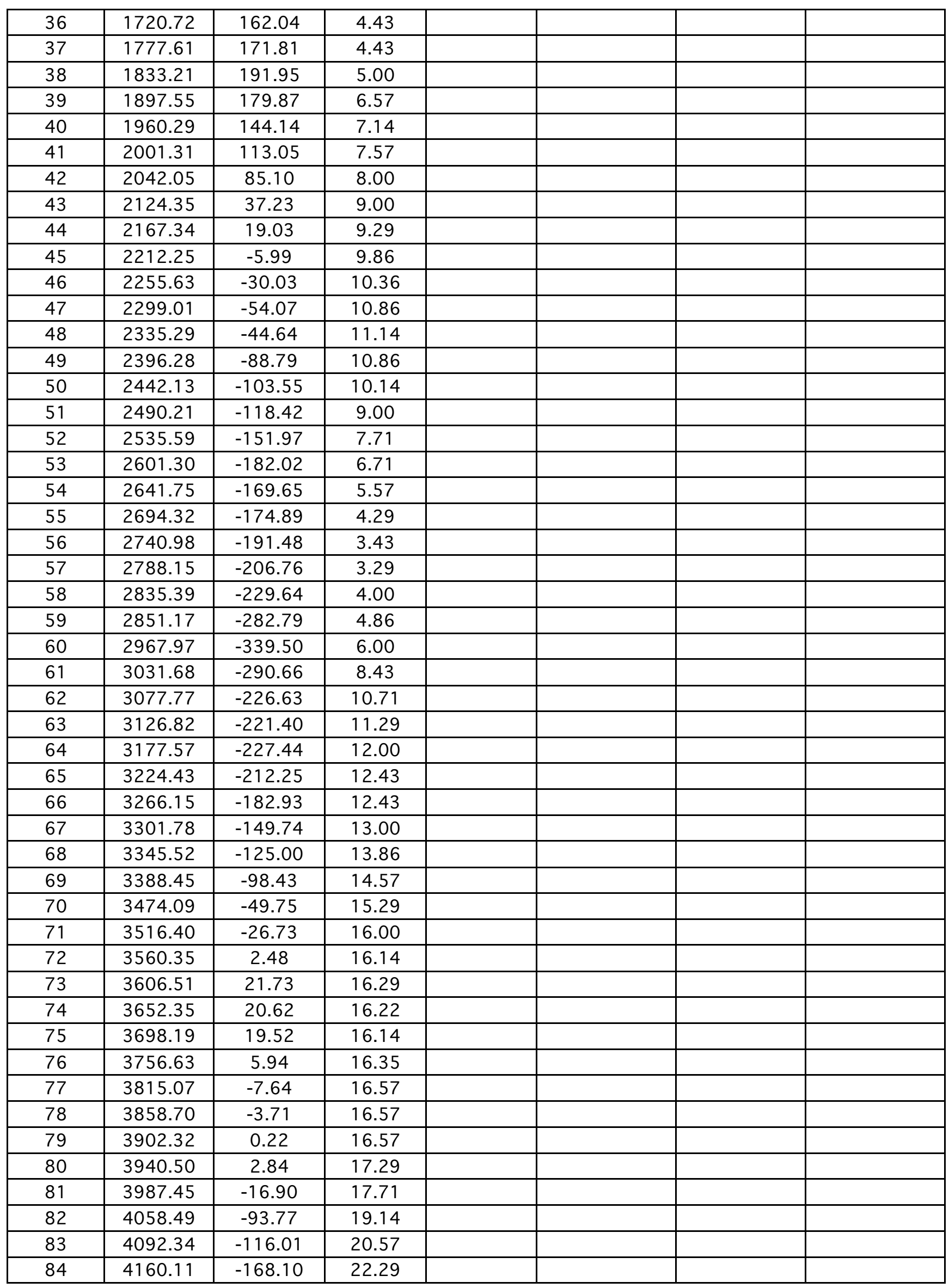




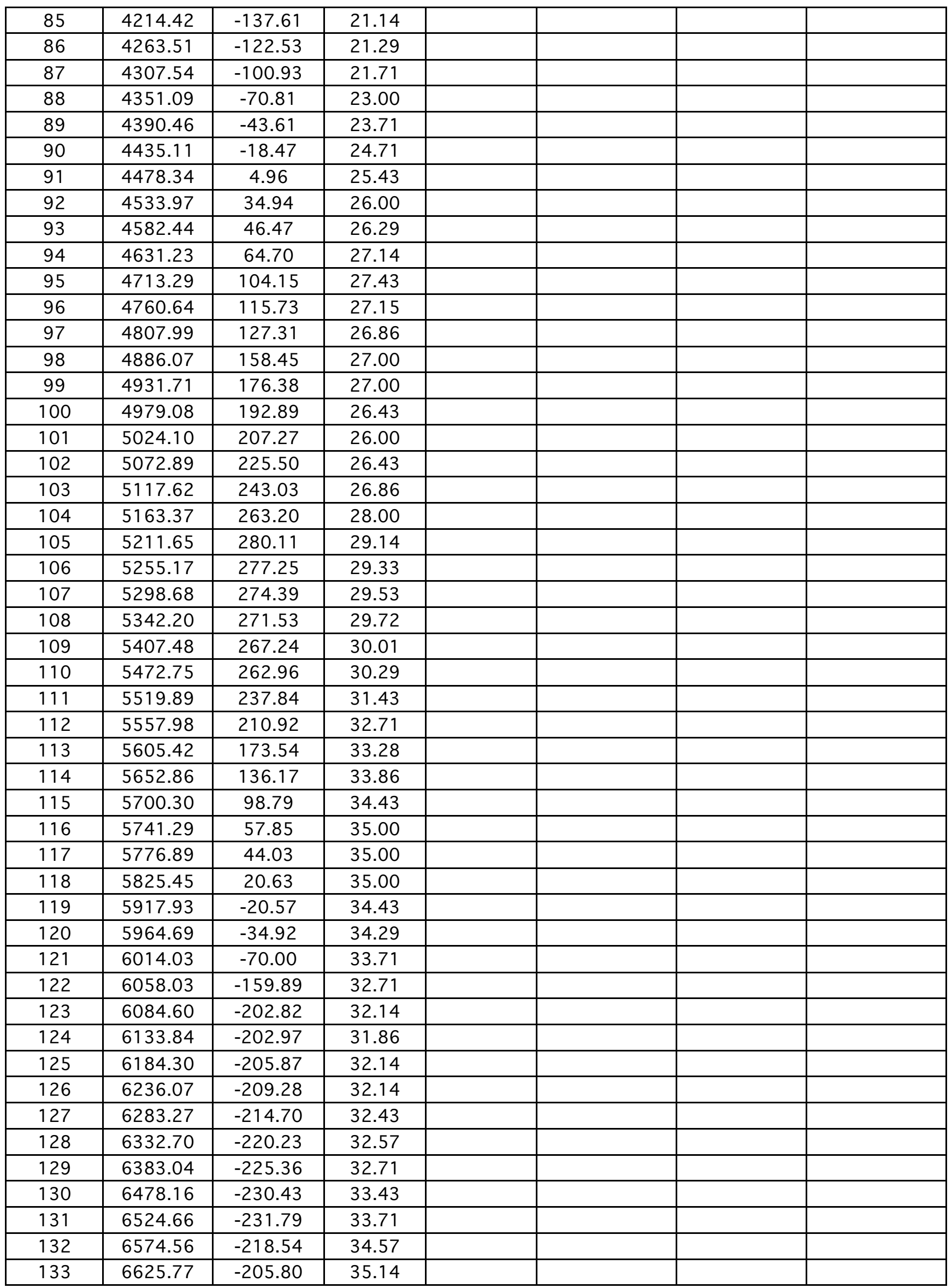




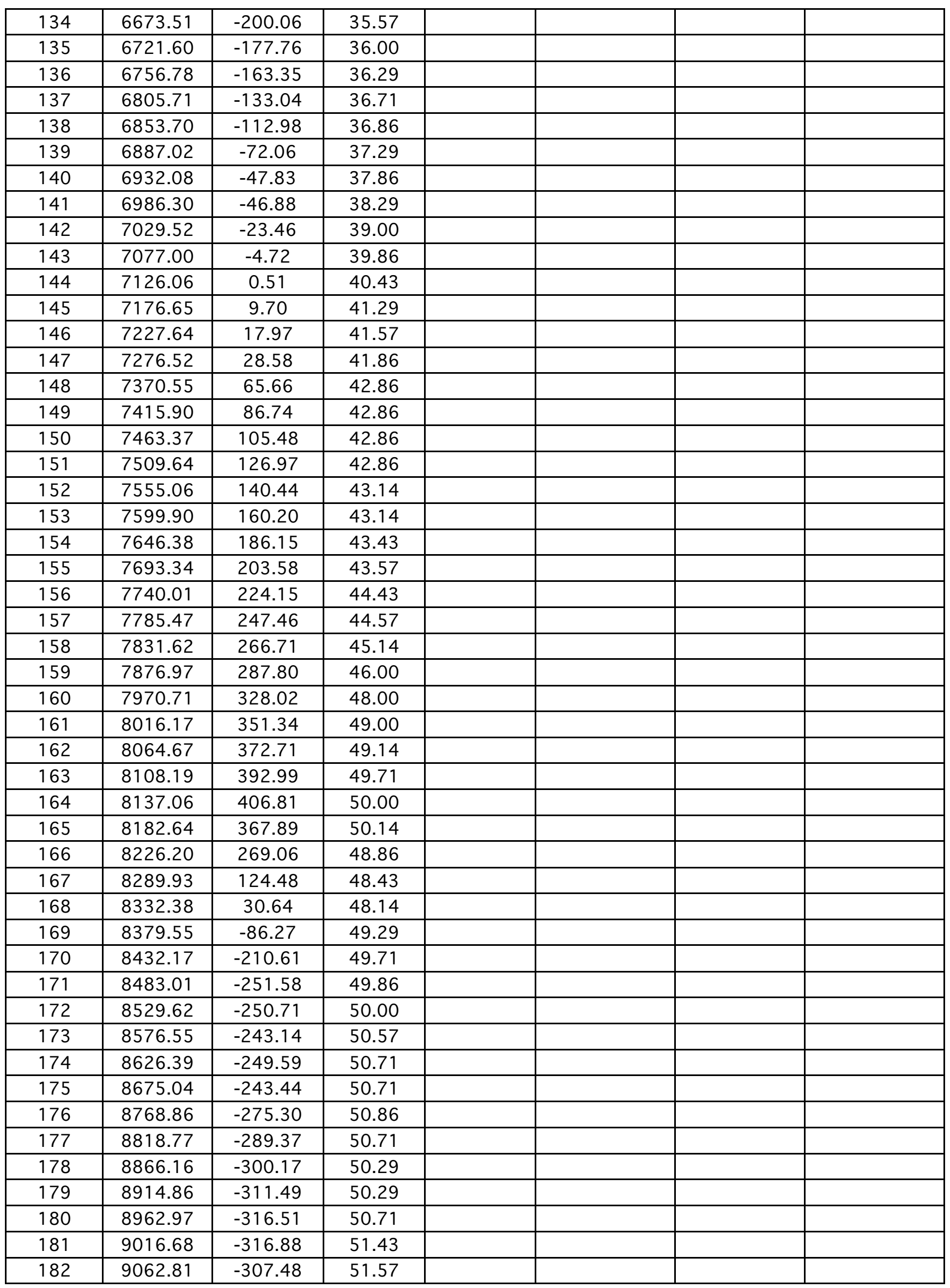




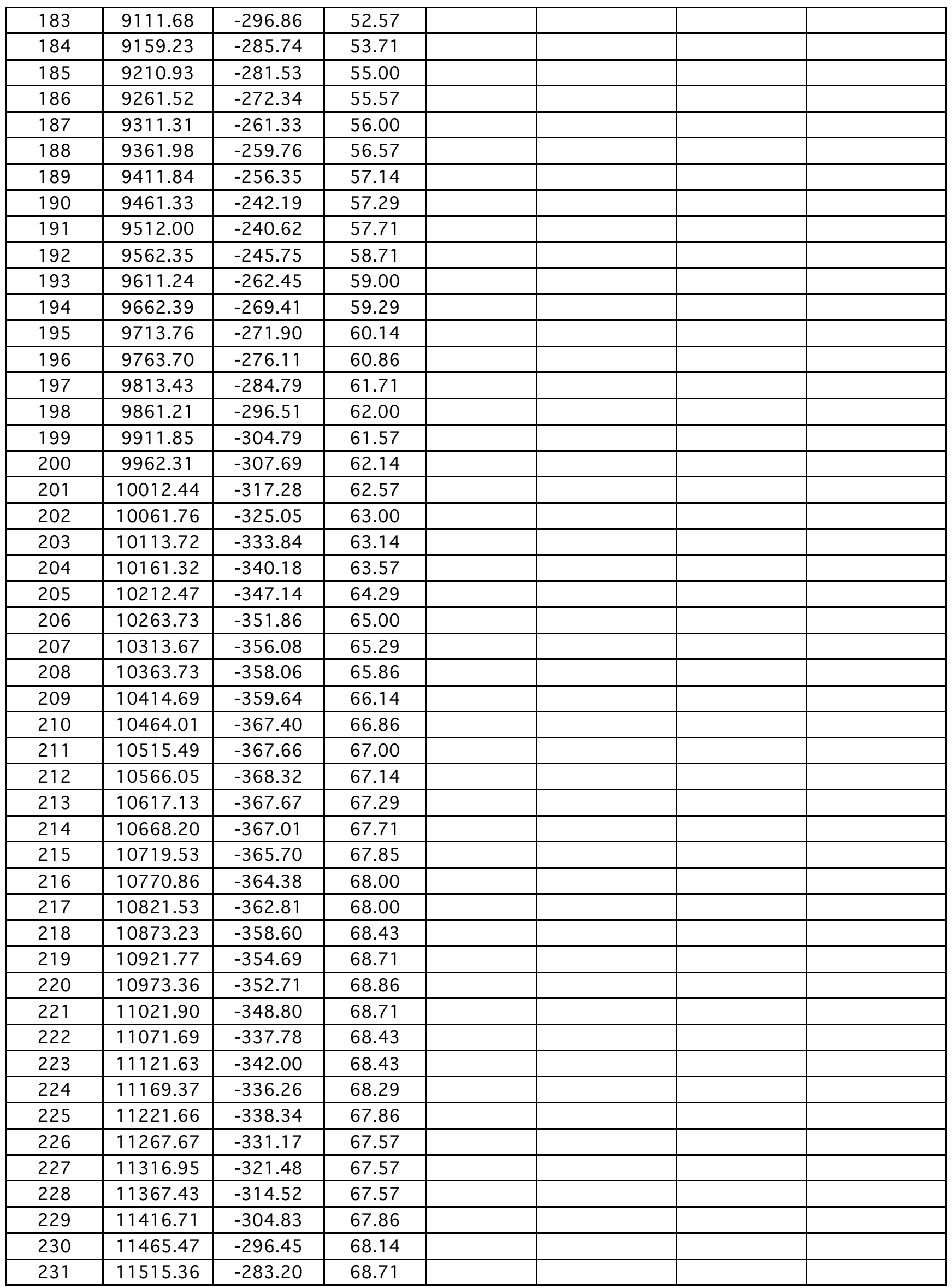




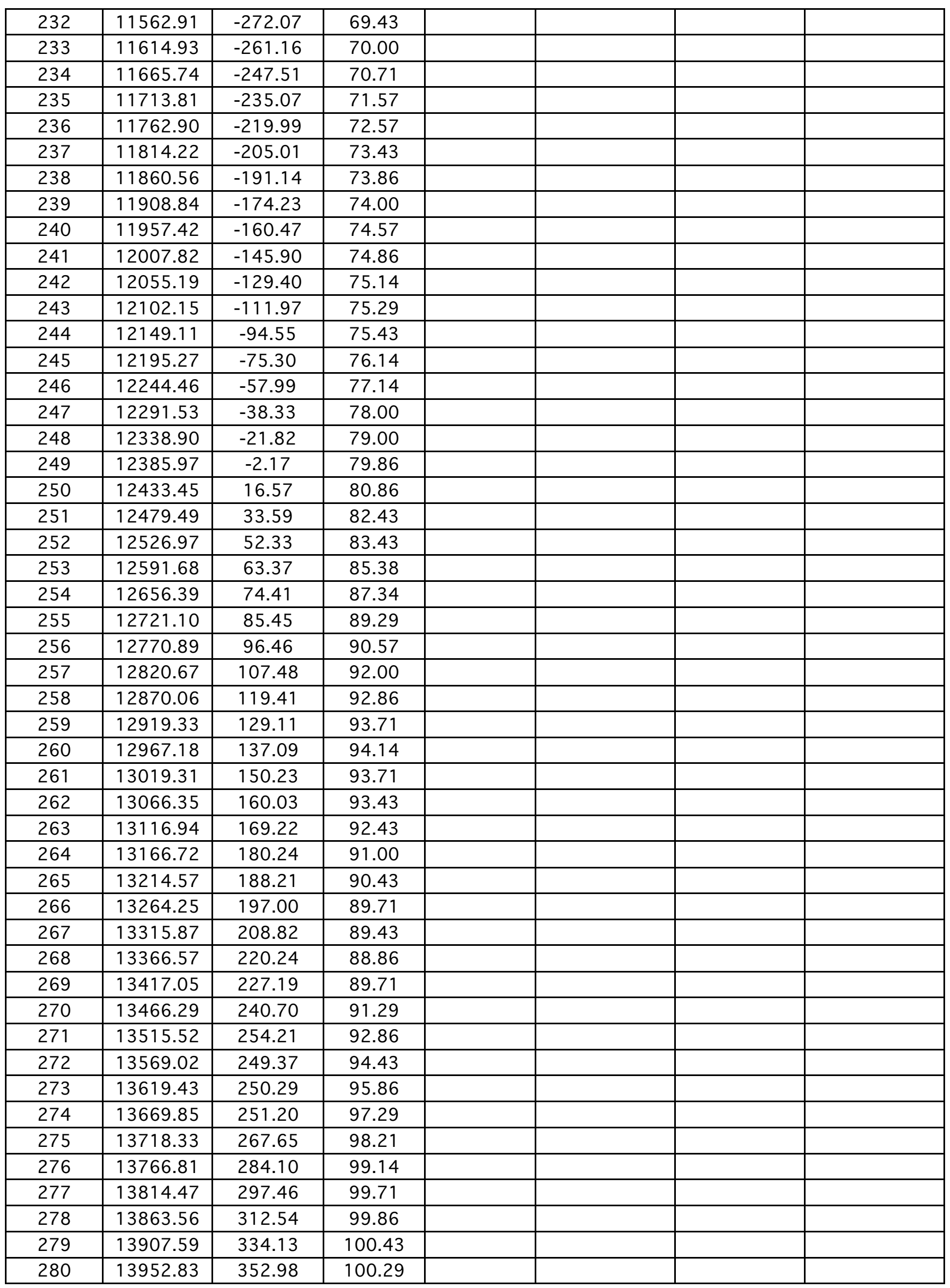




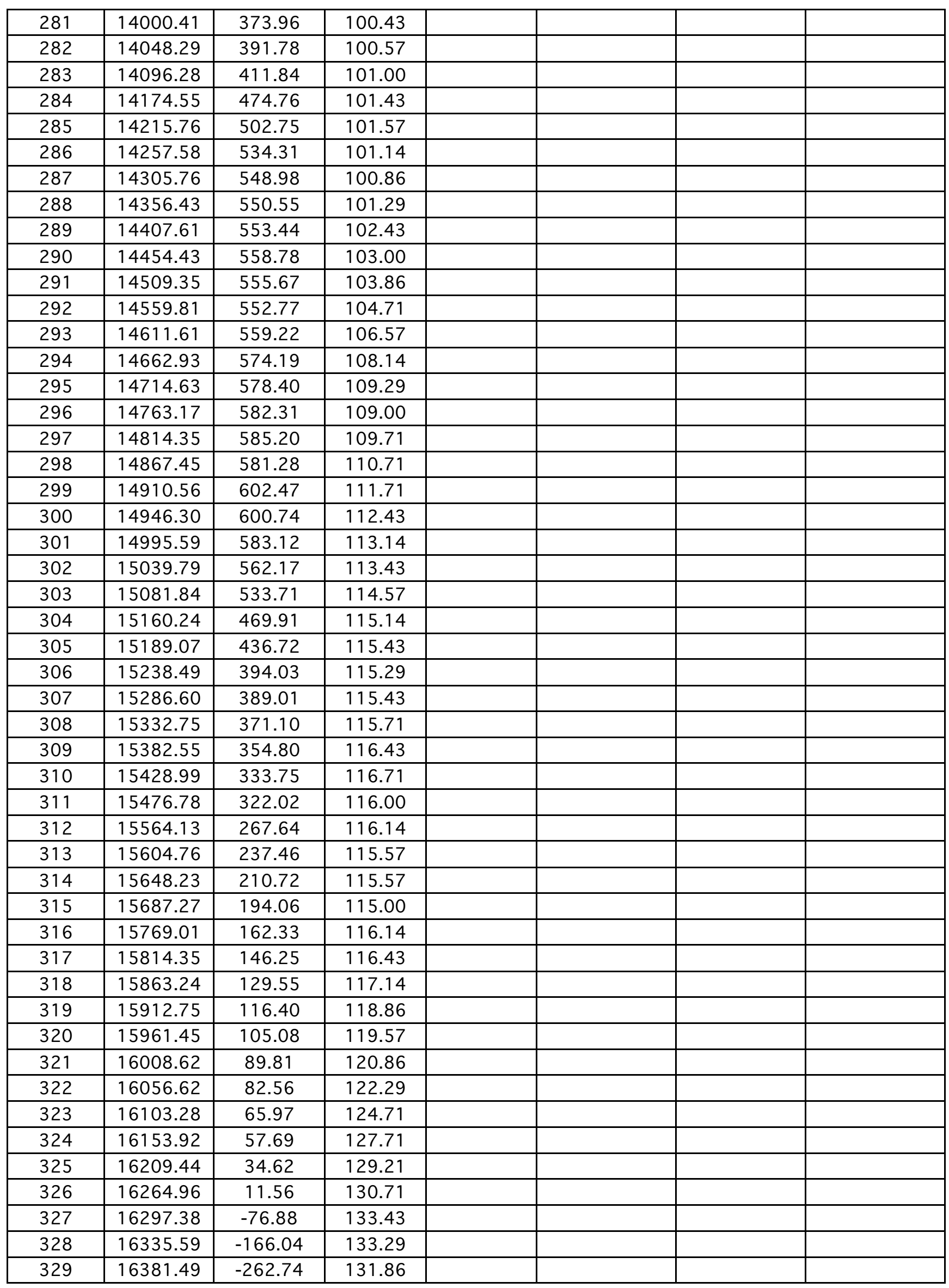




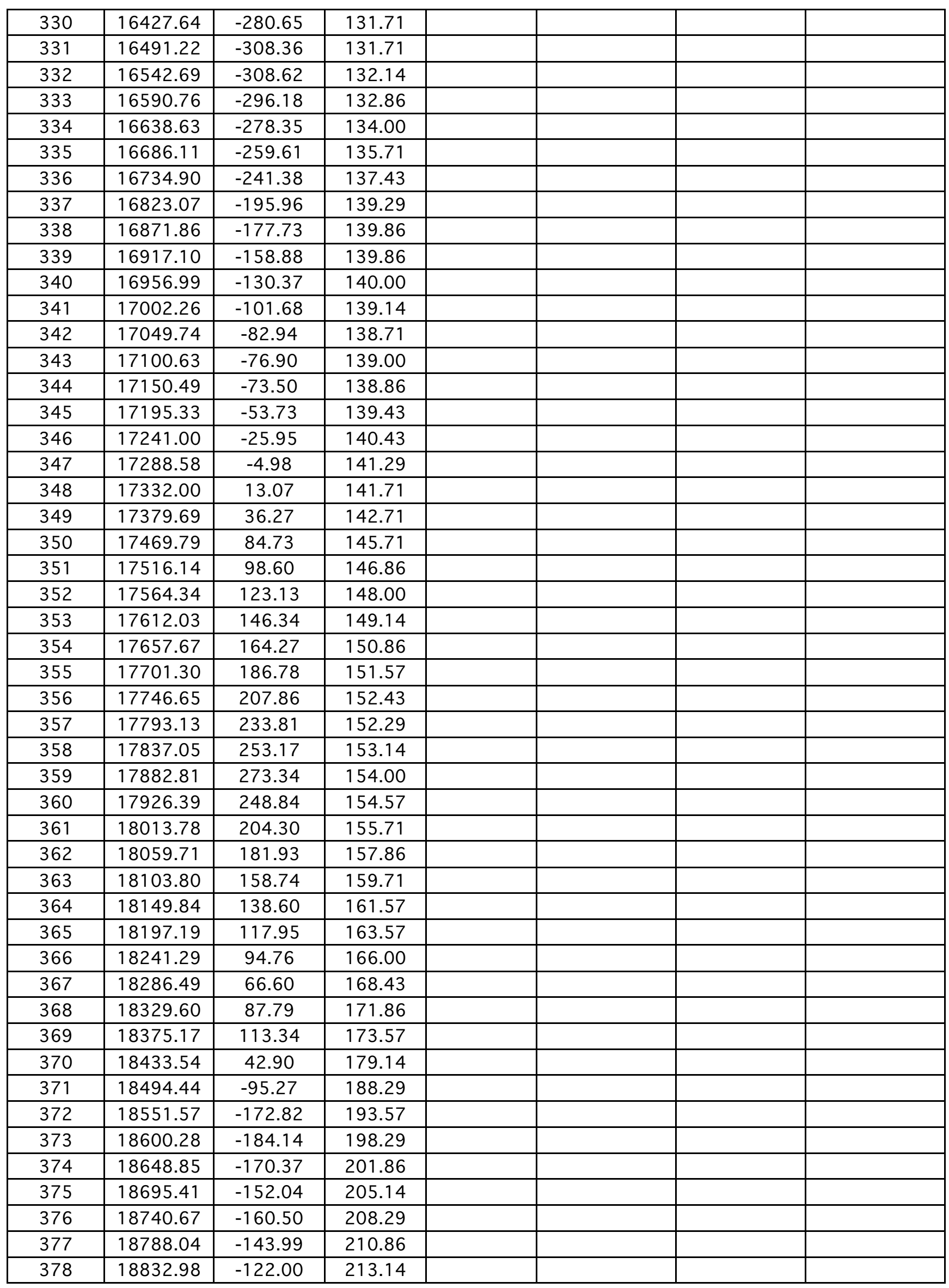




\begin{tabular}{|l|l|l|l|l|l|l|l|}
\hline 379 & 18880.05 & -102.34 & 215.86 & & & & \\
\hline 380 & 18930.13 & -94.47 & 216.14 & & & & \\
\hline 381 & 18978.06 & -94.11 & 217.00 & & & & \\
\hline 382 & 19026.36 & -104.52 & 217.57 & & & & \\
\hline 383 & 19075.63 & -94.82 & 218.14 & & & & \\
\hline 384 & 19126.01 & -90.10 & 219.00 & & & & \\
\hline 385 & 19177.67 & -95.74 & 219.86 & & & & \\
\hline 386 & 19228.34 & -94.17 & 220.00 & & & & \\
\hline 387 & 19277.51 & -86.70 & 220.14 & & & & \\
\hline 388 & 19373.36 & -85.98 & 226.43 & & & & \\
\hline 389 & 19424.06 & -74.56 & 232.00 & & & & \\
\hline 390 & 19458.90 & -104.01 & 238.43 & & & & \\
\hline 391 & 19478.07 & -142.55 & 245.14 & & & & \\
\hline 392 & 19568.75 & -174.71 & 258.57 & & & & \\
\hline 393 & 19606.01 & -209.65 & 263.86 & & & & \\
\hline 394 & 19631.66 & -252.98 & 265.71 & & & & \\
\hline 395 & 19687.88 & -330.93 & 266.43 & & & & \\
\hline 396 & 19755.96 & -413.48 & 264.00 & & & & \\
\hline 397 & 19815.46 & -479.05 & 263.71 & & & & \\
\hline 398 & 19844.99 & -516.31 & 263.57 & & & & \\
\hline 399 & 19885.47 & -494.09 & 263.67 & & & & \\
\hline 400 & 19935.88 & -479.52 & 264.40 & & & & \\
\hline 401 & 19982.38 & -480.89 & 265.50 & & & & \\
\hline
\end{tabular}


Appendix 2

Geometry for the SBHR seismic profile. Distances are relative to the southern-most (first) geophone along the profile, and elevations are relative to topographically lowest geophone along the profile. Station No. refers to geophone number, Receiver Dist. refers to the distance of each geophone from the first geophone, Receiver Elev. refers to the elevation of each geophone relative to the first geophone. Shot No. refers to the shot point number, Shot X. refers to the distance of each shot point from the first geophone, Shot Z. refers to the elevation of each shot point relative to the geophone.

\begin{tabular}{|c|c|c|c|c|c|}
\hline Station No. & Receiver Dist. (m) & $\begin{array}{c}\text { Receiver Elev. } \\
(\mathrm{m})\end{array}$ & Shot No. & Shot Dist. (m) & Shot Elev. (m) \\
\hline 1 & 0 & 1.3 & & & \\
\hline 2 & 5.02 & 1.22 & 1001 & 5.19 & 1.01 \\
\hline 3 & 9.7 & 1.16 & 1002 & 10.04 & 1.07 \\
\hline 4 & 14.77 & 1.01 & 1003 & 14.84 & 0.75 \\
\hline 5 & 19.63 & 0.79 & 1004 & 19.82 & 0.66 \\
\hline 6 & 24.65 & 0.69 & 1005 & 24.75 & 0.58 \\
\hline 7 & 29.59 & 0.63 & 1006 & 29.83 & 0.42 \\
\hline 8 & 34.69 & 0.76 & 1007 & 34.94 & 0.38 \\
\hline 9 & 39.36 & 0.91 & 1008 & 39.47 & 0.65 \\
\hline 10 & 44.47 & 0.69 & 1009 & 44.74 & 0.37 \\
\hline 11 & 49.34 & 0.65 & 1010 & 49.43 & 0.41 \\
\hline 12 & 53.87 & 0.66 & 1011 & 54.09 & 0.58 \\
\hline 13 & 59.14 & 0.77 & 1012 & 59.29 & 0.73 \\
\hline 14 & 64.26 & 0.94 & 1013 & 64.12 & 0.7 \\
\hline 15 & 68.82 & 1.12 & 1014 & 68.93 & 0.91 \\
\hline 16 & 73.94 & 1.24 & 1015 & 74.07 & 0.98 \\
\hline 17 & 78.98 & 1.19 & & & \\
\hline 18 & 83.94 & 1.15 & 1016 & 84.1 & 0.97 \\
\hline 19 & 88.52 & 1.11 & 1017 & 88.77 & 0.96 \\
\hline 20 & 93.8 & 1.09 & 1018 & 93.51 & 0.89 \\
\hline 21 & 98.22 & 1.2 & 1019 & 98.84 & 1.11 \\
\hline 22 & 103.03 & 1.19 & 1020 & 103.66 & 1.06 \\
\hline 23 & 108.65 & 0.92 & 1021 & 108.64 & 0.97 \\
\hline 24 & 113.39 & 0.92 & 1022 & 113.62 & 0.87 \\
\hline 25 & 118.62 & 0.98 & 1023 & 118.78 & 0.95 \\
\hline 26 & 123.33 & 1.03 & 1024 & 123.55 & 1.31 \\
\hline 27 & 128.46 & 1.17 & 1025 & 128.54 & 0.86 \\
\hline 28 & 133.48 & 1.07 & 1026 & 133.68 & 0.9 \\
\hline 29 & 138.34 & 1.1 & 1027 & 138.52 & 1.01 \\
\hline 30 & 143.28 & 1.1 & & & \\
\hline 31 & 148.99 & 1.1 & 1028 & 148.54 & 0.89 \\
\hline 32 & 153.84 & 1.19 & 1029 & 153.87 & 1.01 \\
\hline 33 & 157.96 & 1.64 & 1030 & 157.7 & 1.41 \\
\hline 34 & 163.58 & 1.09 & 1031 & 163.77 & 1.21 \\
\hline 35 & 168.71 & 0.94 & 1032 & 168.63 & 1.15 \\
\hline 36 & 173.73 & 0.75 & 1033 & 173.7 & 1.03 \\
\hline 37 & 178.8 & 0.84 & 1034 & 178.65 & 0.96 \\
\hline 38 & 184.2 & 0.92 & 1035 & 184.03 & 1.19 \\
\hline 39 & 189.09 & 0.92 & 1036 & 189.25 & 1.07 \\
\hline
\end{tabular}




\begin{tabular}{|c|c|c|c|c|c|}
\hline 40 & 193.95 & 1.1 & 1037 & 193.78 & 0.94 \\
\hline 41 & 199.06 & 0.87 & 1038 & 199.06 & 1.05 \\
\hline 42 & 203.16 & 0.89 & 1039 & 203.34 & 0.99 \\
\hline 43 & 208.5 & 0.8 & 1040 & 208.49 & 0.99 \\
\hline 44 & 213.36 & 0.69 & 1041 & 213.35 & 0.99 \\
\hline 45 & 218.73 & 0.63 & 1042 & 218.57 & 0.86 \\
\hline 46 & 223.61 & 0.67 & 1043 & 223.51 & 0.79 \\
\hline 47 & 228.35 & 0.68 & 1044 & 228.29 & 0.75 \\
\hline 48 & 233.5 & 0.64 & 1045 & 233.48 & 0.73 \\
\hline 49 & 238.41 & 0.5 & 1046 & 238.47 & 0.54 \\
\hline 50 & 243.38 & 0.56 & 1047 & 243.5 & 0.66 \\
\hline 51 & 248.42 & 0.57 & 1048 & 248.46 & 0.72 \\
\hline 52 & 253.13 & 0.44 & 1049 & 253.16 & 0.34 \\
\hline 53 & 258.16 & 0.56 & 1050 & 258.4 & 0.56 \\
\hline 54 & 263.29 & 0.6 & 1051 & 263.28 & 0.55 \\
\hline 55 & 268.02 & 0.54 & 1052 & 268.45 & 0.55 \\
\hline 56 & 273.2 & 0.69 & 1053 & 273.19 & 0.64 \\
\hline 57 & 278.14 & 0.68 & 1054 & 278.23 & 0.68 \\
\hline 58 & 283.09 & 0.73 & 1055 & 283.24 & 0.73 \\
\hline 59 & 288.1 & 0.74 & 1056 & 288.29 & 0.76 \\
\hline 60 & 292.85 & 0.88 & 1057 & 293.14 & 0.83 \\
\hline 61 & 298.09 & 0.79 & 1058 & 298.24 & 0.75 \\
\hline 62 & 302.86 & 0.7 & 1059 & 302.97 & 0.75 \\
\hline 63 & 308 & 0.77 & 1060 & 308.11 & 0.78 \\
\hline 64 & 313.05 & 0.93 & 1061 & 312.94 & 0.94 \\
\hline 65 & 317.74 & 0.8 & 1062 & 315.56 & 0.9 \\
\hline 66 & 322.8 & 0.86 & 1063 & 323.06 & 0.92 \\
\hline 67 & 327.9 & 1.03 & 1064 & 328.02 & 1.01 \\
\hline 68 & 332.9 & 1.06 & 1065 & 333.06 & 1.05 \\
\hline 69 & 337.75 & 1.01 & 1066 & 337.94 & 1.05 \\
\hline 70 & 342.95 & 1.09 & 1067 & 342.96 & 1.03 \\
\hline 71 & 346.87 & 0.88 & 1068 & 347.91 & 0.92 \\
\hline 72 & 352.36 & 1.05 & 1069 & 352.39 & 1.04 \\
\hline 73 & 357.75 & 1.01 & 1070 & 357.99 & 1.08 \\
\hline 74 & 364.05 & 0.97 & 1071 & 363.95 & 0.99 \\
\hline 75 & 367.54 & 0.99 & 1072 & 367.86 & 1.01 \\
\hline 76 & 373.04 & 1.02 & 1073 & 373.13 & 0.99 \\
\hline 77 & 378.1 & 1 & 1074 & 378.05 & 0.98 \\
\hline 78 & 382.32 & 0.92 & 1075 & 382.67 & 1.08 \\
\hline 79 & 387.59 & 1.15 & 1076 & 387.42 & 1.3 \\
\hline 80 & 392.63 & 1.19 & 1077 & 392.54 & 1.08 \\
\hline 81 & 397.9 & 1.03 & 1078 & 397.81 & 1.07 \\
\hline 82 & 402.41 & 1.02 & 1079 & 402.82 & 1.05 \\
\hline 83 & 407.59 & 0.97 & 1080 & 407.35 & 0.94 \\
\hline 84 & 412.11 & 0.97 & 1081 & 412.26 & 0.97 \\
\hline 85 & 416.74 & 1.02 & 1082 & 416.93 & 0.98 \\
\hline 86 & 422.2 & 1.06 & 1083 & 422.14 & 1.01 \\
\hline 87 & 427.36 & 0.98 & 1084 & 427.18 & 0.99 \\
\hline 88 & 431.49 & 1.01 & 1085 & 431.68 & 1.06 \\
\hline
\end{tabular}




\begin{tabular}{|c|c|c|c|c|c|}
\hline 89 & 436.9 & 1.1 & 1086 & 436.99 & 1.14 \\
\hline 90 & 442.02 & 1.13 & 1087 & 442.18 & 1.13 \\
\hline 91 & 446.78 & 1.14 & 1088 & 447.11 & 1.1 \\
\hline 92 & 451.54 & 1.21 & 1089 & 451.91 & 1.18 \\
\hline 93 & 456.59 & 1.27 & 1090 & 456.82 & 1.21 \\
\hline 94 & 461.66 & 1.21 & 1091 & 461.75 & 1.14 \\
\hline 95 & 466.54 & 1.05 & 1092 & 466.76 & 1.01 \\
\hline 96 & 471.46 & 1.04 & 1093 & 471.78 & 1.06 \\
\hline 97 & 476.55 & 0.8 & 1094 & 476.6 & 0.99 \\
\hline 98 & 481.65 & 0.9 & 1095 & 481.6 & 0.92 \\
\hline 99 & 487.61 & 0.87 & 1096 & 487.77 & 0.89 \\
\hline 100 & 491.32 & 0.87 & 1097 & 491.54 & 0.9 \\
\hline 101 & 496.31 & 0.89 & 1098 & 496.63 & 0.95 \\
\hline 102 & 501.23 & 0.84 & 1099 & 501.48 & 0.79 \\
\hline 103 & 505.83 & 0.75 & 1100 & 506.08 & 0.65 \\
\hline 104 & 511 & 0.43 & 1101 & 510.94 & 0.38 \\
\hline 105 & 516 & 0.35 & 1102 & 515.41 & 0.31 \\
\hline 106 & 521.42 & 0.28 & 1103 & 521.5 & 0.18 \\
\hline 107 & 526.02 & 0.25 & 1104 & 526.09 & 0.35 \\
\hline 108 & 531.07 & 0.35 & 1105 & 531.01 & 0.4 \\
\hline 109 & 535.76 & 0.37 & 1106 & 535.81 & 0.36 \\
\hline 110 & 540.91 & 0.55 & 1107 & 540.85 & 0.42 \\
\hline 111 & 546.09 & 0.51 & 1108 & 546.11 & 0.44 \\
\hline 112 & 550.84 & 0.29 & 1109 & 550.83 & 0.26 \\
\hline 113 & 556.2 & 0.09 & 1110 & 556.25 & 0.1 \\
\hline 114 & 560.69 & 0.16 & 1111 & 560.78 & 0.2 \\
\hline 115 & 565.23 & 0.19 & 1112 & 565.34 & 0.24 \\
\hline 116 & 570.2 & 0.18 & 1113 & 570.33 & 0.2 \\
\hline 117 & 575.15 & 0.08 & 1114 & 575.23 & 0.14 \\
\hline 118 & 580.05 & 0.05 & 1115 & 580.17 & 0.15 \\
\hline 119 & 584.99 & 0.09 & 1116 & 585.15 & 0.14 \\
\hline 120 & 590.03 & 0 & 1117 & 590.08 & 0.04 \\
\hline 121 & 594.88 & 0.25 & 1118 & 595.03 & 0.16 \\
\hline 122 & 600 & 0.11 & 1119 & 600.02 & 0.18 \\
\hline 123 & 604.8 & 0.15 & 1120 & 604.84 & 0.19 \\
\hline 124 & 609.74 & 0.24 & 1121 & 609.89 & 0.22 \\
\hline 125 & 615.32 & 0.62 & 1122 & 615.47 & 0.57 \\
\hline 126 & 620.01 & 1.31 & 1123 & 620.28 & 1.51 \\
\hline 127 & 625.01 & 2.04 & 1124 & 625.49 & 1.99 \\
\hline 128 & 630.31 & 2.03 & 1125 & 630.44 & 2.02 \\
\hline 129 & 635.12 & 2.18 & 1126 & 635.29 & 2.11 \\
\hline 130 & 640.05 & 2.19 & 1127 & 640.31 & 2.08 \\
\hline 131 & 645.19 & 2.24 & 1128 & 645.24 & 2.23 \\
\hline 132 & 650.26 & 2.25 & 1129 & 650.25 & 2.22 \\
\hline 133 & 655.18 & 2.42 & 1130 & 655.28 & 2.25 \\
\hline 134 & 660.2 & 2.31 & 1131 & 660.35 & 2.24 \\
\hline 135 & 665.18 & 2.39 & 1132 & 665.27 & 2.37 \\
\hline 136 & 670.22 & 2.37 & 1133 & 670.32 & 2.28 \\
\hline 137 & 675.19 & 2.44 & 1134 & 675.3 & 2.48 \\
\hline
\end{tabular}




\begin{tabular}{|c|c|c|c|c|c|}
\hline 138 & 679.66 & 2.37 & 1135 & 680.09 & 2.41 \\
\hline 139 & 684.97 & 2.38 & 1136 & 684.87 & 2.38 \\
\hline 140 & 690.43 & 2.17 & 1137 & 689.76 & 2.37 \\
\hline 141 & 694.49 & 2.24 & 1138 & 694.73 & 2.38 \\
\hline 142 & 699.9 & 2.3 & 1139 & 699.85 & 2.44 \\
\hline 143 & 704.37 & 2.39 & 1140 & 704.79 & 2.41 \\
\hline 144 & 709.8 & 2.46 & 1141 & 709.74 & 2.53 \\
\hline 145 & 715.38 & 2.32 & 1142 & 715.25 & 2.36 \\
\hline 146 & 719.51 & 2.53 & 1143 & 719.8 & 2.51 \\
\hline 147 & 724.67 & 2.59 & 1144 & 724.58 & 2.63 \\
\hline 148 & 730.2 & 2.58 & 1145 & 729.87 & 2.75 \\
\hline 149 & 735.35 & 2.74 & 1146 & 735.48 & 2.81 \\
\hline 150 & 739.9 & 2.85 & 1147 & 739.63 & 2.93 \\
\hline 151 & 744.86 & 2.74 & 1148 & 744.68 & 2.8 \\
\hline 152 & 750.1 & 2.83 & 1149 & 749.72 & 2.89 \\
\hline 153 & 754.91 & 2.78 & 1150 & 754.87 & 2.9 \\
\hline 154 & 759.63 & 2.83 & 1151 & 759.64 & 2.88 \\
\hline 155 & 764.7 & 2.84 & 1152 & 764.7 & 2.89 \\
\hline 156 & 769.9 & 2.76 & 1153 & 769.64 & 2.82 \\
\hline 157 & 774.45 & 2.97 & 1154 & 774.57 & 2.9 \\
\hline 158 & 779.64 & 3.02 & 1155 & 779.71 & 3.02 \\
\hline 159 & 785.24 & 3.03 & 1156 & 784.66 & 3 \\
\hline 160 & 790.36 & 3.05 & 1157 & 789.87 & 2.99 \\
\hline 161 & 794.87 & 3.01 & 1158 & 794.96 & 3.07 \\
\hline 162 & 799.57 & 2.96 & 1159 & 799.57 & 2.92 \\
\hline 163 & 804.79 & 2.92 & 1160 & 804.88 & 2.86 \\
\hline 164 & 809.63 & 2.84 & 1161 & 809.69 & 2.79 \\
\hline 165 & 814.6 & 2.75 & 1162 & 814.55 & 2.72 \\
\hline 166 & 819.65 & 2.67 & 1163 & 819.62 & 2.7 \\
\hline 167 & 825.25 & 2.68 & 1164 & 825.52 & 2.74 \\
\hline 168 & 829.63 & 2.58 & 1165 & 829.63 & 2.44 \\
\hline 169 & 832.57 & 2.21 & 1166 & 832.61 & 2.18 \\
\hline 170 & 839.77 & 1.47 & 1167 & 839.5 & 1.58 \\
\hline 171 & 844.43 & 1.35 & 1168 & 844.17 & 1.49 \\
\hline 172 & 849.74 & 1.23 & 1169 & 849.52 & 1.38 \\
\hline 173 & 853.21 & 1.98 & 1170 & 853.1 & 2.13 \\
\hline 174 & 857.99 & 2.2 & 1171 & 857.77 & 2.48 \\
\hline 175 & 863.31 & 2.53 & 1172 & 863.03 & 2.92 \\
\hline 176 & 868.3 & 3.06 & 1173 & 868.29 & 3.19 \\
\hline 183 & 902.12 & 3.51 & 1174 & 902.06 & 3.5 \\
\hline 184 & 907.11 & 3.7 & 1175 & 906.84 & 3.45 \\
\hline 185 & 911.93 & 3.35 & 1176 & 911.63 & 3.25 \\
\hline 186 & 916.61 & 3.4 & 1177 & 916.38 & 3.16 \\
\hline 187 & 921.36 & 3.14 & 1178 & 921.13 & 3.1 \\
\hline 188 & 925.99 & 3.15 & 1179 & 925.83 & 3.11 \\
\hline 189 & 931.4 & 3.17 & 1180 & 930.91 & 3.15 \\
\hline 190 & 935.64 & 3.15 & 1181 & 935.53 & 3.16 \\
\hline 191 & 940.67 & 3.1 & 1182 & 940.2 & 3.13 \\
\hline 192 & 945.47 & 3.16 & 1183 & 945.09 & 3.23 \\
\hline
\end{tabular}




\begin{tabular}{|c|c|c|c|c|c|}
\hline 193 & 949.42 & 3.07 & 1184 & 949.82 & 3.16 \\
\hline 194 & 954.77 & 3.23 & 1185 & 954.5 & 3.23 \\
\hline 195 & 959.75 & 3.15 & 1186 & 959.36 & 3.26 \\
\hline 196 & 964.16 & 3.18 & 1187 & 963.98 & 3.24 \\
\hline 197 & 968.94 & 3.19 & 1188 & 968.82 & 3.21 \\
\hline 198 & 973.83 & 3.36 & 1189 & 973.6 & 3.26 \\
\hline 199 & 978.87 & 3.29 & & & \\
\hline 200 & 983.27 & 3.16 & 1190 & 982.94 & 3.24 \\
\hline 201 & 987.95 & 3.25 & 1191 & 988.06 & 3.16 \\
\hline 202 & 992.79 & 3.33 & 1192 & 992.45 & 3.37 \\
\hline 203 & 997.29 & 3.27 & 1193 & 996.92 & 3.28 \\
\hline 204 & 1001.97 & 3.37 & 1194 & 1001.77 & 3.33 \\
\hline 205 & 1007.06 & 3.48 & 1195 & 1006.65 & 3.47 \\
\hline 206 & 1011.61 & 3.56 & 1196 & 1011.34 & 3.49 \\
\hline 207 & 1016.44 & 3.55 & 1197 & 1016.22 & 3.6 \\
\hline 208 & 1021.13 & 3.69 & 1198 & 1020.76 & 3.7 \\
\hline 209 & 1025.89 & 3.73 & 1199 & 1025.64 & 3.67 \\
\hline 210 & 1030.65 & 3.86 & 1200 & 1030.25 & 3.82 \\
\hline 211 & 1035.62 & 4.04 & 1201 & 1035.24 & 3.95 \\
\hline 212 & 1040.25 & 4.15 & 1202 & 1039.78 & 4.01 \\
\hline 213 & 1044.73 & 4.23 & 1203 & 1044.44 & 4.02 \\
\hline 214 & 1049.33 & 4.38 & 1204 & 1048.95 & 4.22 \\
\hline 215 & 1053.78 & 4.11 & 1205 & 1053.59 & 4 \\
\hline 216 & 1058.31 & 4.15 & 1206 & 1058.15 & 3.99 \\
\hline 217 & 1063.02 & 4.27 & 1207 & 1062.85 & 4.1 \\
\hline 218 & 1067.49 & 4.34 & 1208 & 1067.28 & 4.16 \\
\hline 219 & 1072.13 & 4.46 & 1209 & 1071.85 & 4.27 \\
\hline 220 & 1077.74 & 4.75 & 1210 & 1076.63 & 4.54 \\
\hline 221 & 1081.4 & 4.94 & 1211 & 1081.25 & 4.84 \\
\hline 222 & 1086.11 & 5 & 1212 & 1085.85 & 4.89 \\
\hline 223 & 1090.86 & 4.94 & 1213 & 1090.39 & 4.82 \\
\hline 224 & 1095.7 & 4.93 & 1214 & 1095.16 & 4.85 \\
\hline 225 & 1100.01 & 4.97 & 1215 & 1099.76 & 4.8 \\
\hline 226 & 1104.51 & 4.83 & 1216 & 1104.48 & 4.84 \\
\hline 227 & 1109.72 & 4.84 & 1217 & 1109.32 & 4.89 \\
\hline 228 & 1113.87 & 4.95 & 1218 & 1113.38 & 4.79 \\
\hline 229 & 1118.34 & 4.88 & 1219 & 1118.01 & 4.87 \\
\hline 230 & 1122.73 & 4.7 & 1220 & 1122.3 & 4.71 \\
\hline 231 & 1127.12 & 4.7 & 1221 & 1126.97 & 4.66 \\
\hline 232 & 1131.85 & 4.67 & 1222 & 1131.59 & 4.69 \\
\hline 233 & 1136.36 & 4.64 & 1223 & 1136.22 & 4.63 \\
\hline 234 & 1140.83 & 4.6 & 1224 & 1140.72 & 4.57 \\
\hline 235 & 1145.9 & 4.46 & 1225 & 1145.49 & 4.66 \\
\hline 236 & 1150.48 & 4.5 & 1226 & 1150.08 & 4.47 \\
\hline 237 & 1154.69 & 4.42 & 1227 & 1154.42 & 4.42 \\
\hline 238 & 1159.22 & 4.5 & 1228 & 1158.72 & 4.43 \\
\hline 239 & 1163.16 & 4.4 & 1229 & 1163.08 & 4.35 \\
\hline 240 & 1168.29 & 4.51 & 1230 & 1168.01 & 4.37 \\
\hline 241 & 1172.47 & 4.35 & 1231 & 1172.17 & 4.35 \\
\hline
\end{tabular}




\begin{tabular}{|c|c|c|c|c|c|}
\hline 242 & 1177.67 & 4.74 & 1232 & 1177.14 & 4.44 \\
\hline 243 & 1181.82 & 4.72 & & & \\
\hline 244 & 1185.97 & 4.7 & & & \\
\hline 245 & 1190.8 & 4.66 & & & \\
\hline 246 & 1195.62 & 4.62 & & & \\
\hline 247 & 1200.45 & 4.58 & & & \\
\hline 248 & 1205.27 & 4.54 & & & \\
\hline 249 & 1210.1 & 4.5 & & & \\
\hline 250 & 1214.92 & 4.47 & & & \\
\hline 251 & 1219.75 & 4.43 & & & \\
\hline 252 & 1224.57 & 4.39 & & & \\
\hline 253 & 1229.4 & 4.35 & & & \\
\hline 254 & 1234.22 & 4.31 & & & \\
\hline 255 & 1239.05 & 4.27 & & & \\
\hline 256 & 1243.48 & 4.03 & 1233 & 1243.37 & 4.25 \\
\hline 257 & 1248.21 & 3.69 & 1234 & 1247.97 & 3.92 \\
\hline 258 & 1253.43 & 3.16 & 1235 & 1252.43 & 3.74 \\
\hline 259 & 1257.83 & 2.38 & 1236 & 1257.55 & 2.74 \\
\hline 260 & 1262.8 & 2.34 & 1237 & 1262.65 & 2.6 \\
\hline 261 & 1267.94 & 2.25 & 1238 & 1267.74 & 2.34 \\
\hline 262 & 1273.75 & 2.2 & 1239 & 1273.41 & 2.24 \\
\hline 263 & 1277.58 & 2.25 & 1240 & 1277.34 & 2.24 \\
\hline 264 & 1282.26 & 2.24 & 1241 & 1282.68 & 2.32 \\
\hline 265 & 1287.41 & 2.35 & 1242 & 1287.05 & 2.38 \\
\hline 266 & 1292.02 & 2.58 & 1243 & 1291.73 & 2.34 \\
\hline 267 & 1296.06 & 2.39 & 1244 & 1295.73 & 2.53 \\
\hline 268 & 1300.86 & 2.46 & 1245 & 1300.46 & 2.44 \\
\hline 269 & 1305.01 & 2.42 & 1246 & 1304.52 & 2.44 \\
\hline 270 & 1309.42 & 2.52 & 1247 & 1308.41 & 2.51 \\
\hline 271 & 1313.88 & 2.5 & 1248 & 1313.34 & 2.5 \\
\hline 272 & 1318.31 & 2.52 & 1249 & 1317.93 & 2.49 \\
\hline 273 & 1322.71 & 2.57 & 1250 & 1322.28 & 2.55 \\
\hline 274 & 1327.02 & 2.57 & 1251 & 1326.72 & 2.57 \\
\hline 275 & 1331.64 & 2.6 & 1252 & 1331.13 & 2.56 \\
\hline 276 & 1335.74 & 2.52 & & & \\
\hline 277 & 1340.02 & 2.5 & 1253 & 1339.81 & 2.47 \\
\hline 278 & 1344.55 & 2.43 & 1254 & 1344.3 & 2.4 \\
\hline 279 & 1349.09 & 2.39 & 1255 & 1348.69 & 2.36 \\
\hline 280 & 1353.22 & 2.41 & & & \\
\hline 281 & 1357.34 & 2.86 & 1256 & 1357.3 & 2.86 \\
\hline 282 & 1362.14 & 3.63 & 1257 & 1362 & 3.61 \\
\hline 283 & 1366.74 & 3.52 & & & \\
\hline 284 & 1371.35 & 3.42 & & & \\
\hline 285 & 1375.95 & 3.31 & & & \\
\hline 286 & 1380.56 & 3.2 & & & \\
\hline 287 & 1385.16 & 3.09 & & & \\
\hline 288 & 1389.76 & 2.99 & & & \\
\hline 289 & 1394.37 & 2.88 & & & \\
\hline 290 & 1398.97 & 2.77 & & & \\
\hline
\end{tabular}




\begin{tabular}{|c|c|c|c|c|c|}
\hline 291 & 1403.58 & 2.67 & & & \\
\hline 292 & 1408.18 & 2.56 & 1258 & 1407.94 & 2.51 \\
\hline 293 & 1412.28 & 2.39 & 1259 & 1412.2 & 2.26 \\
\hline 294 & 1417.2 & 2.34 & 1260 & 1416.9 & 2.35 \\
\hline 295 & 1421.15 & 2.43 & 1261 & 1421 & 2.4 \\
\hline 296 & 1426.14 & 2.54 & 1262 & 1425.73 & 2.49 \\
\hline 297 & 1430.92 & 2.58 & 1263 & 1430.67 & 2.57 \\
\hline 298 & 1434.47 & 2.58 & 1264 & 1434.21 & 2.65 \\
\hline 299 & 1439.4 & 2.72 & 1265 & 1439.02 & 2.66 \\
\hline 300 & 1443.64 & 2.6 & 1266 & 1443.56 & 2.63 \\
\hline 301 & 1448.4 & 2.72 & 1267 & 1448.18 & 2.67 \\
\hline 302 & 1453.03 & 2.81 & 1268 & 1452.57 & 2.72 \\
\hline 303 & 1457.23 & 2.78 & 1269 & 1457.3 & 2.75 \\
\hline 304 & 1461.8 & 2.95 & 1270 & 1461.63 & 2.89 \\
\hline 305 & 1466.42 & 3.01 & 1271 & 1466.28 & 2.84 \\
\hline 306 & 1470.78 & 2.83 & & & \\
\hline 307 & 1475.74 & 3.01 & 1272 & 1475.48 & 2.96 \\
\hline 308 & 1480.13 & 3.06 & 1273 & 1479.76 & 2.98 \\
\hline 309 & 1484.44 & 2.93 & 1274 & 1484.24 & 2.9 \\
\hline 310 & 1490.21 & 2.96 & 1275 & 1489.64 & 2.78 \\
\hline 311 & 1495.39 & 2.96 & 1276 & 1494.77 & 2.9 \\
\hline 312 & 1499.68 & 2.93 & 1277 & 1499.25 & 2.89 \\
\hline 313 & 1507.26 & 2.78 & 1278 & 1506.9 & 2.74 \\
\hline 314 & 1512.49 & 2.77 & 1279 & 1511.94 & 2.64 \\
\hline 315 & 1517.52 & 2.77 & & & \\
\hline 316 & 1523.14 & 3.02 & 1280 & 1522.71 & 2.94 \\
\hline 317 & 1528.15 & 2.93 & 1281 & 1527.64 & 2.85 \\
\hline 318 & 1533.55 & 2.91 & 1282 & 1532.99 & 2.86 \\
\hline 319 & 1538.75 & 2.93 & 1283 & 1538.13 & 2.89 \\
\hline 320 & 1542.78 & 3.12 & 1284 & 1542.5 & 3.12 \\
\hline 321 & 1547.28 & 3.14 & 1285 & 1547.18 & 3.02 \\
\hline 322 & 1551.48 & 3.16 & 1286 & 1551.56 & 3.15 \\
\hline 323 & 1556.77 & 3.12 & 1287 & 1556.12 & 3.07 \\
\hline 324 & 1562.6 & 3.21 & 1288 & 1562.13 & 3.11 \\
\hline 325 & 1567.52 & 3.21 & 1289 & 1567.14 & 3.17 \\
\hline 326 & 1572.47 & 3.19 & & & \\
\hline 327 & 1579.44 & 3.17 & 1290 & 1579.16 & 3.12 \\
\hline 328 & 1583.76 & 3.12 & 1291 & 1583.54 & 3.13 \\
\hline 329 & 1588.11 & 3.12 & 1292 & 1587.78 & 3.12 \\
\hline 330 & 1592.8 & 3.35 & 1293 & 1592.46 & 3.25 \\
\hline 331 & 1597.48 & 3.59 & 1294 & 1596.73 & 3.34 \\
\hline 332 & 1601.91 & 3.43 & 1295 & 1601.54 & 3.33 \\
\hline 333 & 1607.67 & 3.46 & 1296 & 1607.49 & 3.47 \\
\hline 334 & 1615.4 & 3.59 & 1297 & 1614.99 & 3.55 \\
\hline 335 & 1619.84 & 3.34 & 1298 & 1619.39 & 3.51 \\
\hline 336 & 1625.21 & 3.39 & 1299 & 1624.96 & 3.54 \\
\hline 337 & 1629.55 & 3.45 & & & \\
\hline 338 & 1633.29 & 3.45 & 1300 & 1632.86 & 3.63 \\
\hline 339 & 1637.55 & 3.59 & 1301 & 1637.46 & 3.8 \\
\hline
\end{tabular}




\begin{tabular}{|c|c|c|c|c|c|}
\hline 340 & 1642.23 & 3.65 & 1302 & 1642.01 & 3.81 \\
\hline 341 & 1647.17 & 3.78 & & & \\
\hline 342 & 1651.67 & 3.64 & 1303 & 1651.34 & 3.94 \\
\hline 343 & 1656.2 & 3.55 & 1304 & 1655.86 & 3.99 \\
\hline 344 & 1660.88 & 3.81 & 1305 & 1660.55 & 4.11 \\
\hline 345 & 1664.71 & 3.8 & 1306 & 1664.45 & 4.16 \\
\hline 346 & 1669.97 & 3.84 & 1307 & 1669.61 & 4.28 \\
\hline 347 & 1673.63 & 4.27 & 1308 & 1673.7 & 4.44 \\
\hline 348 & 1678.9 & 4.31 & 1309 & 1678.72 & 4.47 \\
\hline 349 & 1684.09 & 4.44 & 1310 & 1683.63 & 4.51 \\
\hline 350 & 1687.6 & 4.29 & & & \\
\hline 351 & 1692.85 & 4.35 & 1311 & 1692.36 & 4.72 \\
\hline 352 & 1698.52 & 4.54 & 1312 & 1698.1 & 4.7 \\
\hline 353 & 1702.48 & 4.53 & 1313 & 1702.5 & 4.66 \\
\hline 354 & 1704.83 & 5.38 & 1314 & 1704.51 & 5.45 \\
\hline 355 & 1708.93 & 5.54 & 1315 & 1708.69 & 5.54 \\
\hline 356 & 1713.58 & 5.7 & 1316 & 1713.34 & 5.69 \\
\hline 357 & 1718.21 & 5.82 & 1317 & 1717.81 & 5.79 \\
\hline 358 & 1722.39 & 5.94 & 1318 & 1722.15 & 5.94 \\
\hline 359 & 1727.27 & 6.07 & 1319 & 1726.81 & 6.08 \\
\hline 360 & 1731.78 & 6.46 & 1320 & 1731.31 & 6.44 \\
\hline 361 & 1736.35 & 6.41 & 1321 & 1735.73 & 6.48 \\
\hline 362 & 1740.66 & 6.44 & 1322 & 1740.02 & 6.49 \\
\hline 363 & 1745.37 & 6.55 & 1323 & 1744.71 & 6.52 \\
\hline 364 & 1749.87 & 6.63 & 1324 & 1749.26 & 6.61 \\
\hline 365 & 1754.26 & 6.67 & 1325 & 1753.55 & 6.64 \\
\hline 366 & 1758.58 & 6.73 & 1326 & 1758.16 & 6.8 \\
\hline 367 & 1763.14 & 6.87 & 1327 & 1762.67 & 6.85 \\
\hline 368 & 1767.72 & 6.95 & 1328 & 1767.23 & 6.91 \\
\hline 369 & 1772.41 & 7.05 & 1329 & 1771.68 & 7 \\
\hline 370 & 1776.4 & 7.06 & 1330 & 1776.27 & 7.08 \\
\hline 371 & 1781.25 & 7.3 & 1331 & 1780.74 & 7.23 \\
\hline 372 & 1785.38 & 7.31 & 1332 & 1785.24 & 7.31 \\
\hline 373 & 1790.11 & 7.43 & 1333 & 1789.73 & 7.41 \\
\hline 374 & 1795.78 & 7.18 & & & \\
\hline 375 & 1801.46 & 6.93 & & & \\
\hline 376 & 1804.72 & 7.01 & 1334 & 1803.82 & 6.88 \\
\hline 377 & 1808.35 & 7.06 & 1335 & 1807.66 & 6.9 \\
\hline 378 & 1813.18 & 7.12 & 1336 & 1812.13 & 6.91 \\
\hline 379 & 1816.8 & 7.21 & 1337 & 1816.23 & 7.02 \\
\hline 380 & 1821.62 & 7.24 & 1338 & 1821.28 & 7.25 \\
\hline 381 & 1826.23 & 7.37 & 1339 & 1825.75 & 7.28 \\
\hline 382 & 1830.45 & 7.47 & 1340 & 1829.9 & 7.46 \\
\hline 383 & 1835.16 & 7.62 & 1341 & 1834.58 & 7.48 \\
\hline 384 & 1840.3 & 7.82 & 1342 & 1839.61 & 7.46 \\
\hline 385 & 1844.82 & 7.95 & 1343 & 1844.26 & 7.62 \\
\hline 386 & 1848.92 & 8.2 & 1344 & 1848.34 & 7.75 \\
\hline 387 & 1853.63 & 8.44 & 1345 & 1853.05 & 8.05 \\
\hline 388 & 1858.09 & 8.46 & 1346 & 1857.6 & 8.12 \\
\hline
\end{tabular}




\begin{tabular}{|c|c|c|c|c|c|}
\hline 389 & 1862.61 & 8.58 & 1347 & 1861.82 & 8.13 \\
\hline 390 & 1865.87 & 8.24 & & & \\
\hline 391 & 1871.32 & 7.79 & & & \\
\hline 392 & 1875.99 & 7.84 & & & \\
\hline 393 & 1880.89 & 7.88 & & & \\
\hline 394 & 1884.87 & 7.97 & & & \\
\hline 395 & 1889.45 & 8.05 & & & \\
\hline 396 & 1894.14 & 8.14 & & & \\
\hline 397 & 1898.58 & 9.87 & & & \\
\hline 398 & 1903.01 & 11.6 & & & \\
\hline 399 & 1907.45 & 13.33 & & & \\
\hline 400 & 1911.88 & 15.06 & 1348 & 1911.5 & 15.04 \\
\hline 401 & 1916.59 & 15.09 & 1349 & 1916.41 & 15.11 \\
\hline 402 & 1921.63 & 15.2 & 1350 & 1921.3 & 15.2 \\
\hline 403 & 1926.21 & 15.23 & 1351 & 1925.98 & 15.21 \\
\hline 404 & 1931.14 & 15.18 & 1352 & 1930.85 & 15.18 \\
\hline 405 & 1935.96 & 15.18 & 1353 & 1935.75 & 15.19 \\
\hline 406 & 1940.69 & 15.2 & 1354 & 1940.46 & 15.21 \\
\hline 407 & 1945.4 & 15.23 & 1355 & 1945.28 & 15.22 \\
\hline 408 & 1950.22 & 15.24 & 1356 & 1950.06 & 15.25 \\
\hline 409 & 1955.15 & 15.26 & 1357 & 1954.97 & 15.24 \\
\hline 410 & 1960.02 & 15.24 & 1358 & 1959.92 & 15.22 \\
\hline 411 & 1965.82 & 15.16 & 1359 & 1965.74 & 15.18 \\
\hline 412 & 1969.46 & 15.18 & 1360 & 1969.32 & 15.2 \\
\hline 413 & 1974.22 & 15.25 & 1361 & 1974.06 & 15.24 \\
\hline 414 & 1978.8 & 15.17 & 1362 & 1978.77 & 15.2 \\
\hline 415 & 1983.72 & 15.2 & 1363 & 1983.68 & 15.13 \\
\hline 416 & 1987.98 & 15.14 & 1364 & 1987.74 & 15.19 \\
\hline 417 & 1993.5 & 15.06 & 1365 & 1993.19 & 15.01 \\
\hline 418 & 1998.26 & 15.06 & 1366 & 1998.02 & 15.01 \\
\hline 419 & 2002.72 & 15 & 1367 & 2002.58 & 15 \\
\hline 420 & 2007.69 & 15.01 & 1368 & 2007.47 & 15.03 \\
\hline 421 & 2012.89 & 14.96 & 1369 & 2012.96 & 14.95 \\
\hline 422 & 2017.5 & 14.94 & 1370 & 2017.36 & 14.96 \\
\hline 423 & 2022.36 & 14.93 & 1371 & 2022.21 & 14.9 \\
\hline 424 & 2026.41 & 14.88 & 1372 & 2026.59 & 14.98 \\
\hline 425 & 2032.24 & 15.02 & 1373 & 2032.15 & 15.01 \\
\hline 426 & 2036.86 & 15.03 & 1374 & 2036.79 & 14.98 \\
\hline 427 & 2041.84 & 14.88 & 1375 & 2041.8 & 14.92 \\
\hline 428 & 2046.72 & 14.93 & 1376 & 2046.81 & 14.94 \\
\hline 429 & 2051.78 & 14.85 & 1377 & 2051.26 & 14.8 \\
\hline 430 & 2057.02 & 14.83 & & & \\
\hline 431 & 2062.08 & 14.95 & 1378 & 2060.98 & 14.96 \\
\hline 432 & 2065.27 & 14.93 & 1379 & 2064.83 & 14.92 \\
\hline 433 & 2069.91 & 15.04 & 1380 & 2069.69 & 15.01 \\
\hline 434 & 2073.78 & 15 & 1381 & 2073.57 & 14.94 \\
\hline 435 & 2081.2 & 14.98 & 1382 & 2081.16 & 14.98 \\
\hline 436 & 2086.34 & 14.94 & 1383 & 2086.25 & 14.93 \\
\hline 437 & 2090.92 & 14.88 & 1384 & 2090.96 & 14.9 \\
\hline
\end{tabular}




\begin{tabular}{|c|c|c|c|c|c|}
\hline 438 & 2096.9 & 14.87 & 1385 & 2096.65 & 14.93 \\
\hline 439 & 2101.11 & 14.94 & 1386 & 2101.08 & 14.92 \\
\hline 440 & 2106.25 & 14.88 & 1387 & 2106.26 & 14.88 \\
\hline 441 & 2111.2 & 14.94 & 1388 & 2111.09 & 14.95 \\
\hline 442 & 2115.8 & 14.92 & 1389 & 2115.93 & 14.91 \\
\hline 443 & 2120.88 & 14.91 & 1390 & 2120.84 & 14.87 \\
\hline 444 & 2126.12 & 14.89 & 1391 & 2125.82 & 14.86 \\
\hline 445 & 2131.56 & 14.82 & 1392 & 2131.42 & 14.82 \\
\hline 446 & 2135.92 & 14.78 & 1393 & 2136.05 & 14.81 \\
\hline 447 & 2140.62 & 14.68 & 1394 & 2140.76 & 14.73 \\
\hline 448 & 2145.59 & 14.79 & 1395 & 2143.24 & 14.62 \\
\hline 449 & 2150.79 & 14.83 & 1396 & 2150.67 & 14.8 \\
\hline 450 & 2155.5 & 14.83 & 1397 & 2155.55 & 14.77 \\
\hline 451 & 2160.4 & 14.77 & & & \\
\hline 452 & 2165.16 & 14.57 & 1398 & 2165.68 & 14.58 \\
\hline 453 & 2170.78 & 14.51 & 1399 & 2170.52 & 14.58 \\
\hline 454 & 2175.57 & 14.66 & 1400 & 2175.52 & 14.69 \\
\hline 455 & 2180.87 & 14.77 & 1401 & 2180.88 & 14.79 \\
\hline 456 & 2185.48 & 14.81 & 1402 & 2185.7 & 14.88 \\
\hline 457 & 2190.95 & 14.87 & 1403 & 2190.81 & 14.85 \\
\hline 458 & 2195.85 & 14.88 & 1404 & 2195.8 & 14.89 \\
\hline 459 & 2200.59 & 14.88 & 1405 & 2200.61 & 14.83 \\
\hline 460 & 2205.75 & 14.82 & 1406 & 2205.72 & 14.76 \\
\hline 461 & 2210.21 & 14.76 & 1407 & 2210.61 & 14.73 \\
\hline 462 & 2215.49 & 14.6 & & & \\
\hline 463 & 2220.74 & 14.57 & 1408 & 2220.68 & 14.55 \\
\hline 464 & 2225.54 & 14.56 & 1409 & 2225.51 & 14.53 \\
\hline 465 & 2230.73 & 14.51 & 1410 & 2230.7 & 14.46 \\
\hline 466 & 2235.55 & 14.44 & 1411 & 2235.62 & 14.41 \\
\hline 467 & 2240.54 & 14.25 & 1412 & 2240.6 & 14.26 \\
\hline 468 & 2245.55 & 14.16 & 1413 & 2245.44 & 14.16 \\
\hline 469 & 2250.54 & 13.94 & 1414 & 2250.64 & 13.99 \\
\hline 470 & 2255.39 & 13.75 & & & \\
\hline 471 & 2260.06 & 13.67 & 1415 & 2260.26 & 13.67 \\
\hline 472 & 2265.67 & 13.62 & 1416 & 2265.93 & 13.69 \\
\hline 473 & 2270.59 & 13.71 & 1417 & 2270.37 & 13.81 \\
\hline 474 & 2275.36 & 13.59 & 1418 & 2275.42 & 13.76 \\
\hline 475 & 2280.05 & 13.74 & 1419 & 2280.32 & 13.81 \\
\hline 476 & 2285.14 & 14.03 & 1420 & 2285.27 & 14 \\
\hline 477 & 2290.74 & 14.02 & 1421 & 2291.42 & 14.16 \\
\hline 478 & 2297.91 & 14.21 & & & \\
\hline 479 & 2300.23 & 14.2 & 1422 & 2300.2 & 14.25 \\
\hline 480 & 2305.2 & 14.24 & 1423 & 2305.2 & 14.26 \\
\hline 481 & 2310.29 & 14.38 & 1424 & 2310.37 & 14.44 \\
\hline 482 & 2315.67 & 14.41 & 1425 & 2315.59 & 14.53 \\
\hline 483 & 2319.88 & 14.49 & 1426 & 2319.84 & 14.51 \\
\hline 484 & 2325.33 & 14.57 & & & \\
\hline 485 & 2330.25 & 14.86 & 1427 & 2330.2 & 14.75 \\
\hline 486 & 2335.37 & 14.78 & 1428 & 2335.42 & 14.74 \\
\hline
\end{tabular}




\begin{tabular}{|c|c|c|c|c|c|}
\hline 487 & 2340.16 & 14.78 & 1429 & 2340.12 & 14.76 \\
\hline 488 & 2344.85 & 14.7 & 1430 & 2345.18 & 14.77 \\
\hline 489 & 2349.79 & 14.8 & 1431 & 2349.73 & 14.8 \\
\hline 490 & 2354.77 & 14.94 & 1432 & 2354.78 & 14.94 \\
\hline 491 & 2359.56 & 15.03 & 1433 & 2359.65 & 15.07 \\
\hline 492 & 2364.77 & 15.15 & 1434 & 2364.72 & 15.15 \\
\hline 493 & 2369.66 & 15.28 & 1435 & 2369.67 & 15.28 \\
\hline 494 & 2374.39 & 15.36 & 1436 & 2374.59 & 15.33 \\
\hline 495 & 2379.48 & 15.28 & 1437 & 2379.54 & 15.31 \\
\hline 496 & 2382.95 & 15.08 & & & \\
\hline 497 & 2389.16 & 14.84 & 1438 & 2389.29 & 14.93 \\
\hline 498 & 2394.22 & 14.84 & 1439 & 2394.1 & 14.98 \\
\hline 499 & 2399.17 & 14.97 & & & \\
\hline 500 & 2404.16 & 15.34 & 1440 & 2404.17 & 15.37 \\
\hline 501 & 2409.04 & 15.26 & 1441 & 2409.01 & 15.29 \\
\hline 502 & 2414.02 & 15.15 & 1442 & 2413.99 & 15.2 \\
\hline 503 & 2419 & 15.15 & 1443 & 2418.94 & 15.15 \\
\hline 504 & 2423.66 & 15.13 & 1444 & 2423.75 & 15.12 \\
\hline 505 & 2428.8 & 15.1 & 1445 & 2428.88 & 15.1 \\
\hline 506 & 2433.65 & 15.07 & 1446 & 2433.76 & 15.12 \\
\hline 507 & 2438.72 & 15.12 & 1447 & 2438.74 & 15.09 \\
\hline 508 & 2443.62 & 15.24 & 1448 & 2443.7 & 15.25 \\
\hline 509 & 2448.69 & 15.11 & 1449 & 2448.6 & 15.08 \\
\hline 510 & 2453.9 & 15.3 & 1450 & 2453.79 & 15.3 \\
\hline 511 & 2458.53 & 15.27 & 1451 & 2458.44 & 15.21 \\
\hline 512 & 2463.29 & 15.31 & 1452 & 2463.23 & 15.28 \\
\hline 513 & 2468.35 & 15.28 & 1453 & 2468.37 & 15.29 \\
\hline 514 & 2473.17 & 15.25 & 1454 & 2473.25 & 15.28 \\
\hline 515 & 2478.02 & 15.2 & 1455 & 2478.17 & 15.23 \\
\hline 516 & 2482.84 & 15.26 & 1456 & 2483.29 & 15.19 \\
\hline 517 & 2488.09 & 15.04 & & & \\
\hline 518 & 2495.03 & 15.34 & & & \\
\hline 519 & 2501.98 & 15.64 & 1457 & 2501.91 & 15.61 \\
\hline 520 & 2506.84 & 15.51 & 1458 & 2506.88 & 15.52 \\
\hline 521 & 2511.43 & 15.44 & 1459 & 2511.16 & 15.47 \\
\hline 522 & 2516.56 & 15.48 & 1460 & 2516.55 & 15.53 \\
\hline 523 & 2521.46 & 15.68 & 1461 & 2521.4 & 15.67 \\
\hline 524 & 2526.36 & 15.81 & 1462 & 2526.54 & 15.84 \\
\hline 525 & 2531.56 & 15.82 & 1463 & 2531.5 & 15.85 \\
\hline 526 & 2536.45 & 15.8 & 1464 & 2536.47 & 15.81 \\
\hline 527 & 2540.82 & 15.82 & 1465 & 2540.9 & 15.89 \\
\hline 528 & 2546.4 & 15.83 & 1466 & 2546.42 & 15.86 \\
\hline 529 & 2551.31 & 15.85 & 1467 & 2551.31 & 15.87 \\
\hline 530 & 2556.21 & 15.84 & 1468 & 2556.27 & 15.88 \\
\hline 531 & 2561.32 & 15.88 & 1469 & 2561.42 & 15.91 \\
\hline 532 & 2566.41 & 15.88 & 1470 & 2566.39 & 15.95 \\
\hline 533 & 2571.19 & 15.96 & 1471 & 2571.19 & 15.99 \\
\hline 534 & 2576.12 & 15.94 & 1472 & 2576.09 & 15.96 \\
\hline 535 & 2580.27 & 15.96 & 1473 & 2580.37 & 15.99 \\
\hline
\end{tabular}




\begin{tabular}{|c|c|c|c|c|c|}
\hline 536 & 2586.03 & 15.88 & & & \\
\hline 537 & 2591.27 & 15.79 & 1474 & 2590.97 & 15.79 \\
\hline 538 & 2595.92 & 15.7 & 1475 & 2595.95 & 15.71 \\
\hline 539 & 2600.72 & 15.66 & 1476 & 2600.74 & 15.67 \\
\hline 540 & 2605.55 & 15.66 & 1477 & 2605.74 & 15.67 \\
\hline 541 & 2610.74 & 15.62 & 1478 & 2610.94 & 15.66 \\
\hline 542 & 2615.76 & 15.58 & 1479 & 2615.81 & 15.61 \\
\hline 543 & 2620.23 & 15.54 & & & \\
\hline 544 & 2626.2 & 15.51 & & & \\
\hline 545 & 2632.18 & 15.49 & & & \\
\hline 546 & 2638.15 & 15.46 & & & \\
\hline 547 & 2644.13 & 15.44 & & & \\
\hline 548 & 2650.1 & 15.41 & 1480 & 2649.68 & 15.49 \\
\hline 549 & 2654.49 & 15.62 & 1481 & 2654.51 & 15.78 \\
\hline 550 & 2658.68 & 15.8 & & & \\
\hline 551 & 2664.21 & 15.61 & & & \\
\hline 552 & 2669.03 & 15.72 & 1482 & 2668.73 & 15.78 \\
\hline 553 & 2674.72 & 15.91 & 1483 & 2674.34 & 15.95 \\
\hline 554 & 2678.72 & 15.86 & 1484 & 2678.68 & 15.92 \\
\hline 555 & 2683.99 & 15.88 & 1485 & 2683.69 & 15.93 \\
\hline 556 & 2688.43 & 15.88 & 1486 & 2688.44 & 15.9 \\
\hline 557 & 2693.87 & 15.69 & & & \\
\hline 558 & 2699.56 & 15.9 & 1487 & 2699.55 & 15.9 \\
\hline 559 & 2703.28 & 15.66 & 1488 & 2703.57 & 15.69 \\
\hline 560 & 2708.16 & 15.77 & 1489 & 2708.57 & 15.88 \\
\hline 561 & 2713.17 & 15.75 & 1490 & 2713.27 & 15.74 \\
\hline 562 & 2718.43 & 15.75 & 1491 & 2718.54 & 15.73 \\
\hline 563 & 2723.89 & 15.74 & 1492 & 2723.72 & 15.82 \\
\hline 564 & 2728.75 & 15.88 & 1493 & 2728.72 & 15.92 \\
\hline 565 & 2733.32 & 15.76 & 1494 & 2733.55 & 15.73 \\
\hline 566 & 2737.35 & 15.66 & 1495 & 2737.96 & 15.72 \\
\hline 567 & 2742.9 & 15.57 & 1496 & 2743.64 & 15.58 \\
\hline 568 & 2747.49 & 15.21 & 1497 & 2748.23 & 15.22 \\
\hline 569 & 2752.77 & 15.5 & 1498 & 2753.15 & 15.54 \\
\hline 570 & 2757.57 & 15.65 & 1499 & 2757.95 & 15.77 \\
\hline 571 & 2762.72 & 16.07 & 1500 & 2762.56 & 15.94 \\
\hline 572 & 2768.05 & 16.4 & 1501 & 2768.03 & 16.41 \\
\hline 573 & 2772.58 & 16.75 & 1502 & 2772.84 & 16.72 \\
\hline 574 & 2777.91 & 17.33 & 1503 & 2778.09 & 17.29 \\
\hline 575 & 2782.77 & 17.88 & 1504 & 2782.64 & 17.58 \\
\hline 576 & 2787.55 & 18.31 & 1505 & 2787.78 & 18.32 \\
\hline 577 & 2792.73 & 18.09 & & & \\
\hline 578 & 2797.91 & 17.87 & & & \\
\hline 579 & 2803.09 & 17.65 & & & \\
\hline 580 & 2808.13 & 16.46 & 1506 & 2808.06 & 17.14 \\
\hline 581 & 2812.37 & 16.19 & 1507 & 2812.13 & 16.24 \\
\hline 582 & 2817.53 & 15.64 & 1508 & 2817.77 & 15.67 \\
\hline 583 & 2822.66 & 15.58 & 1509 & 2822.61 & 15.7 \\
\hline 584 & 2827.53 & 15.6 & 1510 & 2827.55 & 15.66 \\
\hline
\end{tabular}




\begin{tabular}{|c|c|c|c|c|c|}
\hline 585 & 2832.43 & 15.53 & 1511 & 2832.42 & 15.52 \\
\hline 586 & 2837.53 & 15.53 & 1512 & 2837.72 & 15.59 \\
\hline 587 & 2842.68 & 15.66 & 1513 & 2842.41 & 15.62 \\
\hline 588 & 2847.89 & 15.65 & 1514 & 2847.84 & 15.72 \\
\hline 589 & 2852.63 & 15.75 & 1515 & 2852.56 & 15.81 \\
\hline 590 & 2856.18 & 15.86 & 1516 & 2855.88 & 15.87 \\
\hline 591 & 2862.1 & 15.84 & 1517 & 2862.24 & 15.82 \\
\hline 592 & 2867.46 & 15.84 & 1518 & 2867.36 & 15.86 \\
\hline 593 & 2872.46 & 15.93 & 1519 & 2872.26 & 15.96 \\
\hline 594 & 2877.36 & 15.98 & 1520 & 2877.47 & 16.14 \\
\hline 595 & 2882.85 & 16.07 & 1521 & 2882.21 & 16.06 \\
\hline 596 & 2887.17 & 16.12 & 1522 & 2886.81 & 16.14 \\
\hline 597 & 2892.4 & 16.18 & 1523 & 2892.21 & 16.2 \\
\hline 598 & 2896.18 & 16.16 & 1524 & 2896.66 & 16.14 \\
\hline 599 & 2901.88 & 16.12 & 1525 & 2902.15 & 16.06 \\
\hline 600 & 2907.15 & 16.28 & 1526 & 2907.14 & 16.33 \\
\hline 601 & 2912.14 & 16.41 & 1527 & 2912.15 & 16.43 \\
\hline 602 & 2916.92 & 16.48 & & & \\
\hline 603 & 2921.92 & 16.57 & 1528 & 2922.07 & 16.59 \\
\hline 604 & 2926.87 & 16.77 & 1529 & 2926.93 & 16.78 \\
\hline 605 & 2931.71 & 16.97 & 1530 & 2932.06 & 16.97 \\
\hline 606 & 2938.59 & 17.24 & 1531 & 2938.84 & 17.28 \\
\hline 607 & 2942.35 & 17.44 & 1532 & 2941.98 & 17.56 \\
\hline 608 & 2947.55 & 17.64 & 1533 & 2947.14 & 17.75 \\
\hline 609 & 2952.21 & 17.41 & 1534 & 2951.93 & 17.52 \\
\hline 610 & 2956.68 & 16.32 & 1535 & 2956.76 & 16.55 \\
\hline 611 & 2961.42 & 16.09 & 1536 & 2961.8 & 16.27 \\
\hline 612 & 2966.4 & 15.99 & 1537 & 2967.15 & 16.33 \\
\hline 613 & 2972.12 & 16.02 & 1538 & 2972.12 & 16.34 \\
\hline 614 & 2978.05 & 15.96 & 1539 & 2977.61 & 16.03 \\
\hline 615 & 2982.15 & 16.25 & 1540 & 2982.03 & 16.41 \\
\hline 616 & 2986.31 & 16.31 & 1541 & 2986.57 & 16.48 \\
\hline 617 & 2991.32 & 16.64 & 1542 & 2991.79 & 16.76 \\
\hline 618 & 2996.72 & 16.97 & 1543 & 2996.65 & 17.16 \\
\hline 619 & 2999.63 & 17.1 & 1544 & 2999.41 & 17.19 \\
\hline 620 & 3006.09 & 16.19 & & & \\
\hline 621 & 3011.81 & 16.36 & & & \\
\hline 622 & 3017.53 & 16.54 & & & \\
\hline 623 & 3023.25 & 16.71 & & & \\
\hline 624 & 3028.97 & 16.88 & & & \\
\hline 625 & 3034.69 & 17.05 & & & \\
\hline 626 & 3040.41 & 17.23 & & & \\
\hline 627 & 3046.13 & 17.4 & 1545 & 3046.19 & 17.44 \\
\hline 628 & 3050.96 & 17.47 & 1546 & 3050.91 & 17.55 \\
\hline 629 & 3055.28 & 17.59 & 1547 & 3055.18 & 17.62 \\
\hline 630 & 3061.43 & 17.81 & 1548 & 3061.74 & 17.96 \\
\hline 631 & 3066.96 & 17.66 & 1549 & 3067 & 17.75 \\
\hline 634 & 3084.86 & 17.69 & 1550 & 3085.07 & 17.9 \\
\hline 635 & 3090.55 & 17.75 & 1551 & 3090.58 & 17.9 \\
\hline
\end{tabular}




\begin{tabular}{|c|c|c|c|c|c|}
\hline 636 & 3095.03 & 17.72 & & & \\
\hline 637 & 3101.05 & 17.87 & 1552 & 3101.06 & 17.88 \\
\hline 638 & 3106.49 & 17.84 & 1553 & 3107.13 & 17.97 \\
\hline 639 & 3112.3 & 17.78 & 1554 & 3112.25 & 17.97 \\
\hline 640 & 3117.86 & 17.69 & 1555 & 3117.98 & 18.02 \\
\hline 641 & 3123.28 & 17.71 & 1556 & 3123.56 & 18.04 \\
\hline 642 & 3128.68 & 17.75 & 1557 & 3128.82 & 18.03 \\
\hline 643 & 3134.68 & 17.87 & 1558 & 3134.75 & 18.11 \\
\hline 644 & 3139.69 & 17.84 & 1559 & 3139.93 & 18.17 \\
\hline 645 & 3146.1 & 17.61 & 1560 & 3146.44 & 18.16 \\
\hline 646 & 3151.34 & 17.67 & 1561 & 3151.44 & 18.18 \\
\hline 647 & 3157.08 & 17.83 & 1562 & 3156.94 & 18.14 \\
\hline 648 & 3160.87 & 17.74 & 1563 & 3161.21 & 18.14 \\
\hline 649 & 3164.6 & 17.63 & 1564 & 3165.03 & 18.09 \\
\hline 650 & 3169.05 & 17.76 & 1565 & 3169.08 & 18.04 \\
\hline 651 & 3174.5 & 17.73 & 1566 & 3174.56 & 18.04 \\
\hline 652 & 3179.47 & 17.77 & 1567 & 3179.61 & 18.1 \\
\hline 653 & 3184.33 & 17.97 & 1568 & 3184.52 & 18.11 \\
\hline 654 & 3189.32 & 18.05 & 1569 & 3189.68 & 18.15 \\
\hline 655 & 3194.46 & 18.12 & 1570 & 3194.46 & 18.14 \\
\hline 656 & 3199.49 & 18.1 & 1571 & 3199.53 & 18.22 \\
\hline 657 & 3204.43 & 18.08 & & & \\
\hline 658 & 3209.31 & 18.25 & 1572 & 3209.42 & 18.46 \\
\hline 659 & 3214.06 & 18.39 & 1573 & 3214.13 & 18.63 \\
\hline 660 & 3219.1 & 18.44 & 1574 & 3219.39 & 18.62 \\
\hline 661 & 3224.08 & 18.7 & 1575 & 3224.22 & 18.81 \\
\hline 662 & 3229.08 & 18.82 & 1576 & 3229.38 & 18.88 \\
\hline 663 & 3234.01 & 19.15 & 1577 & 3234.11 & 19.1 \\
\hline 664 & 3239.13 & 19.44 & 1578 & 3238.86 & 19.43 \\
\hline 665 & 3243.87 & 19.77 & 1579 & 3244.49 & 19.71 \\
\hline 666 & 3249.05 & 20.02 & 1580 & 3249.09 & 19.94 \\
\hline 667 & 3254.04 & 20.2 & 1581 & 3254.11 & 20.24 \\
\hline 668 & 3258.87 & 20.4 & 1582 & 3259 & 20.35 \\
\hline 669 & 3263.37 & 20.43 & 1583 & 3263.74 & 20.42 \\
\hline 670 & 3269.02 & 20.48 & 1584 & 3268.46 & 20.5 \\
\hline 671 & 3273.65 & 20.48 & & & \\
\hline 672 & 3278.65 & 20.54 & 1585 & 3278.69 & 20.48 \\
\hline 673 & 3283.24 & 20.49 & 1586 & 3283.54 & 20.53 \\
\hline 674 & 3287.99 & 20.55 & 1587 & 3288.56 & 20.55 \\
\hline 675 & 3292.6 & 20.55 & 1588 & 3293.52 & 20.65 \\
\hline 676 & 3298.21 & 20.59 & 1589 & 3298.66 & 20.63 \\
\hline 677 & 3302.96 & 20.68 & 1590 & 3303.62 & 20.69 \\
\hline 678 & 3308.02 & 20.74 & 1591 & 3308.59 & 20.74 \\
\hline 679 & 3312.79 & 20.81 & 1592 & 3313.43 & 20.77 \\
\hline 680 & 3319.09 & 20.83 & 1593 & 3318.32 & 20.82 \\
\hline 681 & 3323.31 & 20.87 & 1594 & 3323.3 & 20.91 \\
\hline 682 & 3328.42 & 20.9 & 1595 & 3328.39 & 20.98 \\
\hline 683 & 3333.04 & 20.96 & 1596 & 3333.3 & 21.06 \\
\hline 684 & 3338.44 & 20.93 & 1597 & 3338.43 & 20.99 \\
\hline
\end{tabular}




\begin{tabular}{|c|c|c|c|c|c|}
\hline 685 & 3343.22 & 20.94 & 1598 & 3343.3 & 21 \\
\hline 686 & 3348.32 & 20.97 & & & \\
\hline 687 & 3353.49 & 21.02 & 1599 & 3353.43 & 21.06 \\
\hline 688 & 3358.4 & 21.13 & 1600 & 3358.32 & 21.15 \\
\hline 689 & 3363.19 & 21.14 & 1601 & 3363.18 & 21.15 \\
\hline 690 & 3368.21 & 21.17 & 1602 & 3368.26 & 21.09 \\
\hline 691 & 3373.13 & 21.13 & 1603 & 3373.19 & 21.22 \\
\hline 692 & 3378.28 & 21.13 & 1604 & 3378.1 & 21.3 \\
\hline 693 & 3383.17 & 21.13 & 1605 & 3383.14 & 21.32 \\
\hline 694 & 3388.29 & 21.07 & 1606 & 3388.26 & 21.25 \\
\hline 695 & 3393.06 & 21.13 & 1607 & 3393.09 & 21.28 \\
\hline 696 & 3398.48 & 21.2 & 1608 & 3398.23 & 21.36 \\
\hline 697 & 3403.14 & 21.26 & 1609 & 3403.11 & 21.47 \\
\hline 698 & 3408.25 & 21.25 & 1610 & 3408.17 & 21.63 \\
\hline 699 & 3413.11 & 21.36 & 1611 & 3413.14 & 21.62 \\
\hline 700 & 3417.87 & 21.46 & 1612 & 3417.95 & 21.6 \\
\hline 701 & 3422.91 & 21.6 & 1613 & 3422.96 & 21.67 \\
\hline 702 & 3427.82 & 21.69 & 1614 & 3427.98 & 21.68 \\
\hline 703 & 3432.7 & 21.71 & 1615 & 3432.73 & 21.71 \\
\hline 704 & 3438.02 & 21.68 & 1616 & 3437.92 & 21.66 \\
\hline 705 & 3442.55 & 21.65 & 1617 & 3442.61 & 21.66 \\
\hline 706 & 3447.86 & 21.69 & 1618 & 3448.15 & 21.65 \\
\hline 707 & 3452.51 & 21.68 & 1619 & 3452.65 & 21.79 \\
\hline 708 & 3457.84 & 21.94 & 1620 & 3457.84 & 21.84 \\
\hline 709 & 3462.77 & 22.08 & 1621 & 3462.82 & 22 \\
\hline 710 & 3467.6 & 21.98 & 1622 & 3467.66 & 22.01 \\
\hline 711 & 3472.49 & 21.86 & 1623 & 3472.55 & 21.91 \\
\hline 712 & 3475.01 & 21.9 & 1624 & 3475.14 & 21.93 \\
\hline 713 & 3482.17 & 21.49 & & & \\
\hline 714 & 3485.91 & 20.98 & & & \\
\hline 715 & 3489.69 & 21.9 & & & \\
\hline 716 & 3495.12 & 21.98 & 1625 & 3495.34 & 21.91 \\
\hline 717 & 3498.19 & 22.06 & 1626 & 3498.34 & 22.04 \\
\hline 718 & 3501.26 & 22.15 & 1627 & 3501.34 & 22.16 \\
\hline 719 & 3506.15 & 22.22 & 1628 & 3506.02 & 22.3 \\
\hline 720 & 3511.9 & 22.34 & 1629 & 3511.36 & 22.33 \\
\hline 721 & 3516.07 & 22.39 & 1630 & 3516.17 & 22.4 \\
\hline 722 & 3521.37 & 22.42 & 1631 & 3521.48 & 22.45 \\
\hline 723 & 3525.49 & 22.43 & 1632 & 3526.09 & 22.47 \\
\hline 724 & 3531.31 & 22.4 & 1633 & 3531.21 & 22.44 \\
\hline 725 & 3536.2 & 22.48 & 1634 & 3536.26 & 22.47 \\
\hline 726 & 3541.3 & 22.54 & 1635 & 3541.18 & 22.52 \\
\hline 727 & 3545.95 & 22.61 & 1636 & 3545.81 & 22.58 \\
\hline 728 & 3551.01 & 22.62 & 1637 & 3550.95 & 22.62 \\
\hline 729 & 3555.93 & 22.67 & 1638 & 3554.74 & 22.68 \\
\hline 730 & 3560.96 & 22.76 & 1639 & 3560.84 & 22.71 \\
\hline 731 & 3565.09 & 22.78 & 1640 & 3565.73 & 22.82 \\
\hline 732 & 3570.51 & 22.77 & & & \\
\hline 733 & 3575.51 & 22.73 & 1641 & 3575.85 & 23.04 \\
\hline
\end{tabular}




\begin{tabular}{|c|c|c|c|c|c|}
\hline 734 & 3580.6 & 22.85 & & & \\
\hline 735 & 3585.33 & 22.78 & 1642 & 3585.26 & 22.77 \\
\hline 736 & 3590.65 & 22.84 & & & \\
\hline 737 & 3595.97 & 22.89 & & & \\
\hline 738 & 3601.29 & 22.95 & & & \\
\hline 739 & 3606.61 & 23 & & & \\
\hline 740 & 3611.93 & 23.06 & 1643 & 3611.7 & 23.06 \\
\hline 741 & 3615.34 & 23.19 & 1644 & 3614.92 & 23.18 \\
\hline 742 & 3619.69 & 23.28 & 1645 & 3619.9 & 23.33 \\
\hline 743 & 3625.06 & 23.29 & 1646 & 3624.65 & 23.4 \\
\hline 744 & 3629.47 & 23.4 & 1647 & 3629.76 & 23.48 \\
\hline 745 & 3634.84 & 23.52 & 1648 & 3634.63 & 23.56 \\
\hline 746 & 3639.49 & 23.65 & 1649 & 3639.65 & 23.65 \\
\hline 747 & 3644.38 & 23.71 & 1650 & 3644.62 & 23.7 \\
\hline 748 & 3649.09 & 23.72 & 1651 & 3649.1 & 23.81 \\
\hline 749 & 3654.15 & 23.78 & 1652 & 3654.6 & 23.78 \\
\hline 750 & 3659.44 & 23.85 & 1653 & 3659.58 & 23.87 \\
\hline 751 & 3664.23 & 23.89 & 1654 & 3664.41 & 23.9 \\
\hline 752 & 3669.34 & 23.96 & 1655 & 3669.45 & 23.98 \\
\hline 753 & 3674.14 & 24.05 & 1656 & 3674.33 & 24.03 \\
\hline 754 & 3679.23 & 24.17 & 1657 & 3678.82 & 24.14 \\
\hline 755 & 3683.91 & 24.27 & 1658 & 3684.28 & 24.2 \\
\hline 756 & 3688.71 & 24.35 & 1659 & 3688.72 & 24.35 \\
\hline 757 & 3693.92 & 24.4 & 1660 & 3693.91 & 24.41 \\
\hline 758 & 3698.88 & 24.37 & 1661 & 3699.01 & 24.4 \\
\hline 759 & 3704.12 & 24.45 & 1662 & 3703.94 & 24.49 \\
\hline 760 & 3708.99 & 24.52 & 1663 & 3708.95 & 24.57 \\
\hline 761 & 3713.78 & 24.54 & 1664 & 3714.12 & 24.53 \\
\hline 762 & 3718.59 & 24.55 & & & \\
\hline 763 & 3724.32 & 24.56 & 1665 & 3723.62 & 24.57 \\
\hline 764 & 3728.77 & 24.63 & & & \\
\hline 765 & 3733.69 & 24.69 & 1666 & 3733.66 & 24.76 \\
\hline 766 & 3738.74 & 24.69 & 1667 & 3738.9 & 24.86 \\
\hline 767 & 3743.84 & 24.83 & 1668 & 3743.65 & 24.93 \\
\hline 768 & 3748.71 & 24.93 & 1669 & 3748.66 & 24.95 \\
\hline 769 & 3753.65 & 24.9 & 1670 & 3753.47 & 25.12 \\
\hline 770 & 3758.73 & 25.02 & 1671 & 3758.68 & 25.04 \\
\hline 771 & 3763.67 & 25.04 & 1672 & 3763.6 & 25.09 \\
\hline 772 & 3768.64 & 25.09 & 1673 & 3768.56 & 25.2 \\
\hline 773 & 3773.81 & 25.22 & 1674 & 3774.06 & 25.33 \\
\hline 774 & 3779.3 & 25.23 & 1675 & 3779.53 & 25.34 \\
\hline 775 & 3784.79 & 25.25 & 1676 & 3784.99 & 25.35 \\
\hline 776 & 3790.29 & 25.26 & & & \\
\hline 777 & 3795.78 & 25.27 & & & \\
\hline 778 & 3801.27 & 25.28 & & & \\
\hline 779 & 3806.76 & 25.3 & & & \\
\hline 780 & 3812.25 & 25.31 & & & \\
\hline 781 & 3817.74 & 25.32 & & & \\
\hline 782 & 3823.24 & 25.33 & & & \\
\hline
\end{tabular}




\begin{tabular}{|c|c|c|c|c|c|}
\hline 783 & 3828.73 & 25.35 & & & \\
\hline 784 & 3834.22 & 25.36 & & & \\
\hline 785 & 3839.13 & 25.47 & 1677 & 3839.16 & 25.58 \\
\hline 786 & 3844.68 & 25.51 & 1678 & 3844.46 & 25.74 \\
\hline 787 & 3849.34 & 25.58 & 1679 & 3849.24 & 25.76 \\
\hline 788 & 3854.04 & 25.69 & & & \\
\hline 789 & 3858.94 & 25.82 & 1680 & 3859.09 & 25.8 \\
\hline 790 & 3863.65 & 25.8 & 1681 & 3863.33 & 25.81 \\
\hline 791 & 3869.28 & 25.94 & 1682 & 3869.16 & 26.02 \\
\hline 792 & 3875.54 & 26.11 & 1683 & 3875.44 & 26.14 \\
\hline 793 & 3879.33 & 25.98 & 1684 & 3879.09 & 26.2 \\
\hline 794 & 3883.64 & 26.02 & 1685 & 3883.94 & 25.95 \\
\hline 795 & 3888.98 & 26.02 & 1686 & 3889.01 & 26.04 \\
\hline 796 & 3893.56 & 26.15 & 1687 & 3893.29 & 26.15 \\
\hline 797 & 3899.08 & 26.06 & 1688 & 3898.85 & 26.16 \\
\hline 798 & 3903.56 & 26.18 & 1689 & 3903.51 & 26.18 \\
\hline 799 & 3908.71 & 26.14 & 1690 & 3908.51 & 26.26 \\
\hline 800 & 3913.83 & 26.22 & 1691 & 3913.54 & 26.26 \\
\hline 801 & 3918.78 & 26.27 & 1692 & 3918.64 & 26.33 \\
\hline 802 & 3923.39 & 26.46 & 1693 & 3923.35 & 26.45 \\
\hline 803 & 3928.15 & 26.47 & 1694 & 3928.42 & 26.56 \\
\hline 804 & 3933.59 & 26.48 & 1695 & 3933.45 & 26.49 \\
\hline 805 & 3938.34 & 26.52 & 1696 & 3938.24 & 26.54 \\
\hline 806 & 3942.87 & 26.62 & 1697 & 3943.16 & 26.63 \\
\hline 807 & 3948.5 & 26.73 & 1698 & 3948.05 & 26.7 \\
\hline 808 & 3953.42 & 26.76 & 1699 & 3953.19 & 26.77 \\
\hline 809 & 3957.78 & 26.83 & 1700 & 3957.9 & 26.84 \\
\hline 810 & 3962.66 & 27.05 & 1701 & 3962.61 & 27.11 \\
\hline 811 & 3967.81 & 27.15 & 1702 & 3967.78 & 27.17 \\
\hline 812 & 3973.04 & 27.29 & 1703 & 3972.78 & 27.31 \\
\hline 813 & 3977.58 & 27.42 & 1704 & 3977.47 & 27.43 \\
\hline 814 & 3982.61 & 27.49 & 1705 & 3982.52 & 27.39 \\
\hline 815 & 3987.41 & 27.48 & & & \\
\hline 816 & 3992.34 & 27.45 & & & \\
\hline 817 & 3996.64 & 27.39 & & & \\
\hline 818 & 4001.55 & 27.44 & & & \\
\hline 819 & 4006.45 & 27.5 & & & \\
\hline 820 & 4011.36 & 27.55 & & & \\
\hline 821 & 4016.26 & 27.6 & & & \\
\hline 822 & 4021.16 & 27.66 & & & \\
\hline 823 & 4026.07 & 27.71 & 1706 & 4026.03 & 27.72 \\
\hline 824 & 4031.75 & 27.69 & 1707 & 4031.7 & 27.69 \\
\hline 825 & 4036.16 & 28.02 & 1708 & 4035.99 & 27.97 \\
\hline 826 & 4041.65 & 27.95 & 1709 & 4041.58 & 27.97 \\
\hline 827 & 4046.56 & 28.01 & 1710 & 4046.55 & 28 \\
\hline 828 & 4052.22 & 28.03 & 1711 & 4051.6 & 28.05 \\
\hline 829 & 4056.55 & 28.14 & 1712 & 4056.42 & 28.12 \\
\hline 830 & 4061.5 & 28.16 & 1713 & 4061.43 & 28.13 \\
\hline 831 & 4066.39 & 28.26 & 1714 & 4066.49 & 28.26 \\
\hline
\end{tabular}




\begin{tabular}{|c|c|c|c|c|c|}
\hline 832 & 4072.14 & 28.35 & 1715 & 4071.97 & 28.37 \\
\hline 833 & 4076.68 & 28.38 & 1716 & 4076.65 & 28.33 \\
\hline 834 & 4081.77 & 28.33 & 1717 & 4081.62 & 28.36 \\
\hline 835 & 4086.74 & 28.37 & 1718 & 4086.47 & 28.29 \\
\hline 836 & 4091.42 & 28.36 & 1719 & 4091.4 & 28.29 \\
\hline 837 & 4096.58 & 28.31 & 1720 & 4096.45 & 28.3 \\
\hline 838 & 4101.25 & 28.33 & 1721 & 4101.17 & 28.37 \\
\hline 839 & 4106.62 & 28.32 & 1722 & 4106.55 & 28.39 \\
\hline 840 & 4111.33 & 28.26 & 1723 & 4111.35 & 28.44 \\
\hline 841 & 4116.63 & 28.52 & 1724 & 4116.51 & 28.53 \\
\hline 842 & 4122.21 & 28.44 & 1725 & 4122.11 & 28.47 \\
\hline 843 & 4126.11 & 28.47 & 1726 & 4126.05 & 28.49 \\
\hline 844 & 4130.89 & 28.58 & 1727 & 4131.02 & 28.57 \\
\hline 845 & 4135.95 & 28.57 & 1728 & 4135.82 & 28.58 \\
\hline 846 & 4141.97 & 28.67 & 1729 & 4141.27 & 28.62 \\
\hline 847 & 4146.55 & 28.76 & 1730 & 4145.96 & 28.8 \\
\hline 848 & 4151.34 & 28.72 & 1731 & 4151.29 & 28.75 \\
\hline 849 & 4157.13 & 28.77 & 1732 & 4156.51 & 28.77 \\
\hline 850 & 4160.33 & 28.86 & 1733 & 4160.19 & 28.87 \\
\hline 851 & 4163.54 & 28.88 & 1734 & 4164.02 & 28.91 \\
\hline 852 & 4170.65 & 28.98 & 1735 & 4170.57 & 29 \\
\hline 853 & 4176.96 & 29.02 & 1736 & 4176.9 & 29.05 \\
\hline 854 & 4183.83 & 29.06 & 1737 & 4183.16 & 29.04 \\
\hline 855 & 4189.32 & 29.18 & 1738 & 4188.82 & 29.17 \\
\hline 856 & 4195.52 & 29.11 & 1739 & 4194.9 & 29.09 \\
\hline 857 & 4201.4 & 29.27 & 1740 & 4200.66 & 29.21 \\
\hline 858 & 4205.34 & 29.07 & 1741 & 4205.48 & 28.97 \\
\hline 859 & 4210.33 & 29.31 & & & \\
\hline 860 & 4215.32 & 29.55 & 1742 & 4214.97 & 29.59 \\
\hline 861 & 4219.73 & 30.79 & 1743 & 4219.81 & 30.93 \\
\hline 862 & 4224.31 & 32.41 & 1744 & 4224.12 & 32.46 \\
\hline 863 & 4228.68 & 33.06 & 1745 & 4228.94 & 33.24 \\
\hline 864 & 4234.29 & 32.74 & 1746 & 4234.3 & 32.86 \\
\hline 865 & 4239.49 & 32.39 & 1747 & 4239.33 & 32.49 \\
\hline 866 & 4244.29 & 32.27 & 1748 & 4244.28 & 32.35 \\
\hline 867 & 4249.35 & 32.3 & & & \\
\hline 868 & 4254.41 & 32.33 & & & \\
\hline 869 & 4259.46 & 32.36 & & & \\
\hline 870 & 4264.52 & 32.39 & & & \\
\hline 871 & 4269.5 & 31.62 & 1749 & 4269.28 & 31.99 \\
\hline 872 & 4274.46 & 30.87 & 1750 & 4274.37 & 31.76 \\
\hline 873 & 4278.97 & 30.34 & 1751 & 4278.72 & 30.97 \\
\hline 874 & 4283.66 & 30.13 & 1752 & 4283.73 & 30.54 \\
\hline 875 & 4289.29 & 29.98 & 1753 & 4289.3 & 30.32 \\
\hline 876 & 4293.87 & 30 & 1754 & 4293.93 & 30 \\
\hline 877 & 4298.87 & 30.12 & 1755 & 4298.74 & 30.12 \\
\hline 878 & 4304.58 & 30.15 & 1756 & 4304.41 & 30.13 \\
\hline 879 & 4308.87 & 30.03 & 1757 & 4308.77 & 30.1 \\
\hline 880 & 4314.81 & 30.21 & 1758 & 4314.66 & 30.29 \\
\hline
\end{tabular}




\begin{tabular}{|c|c|c|c|c|c|}
\hline 881 & 4320.13 & 30.33 & 1759 & 4319.63 & 30.37 \\
\hline 882 & 4323.79 & 30.39 & 1760 & 4323.44 & 30.36 \\
\hline 883 & 4328.33 & 30.32 & 1761 & 4328.67 & 30.3 \\
\hline 884 & 4333.86 & 30.48 & 1762 & 4333.57 & 30.4 \\
\hline 885 & 4338.09 & 30.52 & 1763 & 4338.83 & 30.47 \\
\hline 886 & 4342.91 & 30.56 & 1764 & 4343.7 & 30.57 \\
\hline 887 & 4348.25 & 30.64 & 1765 & 4348.64 & 30.66 \\
\hline 888 & 4353.79 & 30.76 & 1766 & 4354.06 & 30.78 \\
\hline 889 & 4358.63 & 30.71 & 1767 & 4358.68 & 30.76 \\
\hline 890 & 4363.77 & 30.74 & 1768 & 4363.77 & 30.84 \\
\hline 891 & 4368.31 & 30.84 & 1769 & 4368.35 & 30.87 \\
\hline 892 & 4373.51 & 31.04 & 1770 & 4373.1 & 30.98 \\
\hline 893 & 4378.23 & 31.08 & 1771 & 4377.98 & 31.1 \\
\hline 894 & 4384.09 & 31.18 & 1772 & 4383.02 & 31.22 \\
\hline 895 & 4388.28 & 31.21 & 1773 & 4388.9 & 31.24 \\
\hline 896 & 4392.6 & 31.31 & & & \\
\hline 897 & 4397.35 & 31.42 & & & \\
\hline 898 & 4401.63 & 31.73 & 1774 & 4402.29 & 31.81 \\
\hline 899 & 4407.07 & 32.25 & 1775 & 4407.47 & 32.35 \\
\hline 900 & 4412.81 & 32.97 & & & \\
\hline 901 & 4416.45 & 32.85 & 1776 & 4416.21 & 32.54 \\
\hline 902 & 4421.09 & 32.87 & & & \\
\hline 903 & 4426.63 & 32.28 & & & \\
\hline 904 & 4431.62 & 32.17 & & & \\
\hline 905 & 4436.71 & 32.08 & & & \\
\hline 906 & 4441.54 & 32 & & & \\
\hline 907 & 4445.64 & 32.77 & 1777 & 4445.62 & 32.09 \\
\hline 908 & 4451.73 & 31.94 & 1778 & 4451.96 & 31.9 \\
\hline 909 & 4457.09 & 31.91 & 1779 & 4457.09 & 31.75 \\
\hline 910 & 4462.09 & 31.84 & 1780 & 4462.18 & 31.69 \\
\hline 911 & 4467.05 & 31.65 & 1781 & 4467.02 & 31.57 \\
\hline 912 & 4472.04 & 31.59 & & & \\
\hline 913 & 4477.05 & 31.54 & 1782 & 4477.2 & 31.44 \\
\hline 914 & 4481.98 & 31.49 & 1783 & 4482.19 & 31.37 \\
\hline 915 & 4487.01 & 31.48 & 1784 & 4487.15 & 31.3 \\
\hline 916 & 4491.99 & 31.4 & 1785 & 4492.07 & 31.21 \\
\hline 917 & 4496.92 & 31.38 & 1786 & 4497.11 & 31.16 \\
\hline 918 & 4501.79 & 31.32 & 1787 & 4502 & 31.05 \\
\hline 919 & 4506.82 & 31.36 & 1788 & 4506.89 & 31.02 \\
\hline 920 & 4511.17 & 31.09 & 1789 & 4511.5 & 30.98 \\
\hline 921 & 4516.74 & 31 & 1790 & 4516.92 & 30.87 \\
\hline 922 & 4521.43 & 31.14 & 1791 & 4521.9 & 30.76 \\
\hline 923 & 4526.88 & 31.03 & 1792 & 4526.95 & 30.69 \\
\hline 924 & 4531.88 & 30.65 & 1793 & 4531.87 & 30.89 \\
\hline 925 & 4536.56 & 30.55 & 1794 & 4536.77 & 30.69 \\
\hline 926 & 4541.58 & 30.46 & 1795 & 4541.48 & 30.62 \\
\hline 927 & 4546.84 & 30.43 & 1796 & 4546.78 & 30.71 \\
\hline 928 & 4551.74 & 30.31 & 1797 & 4551.66 & 30.7 \\
\hline 929 & 4556.68 & 30.26 & 1798 & 4556.38 & 30.55 \\
\hline
\end{tabular}




\begin{tabular}{|c|c|c|c|c|c|}
\hline 930 & 4561.92 & 30.37 & 1799 & 4561.91 & 30.53 \\
\hline 931 & 4566.99 & 30.07 & 1800 & 4566.75 & 30.84 \\
\hline 932 & 4571.51 & 29.95 & 1801 & 4571.56 & 30.23 \\
\hline 933 & 4576.16 & 29.85 & 1802 & 4576.27 & 30.15 \\
\hline 934 & 4580.76 & 29.74 & 1803 & 4580.87 & 30.12 \\
\hline 935 & 4586.22 & 30.07 & & & \\
\hline 936 & 4591.68 & 30.4 & 1804 & 4591.81 & 30.25 \\
\hline 937 & 4596.89 & 30.31 & 1805 & 4596.91 & 30.18 \\
\hline 938 & 4601.7 & 30.25 & 1806 & 4601.9 & 30.09 \\
\hline 939 & 4606.94 & 30.18 & 1807 & 4606.44 & 30.09 \\
\hline 940 & 4611.53 & 30.19 & 1808 & 4611.49 & 30.02 \\
\hline 941 & 4616.79 & 30.17 & 1809 & 4616.92 & 29.84 \\
\hline 942 & 4621.55 & 30.15 & 1810 & 4621.6 & 29.84 \\
\hline 943 & 4626.58 & 30.02 & 1811 & 4626.7 & 29.66 \\
\hline 944 & 4631.39 & 30.04 & 1812 & 4631.57 & 29.86 \\
\hline 945 & 4636.54 & 30.14 & 1813 & 4636.51 & 29.82 \\
\hline 946 & 4641.6 & 29.97 & 1814 & 4641.56 & 29.74 \\
\hline 947 & 4645.82 & 34.09 & 1815 & 4645.57 & 34.39 \\
\hline 948 & 4650.37 & 34.1 & 1816 & 4650.49 & 34.12 \\
\hline 949 & 4655.57 & 34.06 & 1817 & 4655.38 & 34.09 \\
\hline 950 & 4660.65 & 34.05 & 1818 & 4660.31 & 34.06 \\
\hline 951 & 4665.62 & 34.01 & 1819 & 4665.4 & 34.02 \\
\hline 952 & 4669.95 & 33.95 & 1820 & 4670.33 & 33.98 \\
\hline 953 & 4675.03 & 33.95 & 1821 & 4675.37 & 33.96 \\
\hline 954 & 4680.2 & 33.99 & 1822 & 4680.32 & 33.98 \\
\hline 955 & 4685.06 & 34.07 & 1823 & 4685.1 & 34.05 \\
\hline 956 & 4690.32 & 34.16 & 1824 & 4690.37 & 34.16 \\
\hline 957 & 4695.09 & 34.18 & 1825 & 4695.21 & 34.19 \\
\hline 958 & 4701.33 & 34.2 & 1826 & 4700.89 & 34.21 \\
\hline 959 & 4705.13 & 34.26 & 1827 & 4704.86 & 34.26 \\
\hline 960 & 4710.18 & 34.27 & 1828 & 4710.22 & 34.26 \\
\hline 961 & 4715.26 & 34.28 & 1829 & 4715.25 & 34.27 \\
\hline 962 & 4720.26 & 34.32 & & & \\
\hline 963 & 4725.04 & 34.3 & 1830 & 4725.21 & 34.33 \\
\hline 964 & 4730 & 34.3 & 1831 & 4730.35 & 34.31 \\
\hline 965 & 4735.29 & 34.25 & 1832 & 4735.23 & 34.27 \\
\hline 966 & 4740.26 & 34.21 & 1833 & 4740.02 & 34.28 \\
\hline 967 & 4745.2 & 34.33 & 1834 & 4745.02 & 34.31 \\
\hline 968 & 4750.01 & 34.33 & 1835 & 4749.98 & 34.34 \\
\hline 969 & 4755.14 & 34.38 & 1836 & 4755.03 & 34.39 \\
\hline 970 & 4760.08 & 34.45 & 1837 & 4759.95 & 34.42 \\
\hline 971 & 4763.89 & 34.45 & & & \\
\hline 972 & 4770.18 & 34.44 & 1838 & 4769.96 & 34.45 \\
\hline 973 & 4775.05 & 34.51 & 1839 & 4774.93 & 34.52 \\
\hline 974 & 4780.12 & 34.51 & 1840 & 4779.91 & 34.48 \\
\hline 975 & 4785.01 & 34.5 & 1841 & 4784.91 & 34.5 \\
\hline 976 & 4790.1 & 34.52 & 1842 & 4789.96 & 34.49 \\
\hline 977 & 4794.95 & 34.57 & 1843 & 4794.91 & 34.55 \\
\hline 978 & 4800.2 & 34.64 & 1844 & 4800.08 & 34.64 \\
\hline
\end{tabular}




\begin{tabular}{|c|c|c|c|c|c|}
\hline 979 & 4803.93 & 34.7 & 1845 & 4803.66 & 34.68 \\
\hline 980 & 4809.87 & 34.7 & 1846 & 4809.84 & 34.71 \\
\hline 981 & 4815.12 & 34.8 & 1847 & 4815.01 & 34.84 \\
\hline 982 & 4820.18 & 34.93 & 1848 & 4820.04 & 34.96 \\
\hline 983 & 4825.01 & 35.07 & 1849 & 4824.85 & 35.06 \\
\hline 984 & 4830.02 & 35.06 & 1850 & 4830.01 & 35.07 \\
\hline 985 & 4835.19 & 35.01 & 1851 & 4835.03 & 35.02 \\
\hline 986 & 4840.01 & 34.99 & 1852 & 4839.97 & 35.01 \\
\hline 987 & 4845 & 35.01 & 1853 & 4844.95 & 35.02 \\
\hline 988 & 4849.97 & 35.01 & 1854 & 4850.01 & 34.98 \\
\hline 989 & 4854.84 & 35.13 & 1855 & 4854.74 & 35.15 \\
\hline 990 & 4859.88 & 35.11 & 1856 & 4859.7 & 35.18 \\
\hline 991 & 4864.74 & 35.17 & 1857 & 4864.73 & 35.2 \\
\hline 992 & 4870.16 & 35.16 & 1858 & 4869.99 & 35.19 \\
\hline 993 & 4874.68 & 35.25 & 1859 & 4874.46 & 35.27 \\
\hline 994 & 4880.67 & 35.3 & 1860 & 4880.44 & 35.25 \\
\hline 995 & 4884.82 & 35.29 & 1861 & 4884.69 & 35.33 \\
\hline 996 & 4889.13 & 35.34 & 1862 & 4889.11 & 35.32 \\
\hline 997 & 4894.96 & 35.33 & 1863 & 4894.88 & 35.33 \\
\hline 998 & 4899.73 & 35.35 & 1864 & 4899.7 & 35.33 \\
\hline 999 & 4904.8 & 35.41 & 1865 & 4904.95 & 35.43 \\
\hline 1000 & 4909.93 & 35.42 & 1866 & 4909.85 & 35.42 \\
\hline 1001 & 4914.92 & 35.43 & 1867 & 4914.78 & 35.44 \\
\hline 1002 & 4919.4 & 35.53 & 1868 & 4919.39 & 35.47 \\
\hline 1003 & 4924.64 & 35.74 & 1869 & 4924.54 & 35.7 \\
\hline 1004 & 4929.02 & 35.78 & 1870 & 4929.28 & 35.78 \\
\hline 1005 & 4933.6 & 35.83 & 1871 & 4933.56 & 35.82 \\
\hline 1006 & 4939.54 & 35.7 & 1872 & 4939.32 & 35.69 \\
\hline 1007 & 4944.62 & 35.92 & 1873 & 4944.54 & 35.97 \\
\hline 1008 & 4949.51 & 35.98 & 1874 & 4949.45 & 36.03 \\
\hline 1009 & 4954.32 & 36.06 & 1875 & 4954.56 & 36.01 \\
\hline 1010 & 4959.47 & 36.05 & 1876 & 4959.39 & 36.08 \\
\hline 1011 & 4964.69 & 36.16 & 1877 & 4964.66 & 36.2 \\
\hline 1012 & 4969.57 & 36.16 & 1878 & 4969.39 & 36.2 \\
\hline 1013 & 4974.36 & 36.21 & 1879 & 4974.26 & 36.24 \\
\hline 1014 & 4979.4 & 36.28 & 1880 & 4979.35 & 36.34 \\
\hline 1015 & 4984.57 & 36.28 & 1881 & 4984.51 & 36.33 \\
\hline 1016 & 4989.2 & 36.35 & 1882 & 4989.4 & 36.39 \\
\hline 1017 & 4994.27 & 36.48 & 1883 & 4994.2 & 36.5 \\
\hline 1018 & 4999.52 & 36.58 & 1884 & 4999.5 & 36.6 \\
\hline 1019 & 5004.79 & 36.61 & 1885 & 5004.41 & 36.59 \\
\hline 1020 & 5009.38 & 36.68 & 1886 & 5009.32 & 36.69 \\
\hline 1021 & 5015.28 & 36.75 & 1887 & 5015.18 & 36.67 \\
\hline 1022 & 5019.46 & 36.69 & 1888 & 5019.26 & 36.68 \\
\hline 1023 & 5024.1 & 36.8 & 1889 & 5023.83 & 36.76 \\
\hline 1024 & 5029.27 & 36.82 & 1890 & 5029.17 & 36.83 \\
\hline 1025 & 5034.25 & 36.94 & 1891 & 5034.06 & 36.93 \\
\hline 1026 & 5038.98 & 36.92 & 1892 & 5038.99 & 36.93 \\
\hline 1027 & 5044.24 & 36.91 & 1893 & 5044.15 & 36.88 \\
\hline
\end{tabular}




\begin{tabular}{|c|c|c|c|c|c|}
\hline 1028 & 5049.12 & 36.91 & 1894 & 5049.04 & 36.88 \\
\hline 1029 & 5054.17 & 36.92 & 1895 & 5054.19 & 36.91 \\
\hline 1030 & 5059.13 & 36.97 & 1896 & 5059 & 36.94 \\
\hline 1031 & 5064.34 & 37 & 1897 & 5064.18 & 36.94 \\
\hline 1032 & 5069.26 & 37.07 & 1898 & 5069.04 & 37.01 \\
\hline 1033 & 5073.98 & 37.09 & 1899 & 5073.91 & 37.06 \\
\hline 1034 & 5078.98 & 37.11 & 1900 & 5078.6 & 37.07 \\
\hline 1035 & 5084.41 & 37.2 & 1901 & 5084.23 & 37.17 \\
\hline 1036 & 5089.03 & 37.19 & 1902 & 5088.85 & 37.21 \\
\hline 1037 & 5094.16 & 37.25 & 1903 & 5094.01 & 37.24 \\
\hline 1038 & 5099.32 & 37.25 & 1904 & 5099.13 & 37.25 \\
\hline 1039 & 5104.86 & 37.3 & 1905 & 5104.84 & 37.31 \\
\hline 1040 & 5109.17 & 37.43 & 1906 & 5109.01 & 37.4 \\
\hline 1041 & 5114.33 & 37.57 & 1907 & 5113.97 & 37.63 \\
\hline 1042 & 5119.23 & 37.56 & 1908 & 5118.97 & 37.59 \\
\hline 1043 & 5123.07 & 37.56 & 1909 & 5123.04 & 37.55 \\
\hline 1044 & 5128.95 & 37.51 & 1910 & 5128.96 & 37.47 \\
\hline 1045 & 5134.07 & 37.53 & 1911 & 5133.88 & 37.48 \\
\hline 1046 & 5138.89 & 37.61 & 1912 & 5138.94 & 37.5 \\
\hline 1047 & 5143.92 & 37.65 & 1913 & 5143.89 & 37.56 \\
\hline 1048 & 5148.9 & 37.72 & 1914 & 5148.9 & 37.68 \\
\hline 1049 & 5154.13 & 37.82 & 1915 & 5153.72 & 37.78 \\
\hline 1050 & 5158.23 & 37.91 & 1916 & 5158.38 & 37.82 \\
\hline 1051 & 5163.96 & 38.02 & 1917 & 5163.83 & 37.89 \\
\hline 1052 & 5168.78 & 38.09 & 1918 & 5168.78 & 38.04 \\
\hline 1053 & 5173.96 & 38.12 & 1919 & 5173.84 & 38.11 \\
\hline 1054 & 5179.07 & 38.19 & 1920 & 5178.95 & 38.08 \\
\hline 1055 & 5183.66 & 38.18 & 1921 & 5183.53 & 38.12 \\
\hline 1056 & 5188.82 & 38.22 & 1922 & 5188.66 & 38.13 \\
\hline 1057 & 5193.57 & 38.28 & 1923 & 5193.55 & 38.2 \\
\hline 1058 & 5198.63 & 38.37 & 1924 & 5198.51 & 38.23 \\
\hline 1059 & 5203.7 & 38.31 & 1925 & 5203.72 & 38.3 \\
\hline 1060 & 5208.03 & 38.36 & 1926 & 5208.06 & 38.3 \\
\hline 1061 & 5212.91 & 38.43 & 1927 & 5212.79 & 38.35 \\
\hline 1062 & 5216.46 & 38.55 & & & \\
\hline 1063 & 5222.95 & 38.59 & 1928 & 5222.97 & 38.58 \\
\hline 1064 & 5228.18 & 38.76 & 1929 & 5227.93 & 38.72 \\
\hline 1065 & 5232.89 & 39.01 & 1930 & 5232.88 & 38.97 \\
\hline 1066 & 5237.81 & 40.33 & 1931 & 5237.67 & 40.28 \\
\hline 1067 & 5241.72 & 42.12 & 1932 & 5241.81 & 42.1 \\
\hline 1068 & 5246.94 & 43.87 & 1933 & 5246.33 & 43.75 \\
\hline 1069 & 5251.83 & 43.82 & 1934 & 5251.33 & 43.72 \\
\hline 1070 & 5256.72 & 43.77 & 1935 & 5256.33 & 43.69 \\
\hline 1071 & 5261.6 & 43.71 & 1936 & 5261.33 & 43.67 \\
\hline 1072 & 5266.49 & 43.66 & 1937 & 5266.33 & 43.64 \\
\hline 1073 & 5271.38 & 43.61 & 1938 & 5271.33 & 43.61 \\
\hline 1074 & 5275.61 & 41.64 & 1939 & 5275.57 & 41.63 \\
\hline 1075 & 5281.91 & 39.19 & 1940 & 5281.93 & 39.23 \\
\hline 1076 & 5284.98 & 39.25 & 1941 & 5285.26 & 39.21 \\
\hline
\end{tabular}




\begin{tabular}{|c|c|c|c|c|c|}
\hline 1077 & 5289.99 & 39.19 & 1942 & 5289.8 & 39.16 \\
\hline 1078 & 5295.02 & 39.25 & 1943 & 5294.74 & 39.23 \\
\hline 1079 & 5300.26 & 39.22 & 1944 & 5299.8 & 39.26 \\
\hline 1080 & 5304.81 & 39.27 & 1945 & 5304.89 & 39.27 \\
\hline 1081 & 5309.73 & 39.33 & 1946 & 5310.14 & 39.32 \\
\hline 1082 & 5315.22 & 39.37 & 1947 & 5315.11 & 39.42 \\
\hline 1083 & 5319.89 & 39.42 & 1948 & 5319.72 & 39.35 \\
\hline 1084 & 5324.99 & 39.44 & 1949 & 5324.84 & 39.35 \\
\hline 1085 & 5329.87 & 39.46 & 1950 & 5329.78 & 39.38 \\
\hline 1086 & 5334.79 & 39.5 & 1951 & 5334.75 & 39.48 \\
\hline 1087 & 5339.95 & 39.58 & 1952 & 5339.72 & 39.53 \\
\hline 1088 & 5345.37 & 39.55 & 1953 & 5344.85 & 39.57 \\
\hline 1089 & 5350.62 & 39.68 & 1954 & 5350.49 & 39.64 \\
\hline 1090 & 5354.87 & 39.62 & 1955 & 5354.7 & 39.6 \\
\hline 1091 & 5359.97 & 39.75 & 1956 & 5359.77 & 39.68 \\
\hline 1092 & 5364.71 & 39.8 & 1957 & 5364.29 & 39.75 \\
\hline 1093 & 5369.12 & 39.81 & 1958 & 5369.25 & 39.79 \\
\hline 1094 & 5374.67 & 39.93 & 1959 & 5374.45 & 39.88 \\
\hline 1095 & 5379.58 & 40 & 1960 & 5379.45 & 39.96 \\
\hline 1096 & 5384.38 & 40.03 & 1961 & 5384.31 & 40.01 \\
\hline 1097 & 5389.59 & 40.04 & 1962 & 5389.29 & 40.03 \\
\hline 1098 & 5394.38 & 40.15 & 1963 & 5394.26 & 40.1 \\
\hline 1099 & 5399.24 & 40.23 & 1964 & 5398.73 & 40.22 \\
\hline 1100 & 5404.01 & 40.28 & 1965 & 5403.91 & 40.26 \\
\hline 1101 & 5409.07 & 40.39 & 1966 & 5409.01 & 40.34 \\
\hline 1102 & 5413.97 & 40.43 & 1967 & 5413.98 & 40.4 \\
\hline 1103 & 5419.26 & 40.53 & 1968 & 5419.04 & 40.5 \\
\hline 1104 & 5424.38 & 40.57 & 1969 & 5424.18 & 40.57 \\
\hline 1105 & 5429.02 & 40.62 & 1970 & 5428.75 & 40.65 \\
\hline 1106 & 5434.11 & 40.72 & 1971 & 5433.94 & 40.73 \\
\hline 1107 & 5438.7 & 40.75 & 1972 & 5438.5 & 40.76 \\
\hline 1108 & 5444.25 & 40.77 & 1973 & 5443.94 & 40.76 \\
\hline 1109 & 5448.82 & 40.81 & 1974 & 5448.68 & 40.75 \\
\hline 1110 & 5453.8 & 40.76 & 1975 & 5453.61 & 40.73 \\
\hline 1111 & 5458.71 & 40.76 & 1976 & 5458.6 & 40.83 \\
\hline 1112 & 5463.71 & 40.77 & 1977 & 5463.69 & 40.68 \\
\hline 1113 & 5468.61 & 40.73 & 1978 & 5468.42 & 40.73 \\
\hline 1114 & 5473.77 & 40.72 & & & \\
\hline 1115 & 5478.35 & 40.67 & & & \\
\hline 1116 & 5482.99 & 40.62 & 1979 & 5482.96 & 40.63 \\
\hline 1117 & 5488.32 & 40.55 & 1980 & 5488.15 & 40.57 \\
\hline 1118 & 5493.53 & 40.33 & & & \\
\hline 1119 & 5498.75 & 40.1 & & & \\
\hline 1120 & 5502.55 & 39.97 & 1981 & 5502.89 & 40.12 \\
\hline 1121 & 5507.77 & 40.29 & 1982 & 5507.54 & 40.51 \\
\hline 1122 & 5512.58 & 40.82 & 1983 & 5512.51 & 40.84 \\
\hline 1123 & 5514.9 & 40.86 & & & \\
\hline 1124 & 5522.49 & 40.92 & 1984 & 5522.44 & 41 \\
\hline 1125 & 5527.56 & 41.01 & & & \\
\hline
\end{tabular}




\begin{tabular}{|c|c|c|c|c|c|}
\hline 1126 & 5532.69 & 41.22 & 1985 & 5532.26 & 41.15 \\
\hline 1127 & 5538.19 & 41.23 & 1986 & 5537.97 & 41.21 \\
\hline 1128 & 5543.14 & 41.29 & 1987 & 5543 & 41.34 \\
\hline 1129 & 5547.33 & 41.44 & 1988 & 5547.29 & 41.42 \\
\hline 1130 & 5552.2 & 41.4 & 1989 & 5552.04 & 41.42 \\
\hline 1131 & 5556.89 & 41.54 & 1990 & 5556.79 & 41.53 \\
\hline 1132 & 5562.04 & 41.6 & 1991 & 5561.95 & 41.66 \\
\hline 1133 & 5567.08 & 41.71 & 1992 & 5566.9 & 41.74 \\
\hline 1134 & 5571.87 & 41.85 & 1993 & 5571.64 & 41.85 \\
\hline 1135 & 5576.8 & 41.93 & 1994 & 5576.63 & 41.9 \\
\hline 1136 & 5581.92 & 41.93 & 1995 & 5581.84 & 41.94 \\
\hline 1137 & 5586.88 & 41.99 & 1996 & 5586.79 & 42 \\
\hline 1138 & 5591.9 & 42.09 & 1997 & 5592 & 42.13 \\
\hline 1139 & 5596.86 & 42.12 & 1998 & 5596.72 & 42.16 \\
\hline 1140 & 5601.55 & 42.15 & 1999 & 5601.64 & 42.12 \\
\hline 1141 & 5606.59 & 42.21 & 2000 & 5606.84 & 42.24 \\
\hline 1142 & 5612.15 & 42.28 & 2001 & 5612.23 & 42.28 \\
\hline 1143 & 5617.51 & 42.44 & 2002 & 5617.66 & 42.42 \\
\hline 1144 & 5623.81 & 42.34 & 2003 & 5623.69 & 42.35 \\
\hline 1145 & 5629.97 & 42.4 & 2004 & 5630.2 & 42.39 \\
\hline 1146 & 5636.64 & 42.48 & 2005 & 5636.61 & 42.44 \\
\hline 1147 & 5641.22 & 42.5 & 2006 & 5640.87 & 42.51 \\
\hline 1148 & 5646.03 & 42.54 & 2007 & 5646.13 & 42.53 \\
\hline 1149 & 5651.47 & 42.52 & 2008 & 5651.52 & 42.47 \\
\hline 1150 & 5657.09 & 42.65 & 2009 & 5657.32 & 42.67 \\
\hline 1151 & 5662.77 & 42.47 & 2010 & 5662.88 & 42.39 \\
\hline 1152 & 5668.9 & 42.36 & 2011 & 5668.8 & 42.44 \\
\hline 1153 & 5674.26 & 42.48 & 2012 & 5674.42 & 42.45 \\
\hline 1154 & 5678.89 & 42.5 & 2013 & 5678.87 & 42.5 \\
\hline 1155 & 5681.52 & 42.65 & 2014 & 5681.65 & 42.59 \\
\hline 1156 & 5686.08 & 42.75 & 2015 & 5686.28 & 42.69 \\
\hline 1157 & 5691.2 & 42.66 & 2016 & 5691.51 & 42.64 \\
\hline 1158 & 5695.78 & 42.65 & 2017 & 5695.99 & 42.6 \\
\hline 1159 & 5700.42 & 42.77 & 2018 & 5700.82 & 42.72 \\
\hline 1160 & 5705.95 & 42.8 & 2019 & 5706.25 & 42.72 \\
\hline 1161 & 5710.87 & 42.77 & 2020 & 5711.1 & 42.64 \\
\hline 1162 & 5716.59 & 42.75 & 2021 & 5716.04 & 42.64 \\
\hline 1163 & 5720.89 & 42.96 & 2022 & 5720.78 & 42.86 \\
\hline 1164 & 5725.87 & 43.06 & 2023 & 5726.15 & 42.99 \\
\hline 1165 & 5730.65 & 43.1 & 2024 & 5730.68 & 43.04 \\
\hline 1166 & 5735.66 & 43.22 & 2025 & 5735.67 & 43.18 \\
\hline 1167 & 5740.45 & 43.25 & 2026 & 5740.47 & 43.2 \\
\hline 1168 & 5745.11 & 43.27 & 2027 & 5745.3 & 43.24 \\
\hline 1169 & 5750.2 & 43.27 & 2028 & 5750.36 & 43.2 \\
\hline 1170 & 5755 & 43.43 & 2029 & 5755.16 & 43.38 \\
\hline 1171 & 5759.48 & 43.44 & 2030 & 5759.74 & 43.37 \\
\hline 1172 & 5764.49 & 43.55 & 2031 & 5765.08 & 43.56 \\
\hline 1173 & 5769.1 & 43.58 & 2032 & 5769.91 & 43.53 \\
\hline 1174 & 5775.71 & 43.64 & 2033 & 5775.28 & 43.57 \\
\hline
\end{tabular}




\begin{tabular}{|c|c|c|c|c|c|}
\hline 1175 & 5780.82 & 43.67 & & & \\
\hline 1176 & 5785.4 & 43.73 & & & \\
\hline 1177 & 5789.99 & 43.79 & 2034 & 5789.94 & 43.67 \\
\hline 1178 & 5794.57 & 43.85 & 2035 & 5794.6 & 43.72 \\
\hline 1179 & 5799.68 & 43.71 & 2036 & 5799.67 & 43.51 \\
\hline 1180 & 5804.58 & 43.55 & 2037 & 5804.72 & 43.68 \\
\hline 1181 & 5809.45 & 43.56 & 2038 & 5809.63 & 43.71 \\
\hline 1182 & 5814.7 & 43.69 & 2039 & 5814.59 & 43.83 \\
\hline 1183 & 5819.26 & 43.69 & 2040 & 5819.61 & 43.91 \\
\hline 1184 & 5824.62 & 43.88 & 2041 & 5824.55 & 43.99 \\
\hline 1185 & 5829.54 & 43.72 & 2042 & 5829.48 & 43.79 \\
\hline 1186 & 5834.64 & 44.01 & 2043 & 5834.6 & 44.06 \\
\hline 1187 & 5839.56 & 44.07 & 2044 & 5839.42 & 44.14 \\
\hline 1188 & 5844.42 & 44.15 & 2045 & 5844.37 & 44.24 \\
\hline 1189 & 5849.28 & 44.38 & 2046 & 5849.43 & 44.45 \\
\hline 1190 & 5854.32 & 44.54 & 2047 & 5854.27 & 44.63 \\
\hline 1191 & 5859.16 & 44.5 & 2048 & 5859.09 & 44.83 \\
\hline 1192 & 5864.47 & 44.6 & 2049 & 5864.44 & 44.99 \\
\hline 1193 & 5868.73 & 44.63 & 2050 & 5869.23 & 44.94 \\
\hline 1194 & 5874.23 & 44.44 & & & \\
\hline 1195 & 5879.37 & 44.8 & 2051 & 5879.18 & 45.17 \\
\hline 1196 & 5884.18 & 44.99 & 2052 & 5884.23 & 45.11 \\
\hline 1197 & 5889.17 & 45.05 & 2053 & 5888.9 & 45.11 \\
\hline 1198 & 5893.63 & 45 & 2054 & 5893.73 & 45.06 \\
\hline 1199 & 5898.89 & 45.04 & 2055 & 5898.8 & 45.16 \\
\hline 1200 & 5903.62 & 45 & 2056 & 5903.31 & 45.16 \\
\hline 1201 & 5908.4 & 45.22 & 2057 & 5908.28 & 45.32 \\
\hline 1202 & 5912.76 & 45.32 & 2058 & 5913.1 & 45.4 \\
\hline 1203 & 5917.52 & 45.3 & 2059 & 5917.78 & 45.4 \\
\hline 1204 & 5922.7 & 45.26 & 2060 & 5922.85 & 45.42 \\
\hline 1205 & 5927.58 & 45.25 & 2061 & 5927.43 & 45.37 \\
\hline 1206 & 5932.02 & 45.3 & 2062 & 5932.46 & 45.42 \\
\hline 1207 & 5937.5 & 45.34 & 2063 & 5937.63 & 45.46 \\
\hline 1208 & 5942.02 & 45.43 & 2064 & 5942.32 & 45.49 \\
\hline 1209 & 5947.35 & 45.47 & 2065 & 5947.36 & 45.53 \\
\hline 1210 & 5952.45 & 45.51 & 2066 & 5952.59 & 45.47 \\
\hline 1211 & 5957.33 & 45.51 & 2067 & 5957.31 & 45.52 \\
\hline 1212 & 5962.01 & 45.55 & 2068 & 5962.1 & 45.53 \\
\hline 1213 & 5966.89 & 45.51 & 2069 & 5967.23 & 45.57 \\
\hline 1214 & 5971.81 & 45.58 & 2070 & 5972.05 & 45.59 \\
\hline 1215 & 5977.35 & 45.49 & 2071 & 5977.46 & 45.59 \\
\hline 1216 & 5981.78 & 45.67 & 2072 & 5981.99 & 45.66 \\
\hline 1217 & 5986.77 & 45.77 & 2073 & 5987.05 & 45.73 \\
\hline 1218 & 5991.88 & 45.71 & 2074 & 5991.96 & 45.71 \\
\hline 1219 & 5996.78 & 45.6 & 2075 & 5996.92 & 45.73 \\
\hline 1220 & 6001.09 & 45.65 & 2076 & 6001.22 & 45.71 \\
\hline 1221 & 6006.3 & 45.59 & 2077 & 6006.69 & 45.78 \\
\hline 1222 & 6011.43 & 45.82 & 2078 & 6011.39 & 45.85 \\
\hline 1223 & 6016.2 & 45.85 & 2079 & 6016.29 & 45.92 \\
\hline
\end{tabular}




\begin{tabular}{|c|c|c|c|c|c|}
\hline 1224 & 6021.26 & 45.94 & 2080 & 6021.37 & 45.98 \\
\hline 1225 & 6026.15 & 45.97 & 2081 & 6026.5 & 45.95 \\
\hline 1226 & 6029.94 & 46.01 & 2082 & 6030.39 & 45.99 \\
\hline 1227 & 6035.67 & 45.84 & 2083 & 6036.03 & 46.15 \\
\hline 1228 & 6040.9 & 45.93 & 2084 & 6041.01 & 46.09 \\
\hline 1229 & 6045.94 & 45.71 & 2085 & 6045.86 & 46.1 \\
\hline 1230 & 6050.26 & 45.96 & 2086 & 6050.78 & 46.05 \\
\hline 1231 & 6054.91 & 46.12 & 2087 & 6055.41 & 46.18 \\
\hline 1232 & 6060.18 & 46.1 & 2088 & 6060.17 & 46.26 \\
\hline 1233 & 6065.13 & 46.38 & 2089 & 6064.57 & 46.8 \\
\hline 1234 & 6068.77 & 43.75 & 2090 & 6069.43 & 43.89 \\
\hline 1235 & 6074.47 & 44.38 & & & \\
\hline 1236 & 6080.17 & 45 & & & \\
\hline 1237 & 6084.32 & 46.14 & 2091 & 6084.22 & 46.13 \\
\hline 1238 & 6088.48 & 47.27 & 2092 & 6088.25 & 47.24 \\
\hline 1239 & 6093.68 & 47.28 & & & \\
\hline 1240 & 6098.88 & 47.28 & & & \\
\hline 1241 & 6102.39 & 47.26 & 2093 & 6102.87 & 47.23 \\
\hline 1242 & 6107.64 & 47.31 & & & \\
\hline 1243 & 6112.59 & 47.34 & 2094 & 6113.85 & 47.34 \\
\hline 1244 & 6117.69 & 47.26 & 2095 & 6117.19 & 47.24 \\
\hline 1245 & 6122.62 & 47.26 & 2096 & 6122.41 & 46.98 \\
\hline 1246 & 6127.86 & 47.18 & 2097 & 6127.88 & 47.02 \\
\hline 1247 & 6132.62 & 47.29 & 2098 & 6132.63 & 47.05 \\
\hline 1248 & 6138.05 & 47.35 & 2099 & 6137.95 & 47.07 \\
\hline 1249 & 6142.51 & 47.41 & 2100 & 6142.49 & 47.24 \\
\hline 1250 & 6147.62 & 47.4 & 2101 & 6147.63 & 47.25 \\
\hline 1251 & 6152.54 & 47.47 & 2102 & 6152.63 & 47.35 \\
\hline 1252 & 6157.52 & 47.48 & 2103 & 6157.51 & 47.41 \\
\hline 1253 & 6162.52 & 47.57 & 2104 & 6162.48 & 47.52 \\
\hline 1254 & 6167.43 & 47.62 & 2105 & 6167.39 & 47.58 \\
\hline 1255 & 6172.37 & 47.69 & 2106 & 6172.46 & 47.66 \\
\hline 1256 & 6177.59 & 47.73 & 2107 & 6177.51 & 47.71 \\
\hline 1257 & 6182.63 & 47.76 & 2108 & 6182.45 & 47.72 \\
\hline 1258 & 6187.47 & 47.8 & 2109 & 6187.33 & 47.73 \\
\hline 1259 & 6192.28 & 47.79 & 2110 & 6192.23 & 47.75 \\
\hline 1260 & 6197.19 & 47.81 & 2111 & 6197.15 & 47.79 \\
\hline 1261 & 6202.21 & 47.82 & 2112 & 6202.2 & 47.84 \\
\hline 1262 & 6207.12 & 47.85 & 2113 & 6207.21 & 47.86 \\
\hline 1263 & 6212.22 & 47.84 & 2114 & 6212.19 & 47.87 \\
\hline 1264 & 6216.92 & 47.85 & 2115 & 6217.03 & 47.88 \\
\hline 1265 & 6221.97 & 47.9 & & & \\
\hline 1266 & 6227.16 & 48 & 2116 & 6227.06 & 48.02 \\
\hline 1267 & 6232.21 & 48.07 & 2117 & 6232.01 & 48.1 \\
\hline 1268 & 6237.53 & 48.01 & 2118 & 6237.17 & 48.14 \\
\hline 1269 & 6242.18 & 48.07 & 2119 & 6241.98 & 48.22 \\
\hline 1270 & 6246.98 & 48.13 & 2120 & 6246.94 & 48.17 \\
\hline 1271 & 6251.89 & 48.15 & 2121 & 6251.88 & 48.22 \\
\hline 1272 & 6256.97 & 48.16 & 2122 & 6256.91 & 48.23 \\
\hline
\end{tabular}




\begin{tabular}{|c|c|c|c|c|c|}
\hline 1273 & 6261.74 & 48.24 & 2123 & 6261.78 & 48.3 \\
\hline 1274 & 6266.88 & 48.27 & 2124 & 6266.84 & 48.28 \\
\hline 1275 & 6271.63 & 48.25 & 2125 & 6271.6 & 48.28 \\
\hline 1276 & 6276.66 & 48.24 & 2126 & 6276.45 & 48.28 \\
\hline 1277 & 6281.62 & 48.24 & 2127 & 6281.59 & 48.29 \\
\hline 1278 & 6286.76 & 48.2 & 2128 & 6286.7 & 48.29 \\
\hline 1279 & 6291.65 & 48.2 & 2129 & 6291.47 & 48.28 \\
\hline 1280 & 6296.55 & 48.22 & 2130 & 6296.57 & 48.33 \\
\hline 1281 & 6301.6 & 48.28 & & & \\
\hline 1282 & 6306.48 & 48.28 & 2131 & 6306.39 & 48.38 \\
\hline 1283 & 6311.49 & 48.34 & 2132 & 6311.41 & 48.42 \\
\hline 1284 & 6316.47 & 48.33 & 2133 & 6316.47 & 48.41 \\
\hline 1285 & 6321.44 & 48.35 & 2134 & 6321.38 & 48.43 \\
\hline 1286 & 6326.4 & 48.35 & 2135 & 6326.33 & 48.49 \\
\hline 1287 & 6331.29 & 48.38 & 2136 & 6331.37 & 48.47 \\
\hline 1288 & 6336.34 & 48.39 & 2137 & 6336.22 & 48.49 \\
\hline 1289 & 6341.35 & 48.33 & 2138 & 6341.34 & 48.42 \\
\hline 1290 & 6346.34 & 48.34 & 2139 & 6346.25 & 48.45 \\
\hline 1291 & 6351.24 & 48.4 & 2140 & 6351.14 & 48.48 \\
\hline 1292 & 6356.12 & 48.39 & 2141 & 6356.09 & 48.48 \\
\hline 1293 & 6361.03 & 48.44 & 2142 & 6360.9 & 48.46 \\
\hline 1294 & 6366.03 & 48.51 & 2143 & 6365.99 & 48.56 \\
\hline 1295 & 6371.06 & 48.53 & 2144 & 6370.91 & 48.58 \\
\hline 1296 & 6375.77 & 48.48 & 2145 & 6375.72 & 48.59 \\
\hline 1297 & 6380.84 & 48.5 & 2146 & 6380.71 & 48.61 \\
\hline 1298 & 6385.06 & 48.37 & 2147 & 6384.86 & 48.52 \\
\hline 1299 & 6390.68 & 48.66 & 2148 & 6390.65 & 48.7 \\
\hline 1300 & 6395.67 & 48.74 & 2149 & 6395.67 & 48.77 \\
\hline 1301 & 6400.83 & 48.69 & 2150 & 6400.77 & 48.76 \\
\hline 1302 & 6405.79 & 48.77 & 2151 & 6405.64 & 48.83 \\
\hline 1303 & 6410.77 & 48.85 & 2152 & 6410.84 & 48.91 \\
\hline 1304 & 6415.69 & 48.93 & 2153 & 6415.56 & 48.96 \\
\hline 1305 & 6420.52 & 48.95 & 2154 & 6420.56 & 49.02 \\
\hline 1306 & 6425.93 & 49.06 & 2155 & 6425.64 & 49.01 \\
\hline 1307 & 6430.44 & 49.04 & 2156 & 6430.32 & 49.1 \\
\hline 1308 & 6435.56 & 49.06 & 2157 & 6435.46 & 49.09 \\
\hline 1309 & 6440.92 & 49.16 & 2158 & 6440.74 & 49.15 \\
\hline 1310 & 6445.56 & 49.18 & 2159 & 6445.47 & 49.17 \\
\hline 1311 & 6450.5 & 49.18 & 2160 & 6450.78 & 49.21 \\
\hline 1312 & 6455.52 & 49.27 & 2161 & 6455.57 & 49.28 \\
\hline 1313 & 6460.37 & 49.35 & 2162 & 6460.44 & 49.34 \\
\hline 1314 & 6465.57 & 49.34 & 2163 & 6465.58 & 49.38 \\
\hline 1315 & 6470.38 & 49.3 & 2164 & 6470.4 & 49.49 \\
\hline 1316 & 6475.27 & 49.49 & 2165 & 6475.34 & 49.53 \\
\hline 1317 & 6480.46 & 49.59 & 2166 & 6480.38 & 49.55 \\
\hline 1318 & 6485.61 & 49.6 & 2167 & 6485.49 & 49.58 \\
\hline 1319 & 6490.22 & 49.63 & 2168 & 6490.37 & 49.65 \\
\hline 1320 & 6495.38 & 49.7 & 2169 & 6495.42 & 49.68 \\
\hline 1321 & 6500.25 & 49.78 & 2170 & 6500.33 & 49.74 \\
\hline
\end{tabular}




\begin{tabular}{|c|c|c|c|c|c|}
\hline 1322 & 6505.25 & 49.84 & 2171 & 6505.34 & 49.8 \\
\hline 1323 & 6510.52 & 49.86 & 2172 & 6510.42 & 49.8 \\
\hline 1324 & 6515.35 & 49.9 & 2173 & 6515.36 & 49.84 \\
\hline 1325 & 6520.31 & 49.93 & 2174 & 6520.31 & 49.9 \\
\hline 1326 & 6525.26 & 49.93 & 2175 & 6525.35 & 49.87 \\
\hline 1327 & 6530.32 & 49.96 & 2176 & 6530.32 & 49.93 \\
\hline 1328 & 6535.3 & 50.18 & 2177 & 6535.19 & 49.97 \\
\hline 1329 & 6540.25 & 49.67 & 2178 & 6540.32 & 50.08 \\
\hline 1330 & 6545.17 & 50.16 & 2179 & 6545.14 & 50.11 \\
\hline 1331 & 6549.96 & 50.3 & 2180 & 6550.06 & 50.25 \\
\hline 1332 & 6554.98 & 50.31 & 2181 & 6555.04 & 50.26 \\
\hline 1333 & 6559.71 & 50.32 & 2182 & 6559.96 & 50.27 \\
\hline 1334 & 6565.07 & 50.38 & 2183 & 6565.14 & 50.31 \\
\hline 1335 & 6569.89 & 50.44 & 2184 & 6569.9 & 50.33 \\
\hline 1336 & 6574.79 & 50.43 & 2185 & 6574.98 & 50.33 \\
\hline 1337 & 6579.96 & 50.54 & 2186 & 6579.95 & 50.39 \\
\hline 1338 & 6585.13 & 50.56 & 2187 & 6584.89 & 50.46 \\
\hline 1339 & 6589.87 & 50.56 & 2188 & 6589.9 & 50.38 \\
\hline 1340 & 6594.74 & 50.65 & 2189 & 6595.02 & 50.38 \\
\hline 1341 & 6599.99 & 50.66 & 2190 & 6600.04 & 50.33 \\
\hline 1342 & 6604.85 & 50.61 & 2191 & 6604.84 & 50.39 \\
\hline 1343 & 6609.89 & 50.57 & 2192 & 6609.87 & 50.41 \\
\hline 1344 & 6614.83 & 50.56 & 2193 & 6614.93 & 50.38 \\
\hline 1345 & 6619.34 & 50.6 & 2194 & 6619.42 & 50.37 \\
\hline 1346 & 6624.64 & 50.72 & 2195 & 6624.81 & 50.61 \\
\hline 1347 & 6629.71 & 51.06 & 2196 & 6629.71 & 50.97 \\
\hline 1348 & 6634.68 & 51.31 & 2197 & 6634.64 & 51.27 \\
\hline 1349 & 6639.1 & 51.46 & 2198 & 6639.22 & 51.43 \\
\hline 1350 & 6643.48 & 51.44 & 2199 & 6643.69 & 51.55 \\
\hline 1351 & 6648.13 & 51.42 & 2200 & 6648.41 & 51.71 \\
\hline 1352 & 6653.18 & 50.9 & 2201 & 6653.22 & 51.23 \\
\hline 1353 & 6658.37 & 51.42 & 2202 & 6658.36 & 51.87 \\
\hline 1354 & 6663.23 & 51.74 & 2203 & 6663.09 & 51.97 \\
\hline 1355 & 6667.77 & 51.73 & 2204 & 6668.01 & 51.78 \\
\hline 1356 & 6672.65 & 51.4 & 2205 & 6672.9 & 51.39 \\
\hline 1357 & 6677.84 & 51.4 & 2206 & 6677.82 & 51.31 \\
\hline 1358 & 6680.94 & 51.32 & 2207 & 6681.77 & 51.12 \\
\hline 1359 & 6687.34 & 51.12 & & & \\
\hline 1360 & 6692.43 & 51.25 & 2208 & 6692.39 & 51.06 \\
\hline 1361 & 6697.07 & 51.25 & 2209 & 6697.47 & 51.11 \\
\hline 1362 & 6702.98 & 51.03 & 2210 & 6702.24 & 51.07 \\
\hline 1363 & 6707.24 & 51.19 & 2211 & 6707.16 & 51.16 \\
\hline 1364 & 6712.47 & 51.36 & 2212 & 6712.29 & 51.14 \\
\hline 1365 & 6717.19 & 51.45 & 2213 & 6717.4 & 51.39 \\
\hline 1366 & 6722.13 & 51.31 & 2214 & 6722.34 & 51.31 \\
\hline 1367 & 6727.24 & 51.5 & 2215 & 6727.53 & 51.41 \\
\hline 1368 & 6732.22 & 51.48 & 2216 & 6732.33 & 51.36 \\
\hline 1369 & 6737.5 & 51.61 & 2217 & 6737.27 & 51.51 \\
\hline 1370 & 6742.46 & 51.49 & 2218 & 6742.34 & 51.4 \\
\hline
\end{tabular}




\begin{tabular}{|c|c|c|c|c|c|}
\hline 1371 & 6745.4 & 51.52 & 2219 & 6745.38 & 51.49 \\
\hline 1372 & 6751.5 & 51.49 & 2220 & 6751.38 & 51.4 \\
\hline 1373 & 6757.02 & 51.69 & 2221 & 6757.26 & 51.66 \\
\hline 1374 & 6762.16 & 51.81 & 2222 & 6762.11 & 51.72 \\
\hline 1375 & 6766.89 & 51.81 & 2223 & 6767 & 51.65 \\
\hline 1376 & 6772.51 & 51.97 & 2224 & 6772.21 & 51.78 \\
\hline 1377 & 6777 & 52.11 & 2225 & 6777.07 & 51.82 \\
\hline 1378 & 6782.01 & 51.84 & 2226 & 6782.05 & 51.83 \\
\hline 1379 & 6786.05 & 52.14 & 2227 & 6785.75 & 51.9 \\
\hline 1380 & 6791.94 & 52.2 & 2228 & 6791.87 & 51.91 \\
\hline 1381 & 6796.76 & 51.97 & 2229 & 6796.16 & 51.82 \\
\hline 1382 & 6802.16 & 52.11 & 2230 & 6802.09 & 52 \\
\hline 1383 & 6806.51 & 52.29 & & & \\
\hline 1384 & 6812.22 & 52.27 & 2231 & 6812.09 & 52.28 \\
\hline 1385 & 6817.13 & 52.27 & 2232 & 6816.88 & 52.15 \\
\hline 1386 & 6822.21 & 52.15 & 2233 & 6822.23 & 52.06 \\
\hline 1387 & 6827.26 & 52.01 & 2234 & 6827.01 & 52 \\
\hline 1388 & 6831.94 & 52.02 & 2235 & 6831.9 & 52.01 \\
\hline 1389 & 6836.92 & 52.04 & 2236 & 6836.67 & 52 \\
\hline 1390 & 6841.68 & 52.06 & 2237 & 6841.68 & 52.04 \\
\hline 1391 & 6846.66 & 52.09 & 2238 & 6846.6 & 52.07 \\
\hline 1392 & 6851.82 & 52.1 & 2239 & 6851.51 & 52.11 \\
\hline 1393 & 6856.6 & 52.16 & 2240 & 6856.6 & 52.12 \\
\hline 1394 & 6861.57 & 52.21 & 2241 & 6861.5 & 52.2 \\
\hline 1395 & 6867.28 & 52.36 & 2242 & 6867.16 & 52.31 \\
\hline 1396 & 6871.47 & 52.29 & 2243 & 6871.36 & 52.31 \\
\hline 1397 & 6876.32 & 52.34 & 2244 & 6876.18 & 52.36 \\
\hline 1398 & 6881.42 & 52.4 & 2245 & 6881.34 & 52.39 \\
\hline 1399 & 6886.38 & 52.38 & 2246 & 6886.31 & 52.44 \\
\hline 1400 & 6891.26 & 52.39 & 2247 & 6891.18 & 52.37 \\
\hline 1401 & 6896.53 & 52.42 & 2248 & 6896.43 & 52.43 \\
\hline 1402 & 6901.54 & 52.62 & 2249 & 6901.57 & 52.64 \\
\hline 1403 & 6906.35 & 52.8 & 2250 & 6906.32 & 52.55 \\
\hline 1404 & 6911.91 & 52.55 & 2251 & 6911.26 & 52.55 \\
\hline 1405 & 6916.63 & 52.64 & 2252 & 6916.97 & 52.64 \\
\hline 1406 & 6921.44 & 52.63 & 2253 & 6921.18 & 52.68 \\
\hline 1407 & 6926.45 & 52.72 & 2254 & 6926.15 & 52.73 \\
\hline 1408 & 6931.35 & 52.75 & 2255 & 6931.2 & 52.77 \\
\hline 1409 & 6936.16 & 52.88 & 2256 & 6936.02 & 52.86 \\
\hline 1410 & 6941.59 & 52.9 & 2257 & 6941.4 & 52.93 \\
\hline 1411 & 6946.31 & 52.99 & & & \\
\hline 1412 & 6951.39 & 52.93 & 2258 & 6951.55 & 52.82 \\
\hline 1413 & 6956.21 & 52.87 & 2259 & 6956.01 & 52.84 \\
\hline 1414 & 6961.08 & 52.95 & 2260 & 6960.97 & 52.93 \\
\hline 1415 & 6966.07 & 52.95 & 2261 & 6965.91 & 52.87 \\
\hline 1416 & 6971.14 & 52.97 & 2262 & 6970.96 & 52.87 \\
\hline 1417 & 6976.09 & 53.04 & 2263 & 6975.89 & 52.86 \\
\hline 1418 & 6980.97 & 53.04 & & & \\
\hline 1419 & 6986.17 & 53.05 & 2264 & 6985.92 & 52.97 \\
\hline
\end{tabular}




\begin{tabular}{|c|c|c|c|c|c|}
\hline 1420 & 6990.99 & 53.16 & 2265 & 6990.75 & 53.02 \\
\hline 1421 & 6995.81 & 53.18 & 2266 & 6995.59 & 53.13 \\
\hline 1422 & 7000.88 & 53.17 & 2267 & 7000.43 & 53.15 \\
\hline 1423 & 7005.47 & 53.26 & 2268 & 7005.49 & 53.1 \\
\hline 1424 & 7010.5 & 53.37 & 2269 & 7010.52 & 53.32 \\
\hline 1425 & 7016.01 & 53.44 & 2270 & 7015.61 & 53.35 \\
\hline 1426 & 7020.86 & 53.46 & & & \\
\hline 1427 & 7025.47 & 53.46 & 2271 & 7025.4 & 53.47 \\
\hline 1428 & 7030.47 & 53.51 & 2272 & 7030.41 & 53.48 \\
\hline 1429 & 7035.56 & 53.64 & 2273 & 7035.34 & 53.52 \\
\hline 1430 & 7040.52 & 53.65 & 2274 & 7040.45 & 53.57 \\
\hline 1431 & 7045.26 & 53.74 & 2275 & 7045.38 & 53.68 \\
\hline 1432 & 7050.48 & 53.76 & 2276 & 7050.47 & 53.73 \\
\hline 1433 & 7055.41 & 53.88 & 2277 & 7055.22 & 53.73 \\
\hline 1434 & 7060.05 & 53.98 & 2278 & 7059.84 & 53.93 \\
\hline 1435 & 7062.74 & 54.02 & 2279 & 7062.41 & 53.91 \\
\hline 1436 & 7065.43 & 54.07 & 2280 & 7064.98 & 53.88 \\
\hline 1437 & 7070.42 & 53.93 & 2281 & 7070.31 & 53.91 \\
\hline 1438 & 7075.23 & 54.19 & 2282 & 7074.69 & 54.07 \\
\hline 1439 & 7080.18 & 54.15 & 2283 & 7079.67 & 54.11 \\
\hline 1440 & 7085.17 & 54.29 & 2284 & 7084.96 & 54.18 \\
\hline 1441 & 7090.22 & 54.25 & 2285 & 7090.09 & 54.23 \\
\hline 1442 & 7094.92 & 54.33 & 2286 & 7095.19 & 54.25 \\
\hline 1443 & 7102.33 & 54.53 & 2287 & 7102.11 & 54.39 \\
\hline 1444 & 7104.84 & 54.48 & 2288 & 7104.7 & 54.39 \\
\hline 1445 & 7109.92 & 54.56 & 2289 & 7109.62 & 54.46 \\
\hline 1446 & 7115.28 & 54.56 & 2290 & 7114.86 & 54.49 \\
\hline 1447 & 7120 & 54.77 & 2291 & 7119.69 & 54.58 \\
\hline 1448 & 7124.66 & 54.77 & 2292 & 7124.47 & 54.74 \\
\hline 1449 & 7129.87 & 55.19 & & & \\
\hline 1450 & 7134.69 & 55.18 & 2293 & 7134.83 & 54.91 \\
\hline 1451 & 7139.71 & 55.22 & 2294 & 7139.61 & 55 \\
\hline 1452 & 7144.68 & 55.24 & 2295 & 7144.47 & 55.03 \\
\hline 1453 & 7149.36 & 55.47 & 2296 & 7149.53 & 55.19 \\
\hline 1454 & 7154.35 & 55.63 & 2297 & 7154.18 & 55.3 \\
\hline 1455 & 7158.98 & 55.74 & & & \\
\hline 1456 & 7164.06 & 55.86 & 2298 & 7164.2 & 55.8 \\
\hline 1457 & 7169.21 & 56.05 & 2299 & 7169.23 & 55.86 \\
\hline 1458 & 7174.02 & 55.99 & 2300 & 7174.07 & 55.85 \\
\hline 1459 & 7178.46 & 56.09 & 2301 & 7178.45 & 55.91 \\
\hline 1460 & 7182.52 & 56.33 & 2302 & 7182.35 & 55.98 \\
\hline 1461 & 7188.19 & 56.01 & 2303 & 7188.19 & 55.93 \\
\hline 1462 & 7192.43 & 56.12 & 2304 & 7192.39 & 56 \\
\hline 1463 & 7197.91 & 56.08 & 2305 & 7197.72 & 56.06 \\
\hline 1464 & 7202.59 & 56.03 & 2306 & 7202.37 & 55.98 \\
\hline 1465 & 7207.54 & 56.1 & 2307 & 7207.26 & 56.11 \\
\hline 1466 & 7211.94 & 56.2 & 2308 & 7212.12 & 56.16 \\
\hline 1467 & 7217.21 & 56.31 & 2309 & 7216.69 & 56.3 \\
\hline 1468 & 7221.61 & 56.38 & 2310 & 7221.31 & 56.4 \\
\hline
\end{tabular}




\begin{tabular}{|c|c|c|c|c|c|}
\hline 1469 & 7226.42 & 56.48 & 2311 & 7226.22 & 56.45 \\
\hline 1470 & 7231.48 & 56.61 & 2312 & 7231.04 & 56.6 \\
\hline 1471 & 7235.64 & 56.61 & 2313 & 7235.47 & 56.65 \\
\hline 1472 & 7240.32 & 56.62 & 2314 & 7240.59 & 56.64 \\
\hline 1473 & 7245.33 & 56.65 & & & \\
\hline 1474 & 7250.49 & 56.72 & 2315 & 7250.33 & 56.73 \\
\hline 1475 & 7255.12 & 56.85 & 2316 & 7255.05 & 56.86 \\
\hline 1476 & 7260.41 & 56.97 & 2317 & 7260.14 & 56.96 \\
\hline 1477 & 7265.34 & 57.08 & 2318 & 7265.32 & 57.06 \\
\hline 1478 & 7270.19 & 57.07 & 2319 & 7270.16 & 57.1 \\
\hline 1479 & 7275.33 & 57.09 & 2320 & 7275.11 & 57.09 \\
\hline 1480 & 7280.2 & 57.23 & 2321 & 7280.02 & 57.22 \\
\hline 1481 & 7285.23 & 57.23 & 2322 & 7285.06 & 57.22 \\
\hline 1482 & 7290.35 & 57.25 & 2323 & 7290.12 & 57.24 \\
\hline 1483 & 7293.94 & 57.29 & 2324 & 7293.65 & 57.32 \\
\hline 1484 & 7297.06 & 57.33 & 2325 & 7296.74 & 57.31 \\
\hline 1485 & 7300.19 & 57.36 & 2326 & 7299.83 & 57.31 \\
\hline 1486 & 7304.97 & 57.45 & 2327 & 7304.73 & 57.41 \\
\hline 1487 & 7309.92 & 57.52 & 2328 & 7309.81 & 57.44 \\
\hline 1488 & 7315.23 & 57.74 & 2329 & 7314.88 & 57.6 \\
\hline 1489 & 7320.23 & 57.82 & 2330 & 7319.97 & 57.72 \\
\hline 1490 & 7325.16 & 57.98 & 2331 & 7324.77 & 57.78 \\
\hline 1491 & 7330.13 & 57.96 & & & \\
\hline 1492 & 7334.23 & 58.16 & 2332 & 7334.21 & 57.9 \\
\hline 1493 & 7336.92 & 58.06 & & & \\
\hline 1494 & 7339.61 & 57.97 & 2333 & 7339.13 & 58.01 \\
\hline 1495 & 7345.03 & 58.08 & 2334 & 7344.62 & 57.91 \\
\hline 1496 & 7349.55 & 58.09 & 2335 & 7349.26 & 57.83 \\
\hline 1497 & 7354.09 & 58.07 & 2336 & 7354.13 & 57.95 \\
\hline 1498 & 7359.01 & 58.06 & 2337 & 7359.02 & 57.89 \\
\hline 1499 & 7363.89 & 58.02 & 2338 & 7364.02 & 57.92 \\
\hline 1500 & 7368.6 & 58.09 & 2339 & 7368.57 & 58.04 \\
\hline 1501 & 7374.01 & 58.17 & 2340 & 7373.8 & 57.96 \\
\hline 1502 & 7378.92 & 58.21 & 2341 & 7378.79 & 58.09 \\
\hline 1503 & 7384.22 & 58.25 & 2342 & 7384.33 & 58.01 \\
\hline 1504 & 7388.66 & 58.15 & 2343 & 7388.81 & 58.05 \\
\hline 1505 & 7393.49 & 58.08 & 2344 & 7393.46 & 58.04 \\
\hline 1506 & 7398.56 & 58.11 & 2345 & 7398.34 & 58.08 \\
\hline 1507 & 7403.11 & 58.22 & 2346 & 7402.99 & 58.15 \\
\hline 1508 & 7407.79 & 58.24 & 2347 & 7408.07 & 58.2 \\
\hline 1509 & 7412.91 & 58.51 & 2348 & 7412.82 & 58.42 \\
\hline 1510 & 7417.24 & 58.33 & 2349 & 7417.55 & 58.37 \\
\hline 1511 & 7423.07 & 58.5 & 2350 & 7422.48 & 58.45 \\
\hline 1512 & 7427.59 & 58.5 & 2351 & 7427.47 & 58.56 \\
\hline 1513 & 7432.43 & 58.53 & 2352 & 7432.07 & 58.56 \\
\hline 1514 & 7436.8 & 58.67 & 2353 & 7436.69 & 58.65 \\
\hline 1515 & 7442.19 & 58.77 & 2354 & 7442.1 & 58.78 \\
\hline 1516 & 7447 & 58.89 & 2355 & 7446.56 & 58.88 \\
\hline 1517 & 7451.86 & 59.06 & 2356 & 7452.04 & 59.06 \\
\hline
\end{tabular}




\begin{tabular}{|c|c|c|c|c|c|}
\hline 1518 & 7456.74 & 59.12 & 2357 & 7456.68 & 59.12 \\
\hline 1519 & 7460.95 & 59.15 & 2358 & 7461.55 & 59.18 \\
\hline 1520 & 7466.33 & 59.19 & 2359 & 7466.25 & 59.16 \\
\hline 1521 & 7470.51 & 59.24 & 2360 & 7470.96 & 59.23 \\
\hline 1527 & 7500.93 & 59.44 & 2361 & 7500.89 & 59.39 \\
\hline 1528 & 7505.85 & 59.49 & & & \\
\hline 1529 & 7511.23 & 59.54 & 2362 & 7511.25 & 59.58 \\
\hline 1530 & 7515.62 & 59.58 & 2363 & 7515.44 & 59.58 \\
\hline 1531 & 7520.08 & 59.47 & 2364 & 7520.15 & 59.53 \\
\hline 1532 & 7525.29 & 59.62 & 2365 & 7525.44 & 59.66 \\
\hline 1533 & 7530.21 & 59.6 & 2366 & 7530.36 & 59.68 \\
\hline 1534 & 7535.13 & 59.69 & 2367 & 7535.04 & 59.61 \\
\hline 1535 & 7540.16 & 59.55 & 2368 & 7540 & 59.58 \\
\hline 1536 & 7545.33 & 59.56 & 2369 & 7545.42 & 59.6 \\
\hline 1537 & 7550.28 & 59.59 & 2370 & 7550.22 & 59.68 \\
\hline 1538 & 7555.42 & 59.72 & 2371 & 7555.5 & 59.73 \\
\hline 1539 & 7560.3 & 59.7 & 2372 & 7560.51 & 59.72 \\
\hline 1540 & 7565.68 & 59.75 & 2373 & 7565.68 & 59.78 \\
\hline 1541 & 7570.58 & 59.76 & 2374 & 7570.57 & 59.8 \\
\hline 1542 & 7575.22 & 59.74 & 2375 & 7575.34 & 59.74 \\
\hline 1543 & 7578.98 & 59.77 & 2376 & 7579.03 & 59.75 \\
\hline 1544 & 7585.21 & 59.82 & 2377 & 7585.34 & 59.88 \\
\hline 1545 & 7590.04 & 59.93 & 2378 & 7589.92 & 59.88 \\
\hline 1546 & 7593.9 & 59.63 & 2379 & 7595.27 & 59.64 \\
\hline 1547 & 7599.51 & 59.7 & 2380 & 7600.27 & 59.66 \\
\hline 1548 & 7605.47 & 59.98 & 2381 & 7605.2 & 59.74 \\
\hline 1549 & 7610.35 & 59.99 & 2382 & 7610.16 & 59.75 \\
\hline 1550 & 7615.25 & 60.01 & 2383 & 7615.15 & 59.82 \\
\hline 1551 & 7620.51 & 60.03 & 2384 & 7620.17 & 59.82 \\
\hline 1552 & 7625.18 & 60.06 & 2385 & 7625.14 & 59.85 \\
\hline 1553 & 7630.08 & 60.06 & 2386 & 7630.14 & 59.86 \\
\hline 1554 & 7635.18 & 60.09 & 2387 & 7635.12 & 59.9 \\
\hline 1555 & 7640.1 & 60.13 & 2388 & 7640.08 & 59.93 \\
\hline 1556 & 7645.5 & 60.16 & 2389 & 7645.05 & 59.96 \\
\hline 1557 & 7651.56 & 60.2 & 2390 & 7650.78 & 59.98 \\
\hline 1558 & 7656.1 & 60.23 & 2391 & 7655.79 & 60 \\
\hline 1559 & 7661.09 & 60.26 & 2392 & 7660.55 & 60.03 \\
\hline 1560 & 7665.83 & 60.28 & & & \\
\hline 1561 & 7670.78 & 60.3 & 2393 & 7670.8 & 60.05 \\
\hline 1562 & 7675.68 & 60.32 & 2394 & 7675.73 & 60.09 \\
\hline 1563 & 7680.55 & 60.33 & 2395 & 7680.7 & 60.13 \\
\hline 1564 & 7686.11 & 60.38 & 2396 & 7685.74 & 60.15 \\
\hline 1565 & 7690.91 & 60.41 & 2397 & 7690.56 & 60.18 \\
\hline 1566 & 7695.68 & 60.45 & 2398 & 7695.58 & 60.22 \\
\hline 1567 & 7701 & 60.49 & 2399 & 7700.6 & 60.25 \\
\hline 1568 & 7705.79 & 60.52 & 2400 & 7705.63 & 60.3 \\
\hline 1569 & 7710.67 & 60.57 & 2401 & 7710.57 & 60.34 \\
\hline 1570 & 7715.73 & 60.62 & 2402 & 7715.52 & 60.4 \\
\hline 1571 & 7720.6 & 60.66 & 2403 & 7720.53 & 60.44 \\
\hline
\end{tabular}




\begin{tabular}{|c|c|c|c|c|c|}
\hline 1572 & 7725.59 & 60.72 & 2404 & 7725.46 & 60.51 \\
\hline 1573 & 7730.64 & 60.79 & 2405 & 7730.23 & 60.56 \\
\hline 1574 & 7735.64 & 60.88 & 2406 & 7735.3 & 60.68 \\
\hline 1575 & 7740.47 & 60.9 & 2407 & 7740.23 & 60.68 \\
\hline 1576 & 7744.9 & 60.94 & 2408 & 7744.78 & 60.72 \\
\hline 1577 & 7749.94 & 61.01 & 2409 & 7749.61 & 60.78 \\
\hline 1578 & 7755.44 & 61.06 & 2410 & 7755.12 & 60.84 \\
\hline 1579 & 7761.35 & 61.13 & 2411 & 7761.14 & 60.92 \\
\hline 1580 & 7765.24 & 61.17 & & & \\
\hline 1581 & 7770.05 & 61.23 & 2412 & 7769.73 & 61.01 \\
\hline 1582 & 7775 & 61.29 & 2413 & 7774.78 & 61.06 \\
\hline 1583 & 7780.05 & 61.34 & 2414 & 7779.75 & 61.12 \\
\hline 1584 & 7785.32 & 61.44 & 2415 & 7784.78 & 61.17 \\
\hline 1585 & 7789.98 & 61.47 & 2416 & 7789.74 & 61.23 \\
\hline 1586 & 7794.69 & 61.52 & 2417 & 7794.75 & 61.28 \\
\hline 1587 & 7799.96 & 61.58 & 2418 & 7799.68 & 61.35 \\
\hline 1588 & 7804.94 & 61.51 & 2419 & 7804.64 & 61.4 \\
\hline 1589 & 7809.8 & 61.69 & 2420 & 7809.38 & 61.47 \\
\hline 1590 & 7814.14 & 61.73 & 2421 & 7814.47 & 61.51 \\
\hline 1591 & 7820.14 & 61.8 & 2422 & 7819.4 & 61.56 \\
\hline 1592 & 7824.34 & 61.85 & 2423 & 7824.44 & 61.62 \\
\hline 1593 & 7829.34 & 61.9 & 2424 & 7829.43 & 61.67 \\
\hline 1594 & 7834.44 & 61.96 & 2425 & 7834.43 & 61.72 \\
\hline 1595 & 7839.46 & 62.02 & 2426 & 7839.4 & 61.78 \\
\hline 1596 & 7845.91 & 62.09 & & & \\
\hline 1597 & 7849.57 & 62.12 & 2427 & 7849.39 & 61.88 \\
\hline 1598 & 7854.31 & 62.17 & 2428 & 7854.49 & 61.92 \\
\hline 1599 & 7859.56 & 62.24 & & & \\
\hline 1600 & 7864.92 & 62.28 & & & \\
\hline 1601 & 7869.75 & 62.33 & 2429 & 7869.48 & 62.06 \\
\hline 1602 & 7874.86 & 62.37 & 2430 & 7874.52 & 62.12 \\
\hline 1603 & 7879.82 & 62.39 & 2431 & 7879.52 & 62.16 \\
\hline 1604 & 7884.85 & 62.45 & 2432 & 7884.49 & 62.21 \\
\hline 1605 & 7889.49 & 62.47 & 2433 & 7888.78 & 62.22 \\
\hline 1606 & 7894.52 & 62.52 & 2434 & 7893.67 & 62.29 \\
\hline 1607 & 7899.87 & 62.57 & 2435 & 7898.59 & 62.33 \\
\hline 1608 & 7904.41 & 62.59 & 2436 & 7903.49 & 62.38 \\
\hline 1609 & 7909.12 & 62.64 & 2437 & 7908.46 & 62.42 \\
\hline 1610 & 7913.28 & 62.68 & & & \\
\hline 1611 & 7917.82 & 62.95 & 2438 & 7917.74 & 62.87 \\
\hline 1612 & 7923.11 & 63.12 & 2439 & 7922.93 & 62.94 \\
\hline 1613 & 7927.56 & 63.17 & 2440 & 7926.91 & 62.86 \\
\hline 1614 & 7932.66 & 63.14 & 2441 & 7932.65 & 62.95 \\
\hline 1615 & 7937.46 & 63.2 & 2442 & 7937.05 & 62.99 \\
\hline 1616 & 7942.33 & 63.23 & 2443 & 7942.21 & 63.08 \\
\hline 1617 & 7951.14 & 63.32 & 2444 & 7950.77 & 63.21 \\
\hline 1618 & 7956.68 & 63.43 & 2445 & 7956.18 & 63.4 \\
\hline 1619 & 7961.33 & 63.5 & 2446 & 7960.92 & 63.45 \\
\hline 1620 & 7966.58 & 63.62 & 2447 & 7966.23 & 63.63 \\
\hline
\end{tabular}




\begin{tabular}{|c|c|c|c|c|c|}
\hline 1621 & 7975.12 & 63.82 & 2448 & 7974.61 & 63.79 \\
\hline 1622 & 7980.07 & 63.97 & & & \\
\hline 1623 & 7983.74 & 63.95 & 2449 & 7983.56 & 63.94 \\
\hline 1624 & 7989 & 64.08 & 2450 & 7988.37 & 64.07 \\
\hline 1625 & 7994.03 & 64.12 & 2451 & 7993.83 & 64.06 \\
\hline 1626 & 7998.83 & 64.1 & 2452 & 7998.46 & 64.07 \\
\hline 1627 & 8003.83 & 64.09 & & & \\
\hline 1628 & 8008.83 & 64.07 & & & \\
\hline 1629 & 8013.83 & 64.06 & 2453 & 8013.8 & 64.04 \\
\hline 1630 & 8020.29 & 64.15 & 2454 & 8020.35 & 64.16 \\
\hline 1631 & 8026.16 & 64.19 & 2455 & 8026.3 & 64.14 \\
\hline 1632 & 8032.1 & 64.18 & 2456 & 8031.96 & 64.17 \\
\hline 1633 & 8038.15 & 64.33 & 2457 & 8038.05 & 64.3 \\
\hline 1634 & 8042.9 & 64.35 & 2458 & 8042.67 & 64.37 \\
\hline 1635 & 8047.98 & 64.42 & 2459 & 8048.2 & 64.35 \\
\hline 1636 & 8053.36 & 64.5 & 2460 & 8053.32 & 64.39 \\
\hline 1637 & 8058.39 & 64.56 & 2461 & 8058.26 & 64.46 \\
\hline 1638 & 8063.44 & 64.7 & 2462 & 8063.09 & 64.43 \\
\hline 1639 & 8068.01 & 64.52 & 2463 & 8067.66 & 64.43 \\
\hline 1640 & 8072.51 & 64.65 & 2464 & 8072.95 & 64.51 \\
\hline 1641 & 8077.19 & 64.42 & 2465 & 8076.75 & 64.28 \\
\hline 1642 & 8082.23 & 64.78 & 2466 & 8082.01 & 64.67 \\
\hline 1643 & 8087.49 & 64.69 & 2467 & 8086.93 & 64.63 \\
\hline 1644 & 8091.39 & 64.78 & 2468 & 8091.08 & 64.71 \\
\hline 1645 & 8096.3 & 64.8 & 2469 & 8095.62 & 64.67 \\
\hline 1646 & 8100.49 & 64.83 & 2470 & 8100.1 & 64.72 \\
\hline 1647 & 8104.55 & 64.71 & 2471 & 8103.93 & 64.6 \\
\hline 1648 & 8109.73 & 64.71 & 2472 & 8109.09 & 64.69 \\
\hline 1649 & 8114.16 & 64.75 & 2473 & 8113.64 & 64.72 \\
\hline 1650 & 8118.94 & 64.95 & 2474 & 8118.61 & 64.8 \\
\hline 1651 & 8122.99 & 64.85 & 2475 & 8122.55 & 64.77 \\
\hline 1652 & 8127.42 & 64.99 & 2476 & 8127.18 & 64.87 \\
\hline 1653 & 8131.82 & 65.04 & 2477 & 8131.36 & 64.84 \\
\hline 1654 & 8136.2 & 65.1 & 2478 & 8136.09 & 64.87 \\
\hline 1655 & 8140.53 & 65.15 & 2479 & 8140.2 & 64.95 \\
\hline 1656 & 8145.49 & 65.29 & 2480 & 8144.91 & 65.13 \\
\hline 1657 & 8148.61 & 65.21 & 2481 & 8148.69 & 65.15 \\
\hline 1658 & 8152.96 & 65.31 & 2482 & 8152.53 & 65.24 \\
\hline 1659 & 8157.61 & 65.49 & 2483 & 8156.48 & 65.28 \\
\hline 1660 & 8162.33 & 65.57 & 2484 & 8161.81 & 65.44 \\
\hline 1661 & 8166.75 & 65.73 & 2485 & 8166.26 & 65.58 \\
\hline 1662 & 8171.04 & 65.87 & 2486 & 8170.7 & 65.71 \\
\hline 1663 & 8175.76 & 65.99 & 2487 & 8175.12 & 65.85 \\
\hline 1664 & 8179.72 & 66.09 & 2488 & 8178.98 & 65.87 \\
\hline 1665 & 8184.1 & 66.16 & 2489 & 8183.29 & 66.01 \\
\hline 1666 & 8187.44 & 66.23 & 2490 & 8187.39 & 66.29 \\
\hline 1667 & 8191.61 & 66.35 & 2491 & 8191.96 & 66.31 \\
\hline 1668 & 8195.94 & 66.22 & 2492 & 8195.45 & 66.14 \\
\hline 1669 & 8199.83 & 66.39 & 2493 & 8199.4 & 66.3 \\
\hline
\end{tabular}




\begin{tabular}{|c|c|c|c|c|c|}
\hline 1670 & 8204.13 & 66.35 & 2494 & 8203.66 & 66.2 \\
\hline 1671 & 8207.9 & 66.35 & 2495 & 8207.27 & 66.17 \\
\hline 1672 & 8212.52 & 66.44 & 2496 & 8211.31 & 66.23 \\
\hline 1673 & 8216.1 & 66.44 & 2497 & 8215.42 & 66.27 \\
\hline 1674 & 8221.62 & 66.7 & 2498 & 8221.03 & 66.42 \\
\hline 1675 & 8224.46 & 66.74 & 2499 & 8223.79 & 66.48 \\
\hline 1676 & 8228.84 & 66.8 & 2500 & 8228.32 & 66.61 \\
\hline 1677 & 8232.22 & 66.73 & 2501 & 8231.82 & 66.6 \\
\hline 1678 & 8235.96 & 66.82 & 2502 & 8235.66 & 66.61 \\
\hline 1679 & 8239.29 & 66.76 & 2503 & 8239.29 & 66.73 \\
\hline 1680 & 8243.44 & 66.64 & 2504 & 8243.13 & 66.61 \\
\hline 1681 & 8246.52 & 66.59 & 2505 & 8246.32 & 66.54 \\
\hline 1682 & 8252 & 67 & & & \\
\hline 1683 & 8257 & 67 & & & \\
\hline 1684 & 8262 & 67 & & & \\
\hline 1685 & 8267 & 67 & & & \\
\hline 1686 & 8272 & 67 & & & \\
\hline 1687 & 8277 & 67 & & & \\
\hline 1688 & 8282 & 67 & & & \\
\hline 1689 & 8287 & 67 & & & \\
\hline 1690 & 8292 & 67 & & & \\
\hline 1691 & 8297 & 67 & & & \\
\hline 1692 & 8302 & 67 & & & \\
\hline 1693 & 8307 & 67 & & & \\
\hline 1694 & 8312 & 67 & & & \\
\hline 1695 & 8317 & 67 & & & \\
\hline 1696 & 8322 & 67 & & & \\
\hline 1697 & 8327 & 67 & & & \\
\hline 1698 & 8332 & 67 & & & \\
\hline 1699 & 8337 & 67 & & & \\
\hline 1700 & 8342 & 67 & & & \\
\hline 1701 & 8347 & 67 & & & \\
\hline 1702 & 8352 & 67 & & & \\
\hline 1703 & 8357 & 67 & & & \\
\hline 1704 & 8362 & 67 & & & \\
\hline 1705 & 8367 & 67 & & & \\
\hline 1706 & 8372 & 67 & & & \\
\hline 1707 & 8377 & 67 & & & \\
\hline 1708 & 8382 & 67 & & & \\
\hline 1709 & 8387 & 67 & & & \\
\hline 1710 & 8392 & 67 & & & \\
\hline 1711 & 8397 & 67 & & & \\
\hline 1712 & 8402 & 67 & & & \\
\hline 1713 & 8407 & 67 & & & \\
\hline 1714 & 8412 & 67 & & & \\
\hline 1715 & 8417 & 67 & & & \\
\hline 1716 & 8422 & 67 & & & \\
\hline 1717 & 8427 & 67 & & & \\
\hline
\end{tabular}




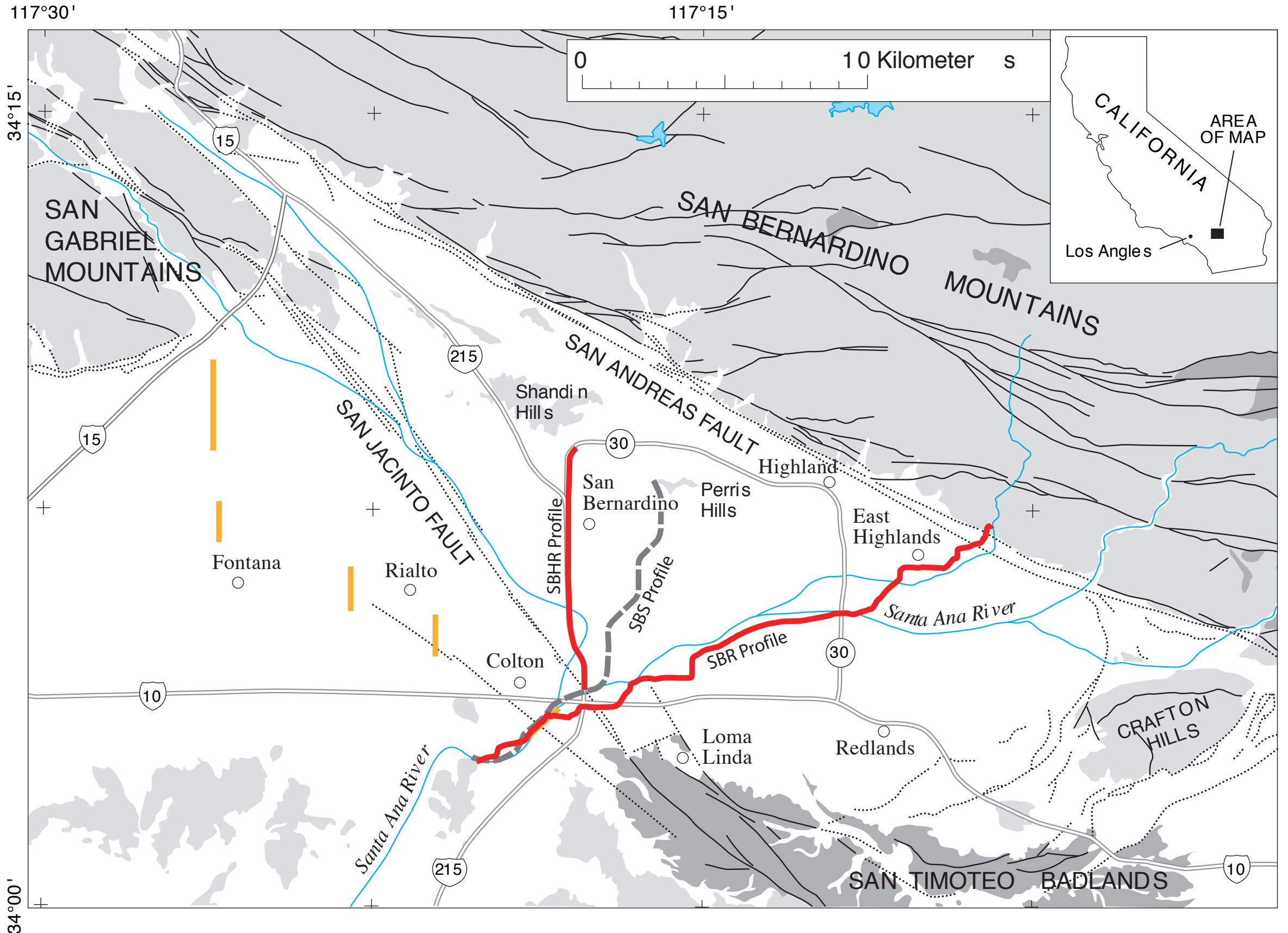

Fig. 1 


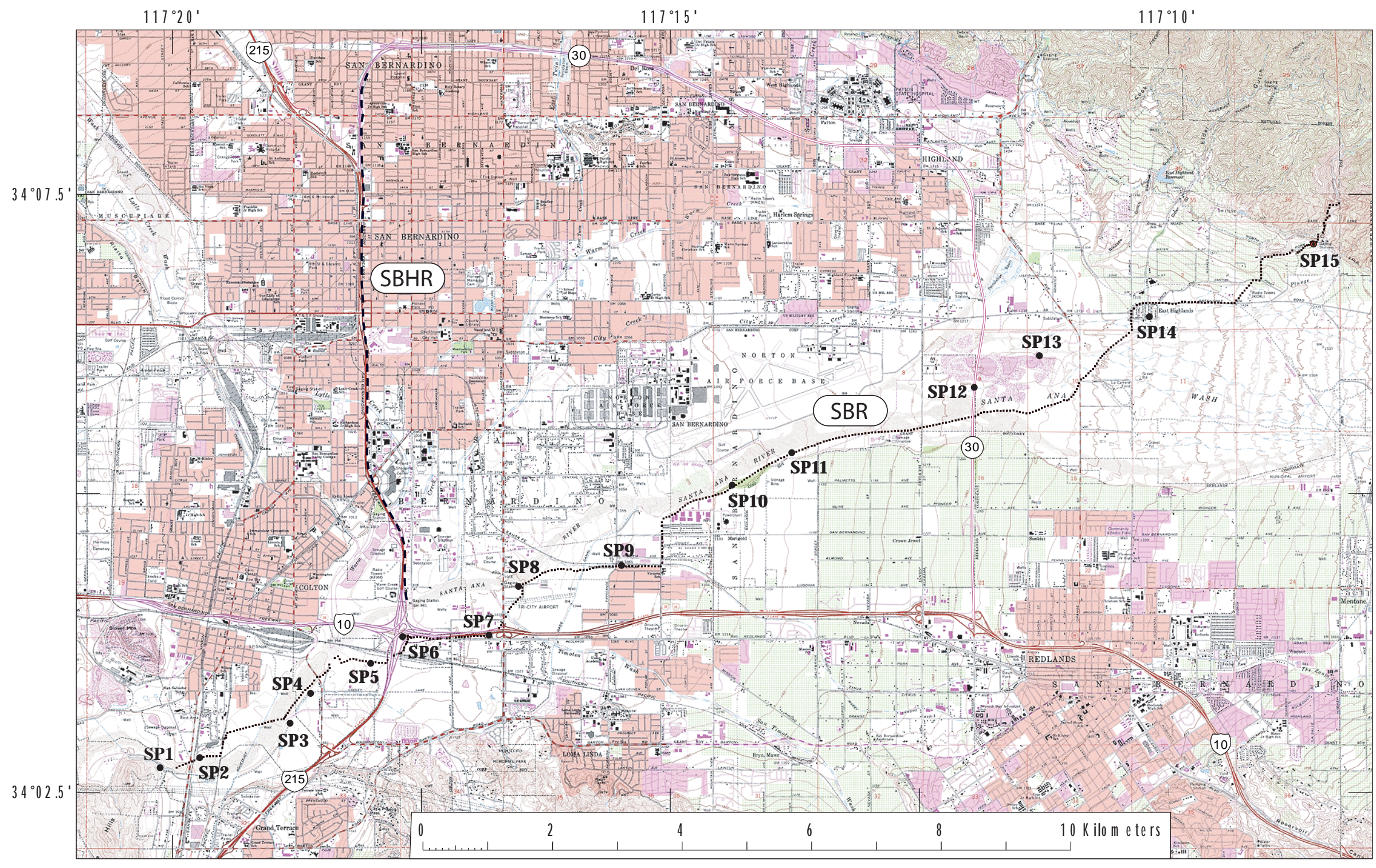

Fig. 2 

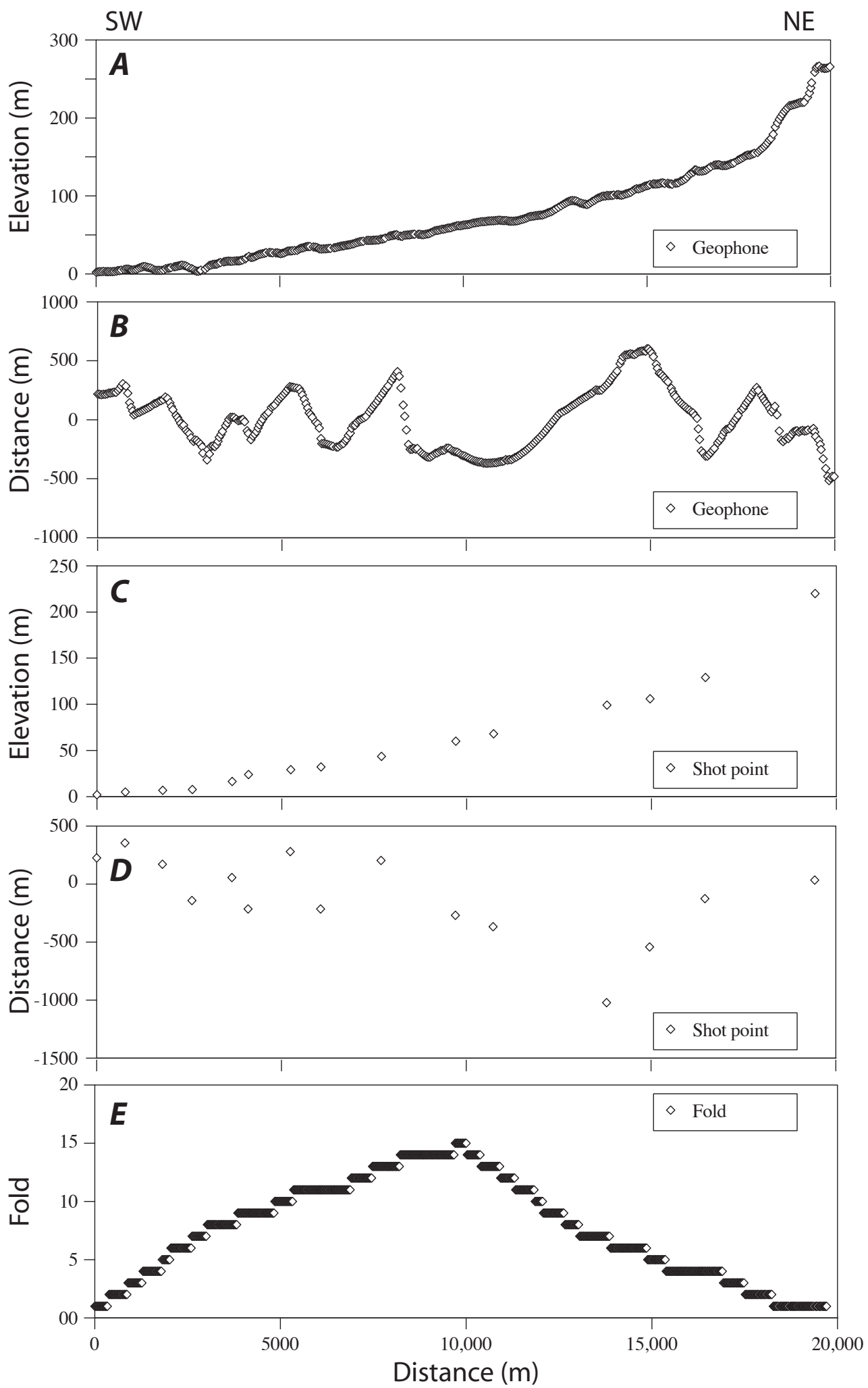

Fig. 3 


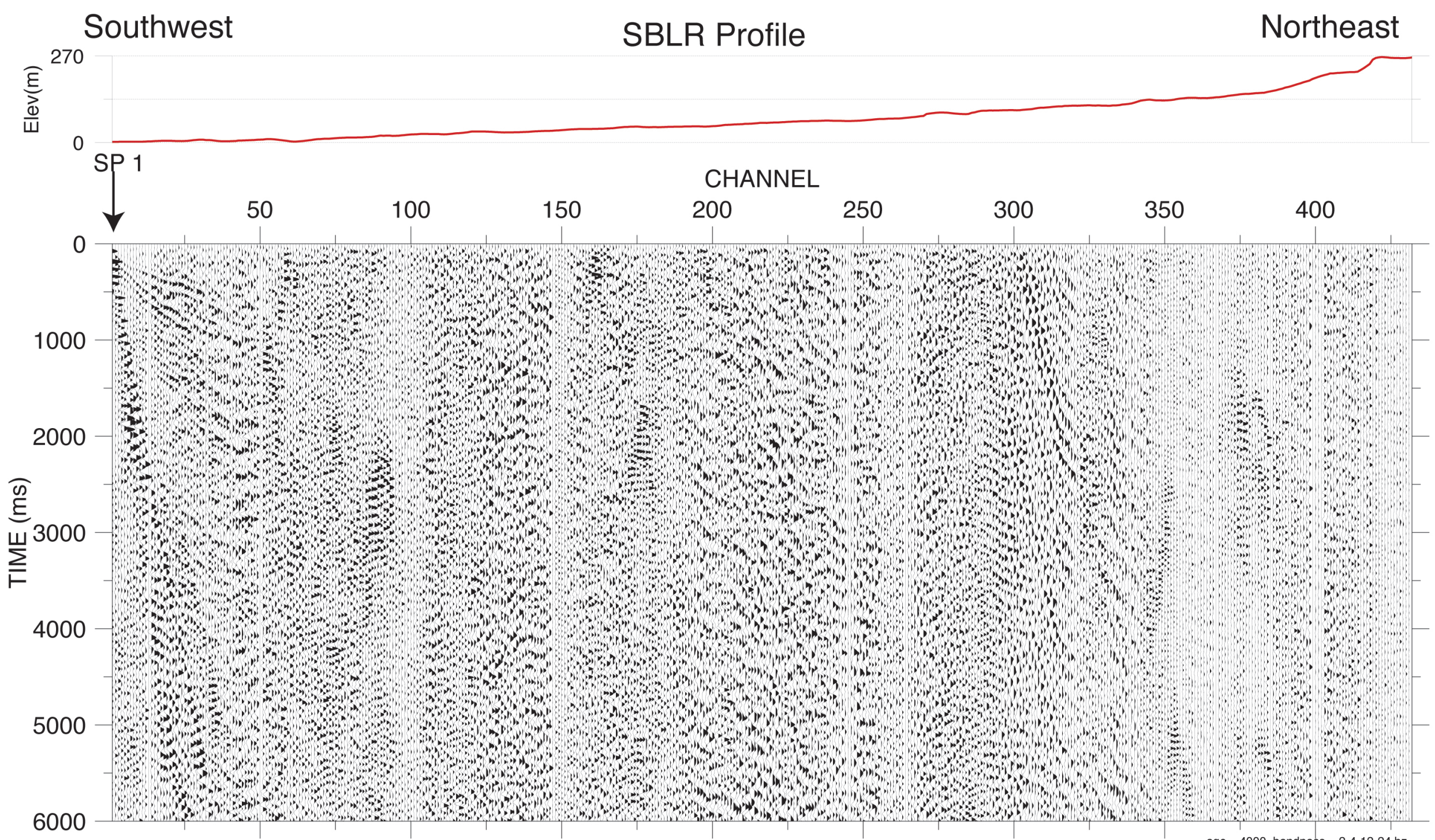

Fig $4 \mathrm{a}$

$\operatorname{agc}=4000$, bandpass $=2-4-12-24 \mathrm{hz}$ 


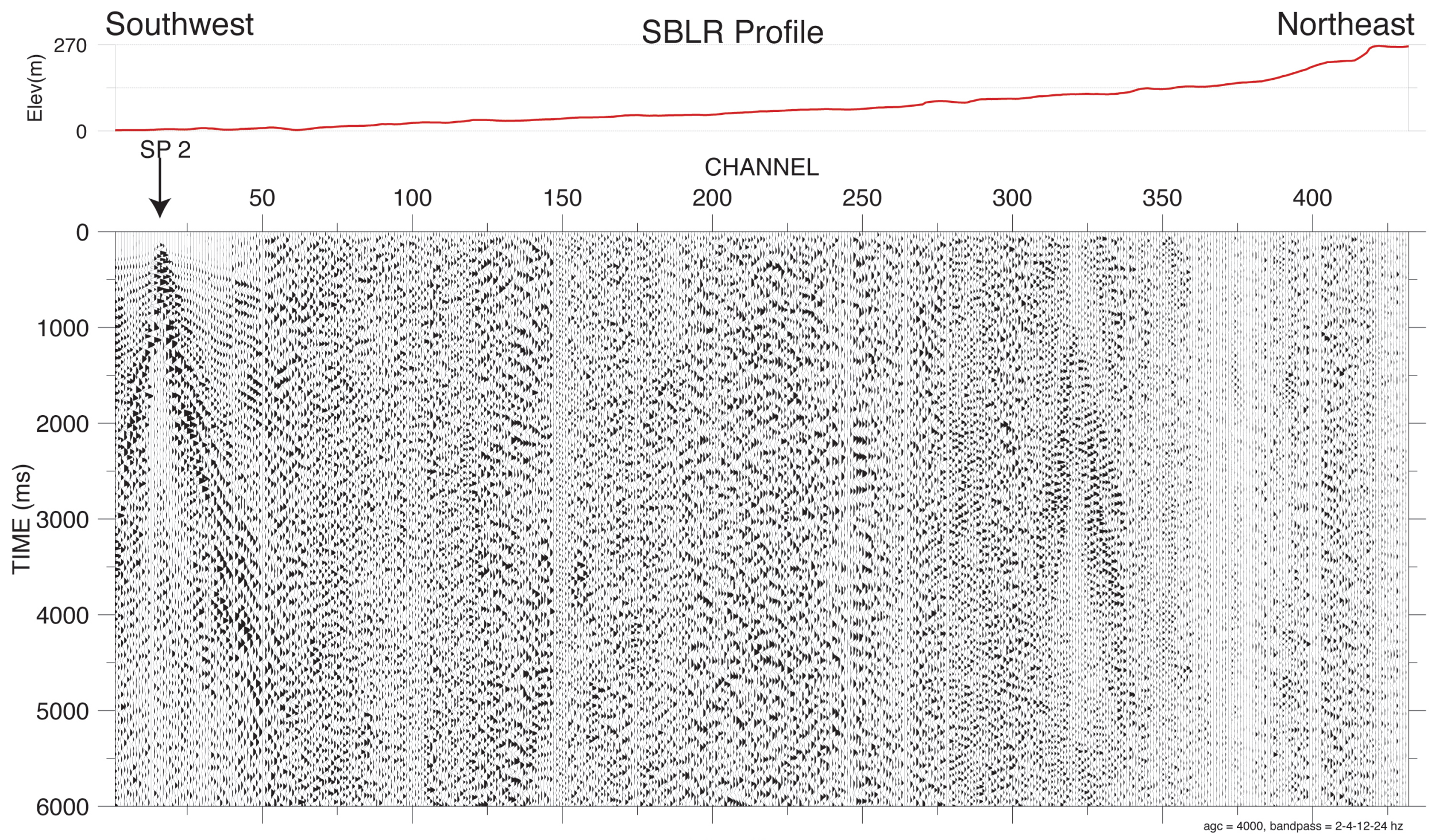

Fig 4b 


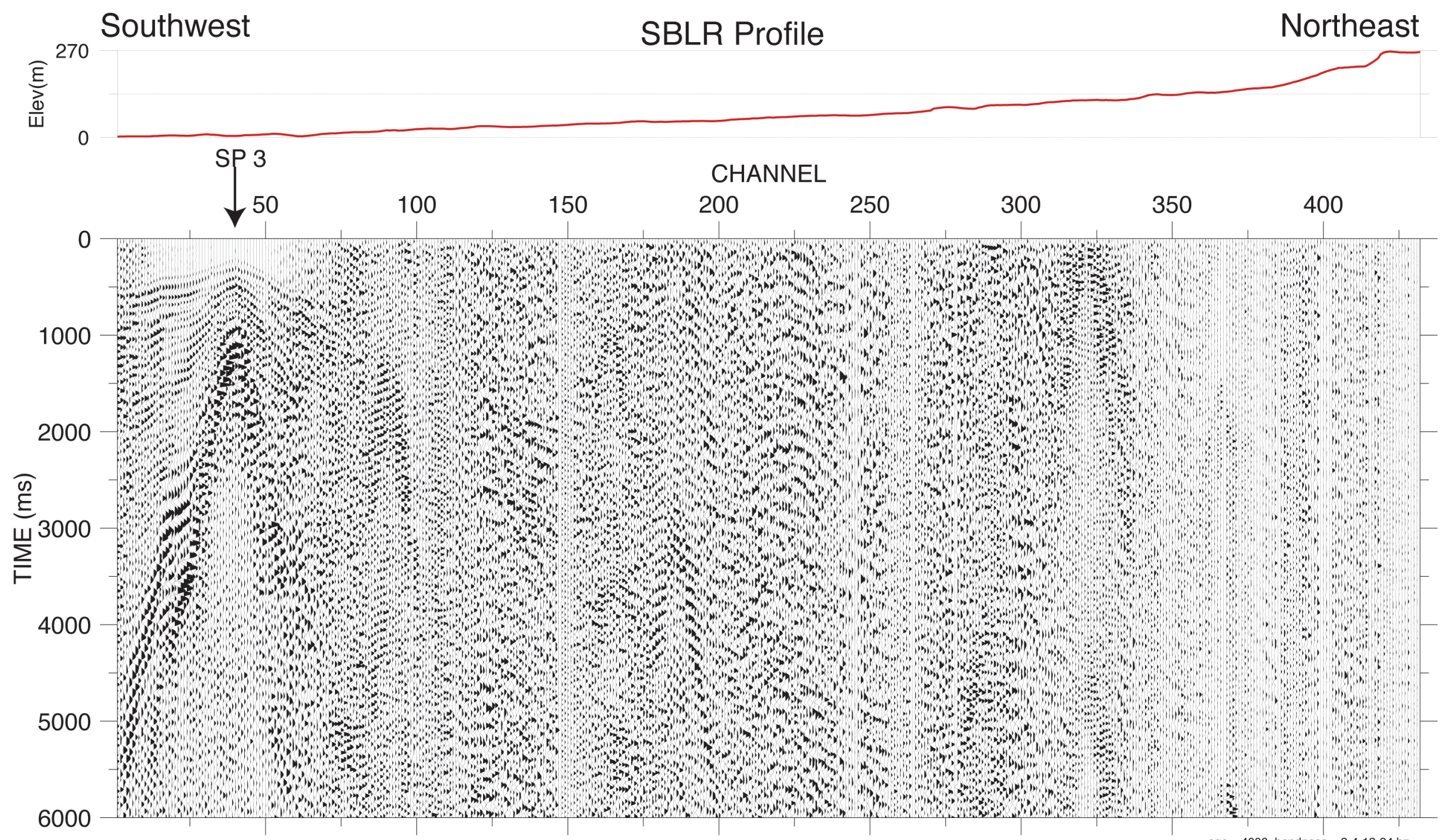

Fig 4c 


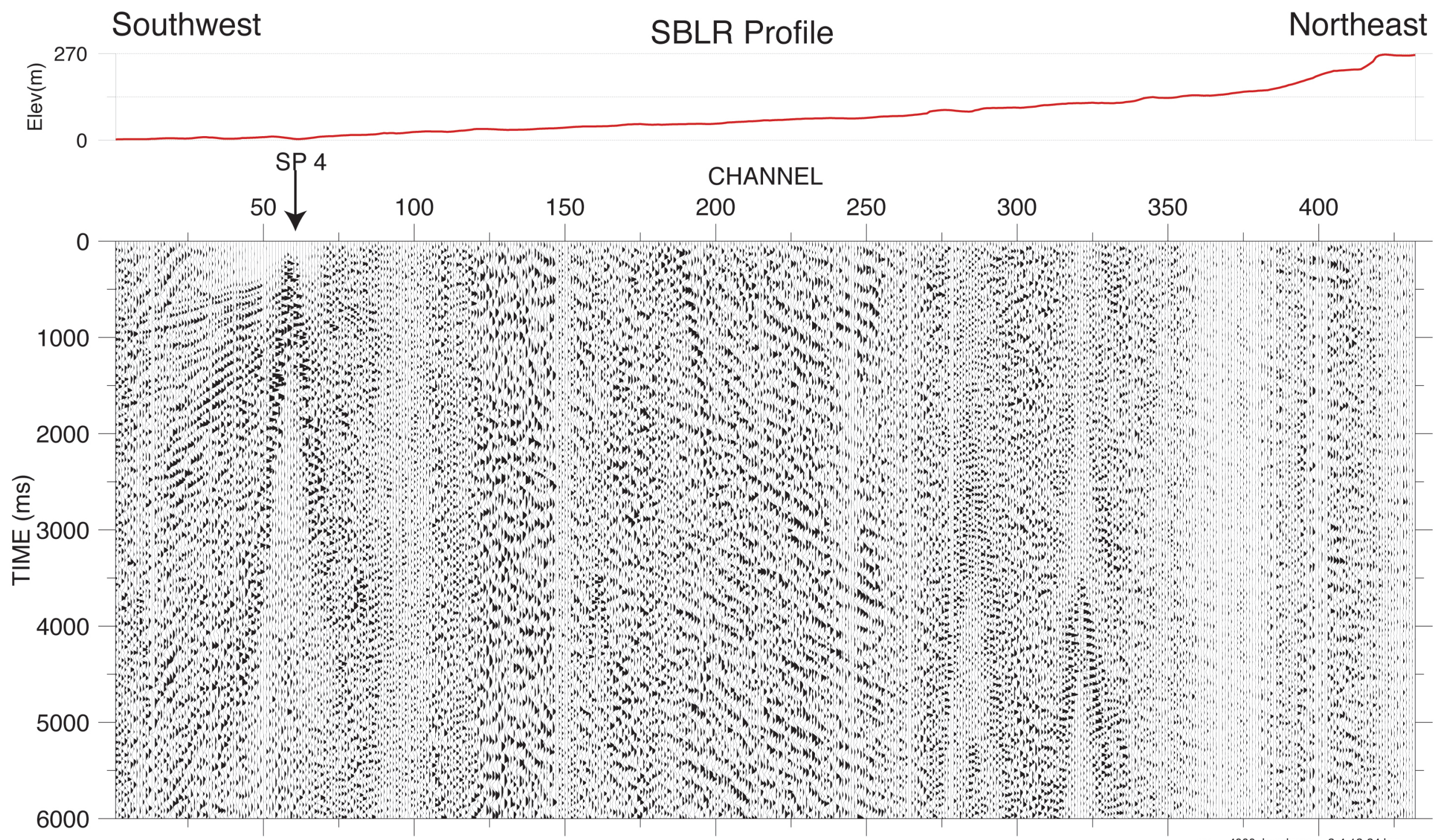

Fig 4d

agc $=4000$, bandpass $=2-4-12-24 \mathrm{hz}$ 


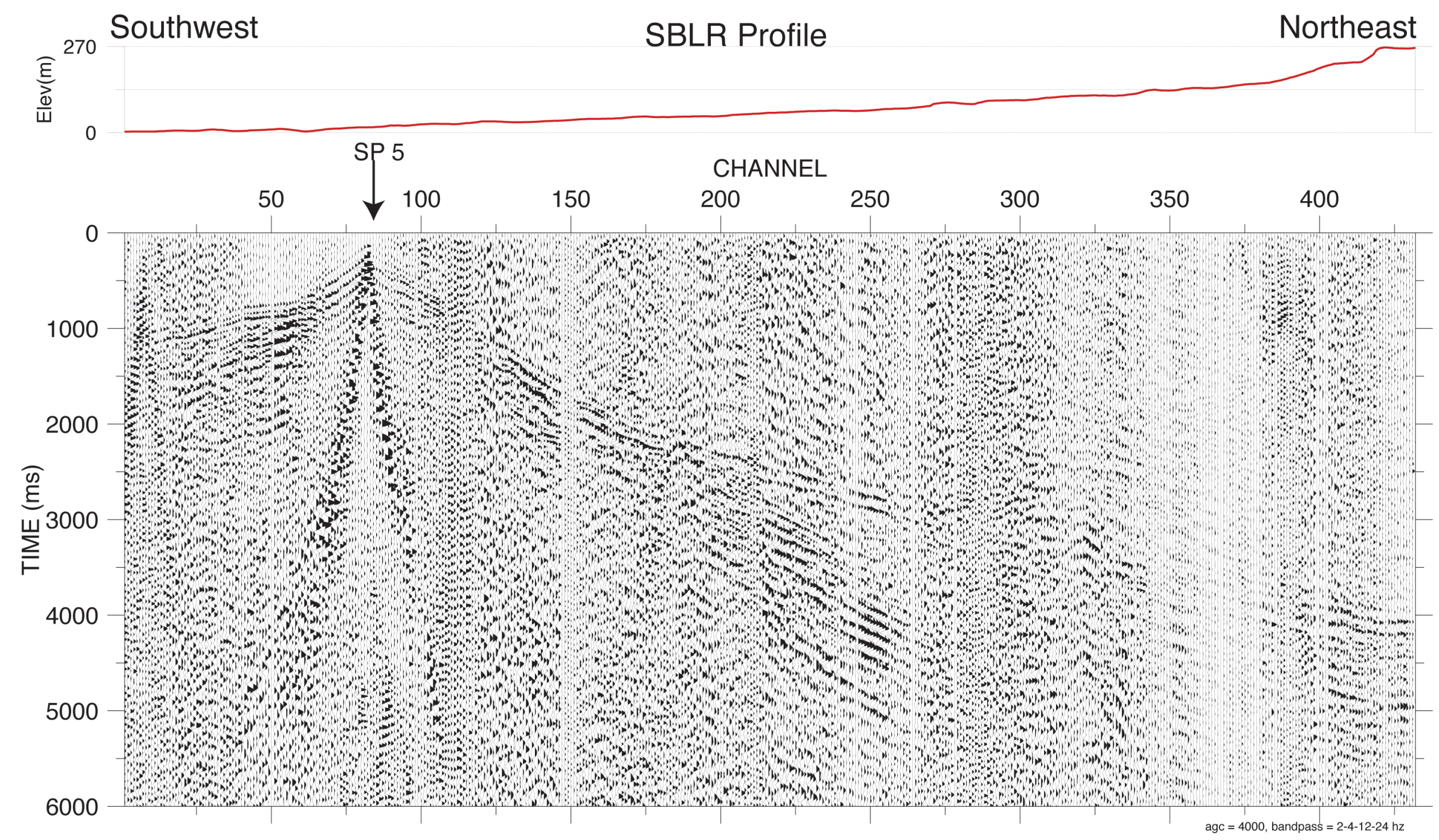

Fig $4 \mathrm{e}$ 


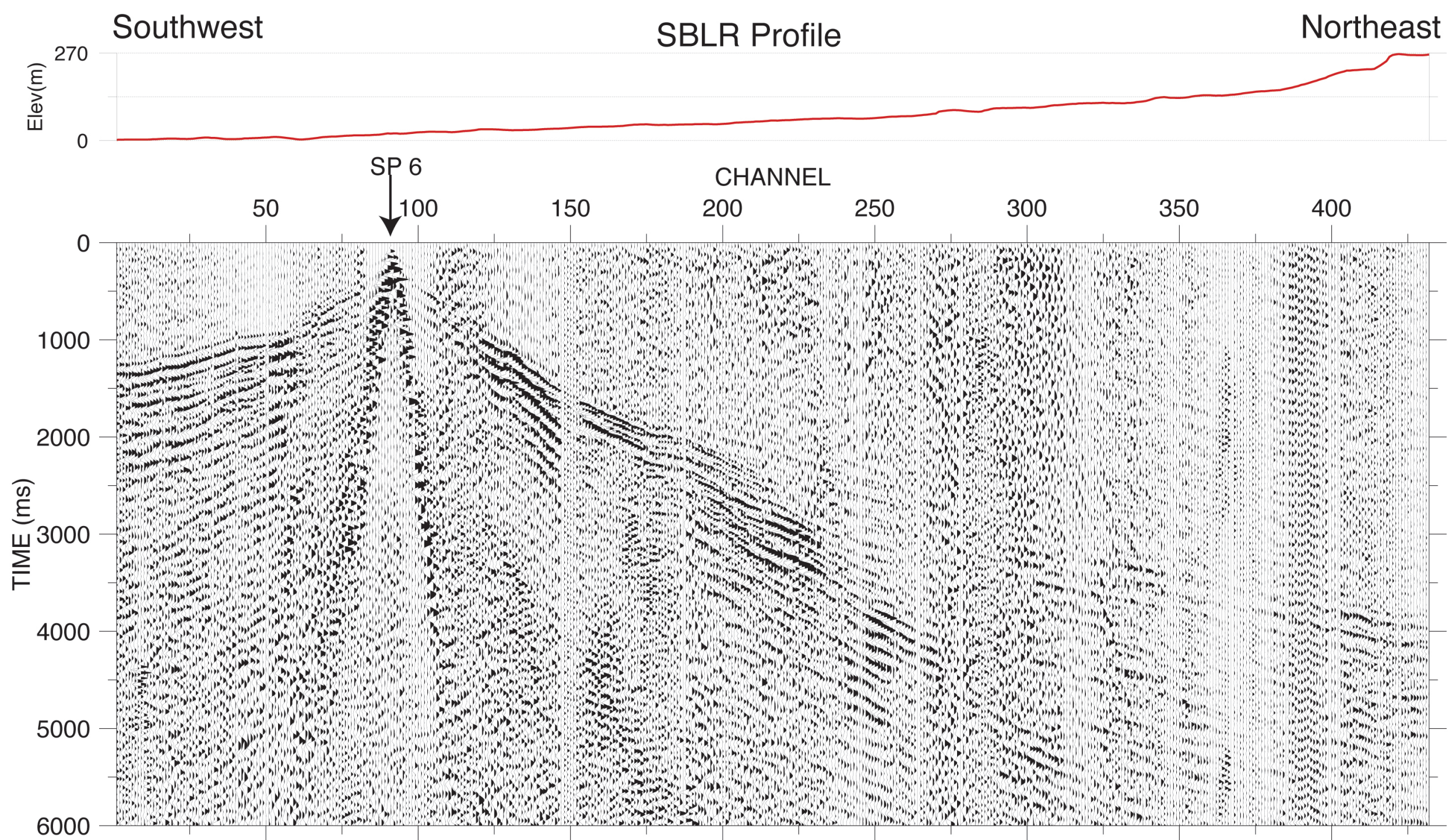

Fig $4 f$

agc $=4000$, bandpass $=2-4-12-24 \mathrm{hz}$ 


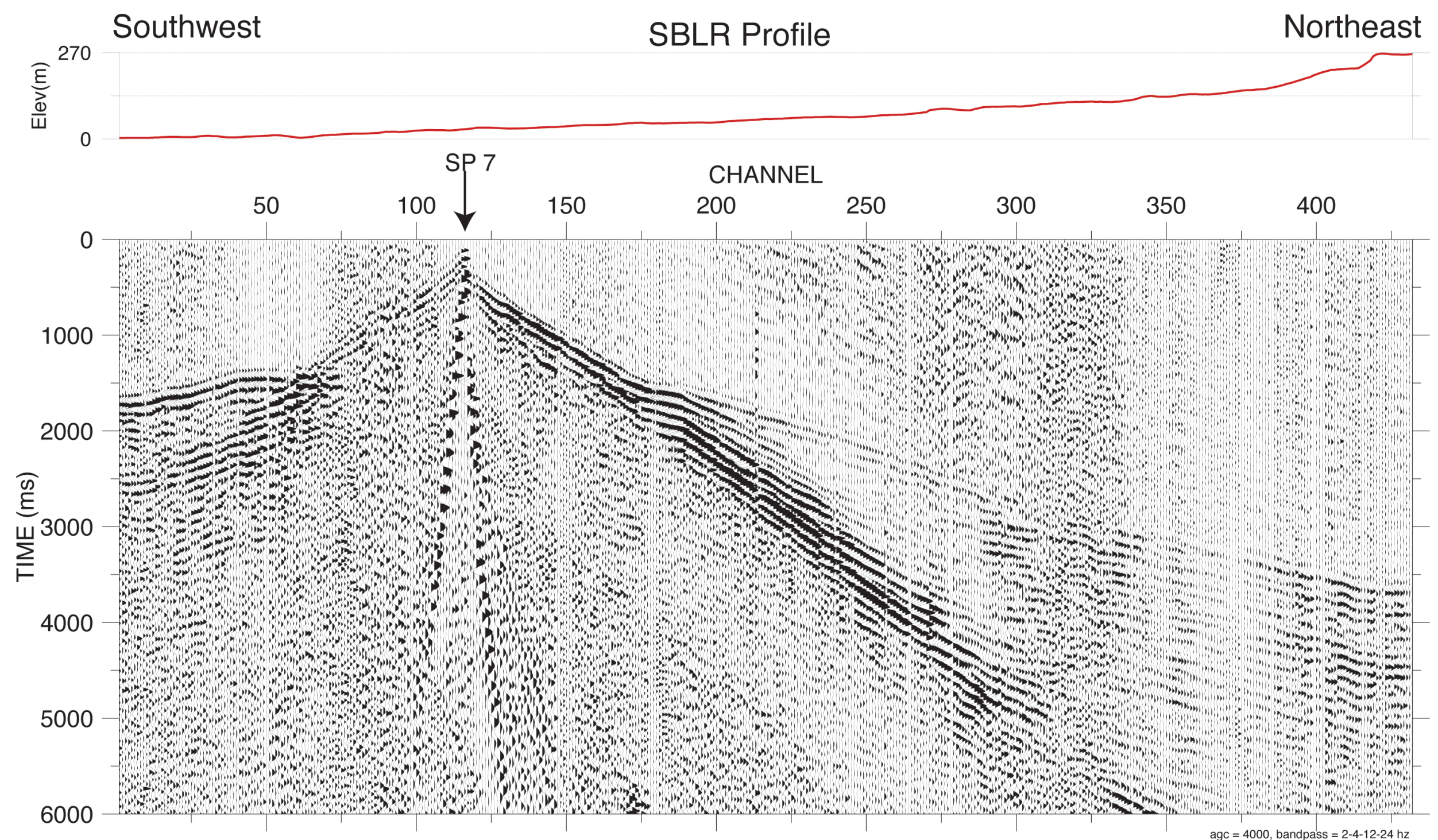

Fig $4 \mathrm{~g}$ 


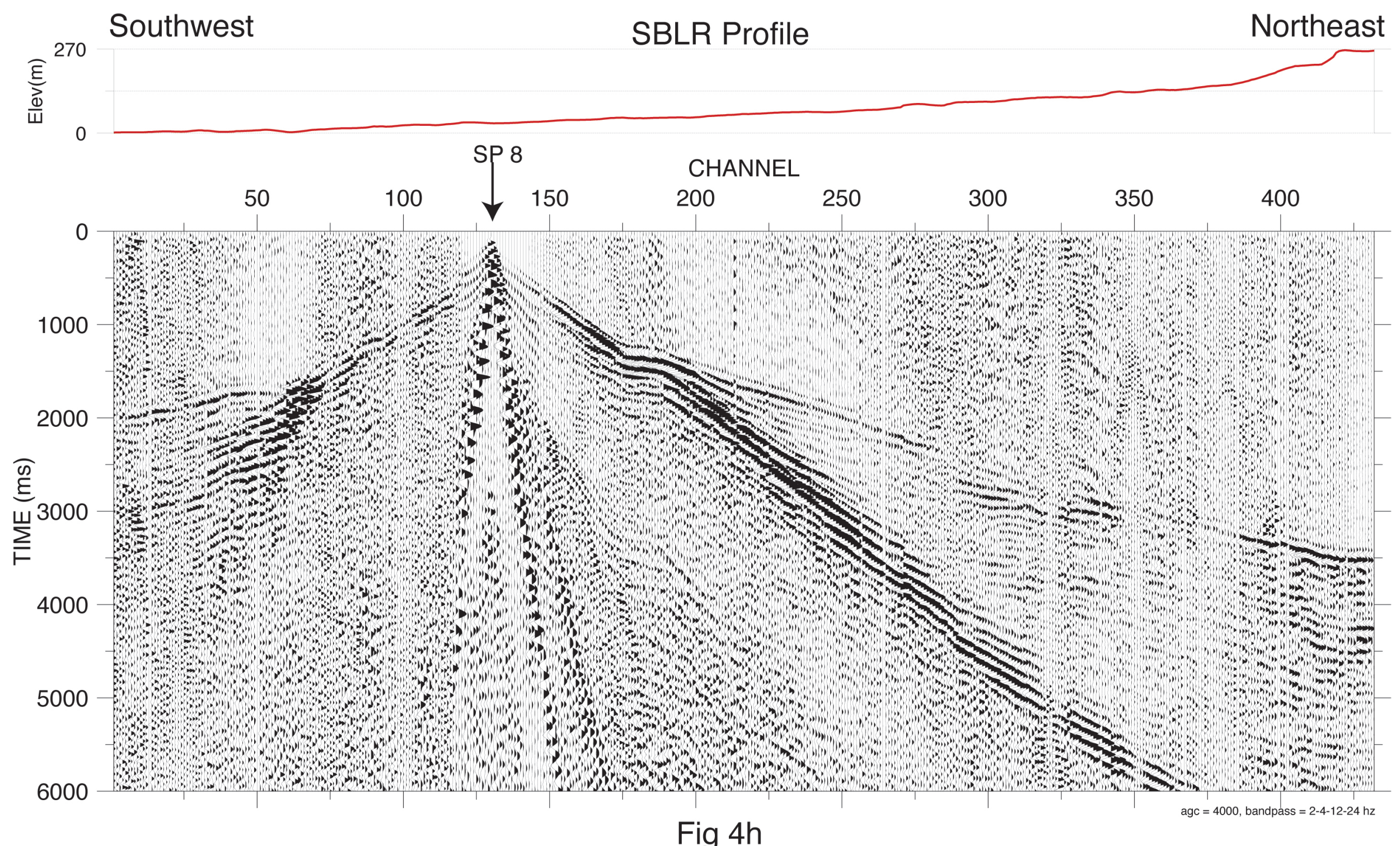

Fig 4h 


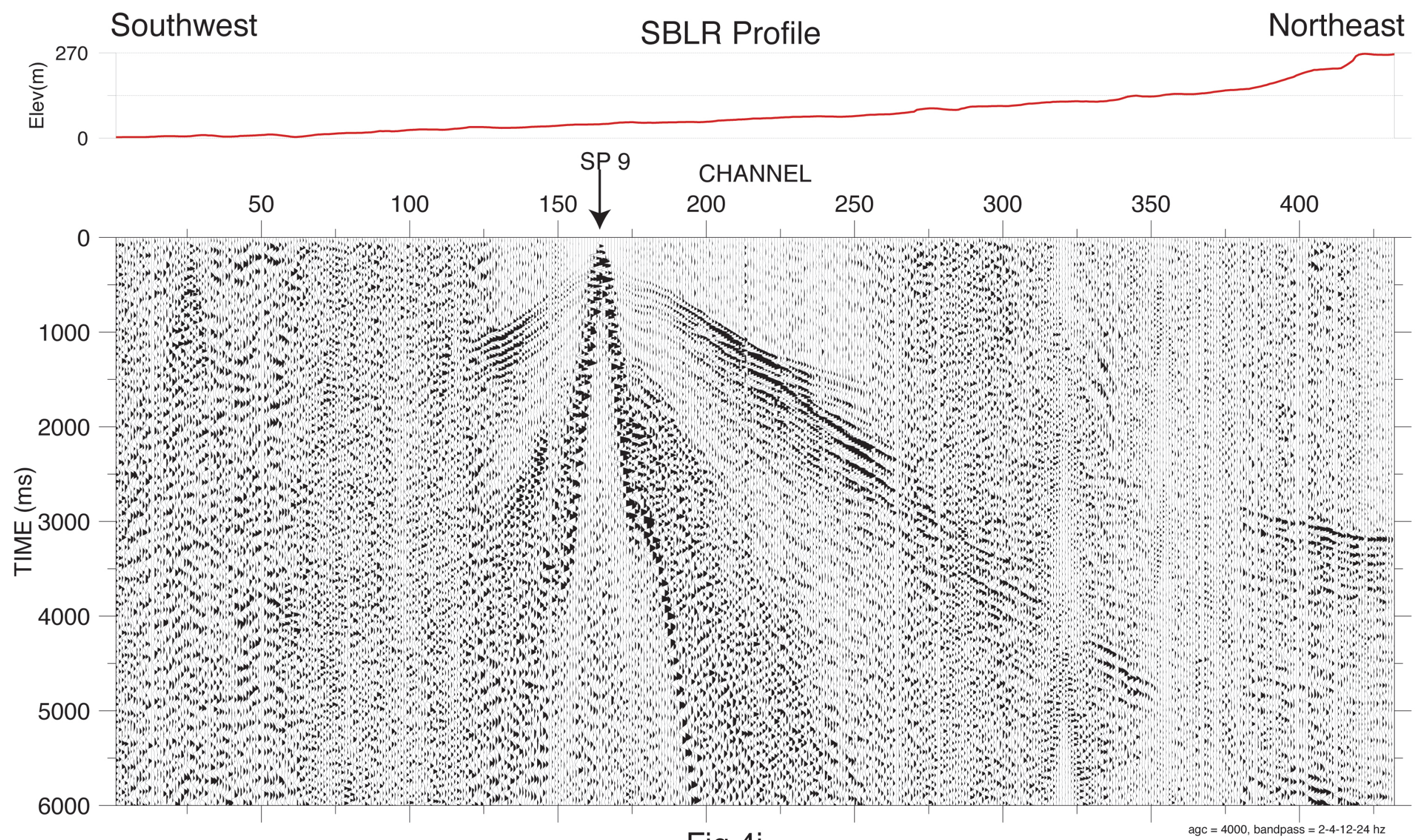

Fig 4i

$\operatorname{agc}=4000$, bandpass $=2-4-12-24 \mathrm{hz}$ 


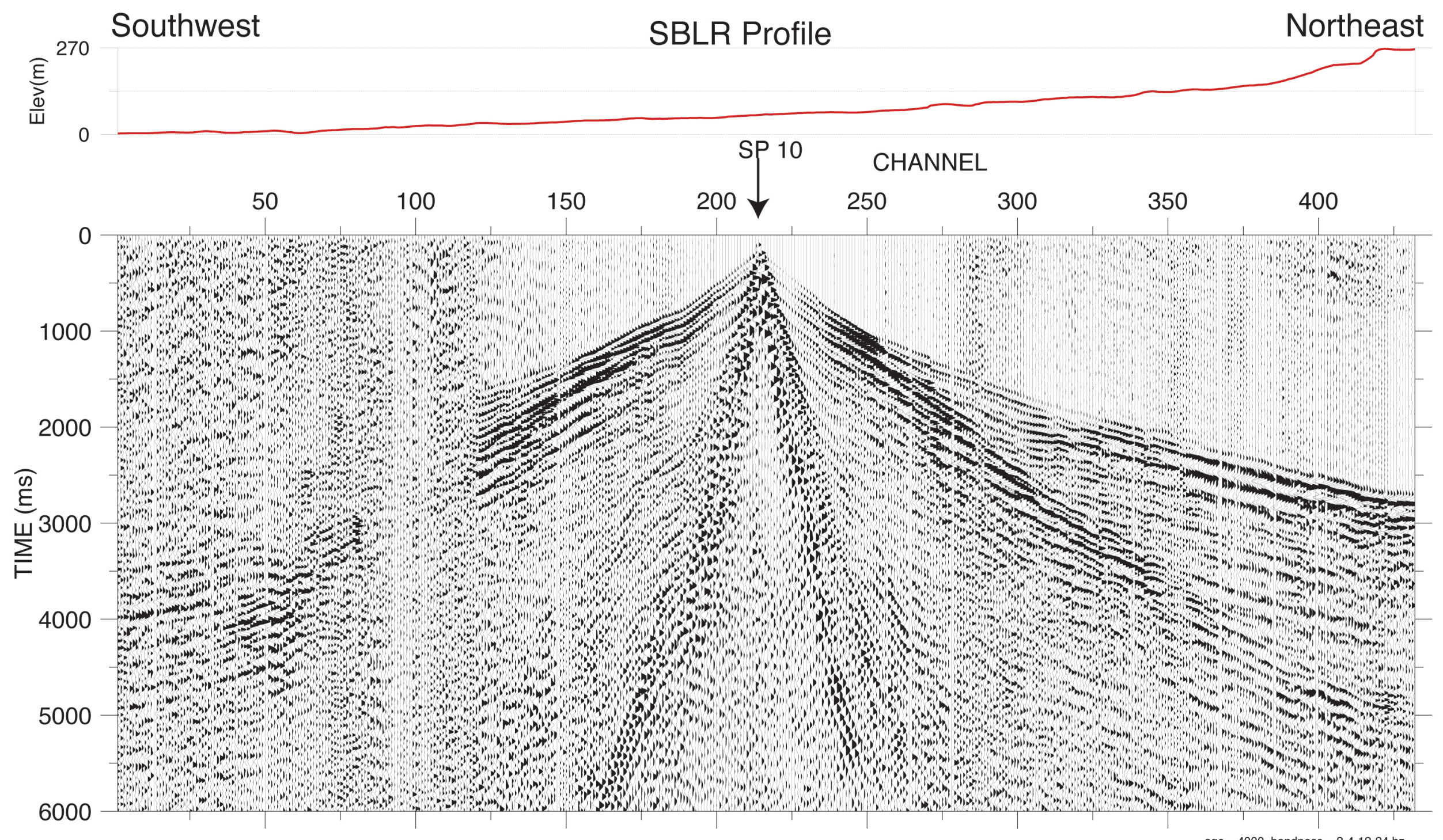

Fig $4 \mathrm{j}$

$\operatorname{agc}=4000$, bandpass $=2-4-12-24 \mathrm{hz}$ 


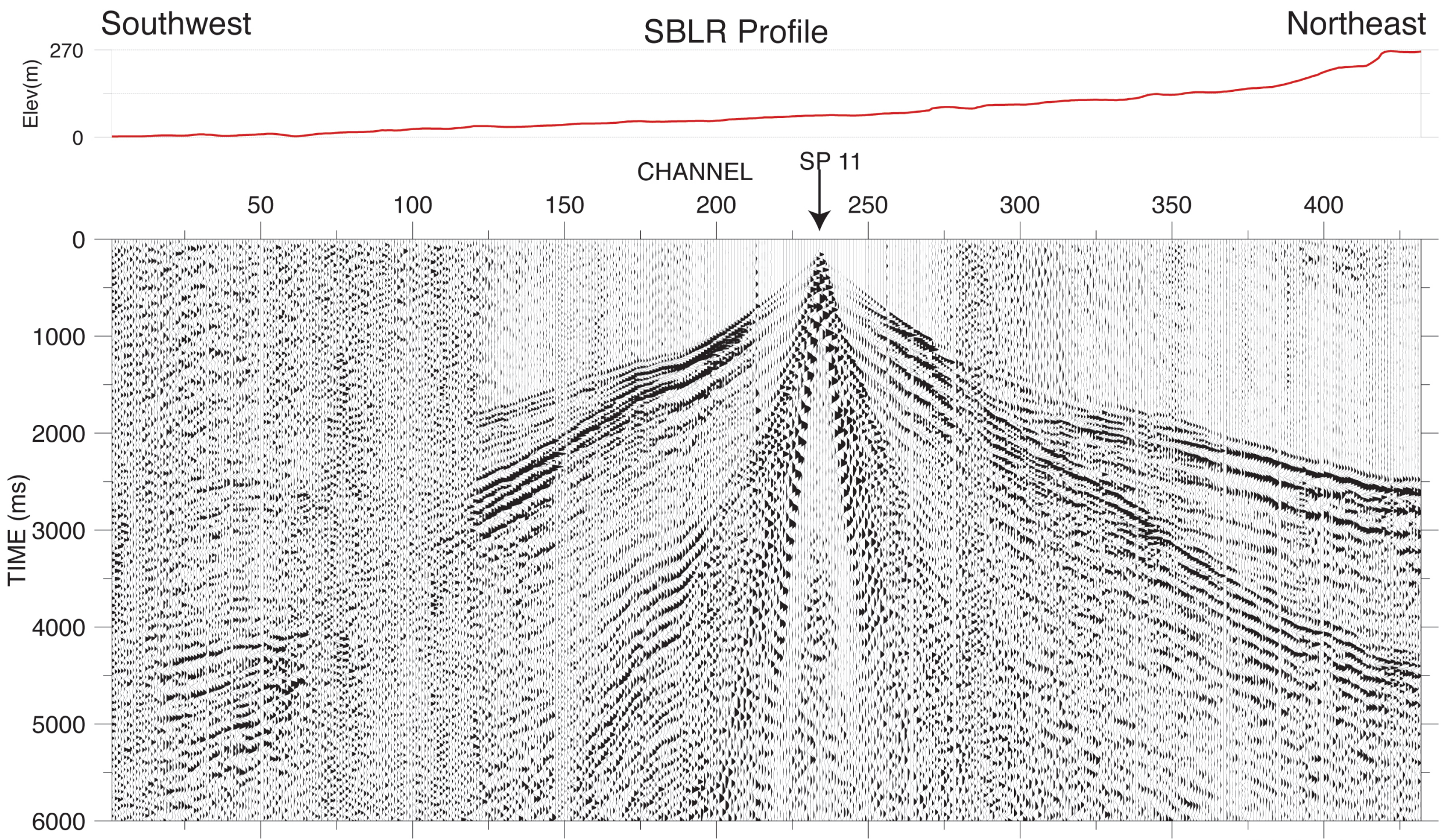

Fig 4k

agc $=4000$, bandpass $=2-4-12-24 \mathrm{hz}$ 


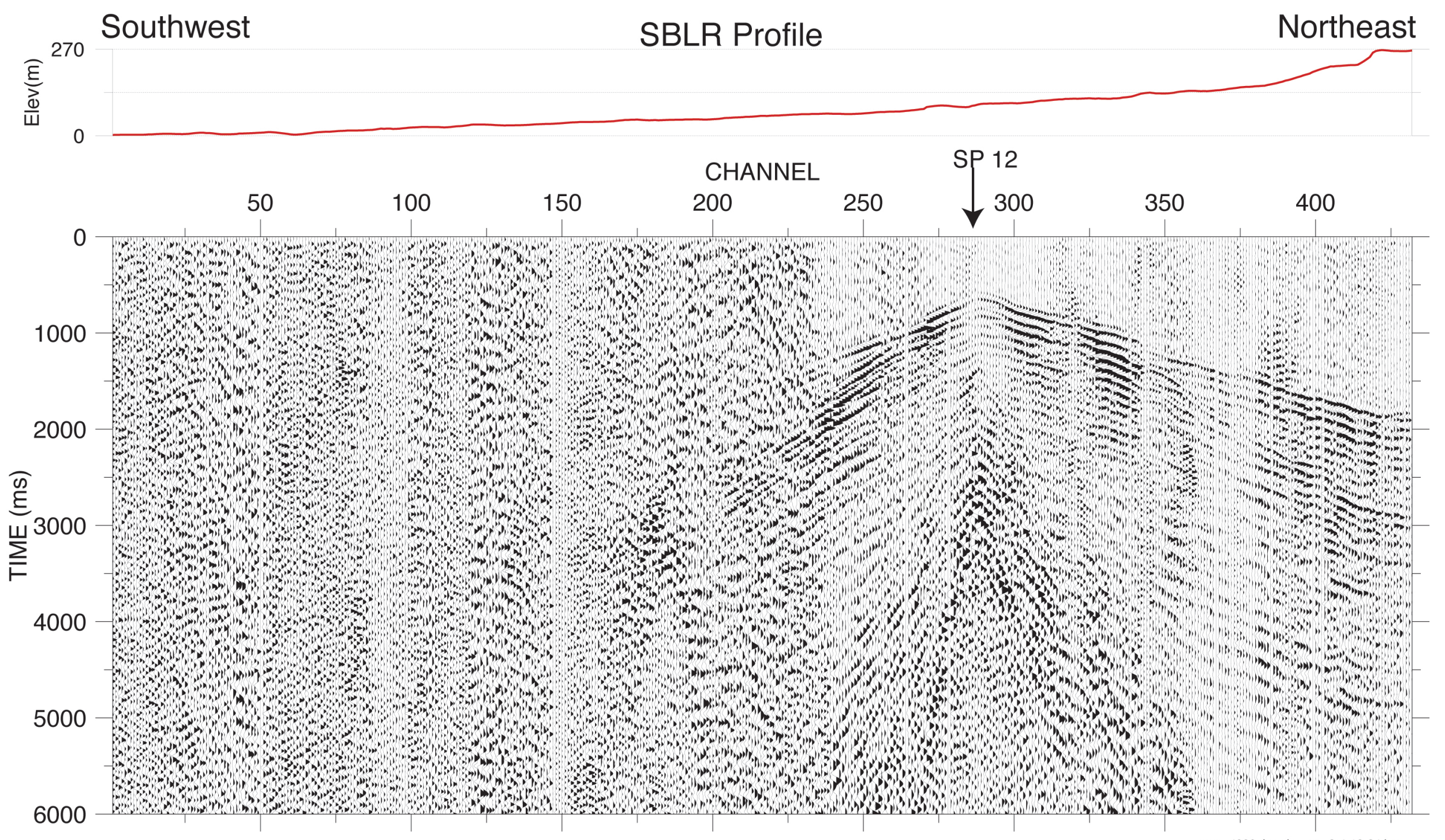

Fig 4L

$\operatorname{agc}=4000$, bandpass $=2-4-12-24 \mathrm{hz}$ 


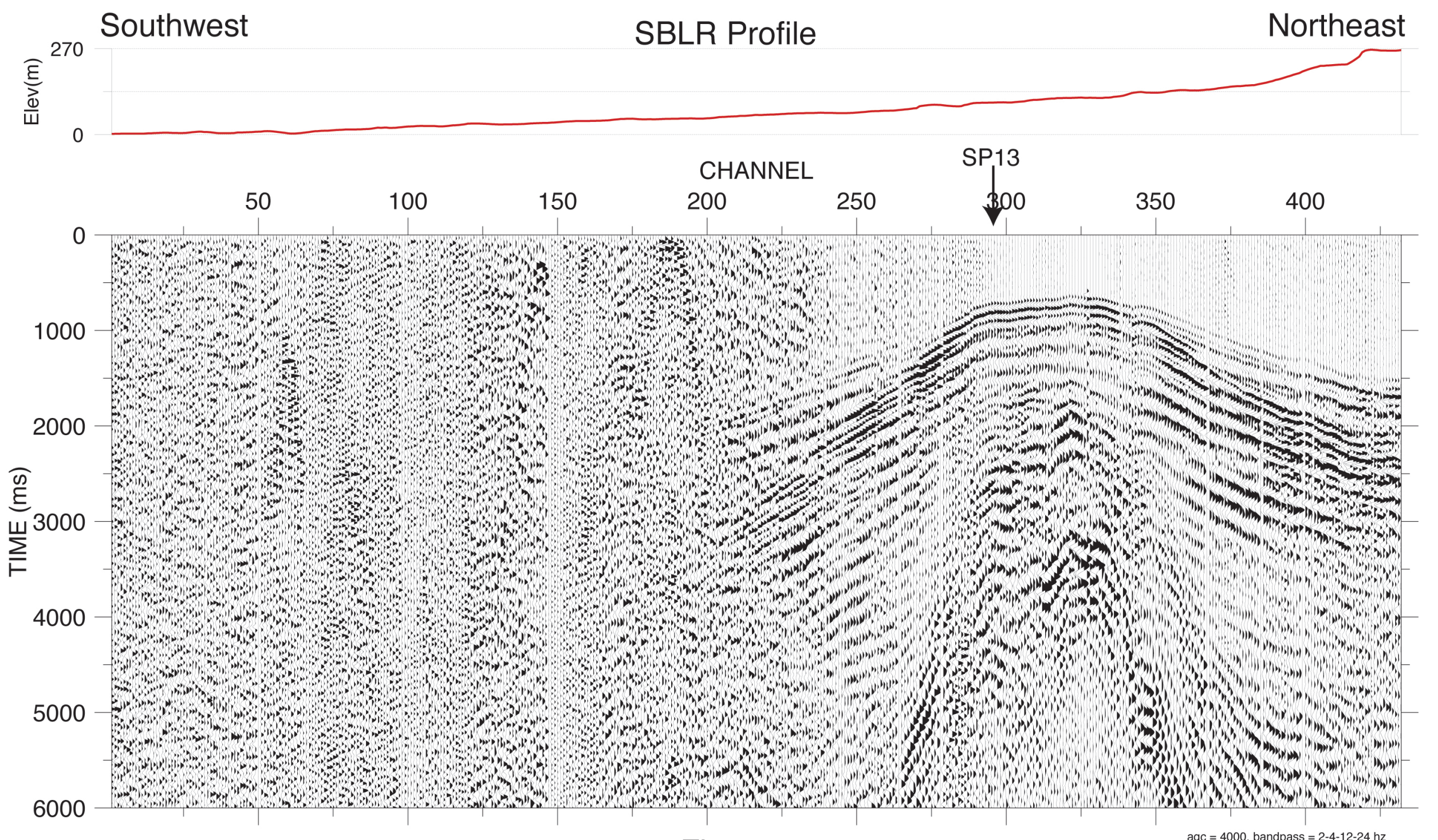

Fig $4 m$

$\operatorname{agc}=4000$, bandpass $=2-4-12-24 \mathrm{hz}$ 


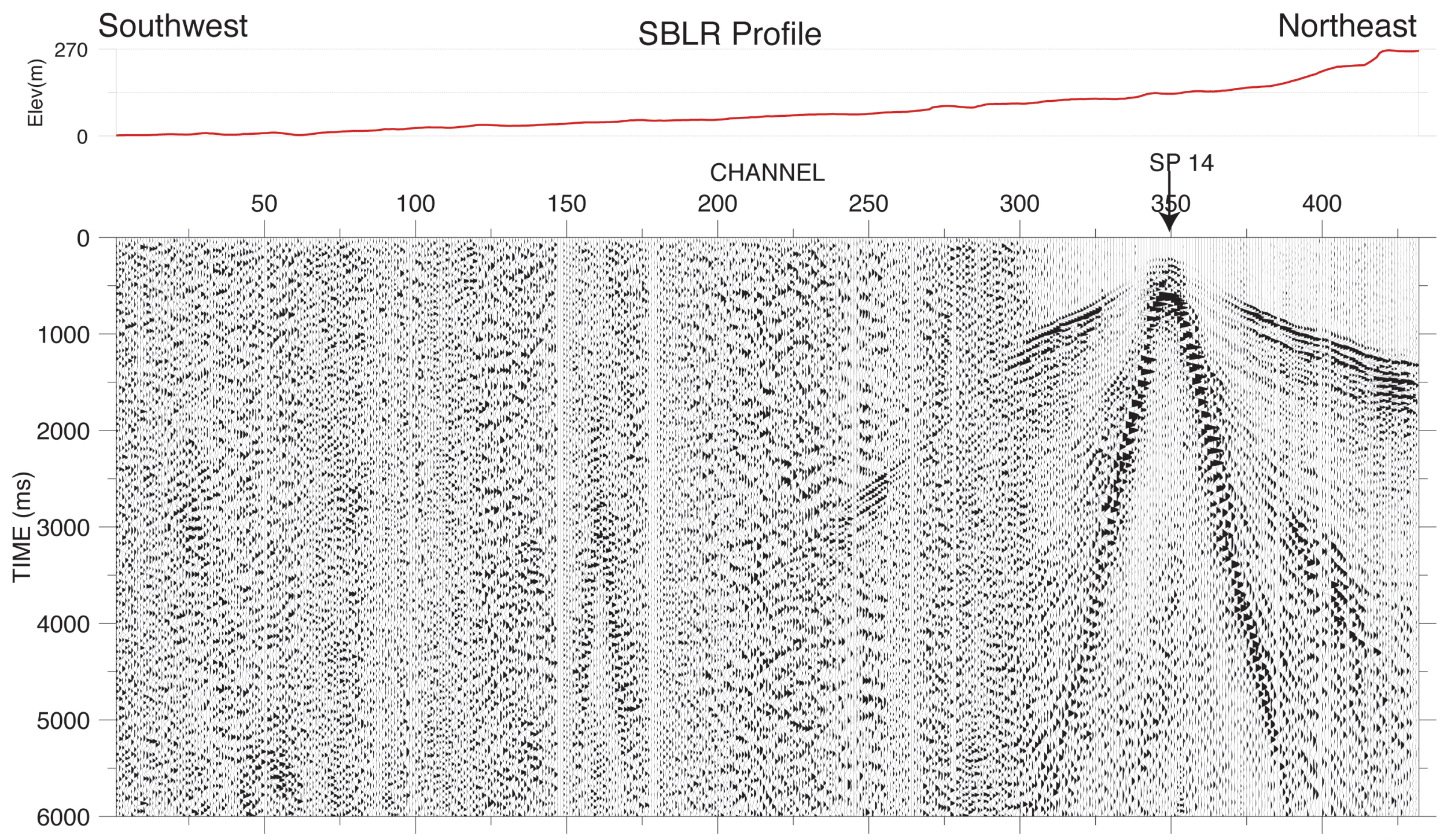

Fig 4n

$\operatorname{agc}=4000$, bandpass $=2-4-12-24 \mathrm{hz}$ 


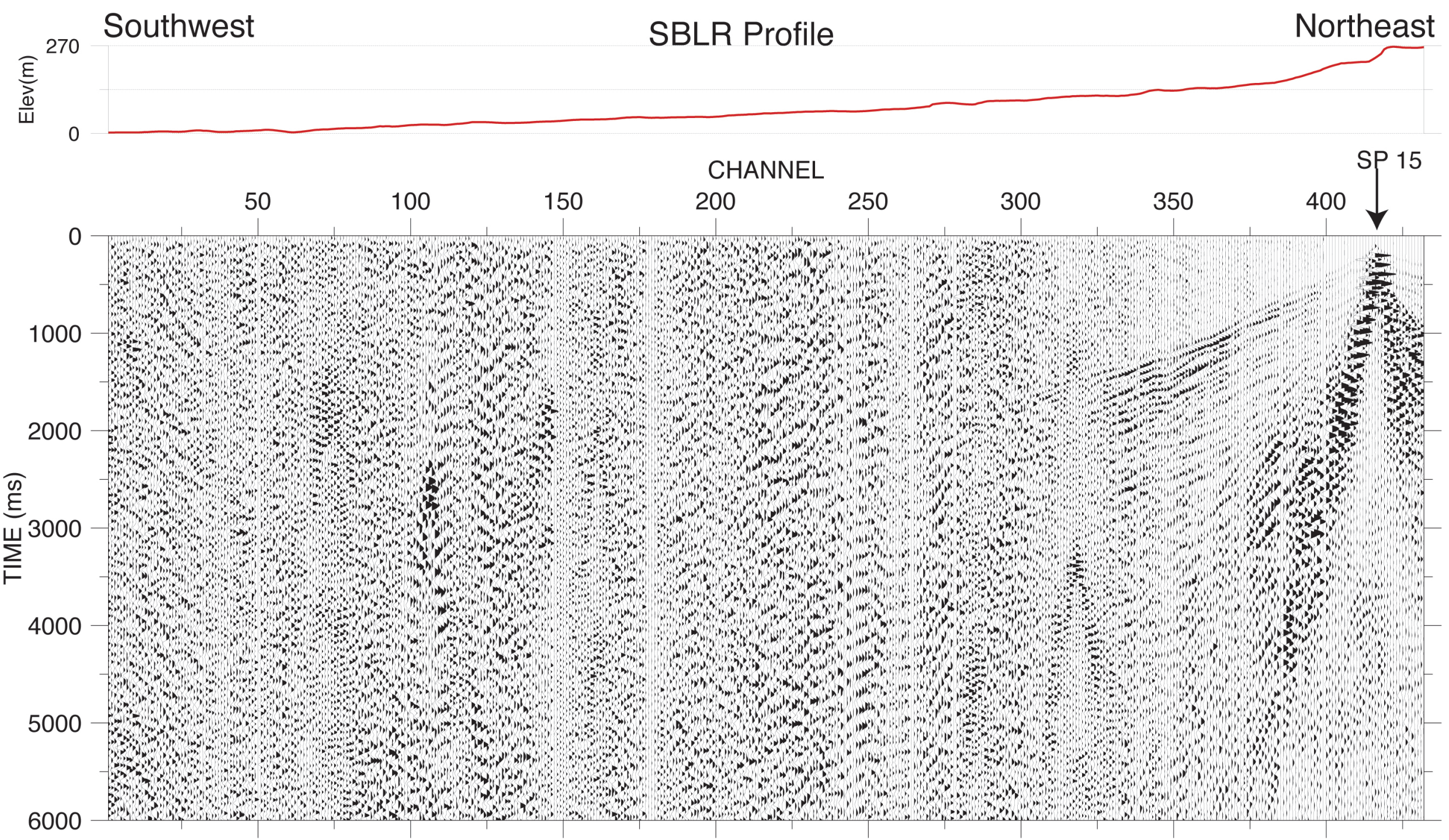

Fig 40

agc $=4000$, bandpass $=2-4-12-24 \mathrm{hz}$ 

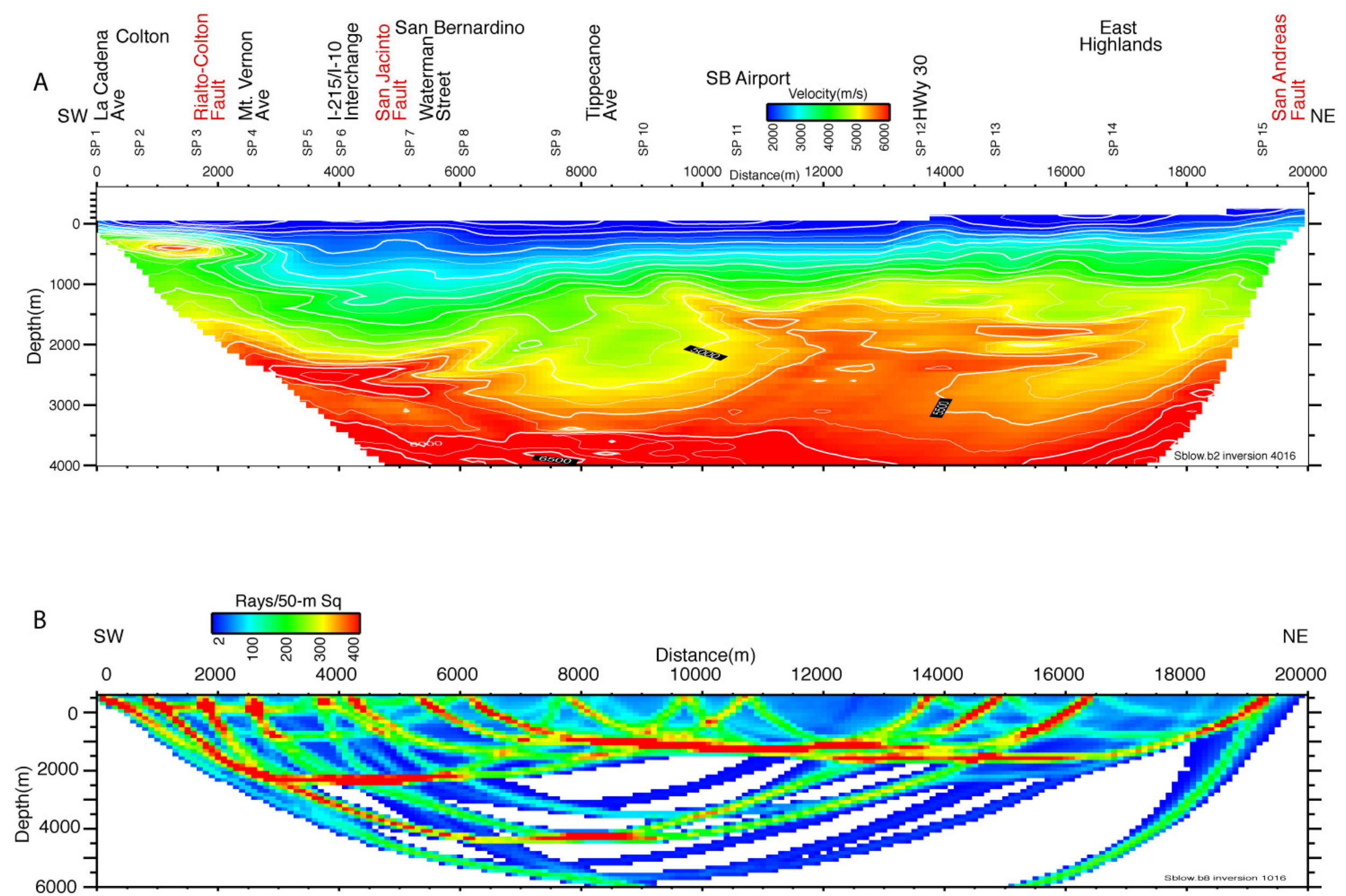

Fig. 5 


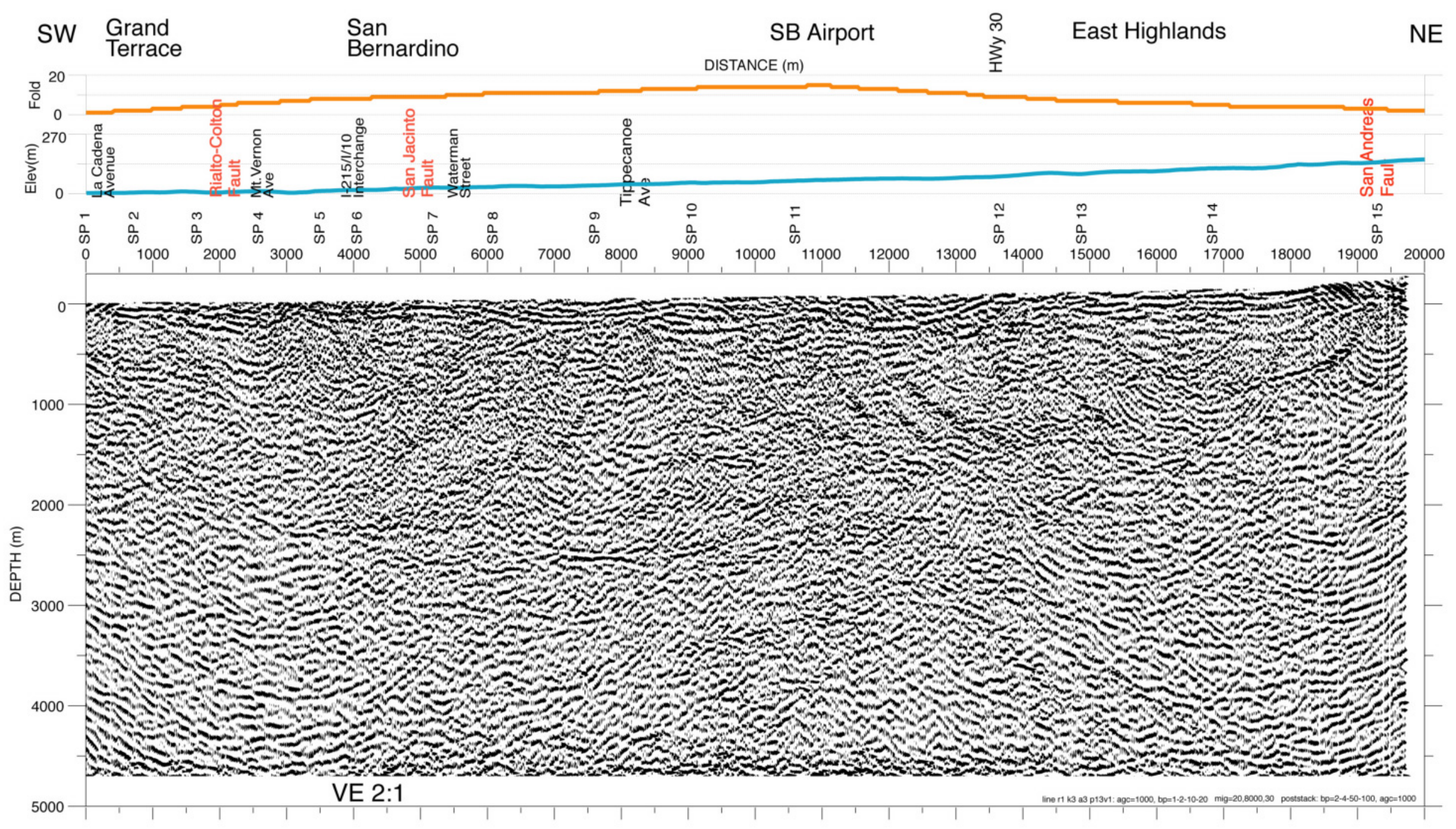

Fig.6 


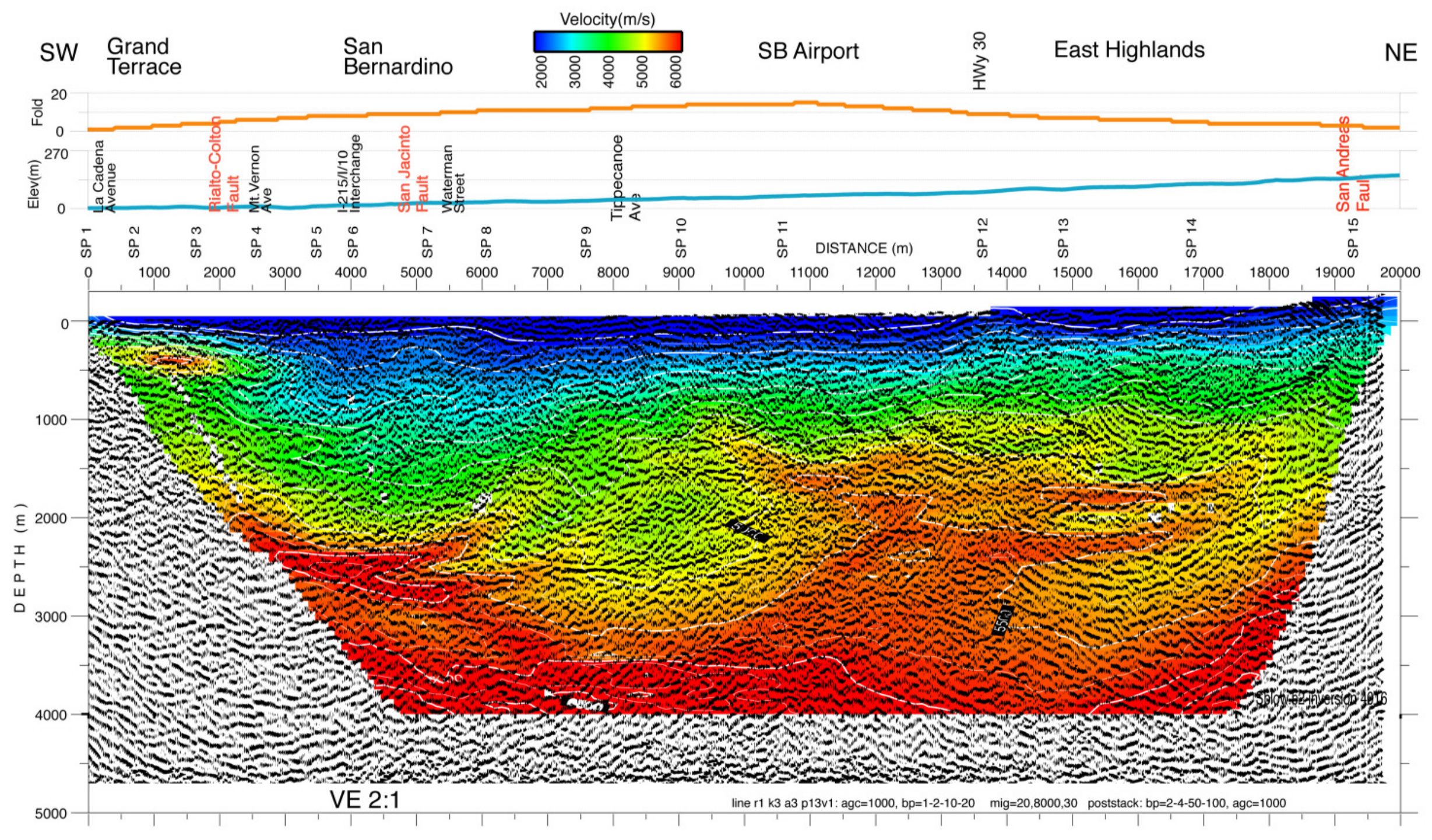

Fig. 7 


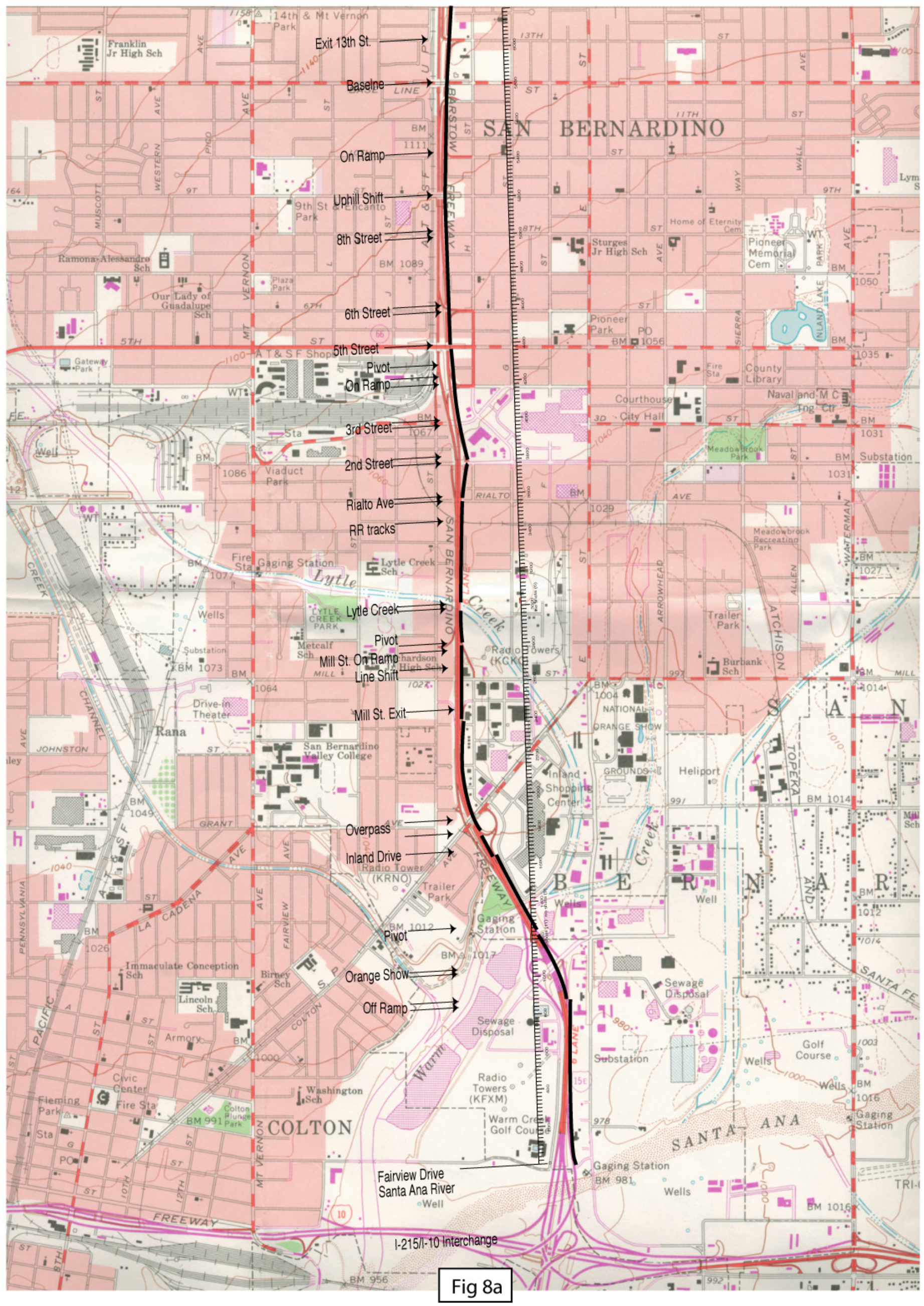




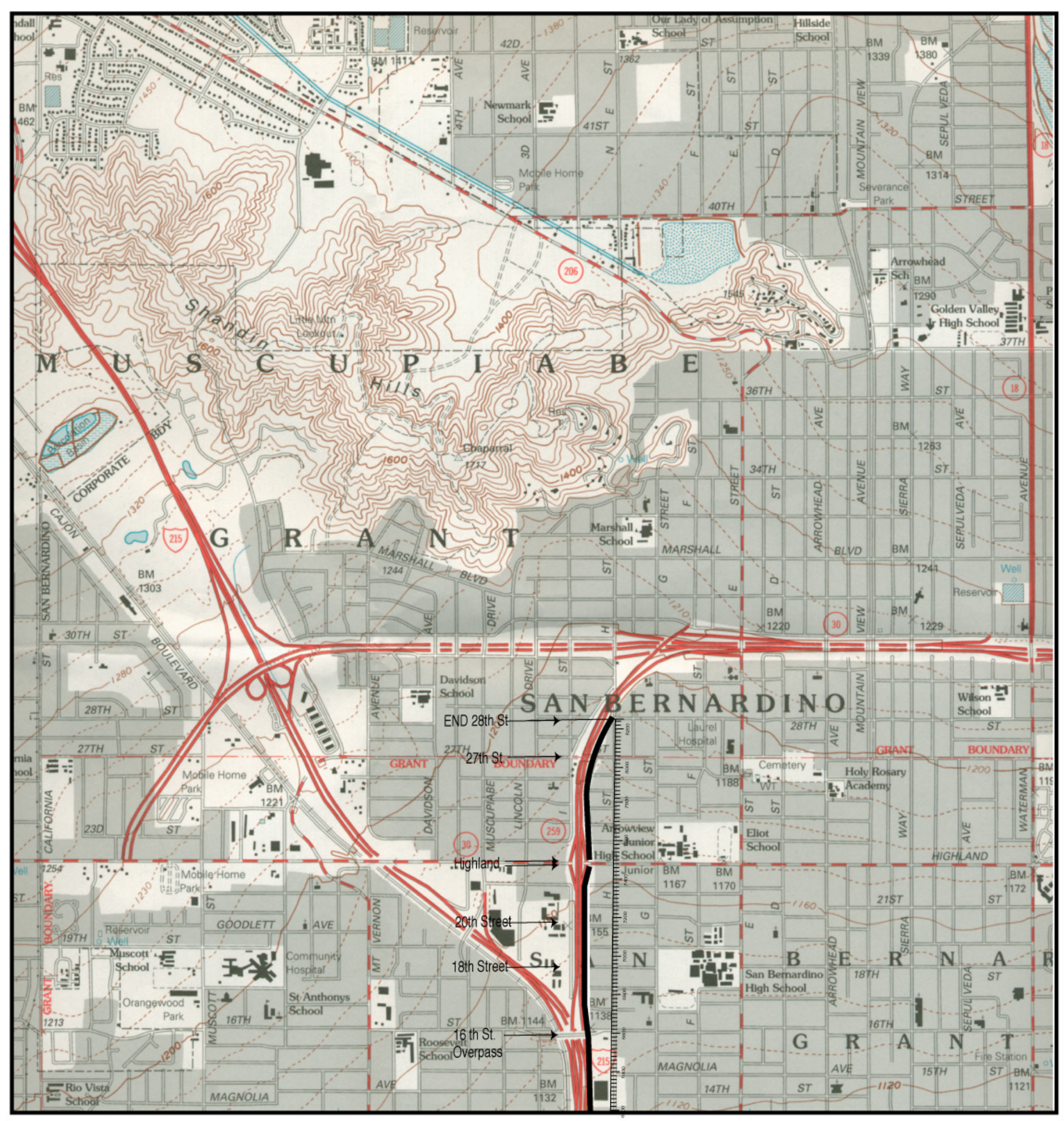

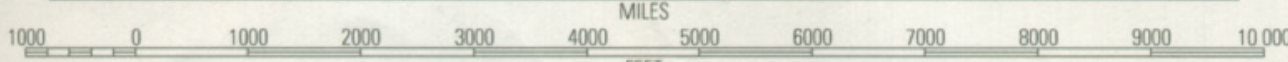

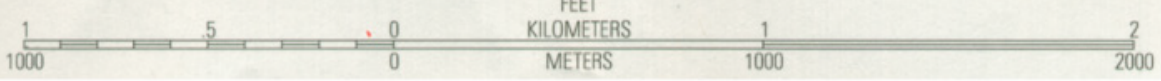

Fig $8 b$ 

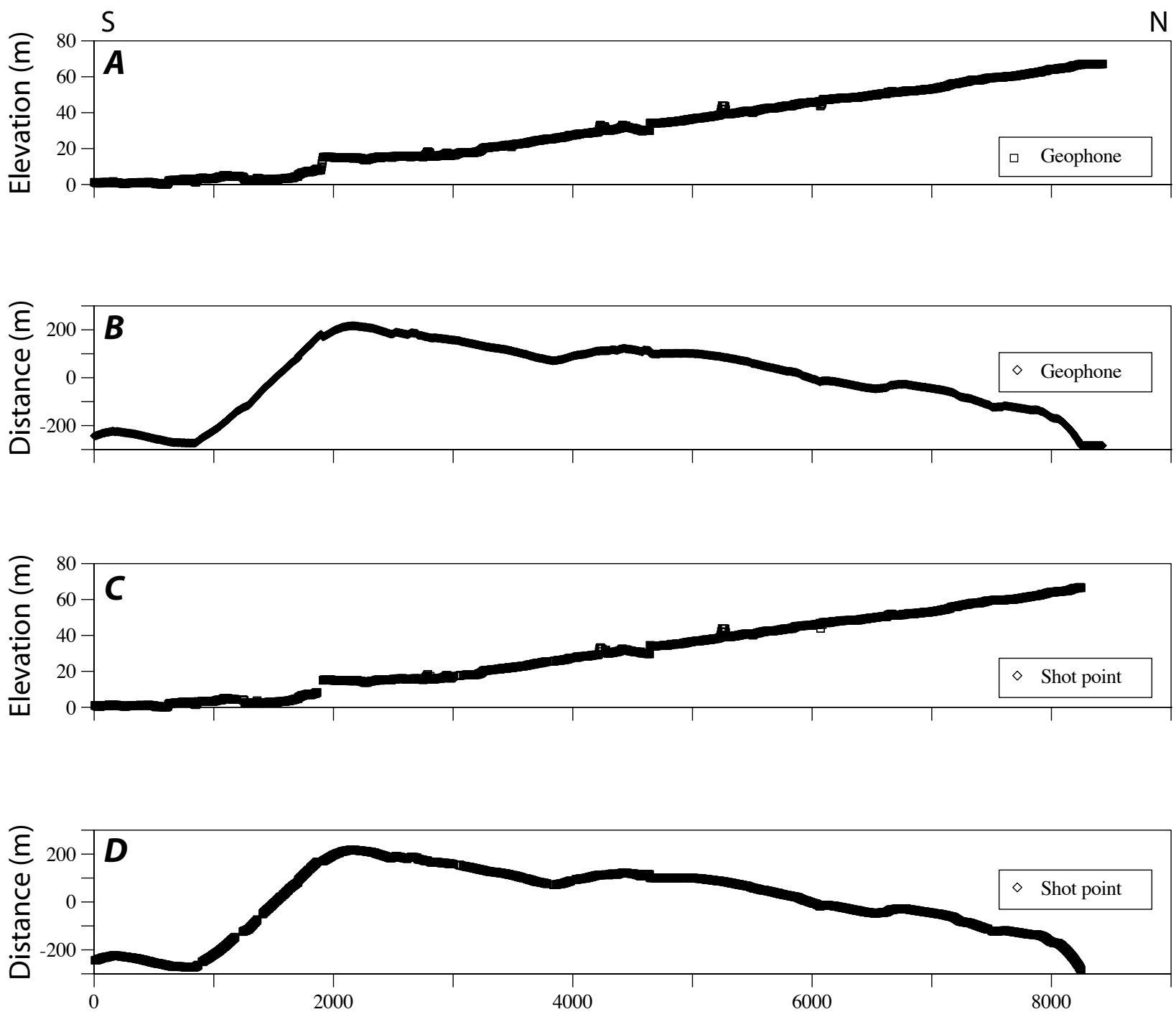

Distance (m)

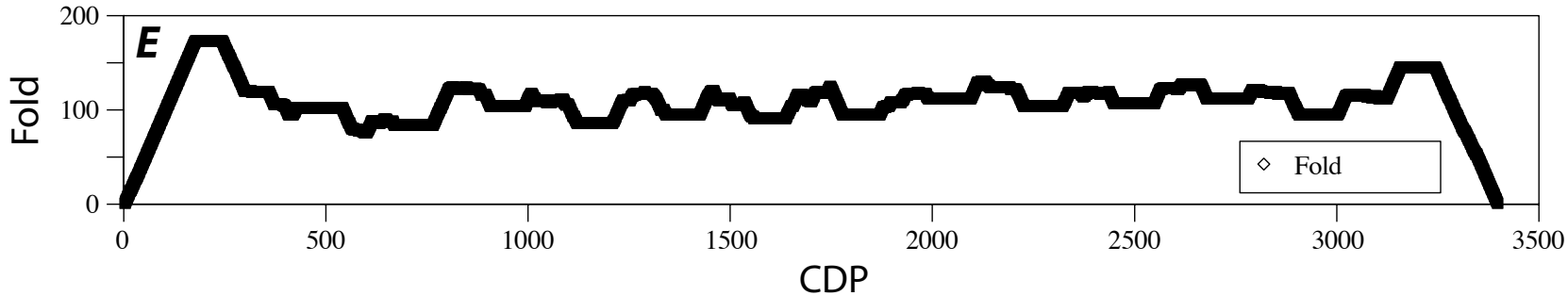

Fig. 9 


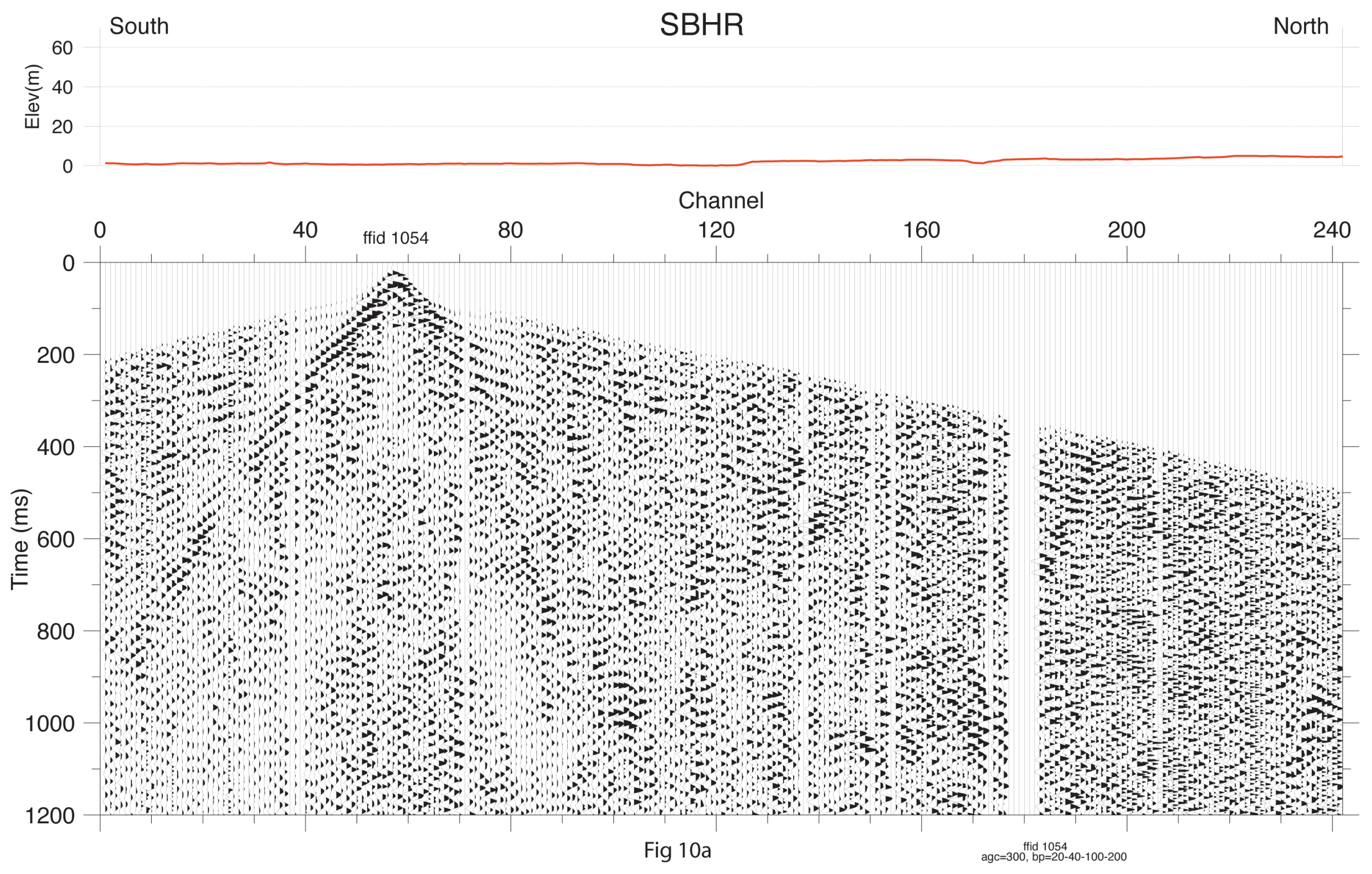


South

SBHR

North
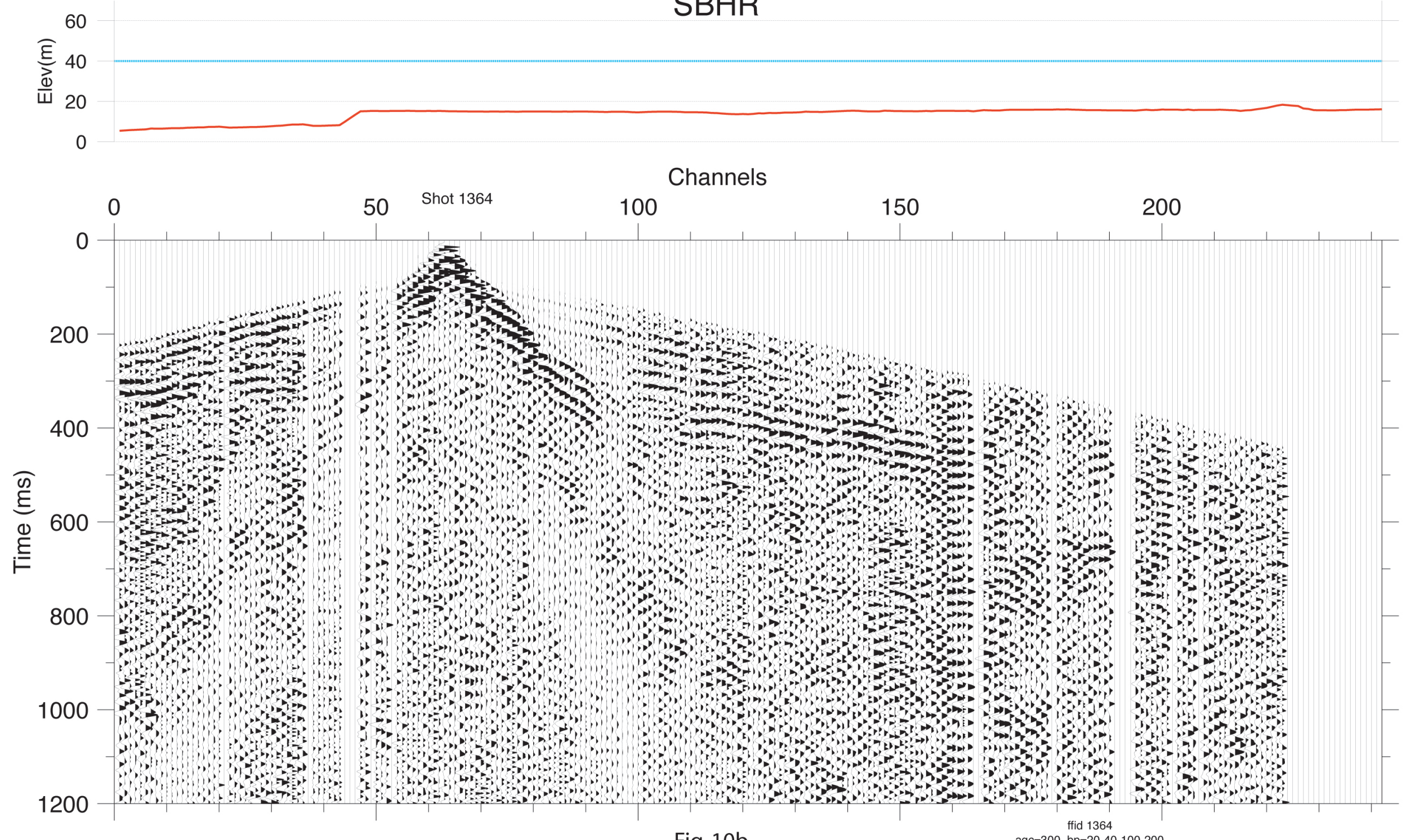

Fig. $10 \mathrm{~b}$

$\mathrm{agc}=300, \mathrm{bp}=20-40-100-200$ 


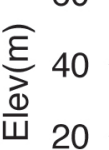

0

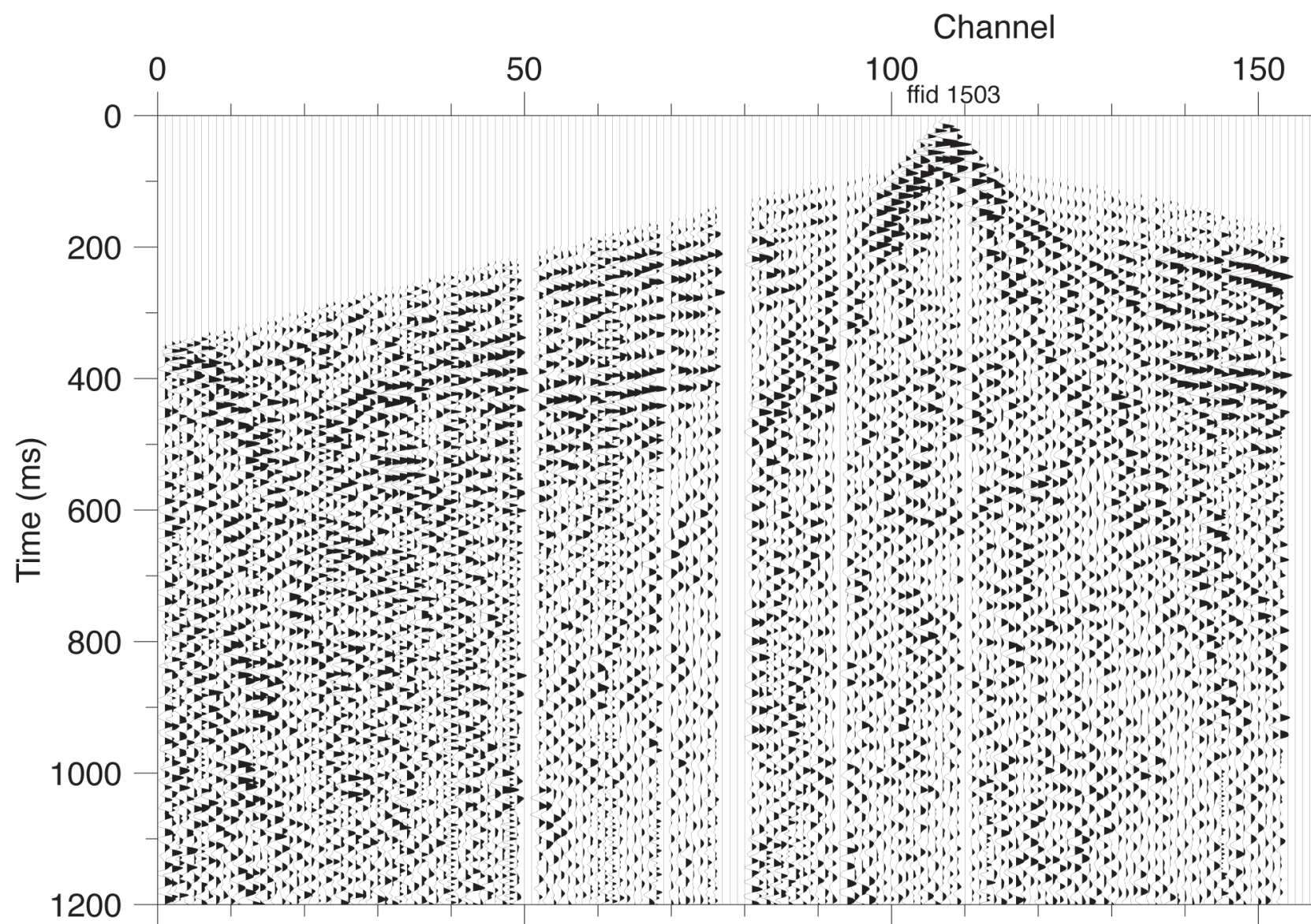

Fig $10 c$
200

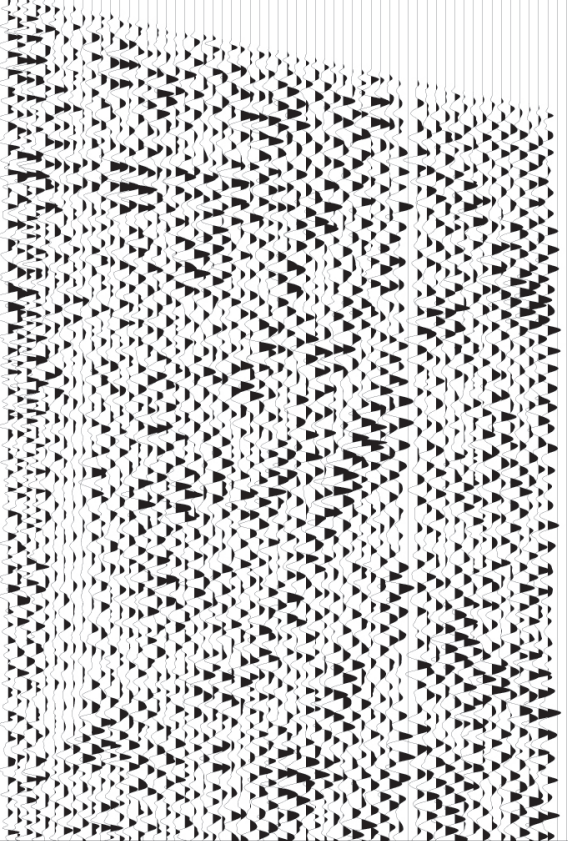

agc $=300$, ffid $1503=20-40-100-200$ 


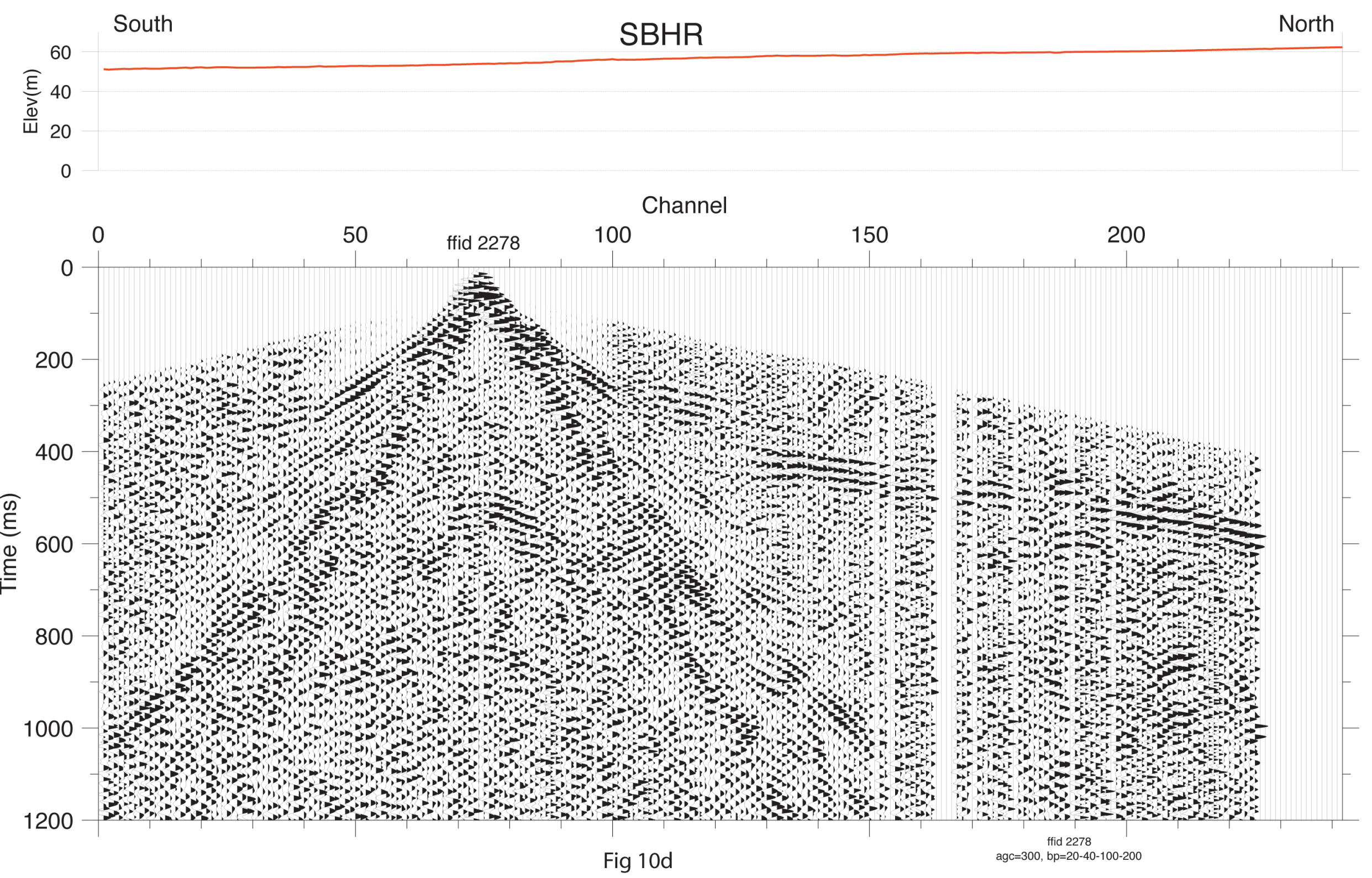




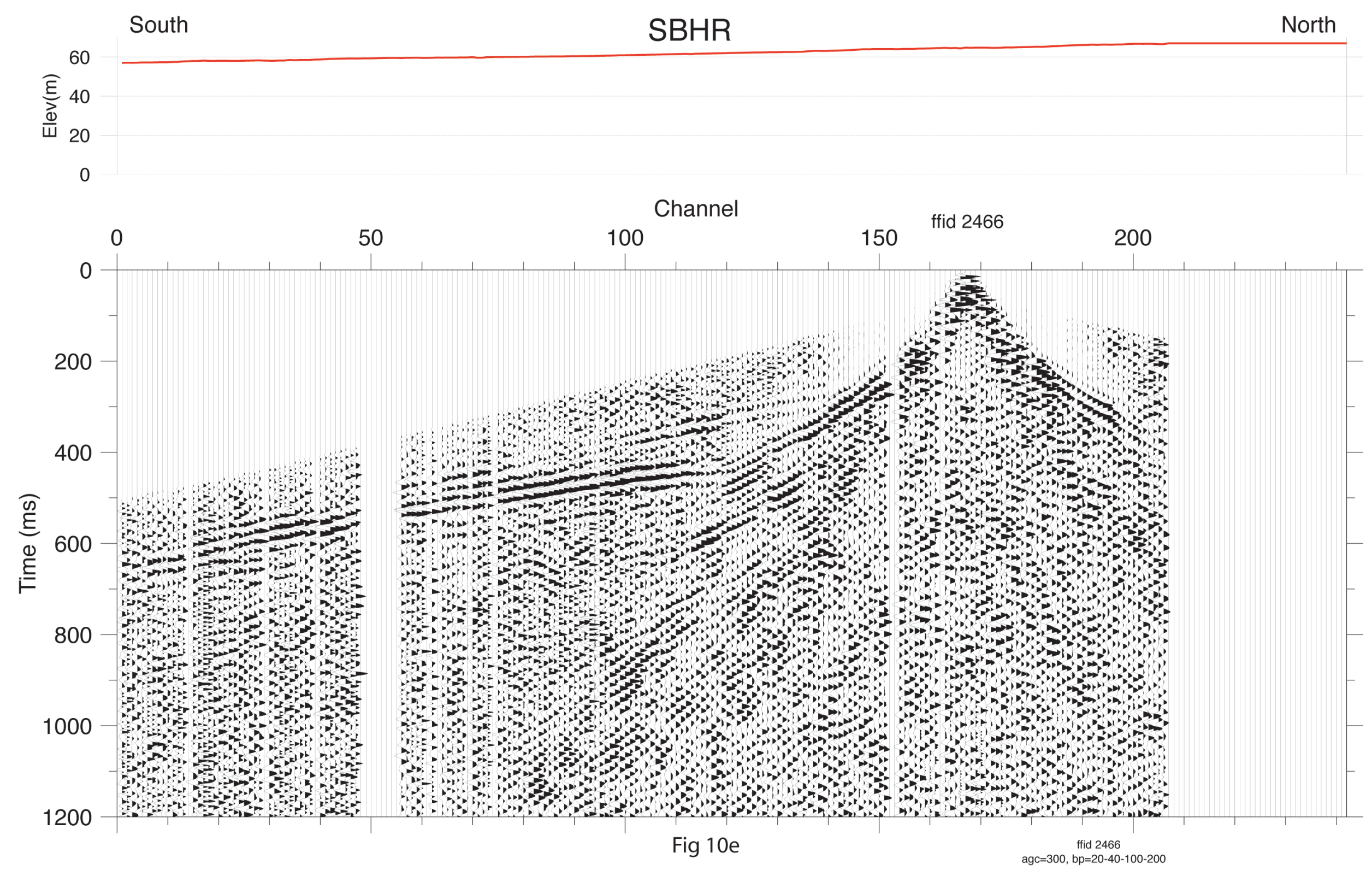



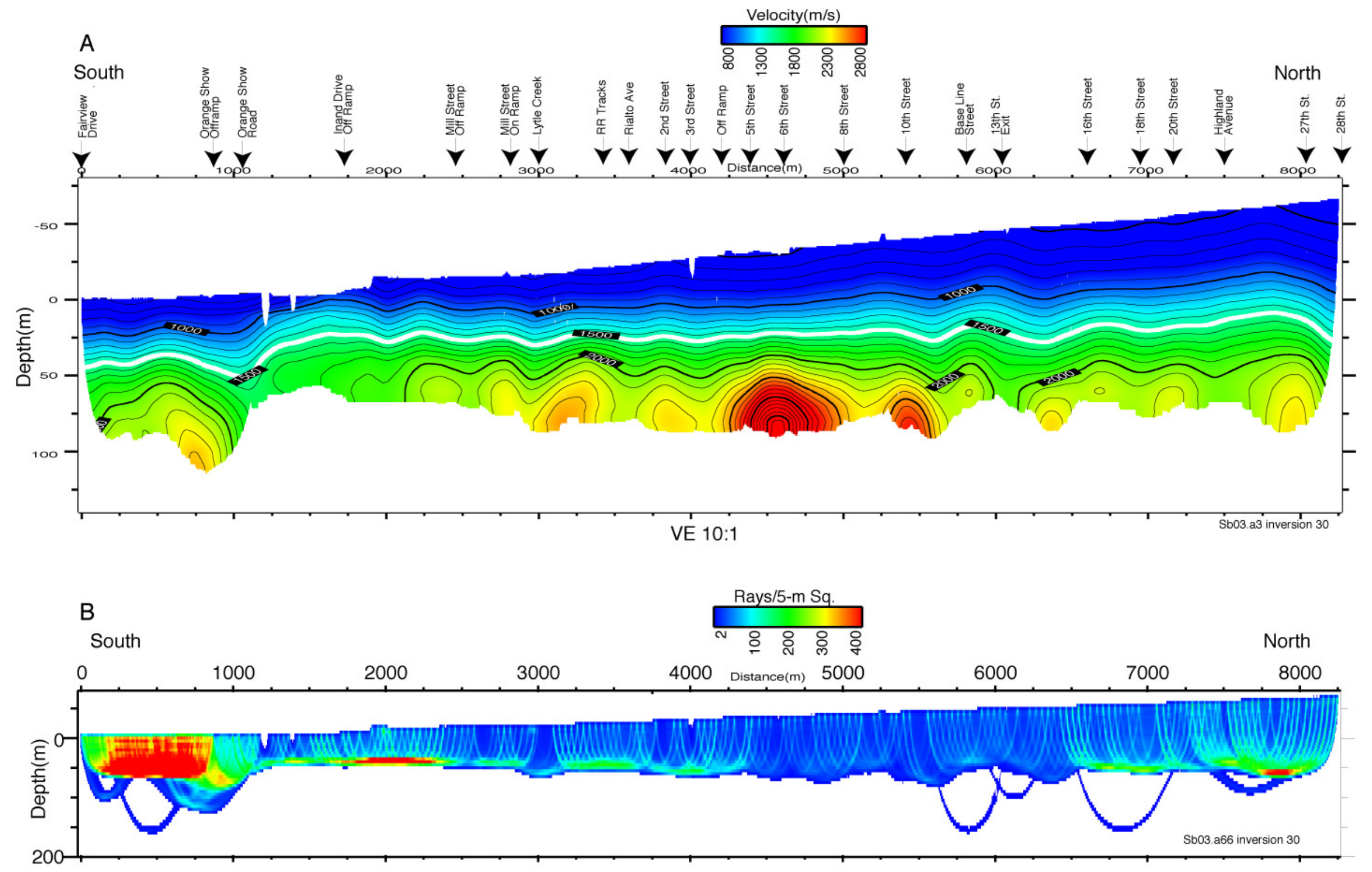

Fig. 11 


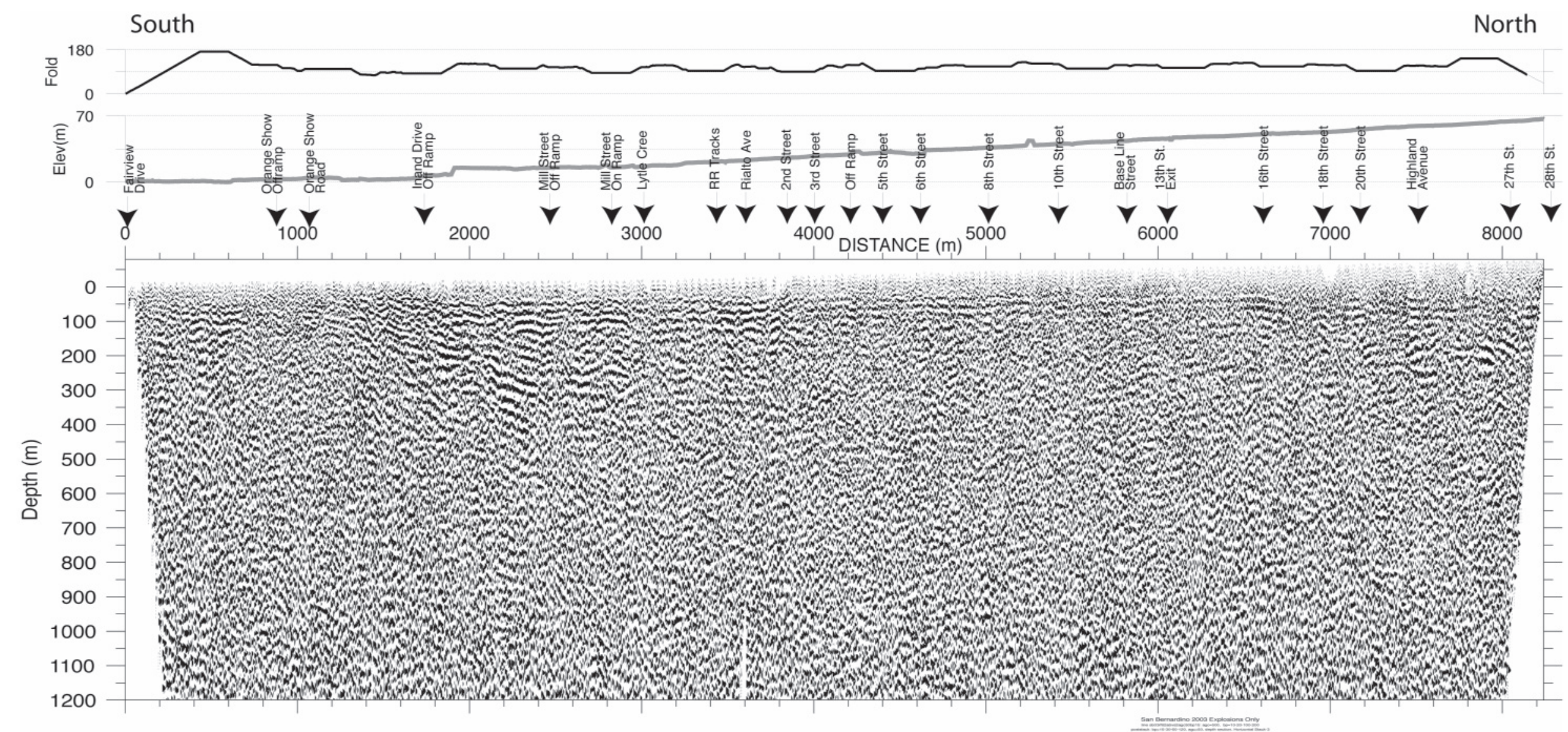

Fig. $12 a$ 

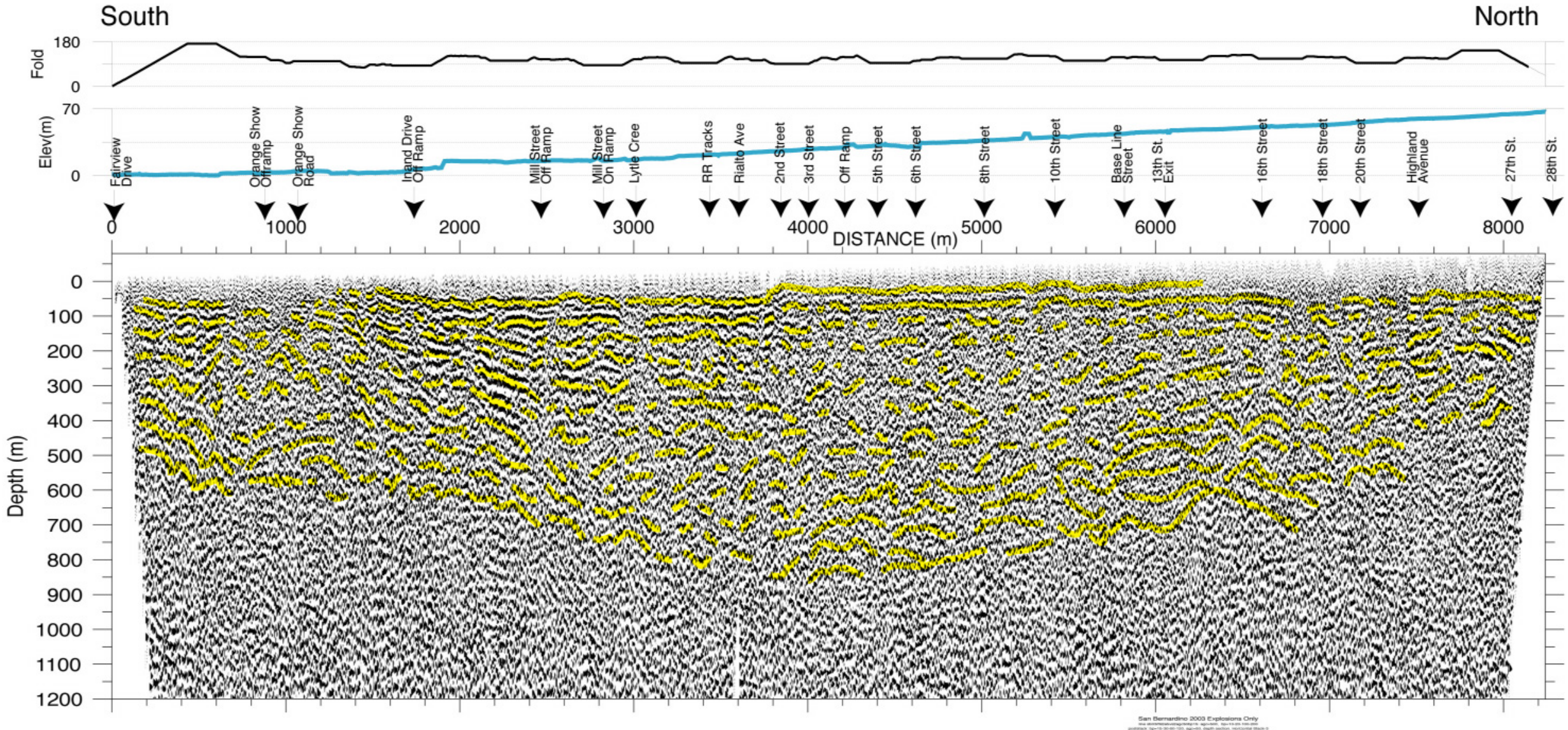

Fig. 12b 



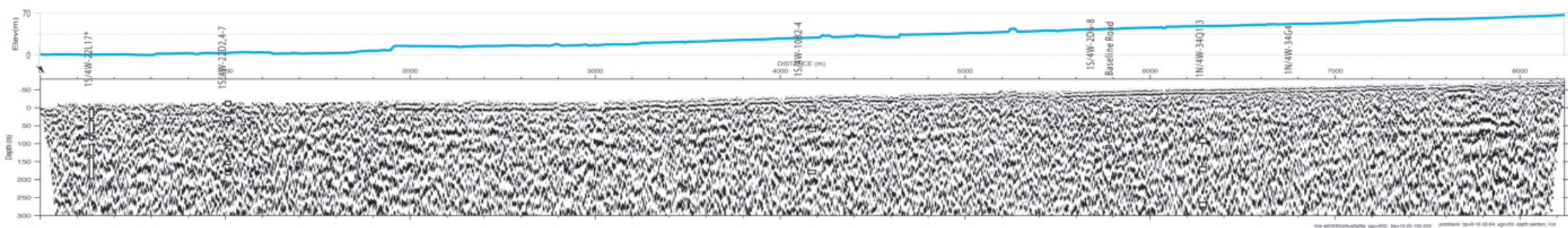

B

50 .

0 a

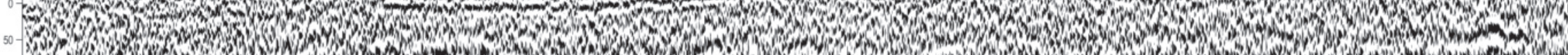

$\hat{E}_{100}$.

W

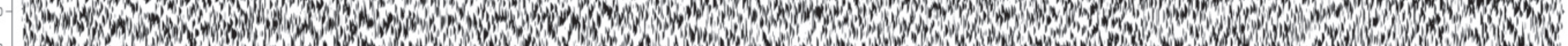

Co

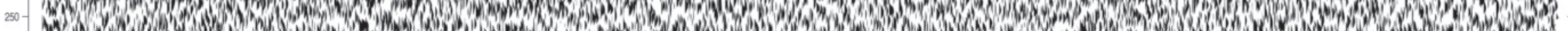

${ }_{300}$.

Fig. 12d 


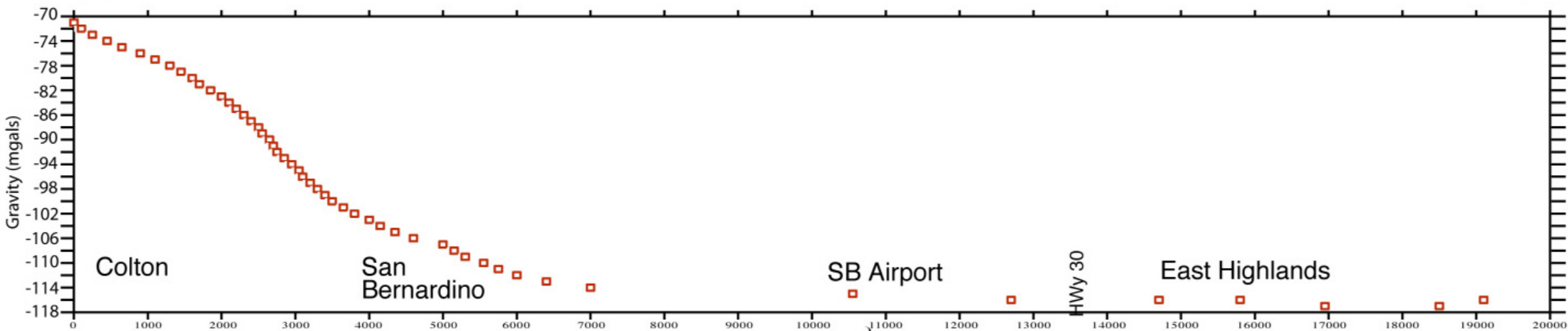

운

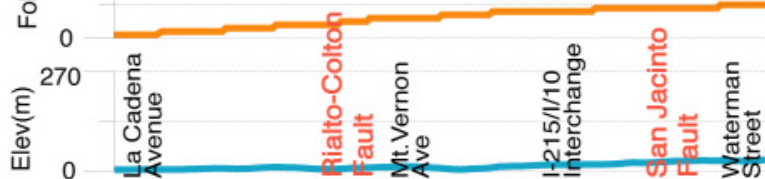

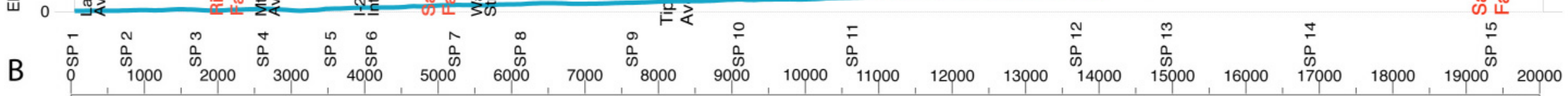

0

3

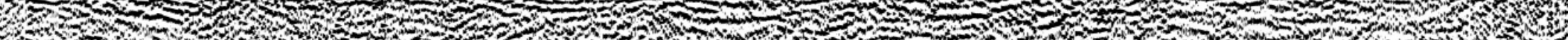

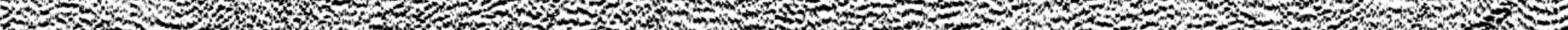

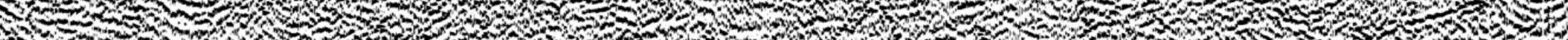

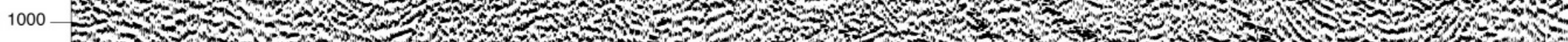

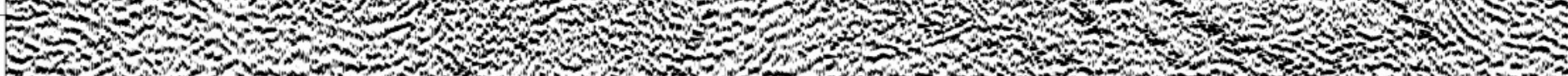

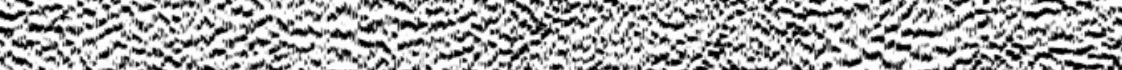

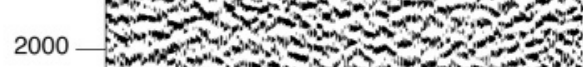

点
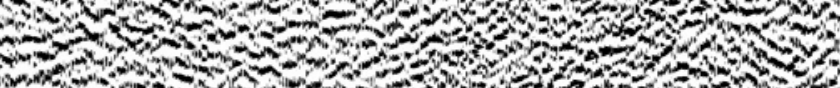

\section{$2 x+2=0$}

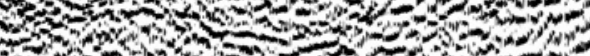

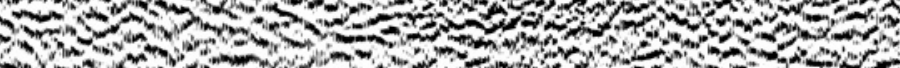

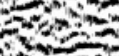

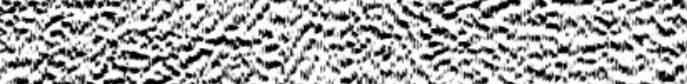

$2+20$

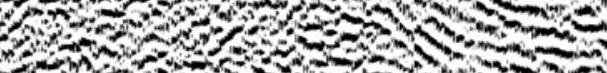

$+2$

- 02020

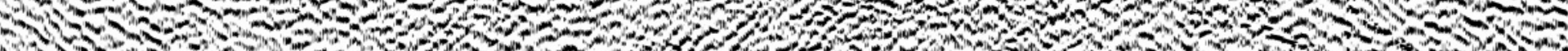

4000

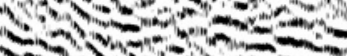

(1)

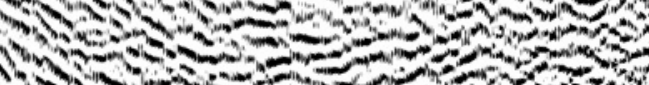

$x+2=0$ 


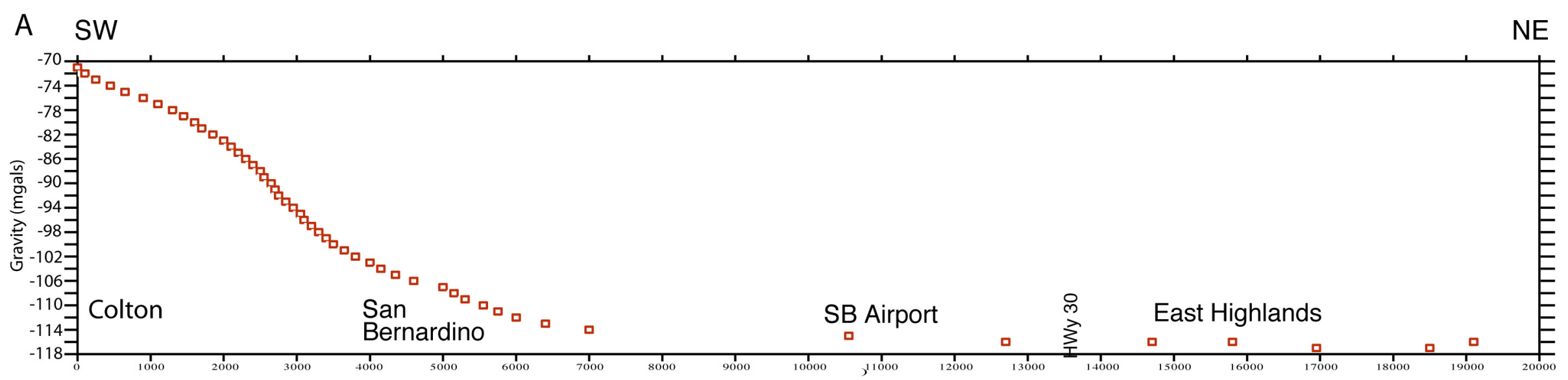

훈 $^{20}$
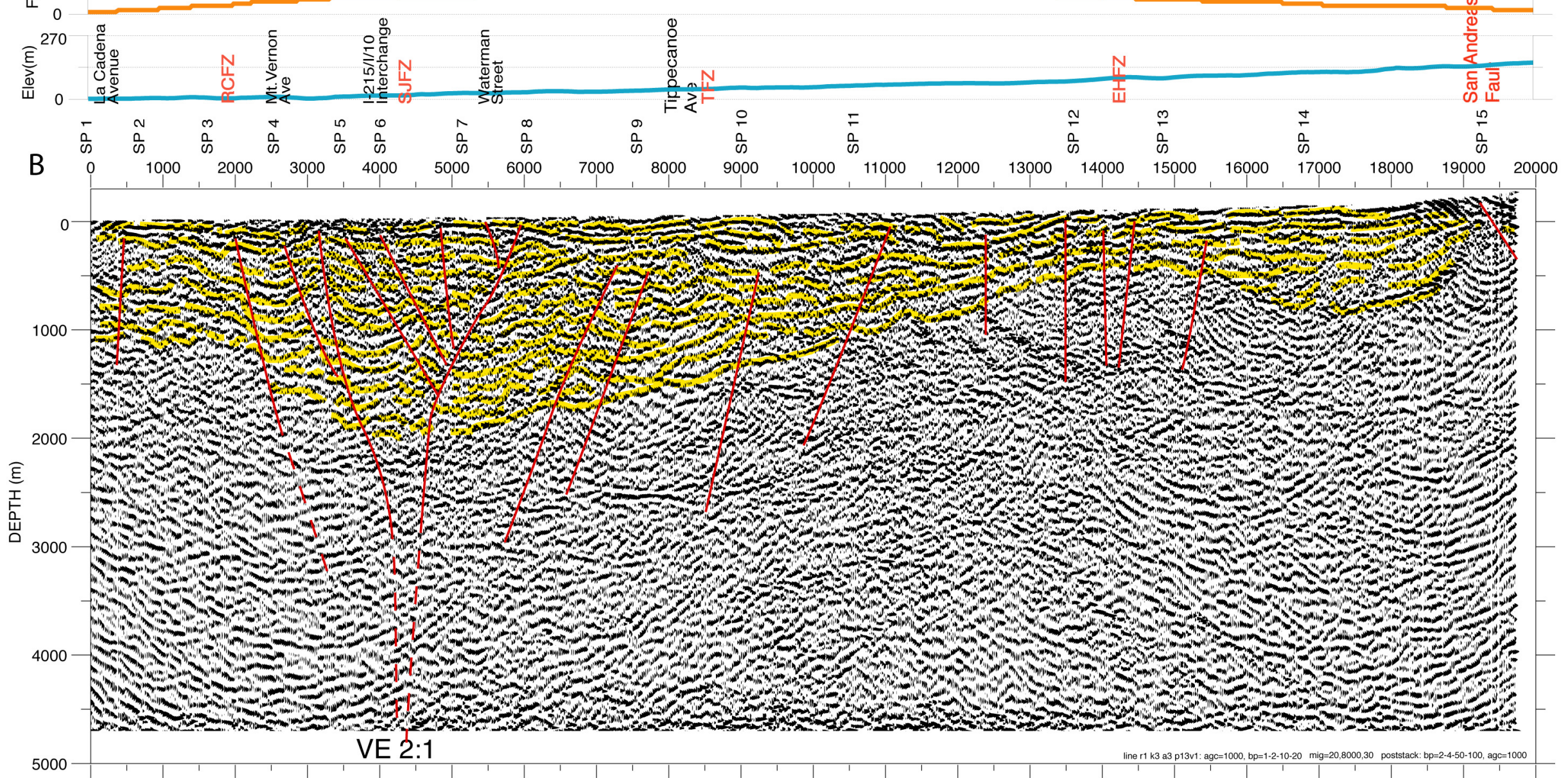

Fig.14 


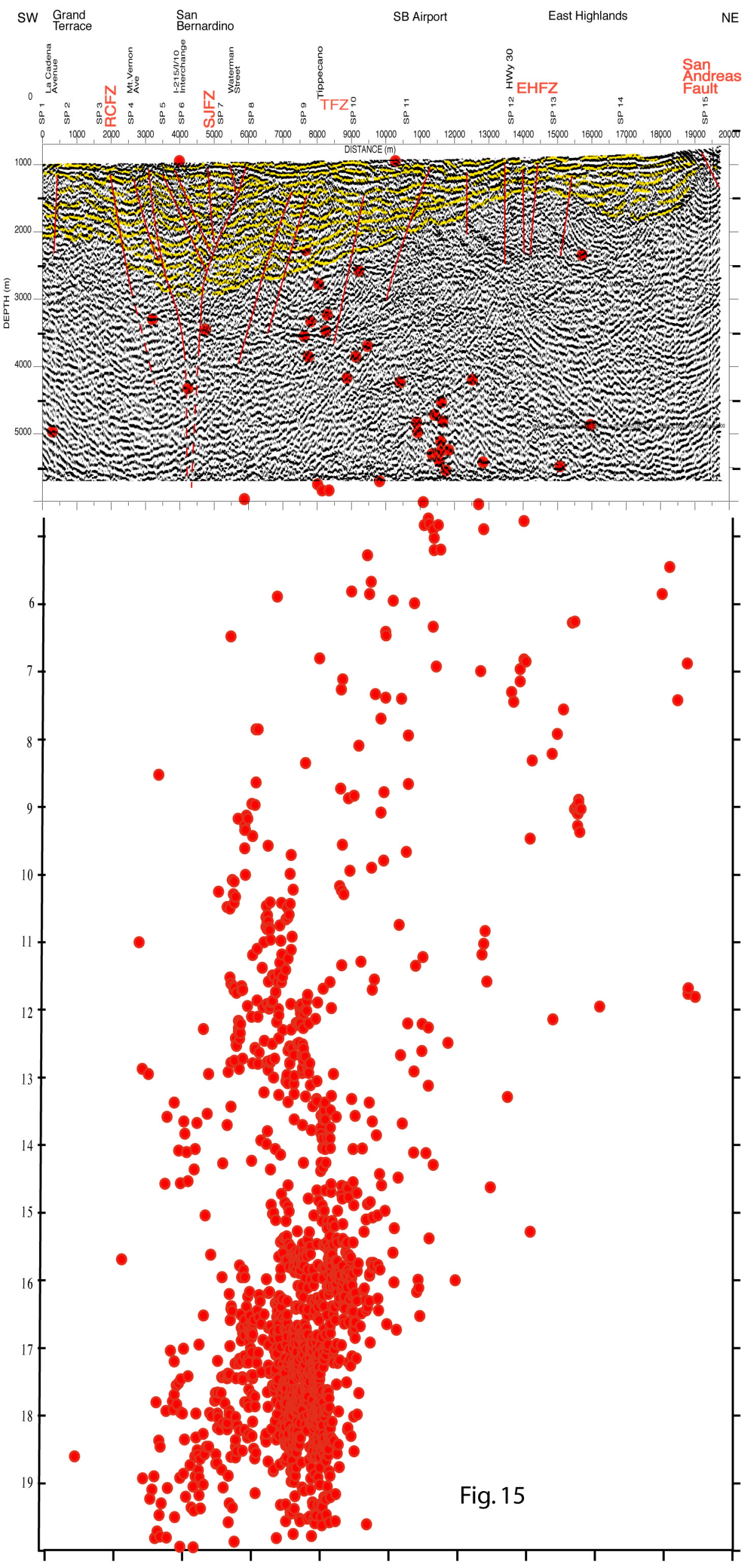




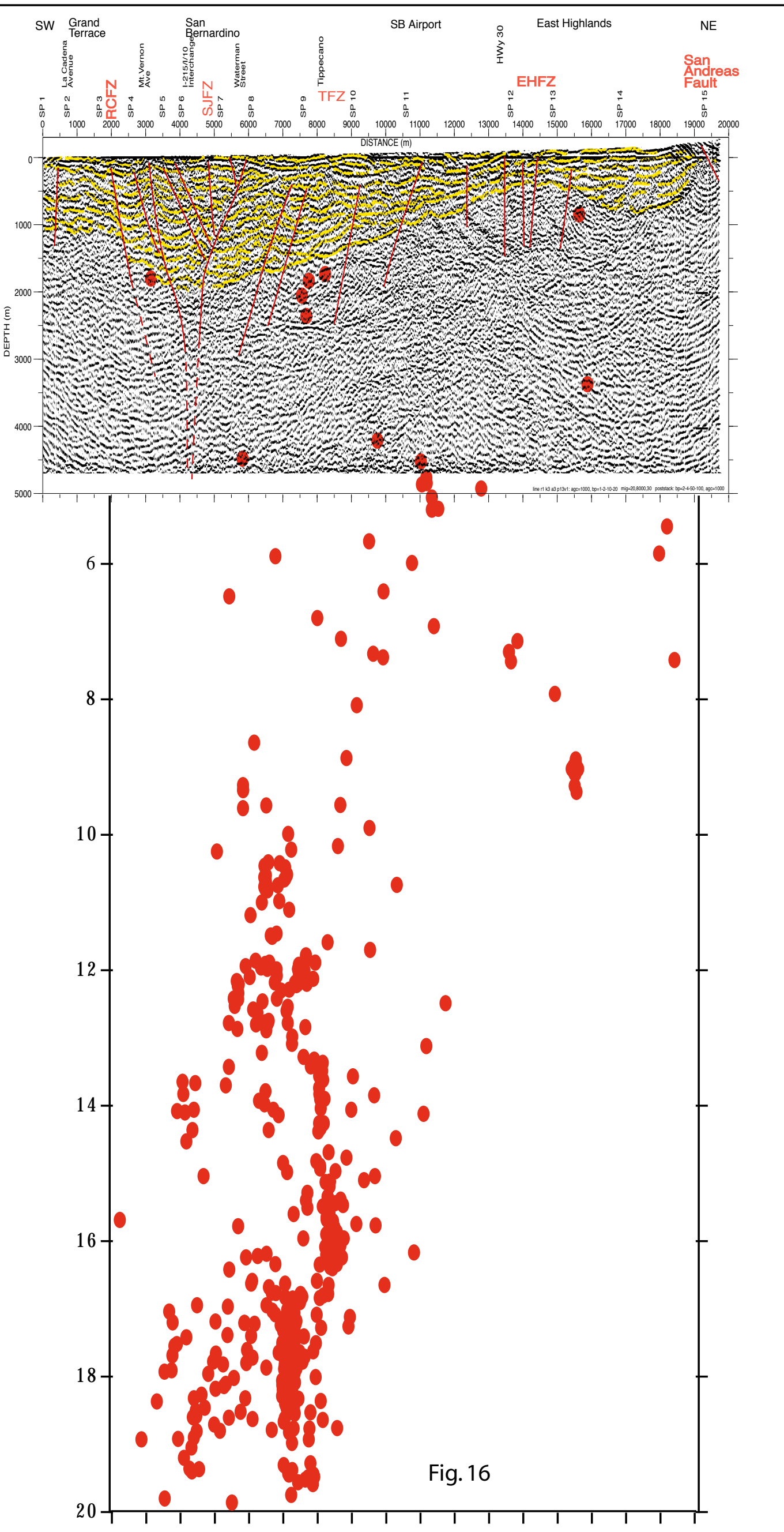




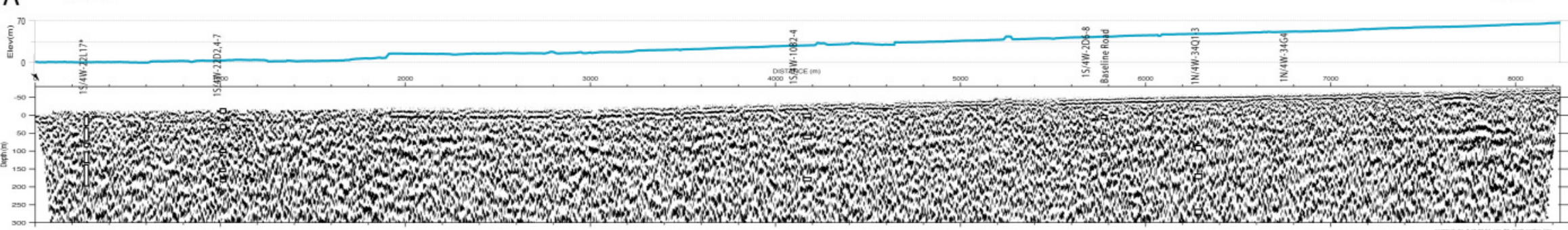

B

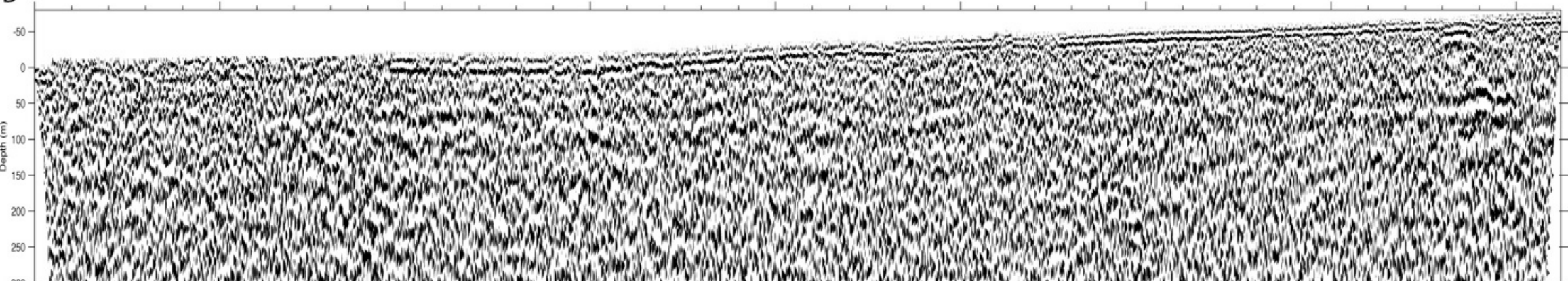

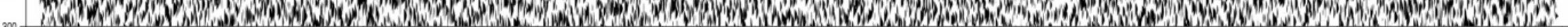

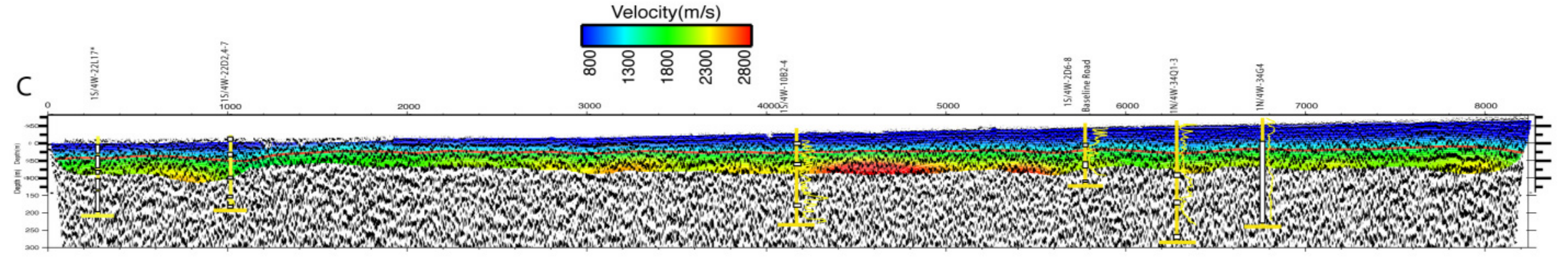

D

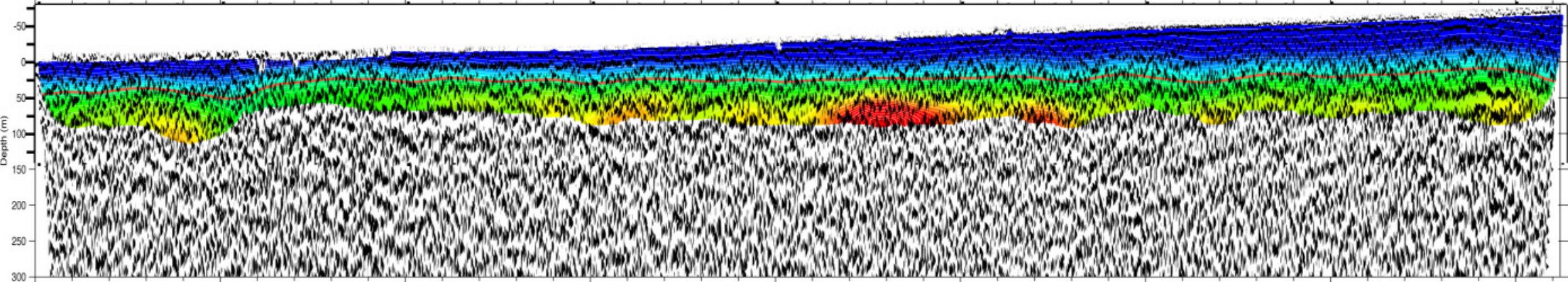

Fig. 17 


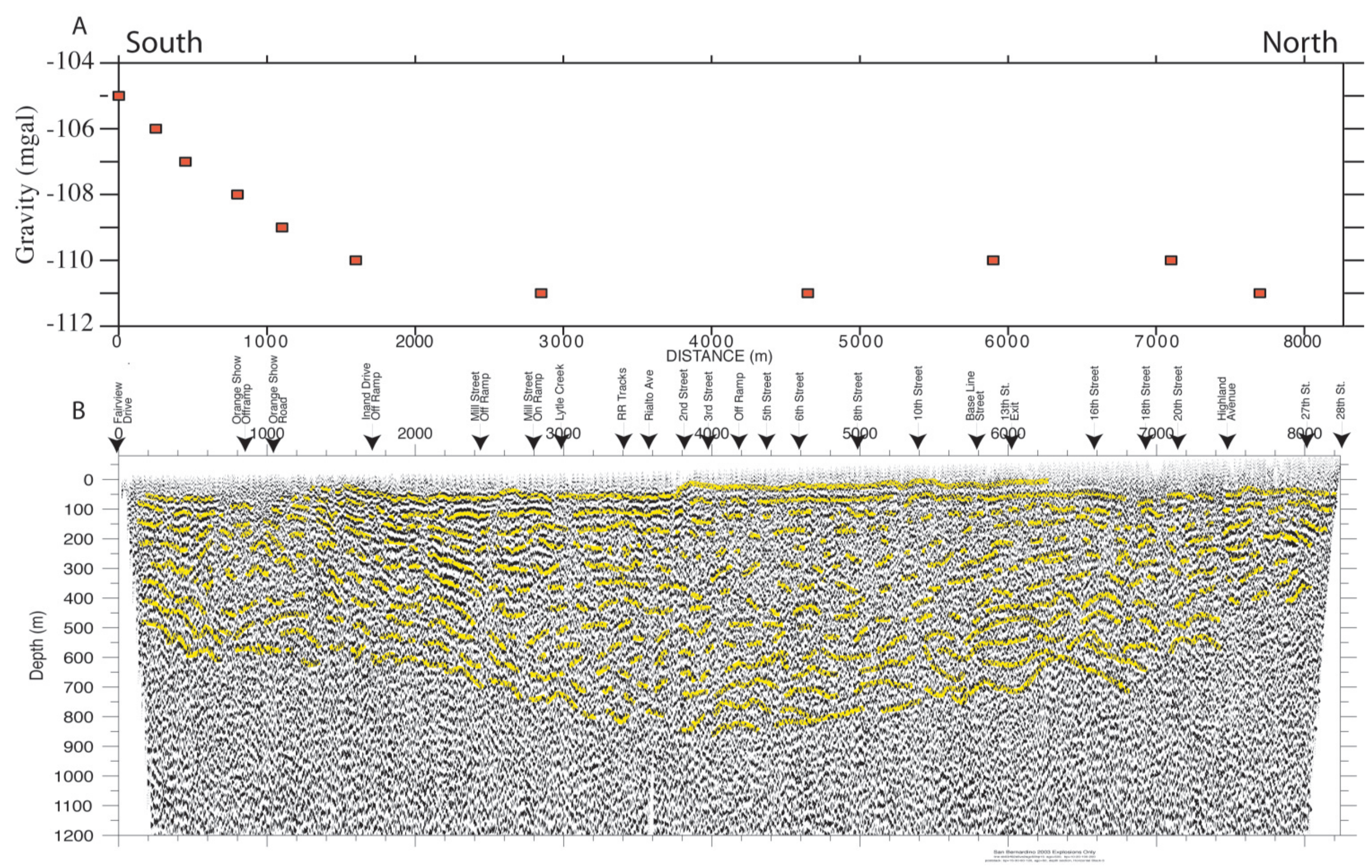

Fig. 18 


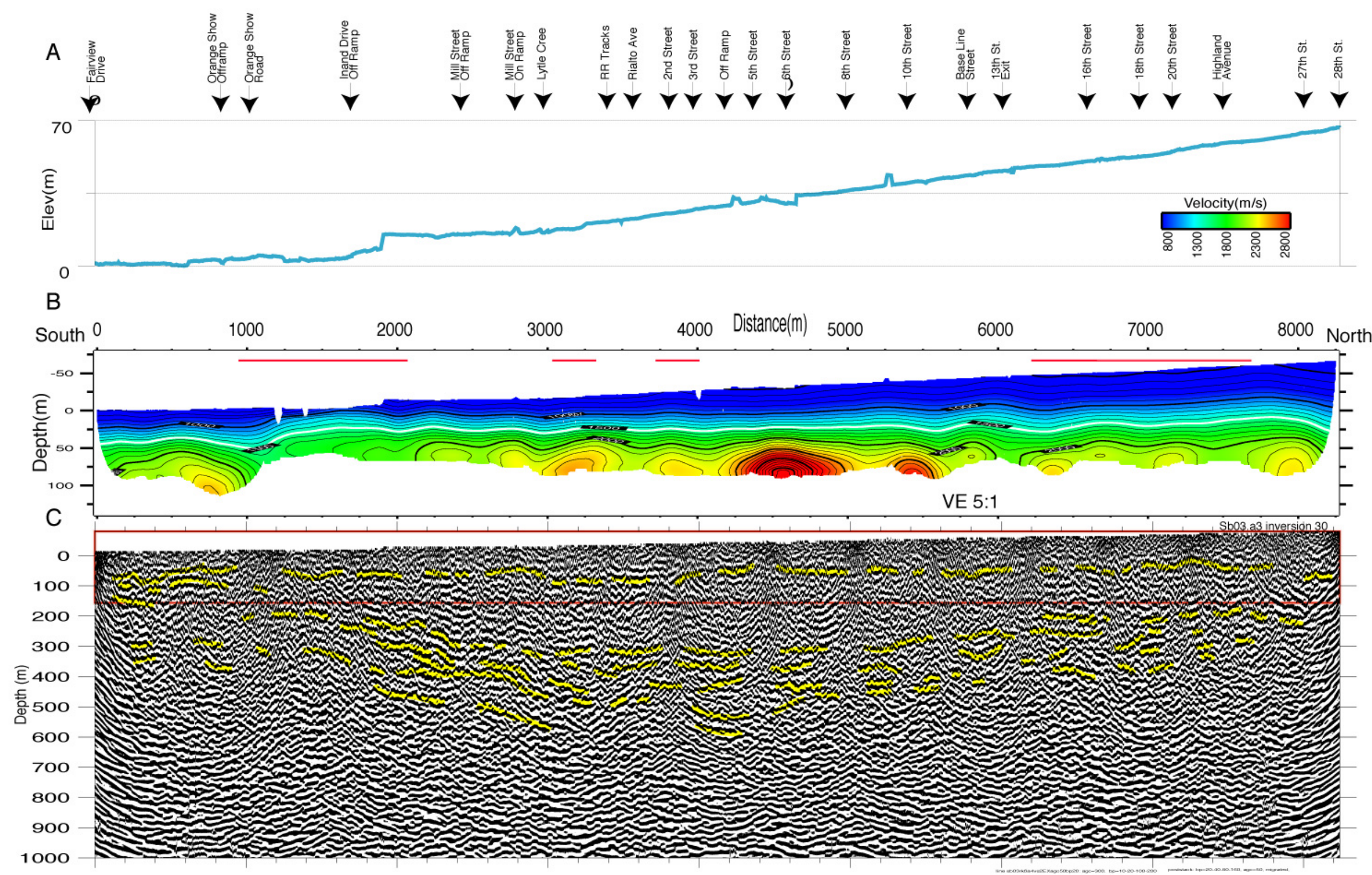

Fig. 19 

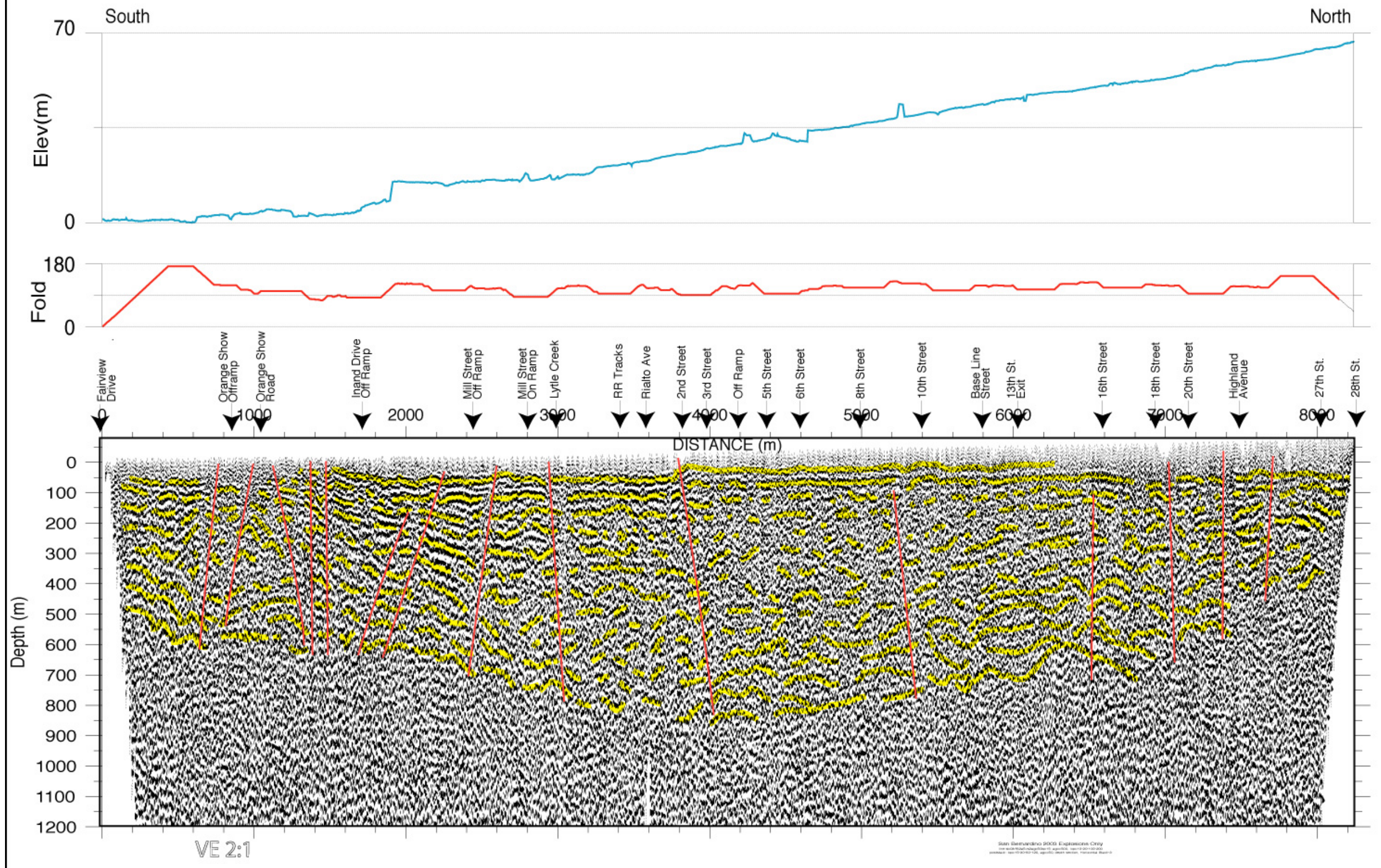

Fig. 20 
A South

North

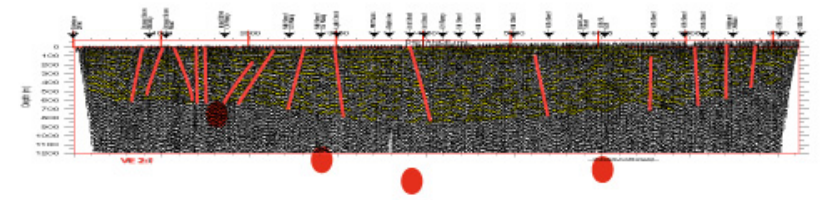

$$
3-0
$$

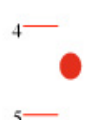<smiles>[CH][CH]</smiles>

6

$$
7 \text { - }
$$

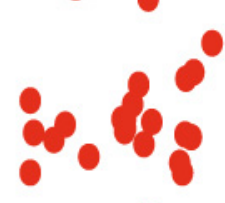

- 08

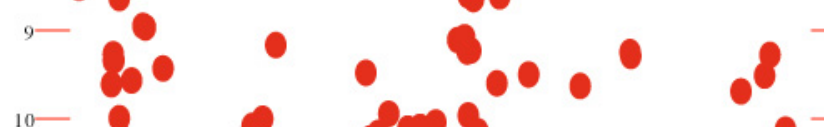

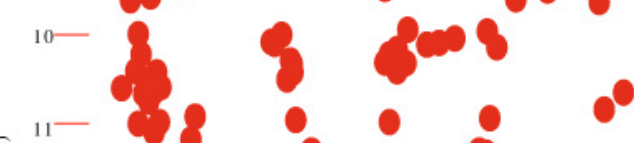

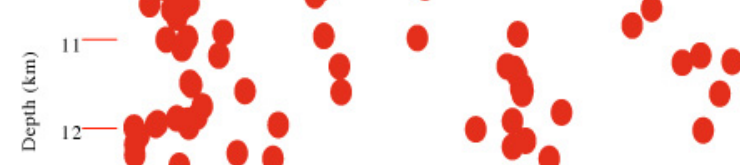

$\overbrace{13-20}^{2}$

${ }_{14-}^{0}+0_{0}^{0}$

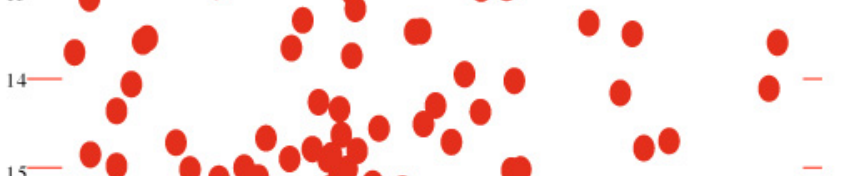

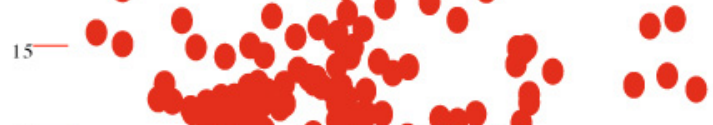

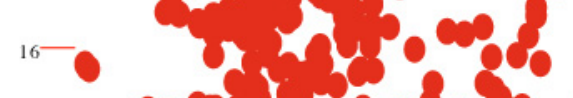

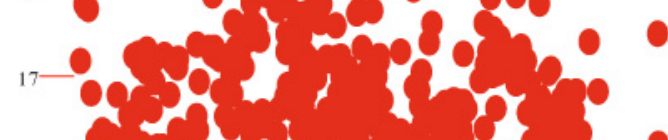

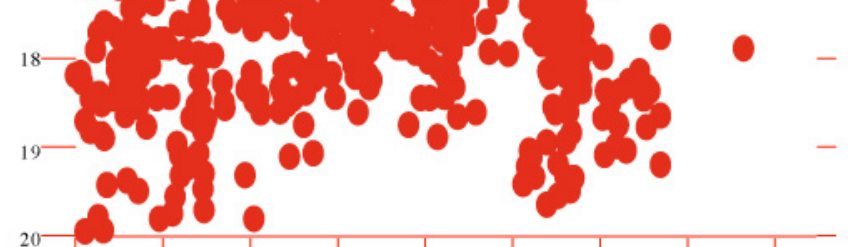

B South

North
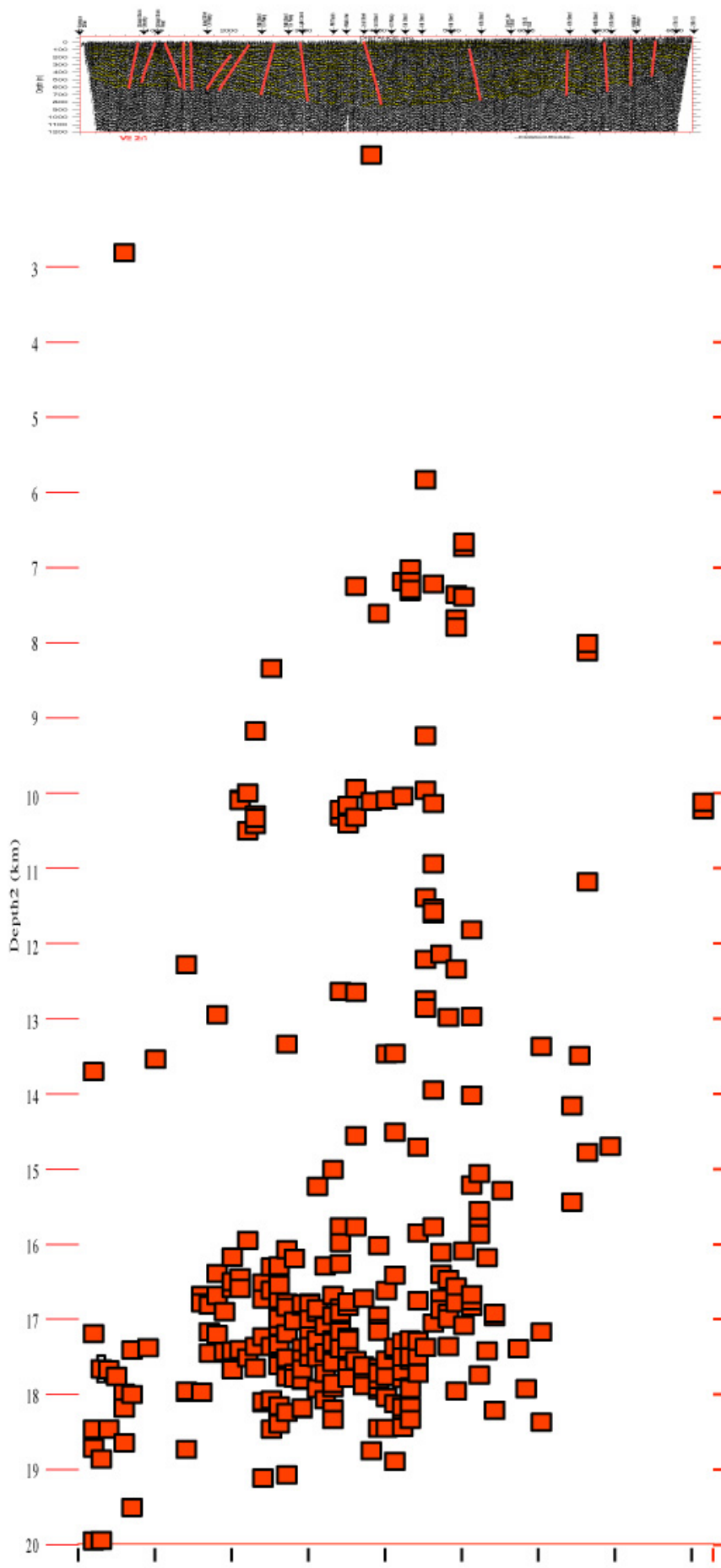

Fig. 21 
A

La
Cadena St.

SW

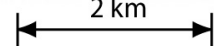

B

1000

Grand Terrace

San' Bernardino

SB Airport 을

East Highlands.

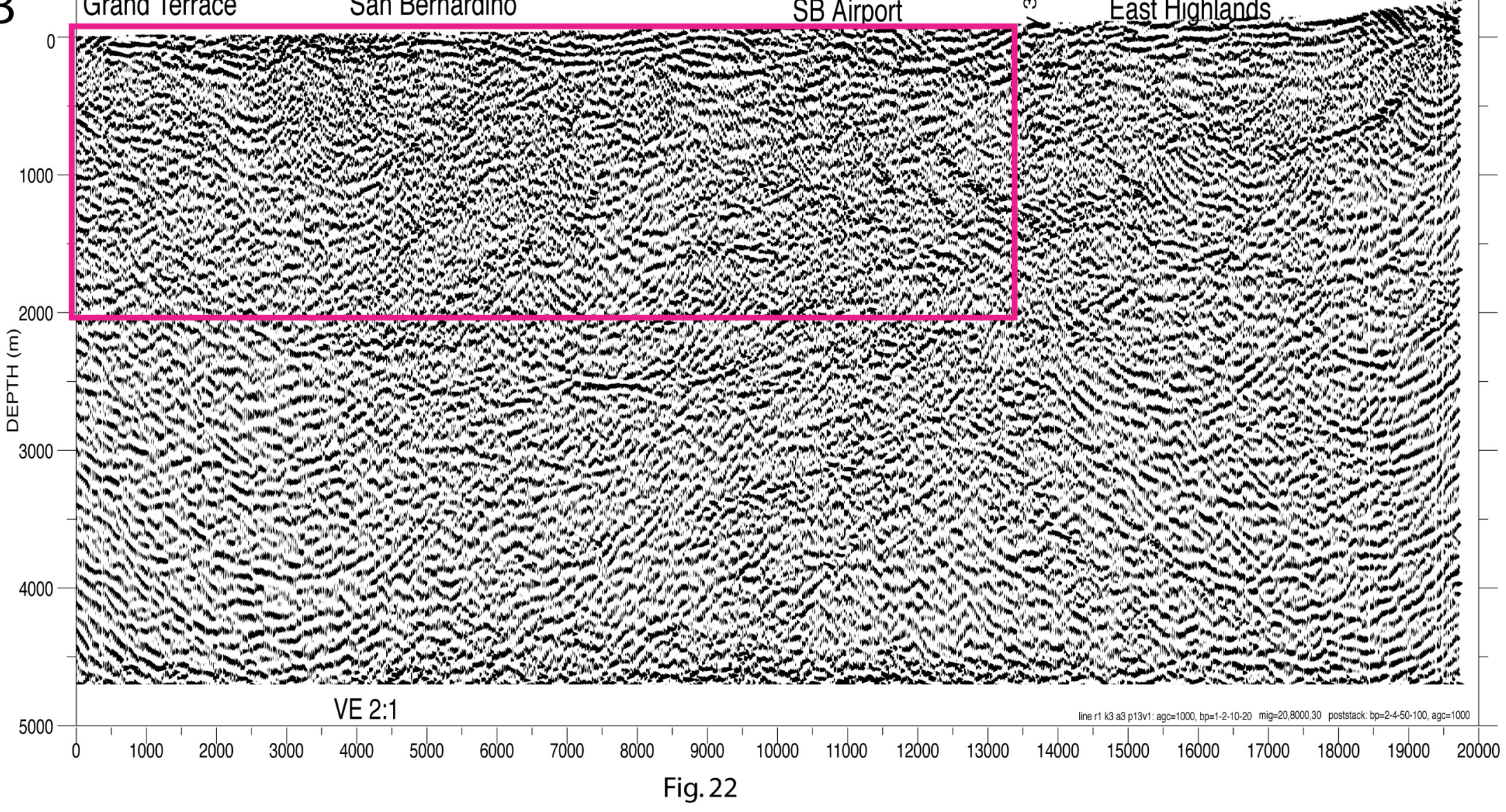

Fig. 22 


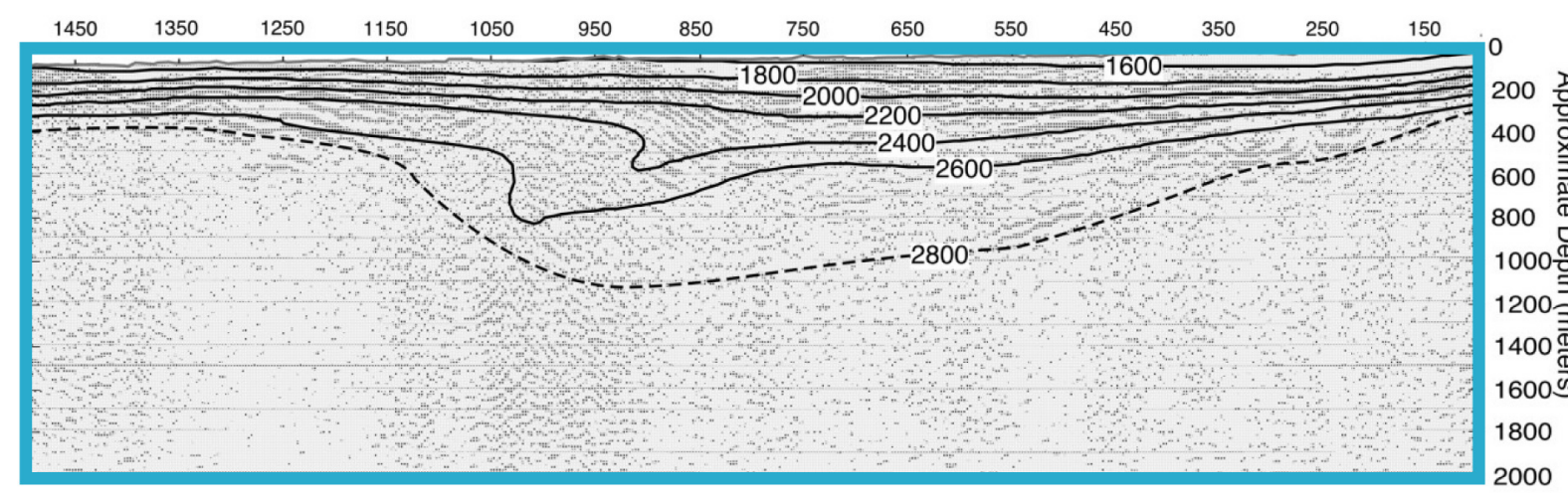

Southwest

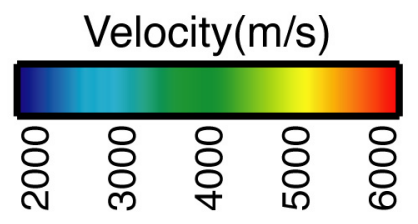

Northeast

$1000-$

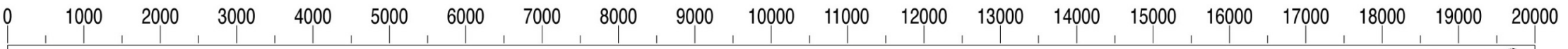

\footnotetext{
$0-\frac{1}{2}$
}

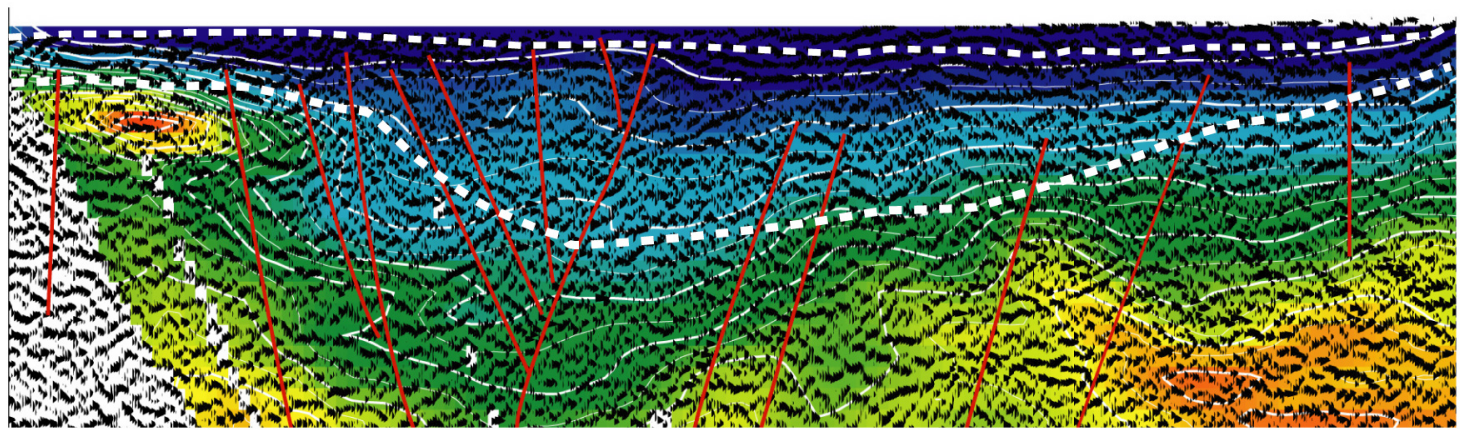

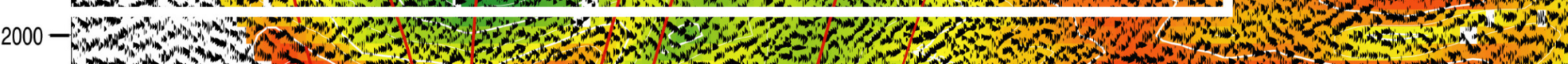

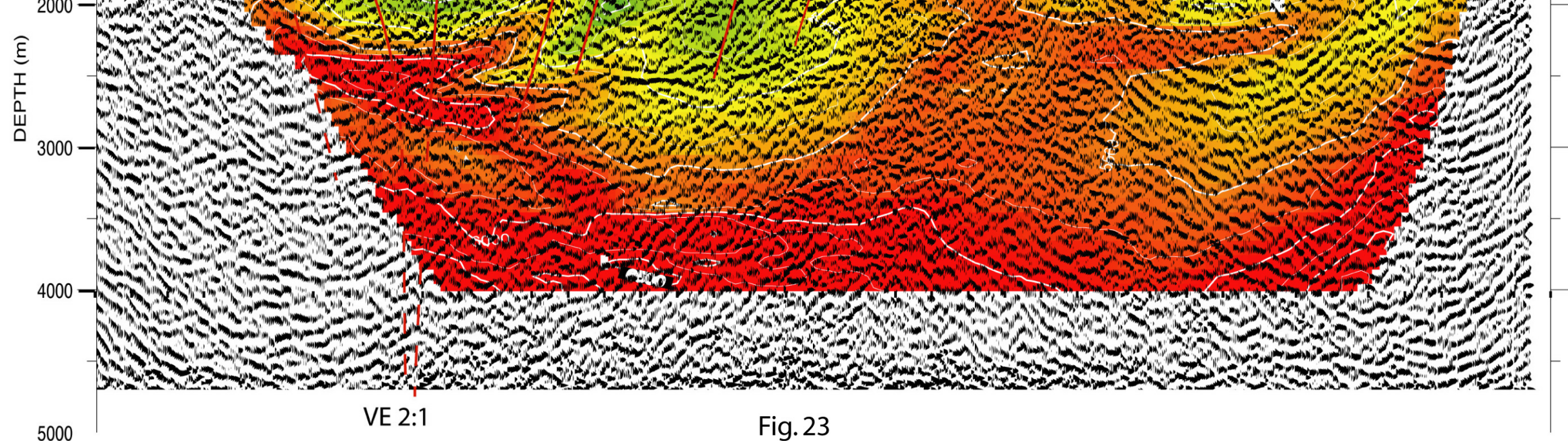




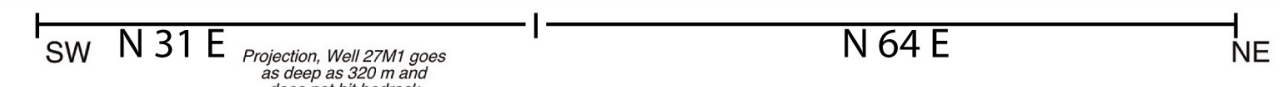

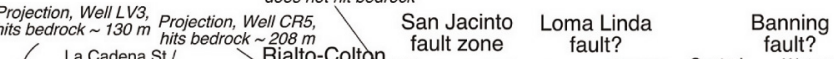

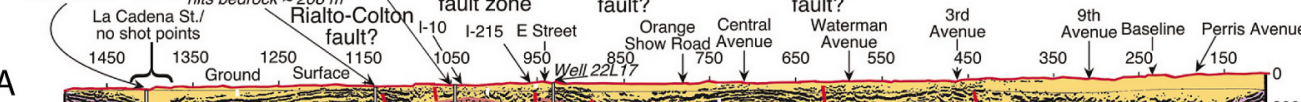
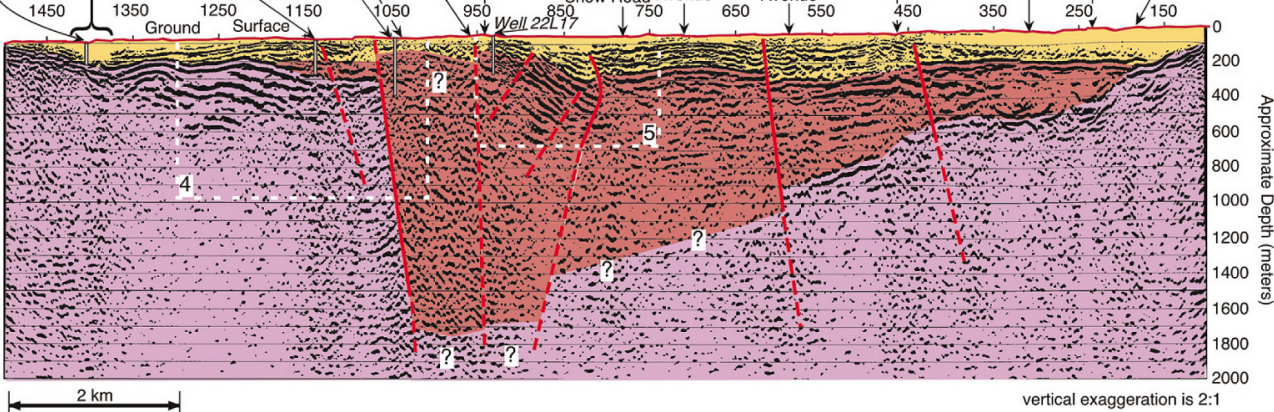

B

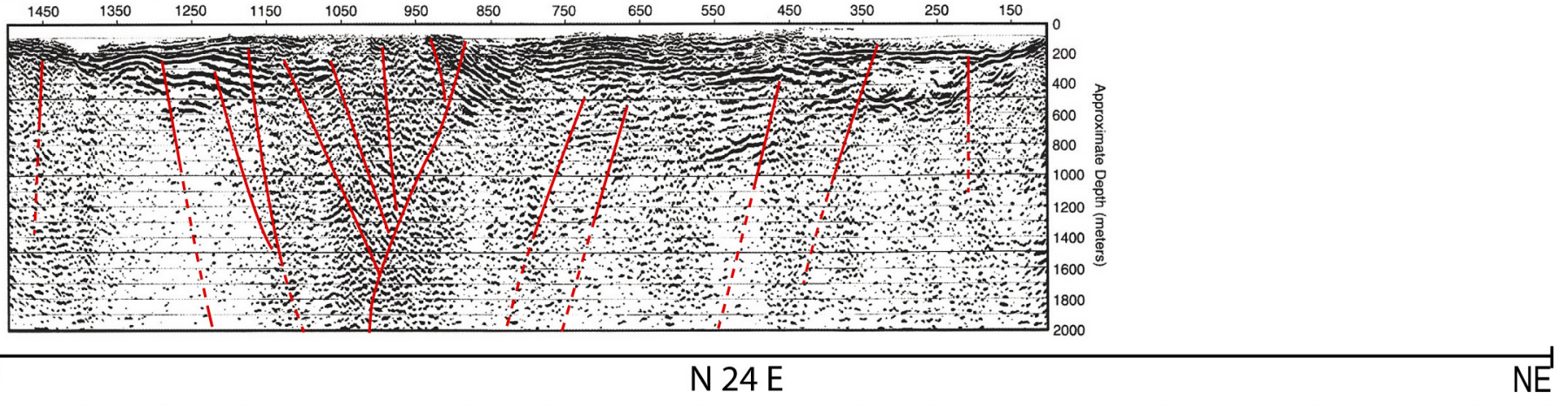

SW

$\mathrm{N} 24 \mathrm{E}$

0

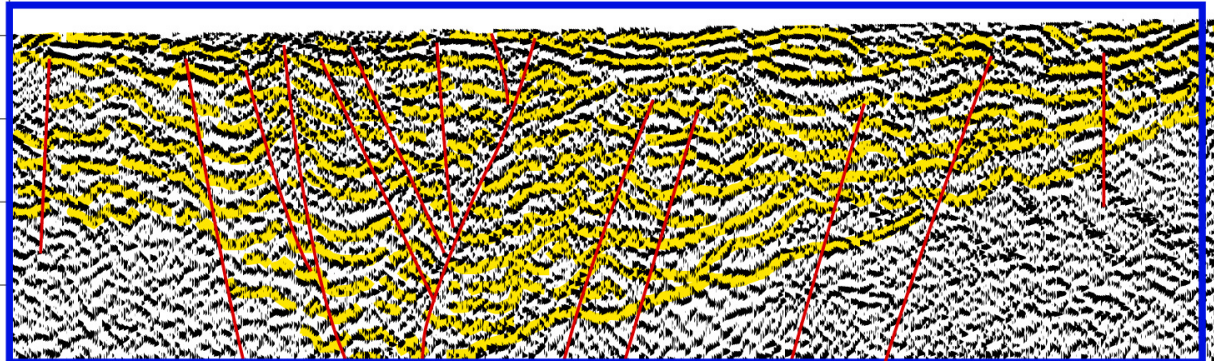

2000

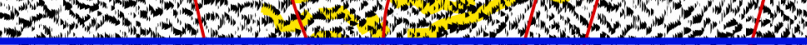

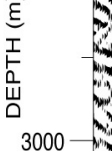

Fig. 24

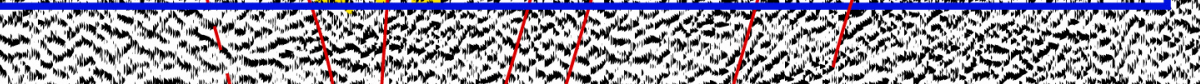
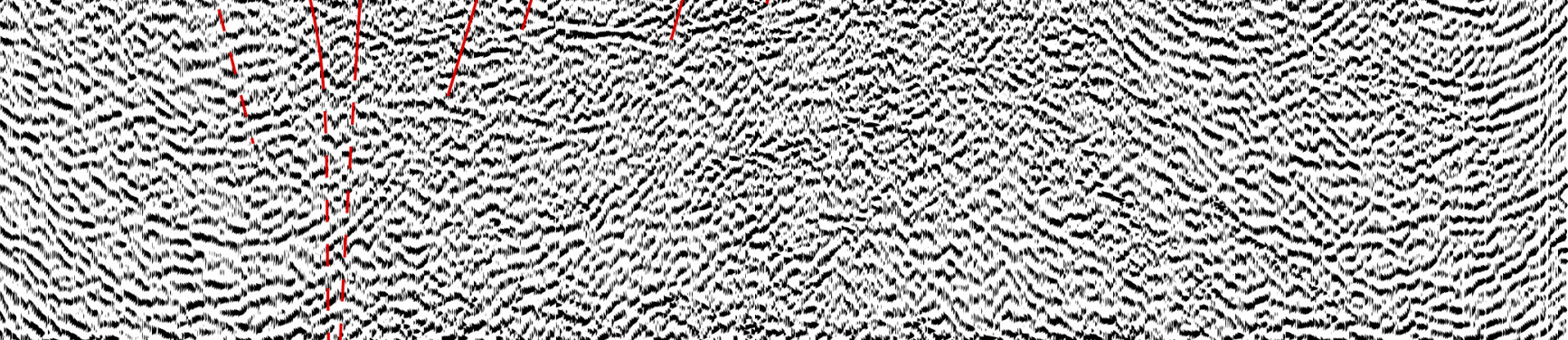

4000

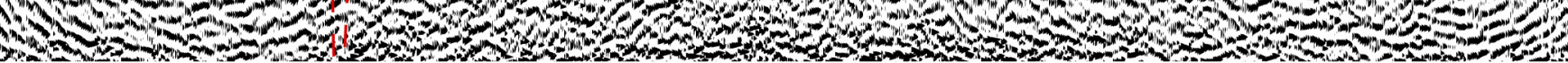

5000

VE $2: 1$

Distance $(\mathrm{m})$

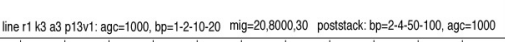

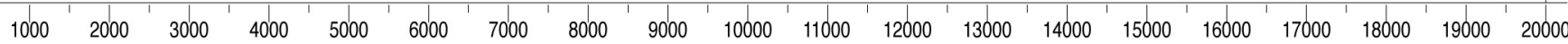




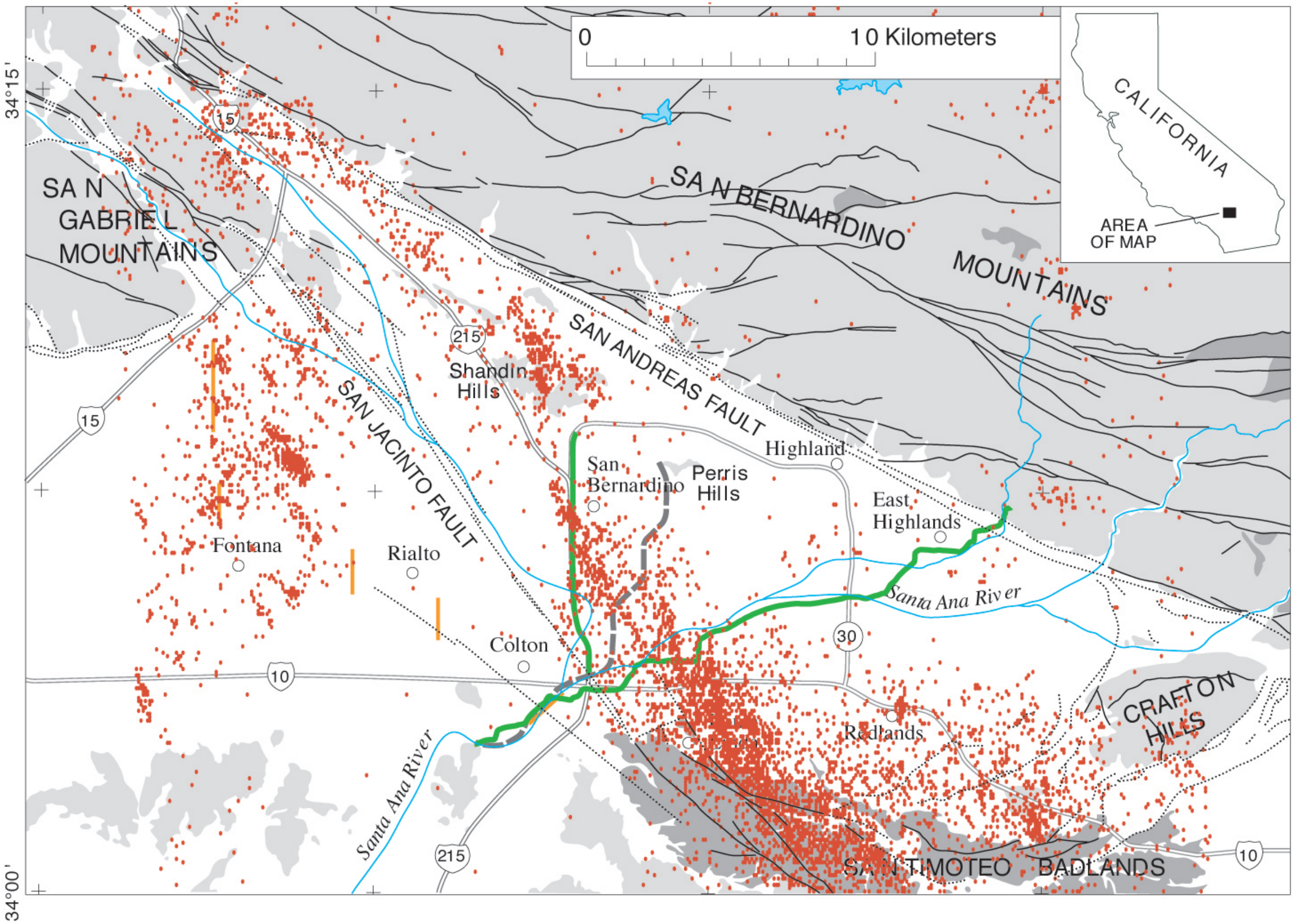

Fig. 25a 


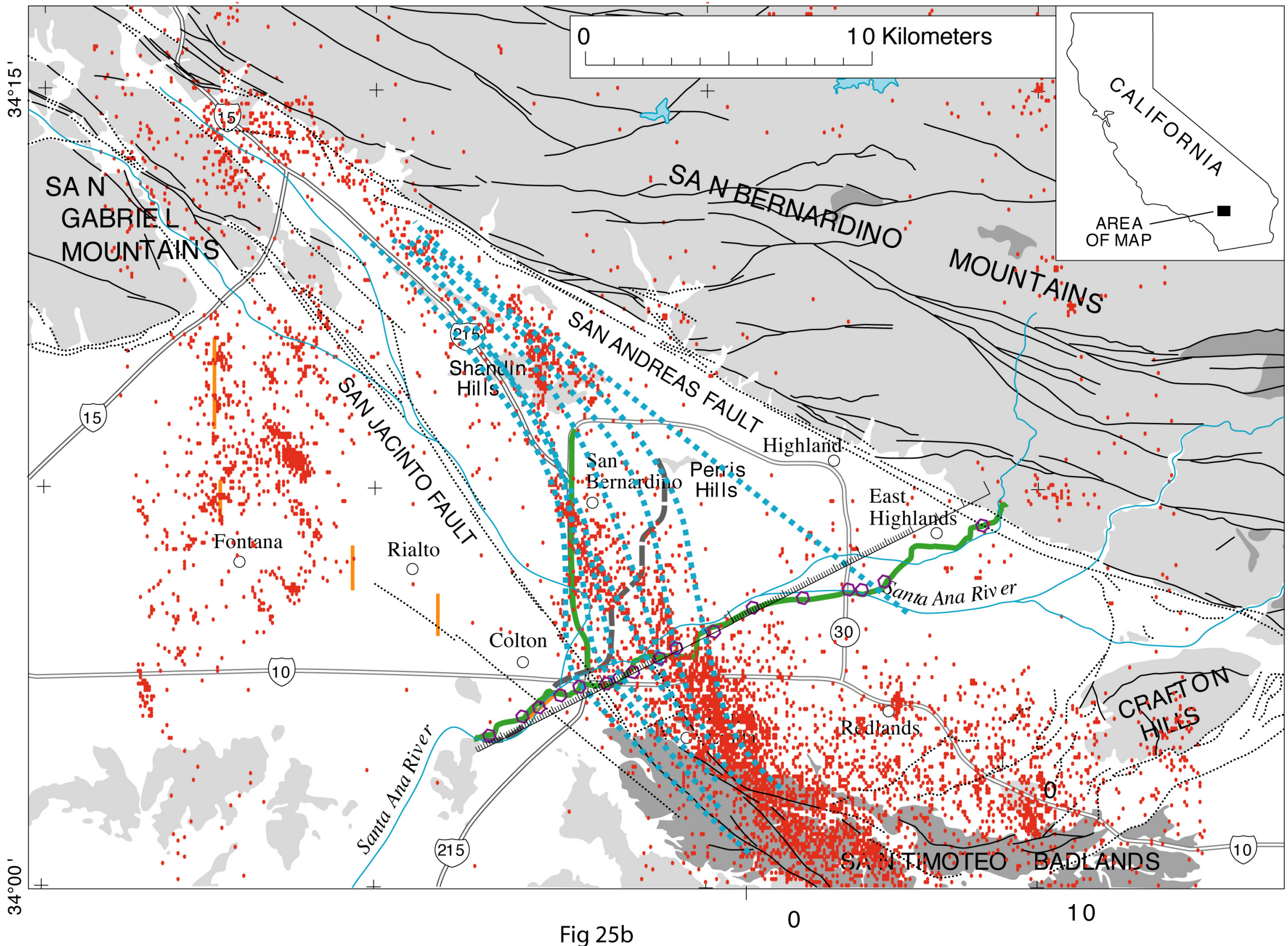




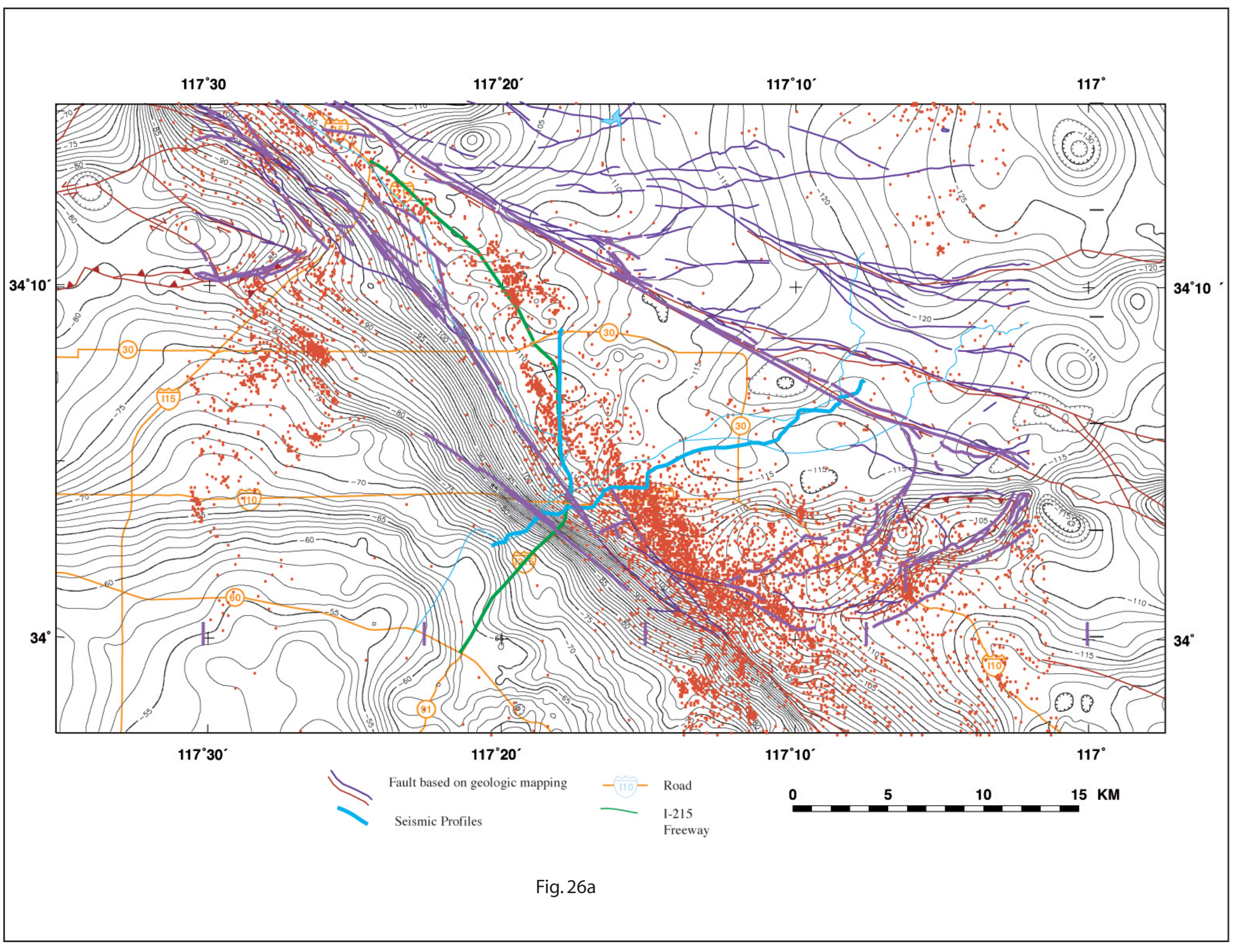




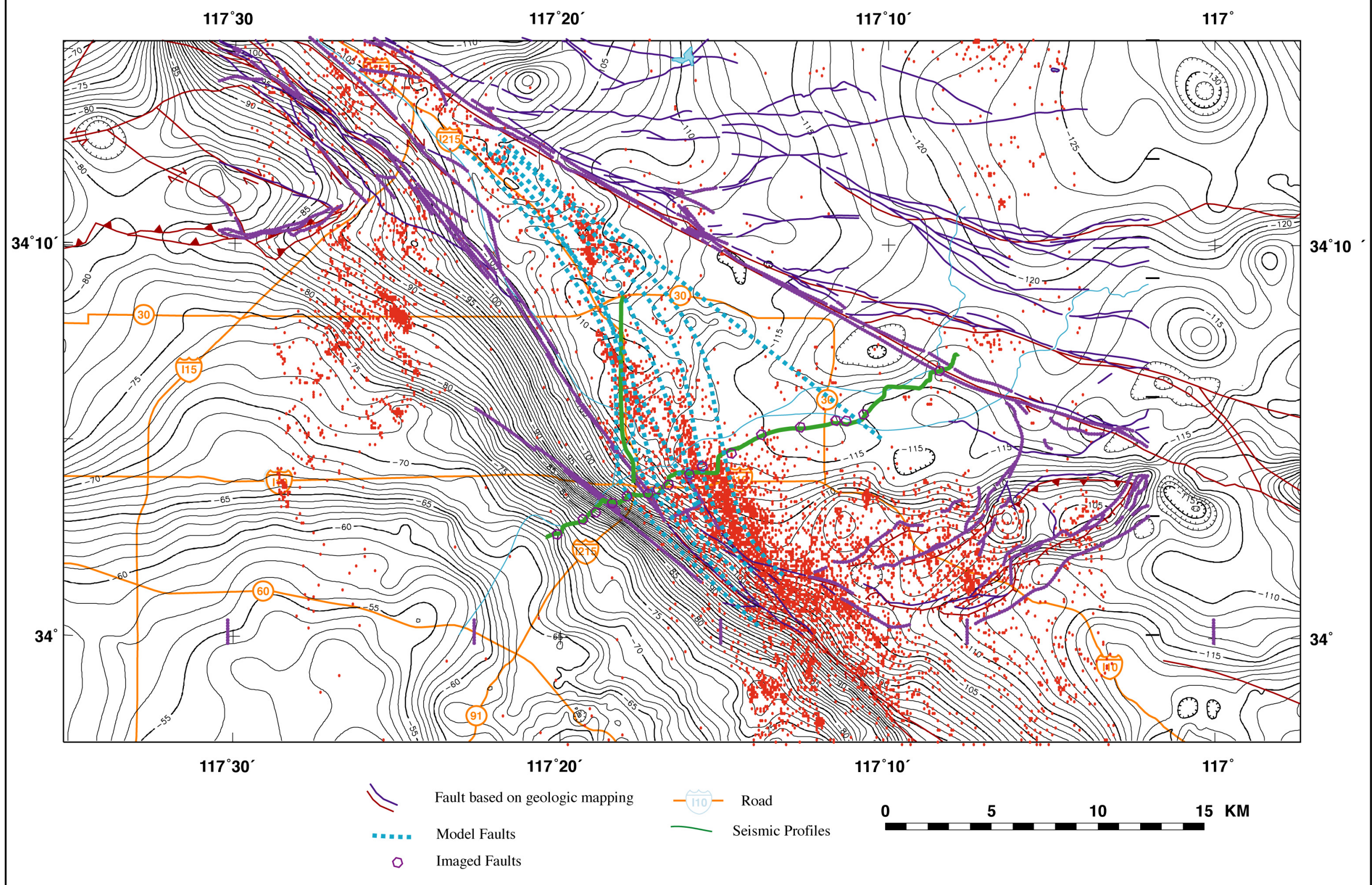

Fig. 26b 


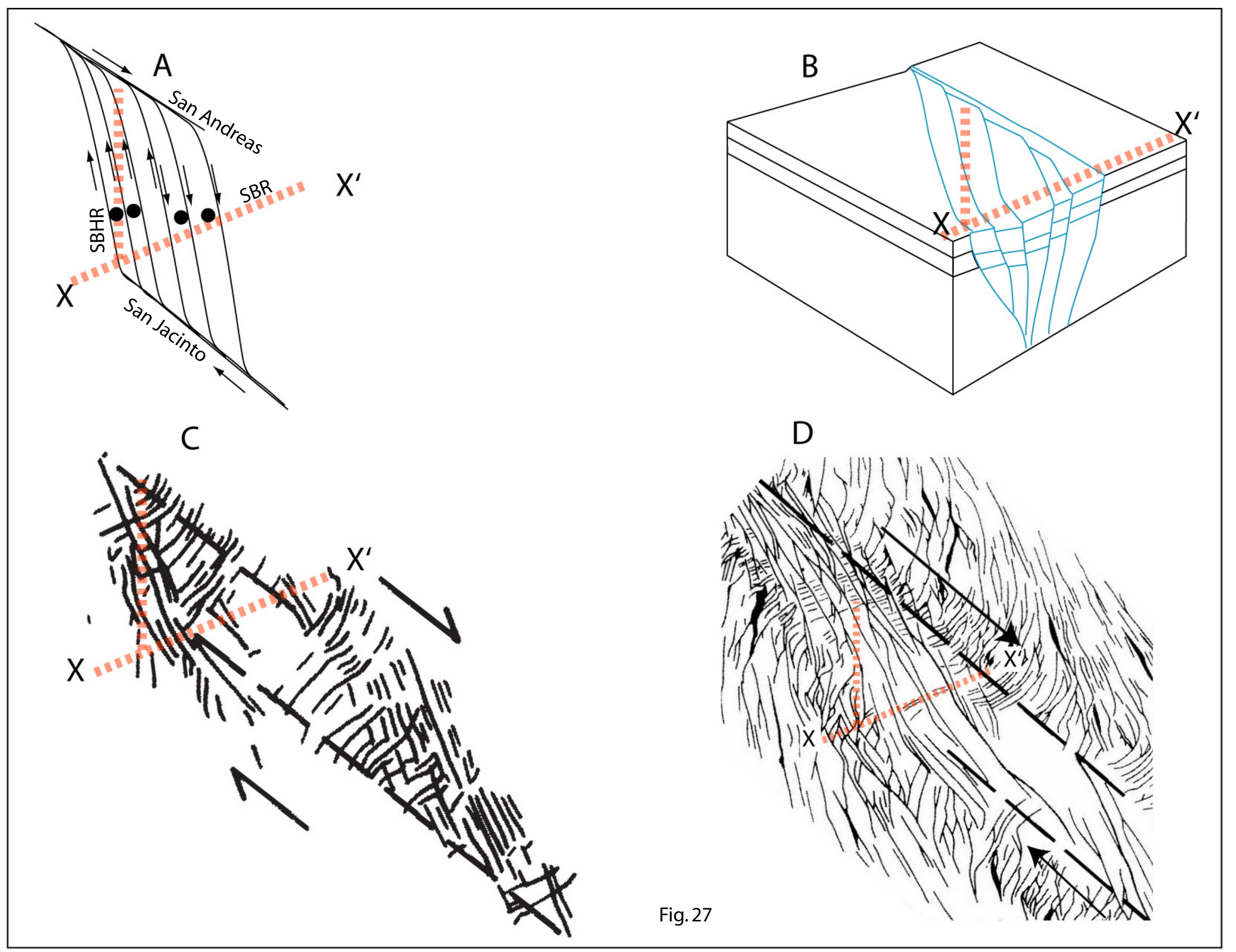




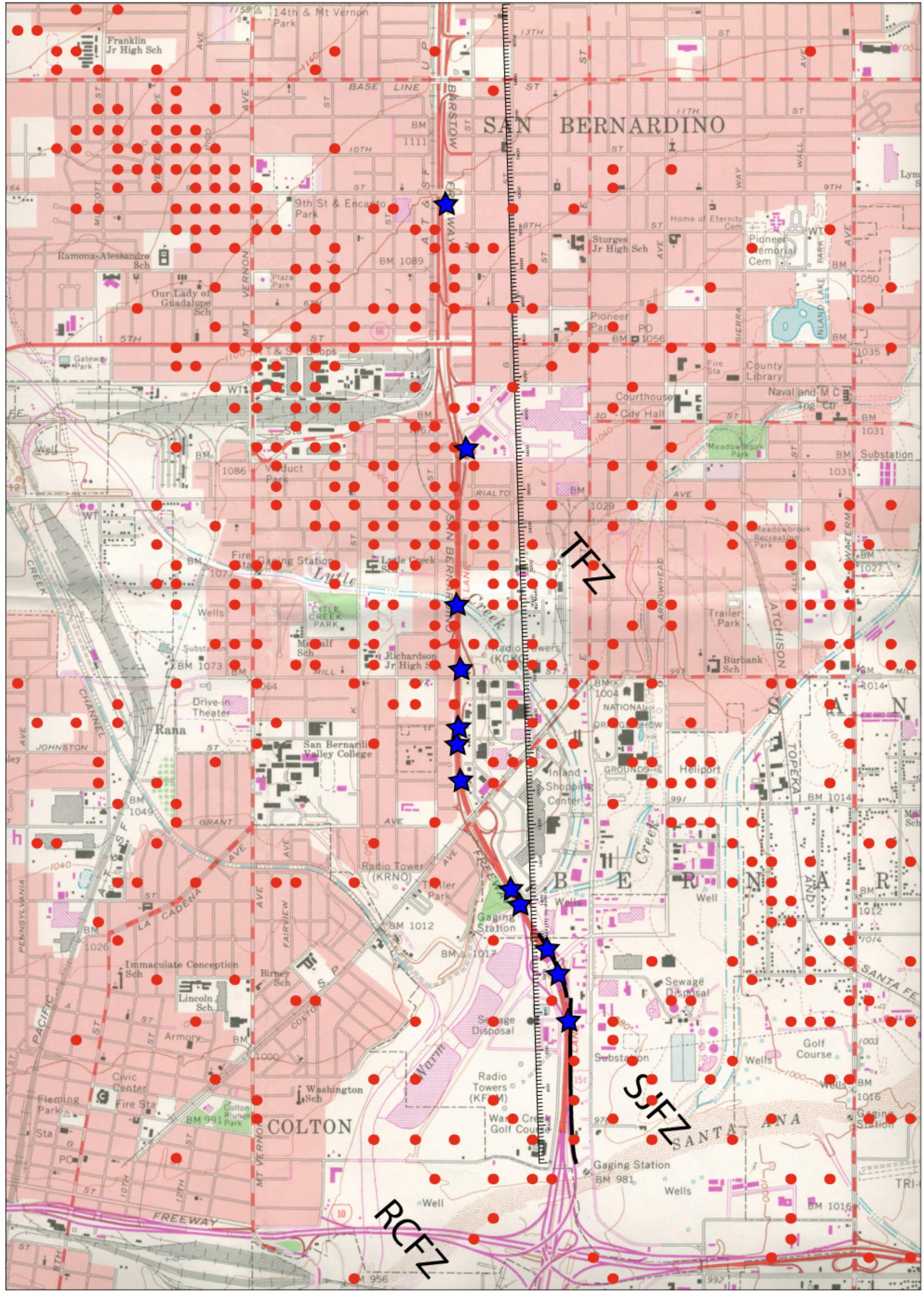

Fig. 28a 


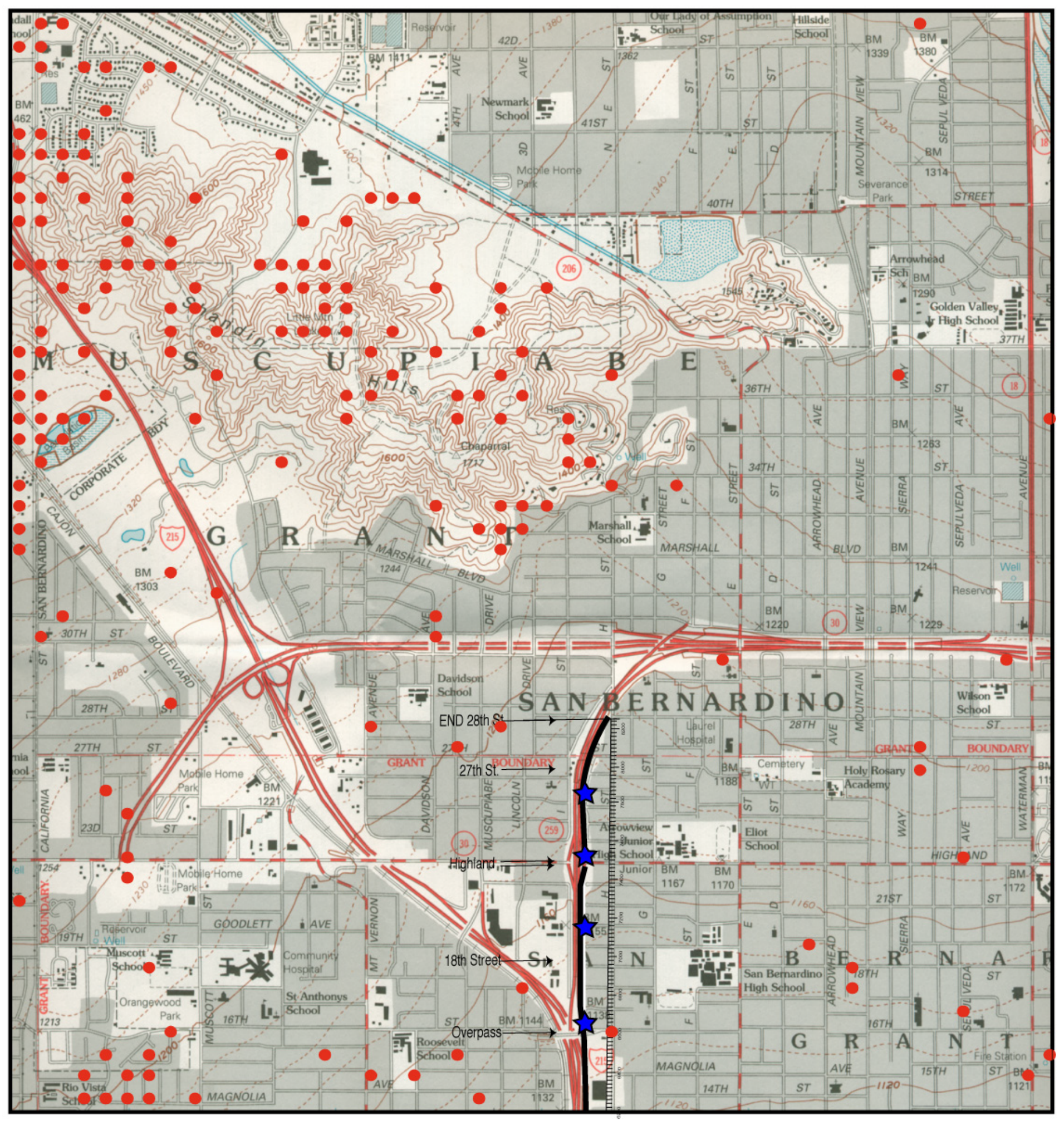

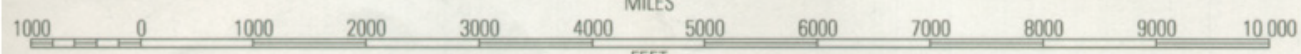

FEET
KILOMETERS
METEST

Fig. 28b 


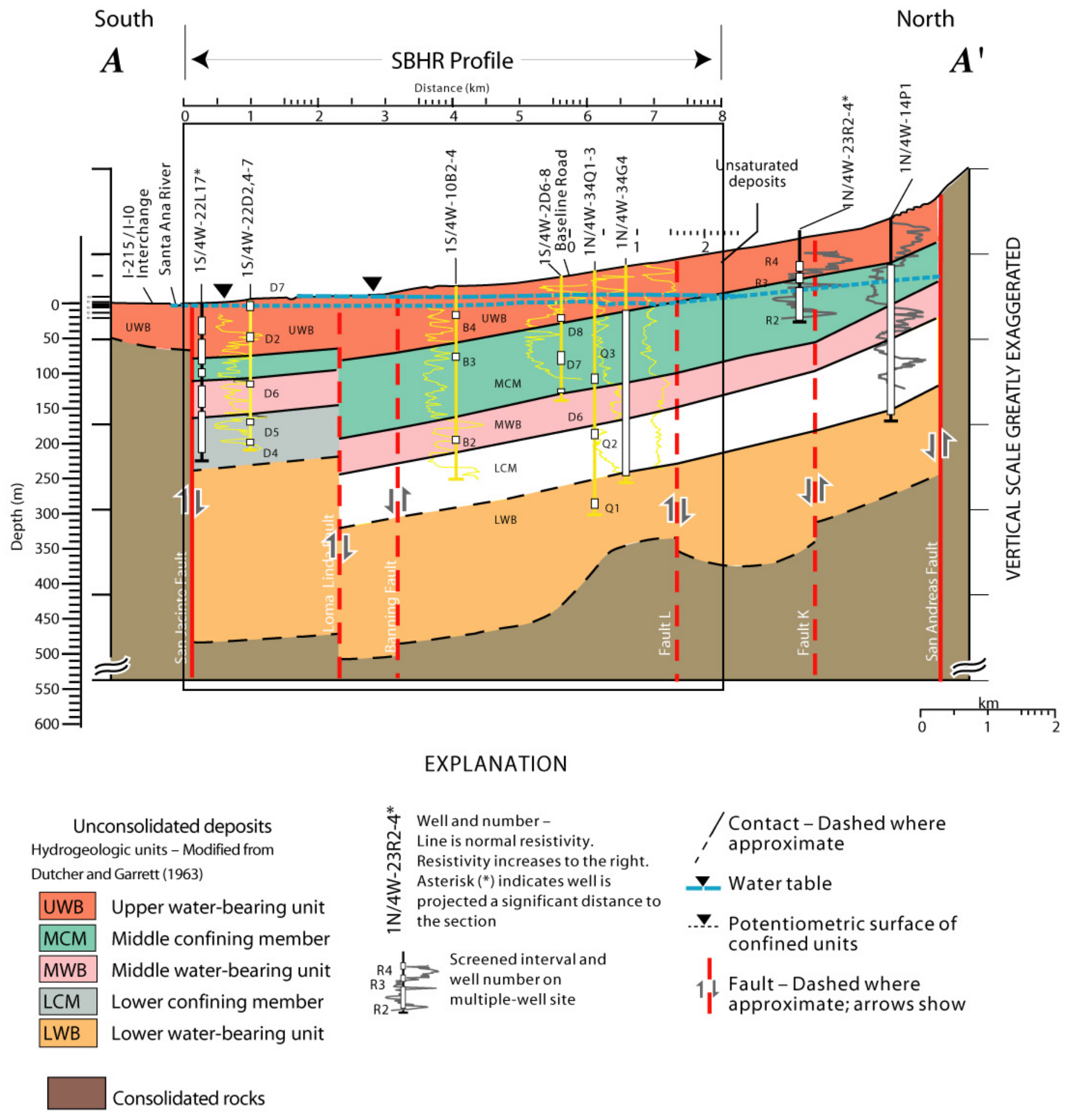

Fig. 29a 


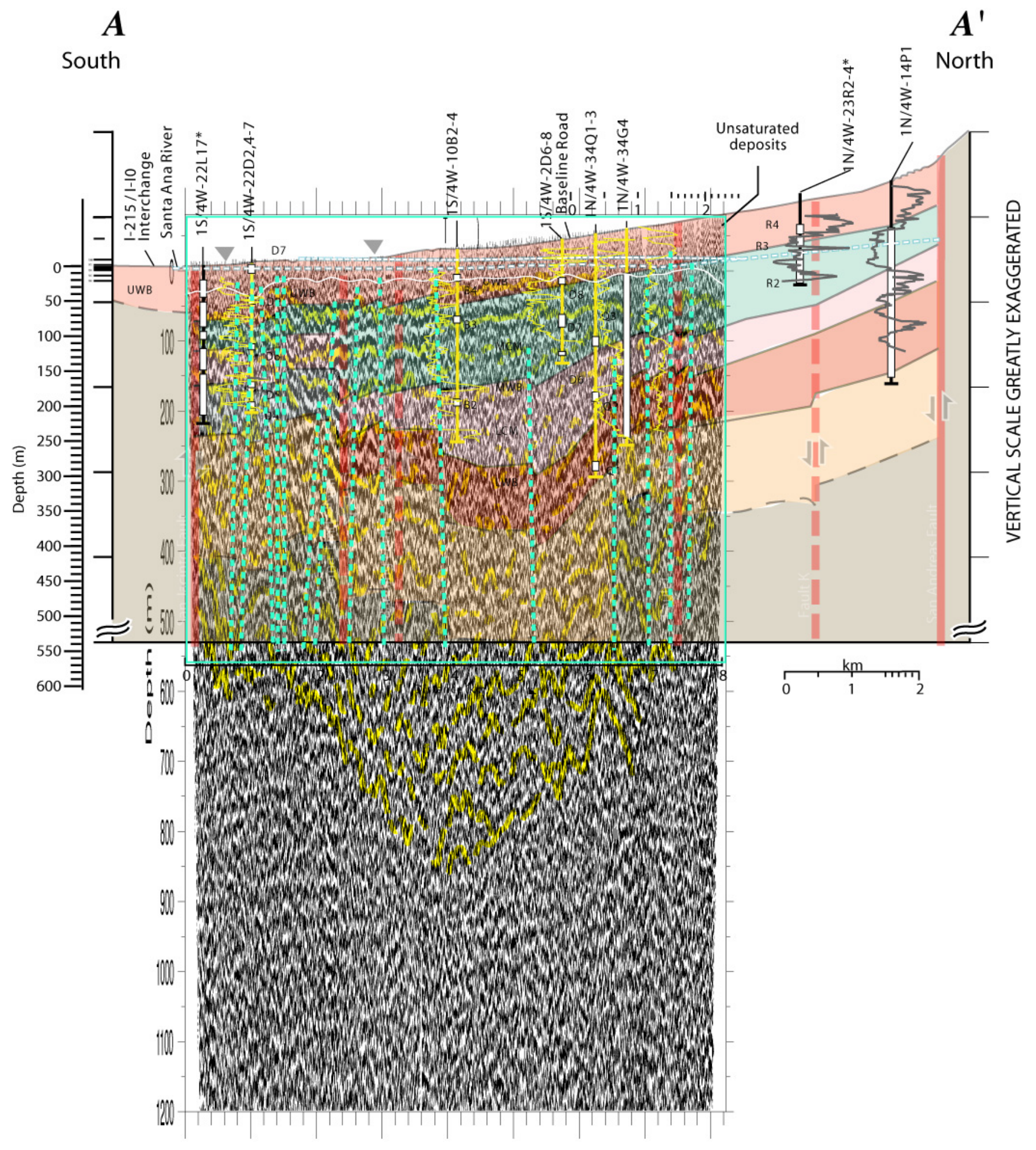

Fig. 29b 